agy Occupational Health T'eam Work

' $d$ ds ORganizational Comn 小ín=| urces Positive Ps 5 eam performance OrGin

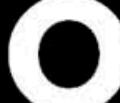
rk
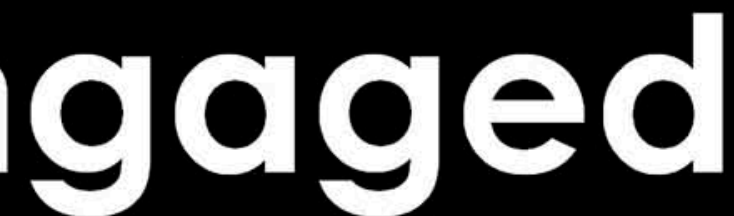
Ieam Work Engagement Te nands ORganizational CC TIRL RESOUREES Social Resour

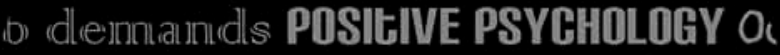

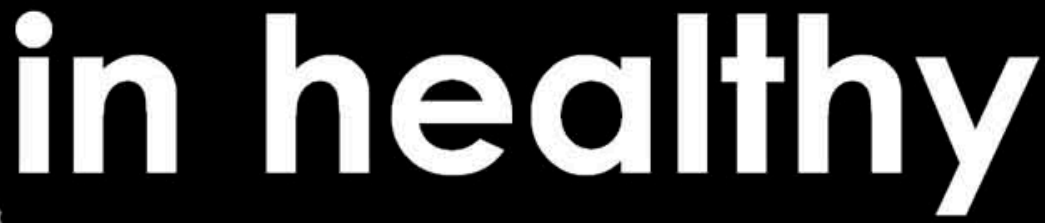
k Engaøement Team Perfommo JMMITMENT Customer Lo. Ally ination Job Resources Oraanizat

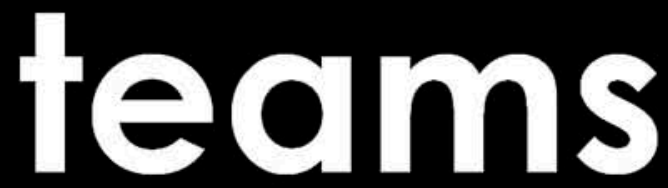

rmance Organizatic by adlennuaundls POSIEIVE F Organizational Demi n Perform ance Orge xcial Reso irces Cor Ith Team Jork Gne ; Orgal atIONA cial Re! :es Cor upatio Healtl

- COM IENT C
is Pos re Psj in Jol Jurces ance $D_{1} \quad$ 깅tic mnatunudls I :JVE PSYL ids OR sitiv

\section{drivers, processes and}

\section{Pedro Torrente Barberò}

PhD. Defense

Promoters:

PhD. Marisa Salanova

$\mathrm{PhD}$. Susana Llorens

PhD. Wilmar B. Schaufeli 
Engaged work teams in healthy companies:

Drivers, processes and outcomes of team work engagement

Pedro Torrente Barberà

2014 
(c) Pedro Torrente Barberà, 2014

\section{Cover: Cinta Torres Pastor, 2014}

All rights reserved. No part of this publication may be reproduced or transmitted in any form or by any means, electronic or mechanical, including photocopying, recording, or any information storage and retrieval system, without prior permission from the author. 
Engaged work teams in healthy companies:

Drivers, processes and outcomes of team work engagement

Pedro Torrente Barberà

Departament de Psicologia Evolutiva, Educativa, Social i Metodologia

Promoters:

Dr. Marisa Salanova Soria

Dr. Susana LlorensGumbau

Dr. Wilmar B. Schaufeli 
The current thesis project was funded by the Spanish Ministry of Work and Social Affairs (\#411/UJI/SALUD), the Spanish Ministry of Science and Innovation (\#PSI2008-01376/PSIC), the Spanish Ministry of Economy and Competitiveness (\#PSI201122400), Fundação para a Ciência e a Tecnologia (SFRH/BD/36218/2007), UniversitatJaume I \&Bancaixa (\#P11B2008-06), and GeneralitatValenciana (ProgramaVALi+d). 
Engaged work teams in healthy companies:

Drivers, processes and outcomes of team work engagement

\section{Contents}

Pages

Foreword

Foreword in Spanish

Introduction

Chapter 1

The pursue of an engaged team: State-of-the-art in team work engagement

Chapter 2

Organizational antecedents of burnout and work engagement: A multilevel study with Portuguese fire brigades

Chapter 3

Spreading engagement: On the role of similarity on the positive contagion of team work engagement

Chapter 4

From I to We: The factorial validity of a team work engagement scale

Chapter 5

Teams make it work: How team work engagement mediates between social resources and performance in teams

Chapter 6

Committing the engaged: On the interplay of team work engagement and organizational affective commitment.

Chapter 7

General discussion

References

Appendixes

Team Work Engagement Scale

Summary

Summary in Spanish

Acknowledgements Acknowledgements in Catalan 



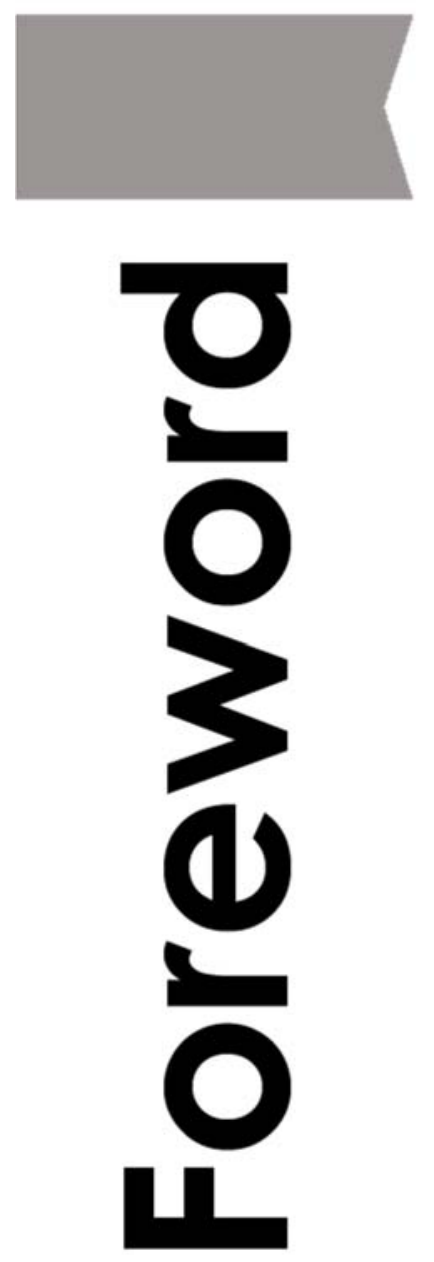




\section{Foreword}

\section{Prólogo (foreword)}

La psicología es una ciencia atrayente ya que trata de todos aquellos aspectos que afectan a los seres humanos en su vida diaria. Cada persona alberga un punto de vista único sobre su vida y un ideal sobre cómo debería ser en cada una de sus facetas. El trabajo es uno de esos aspectos clave de la vida en el mundo moderno ya que estructura nuestro tiempo y ofrece los medios para construir una vida digna. También puede contribuir a darle sentido y, en el mejor de los casos, puede llegar a ser una fuente de oportunidades, de desarrollo personal, de apoyo social y de bienestar psicológico.

Antes de iniciarme en la investigación, tuve la oportunidad de vivir de cerca esta búsqueda de sentido en el trabajo. Durante las vacaciones de verano trabajaba en algunas de las muchas fábricas que la industria cerámica ha levantado a lo ancho de la provincia de Castellón. Es un trabajo que puede resultar monótono, repetitivo, alienante para con los compañeros y los supervisores, y anónimo en cuanto a la contribución del empleado al producto final. Aquel mundo me resultaba muy cercano por dos motivos. Por un lado, muchos miembros de mi familia trabajaron en la industria cerámica durante muchos años o lo siguen haciendo hoy en día. Por otro lado, mi interés por la Psicología del Trabajo era ya evidente y asistí con total inmersión a la amalgama de emociones y pensamientos, experimentados por cualquiera de los operarios a pie de planta.

Fruto de aquellas experiencias y de mi afortunado encuentro con un equipo de investigación de referencia en el estudio de la Psicología del trabajo y las organizaciones, surge esta tesis. En esta ocasión mi trabajo consistió en investigar cómo los equipos de trabajo pueden desarrollar la pasión por el trabajo, ser más felices y al mismo tiempo más efectivos. En este reto he puesto todo mi empeño e ilusión, y el sólo hecho de que vea la luz es una buena muestra de que el objetivo de estar vinculados con el trabajo, engaged con el trabajo y con la vida, es posible y valioso. 


\section{Introduction}

\section{Introduction}

We are currently living in a period of economic turmoil and crisis in the labor market with vivid consequences. In this time of uncertainty and job insecurity it is even more obvious that workers are exposed to strain and pushing demands in any position within any given organization, from management staff to employees delivering the final product or service offered. This insecurity adds to the full range of daily stressors that affect any worker in modern companies. Nowadays, the economy is characterized by forming a global network of communication, information, and transportation of people and goods (Bhagwati, 2004), which forms a rapidly changing work environment that is strongly dependent on information and communication technologies (Green, 2004).

Far from being just a bunch of individual employees, organizations are made up of workers in constant coordination and interaction so as to be able to fulfill their work duties. Hence, every day employees are immersed in a social environment and are subject to its influence. These collective influences include the contagion of emotions (Hatfield, Cacciopo, \&Rapson, 1994) or the effect of the norms of emotional expression at work (Morgeson\& Hofmann, 1999). The study of emotions at work has stressed the importance of negative emotions over positive ones (Seligman \&Czikszentmihalyi, 1999). Since the turn of the century, the study of work engagement as a positive, affective-motivational state at work has received an increasing amount of attention (Schaufeli\& Bakker, 2010). Nevertheless, literature reviews on the models that are most widely applied to work engagement highlight that the social component in organizations has been forgotten or rarely considered. That is the case of the Job Demands-Resources model (JD-R Model; Demerouti, Schaufeli, Bakker, \&Nachreiner, 2001), which has been further developed to include the Social Cognitive Theory (Bandura, 2001) and the Conservation of Resources Theory (Hobfoll, 1989). Recent reviews on the JD-R model acknowledged the lack of a collective perspective and called for the inclusion of a multilevel framework in order to attain further theoretical 


\section{Introduction}

developments where groups and organizations are the main protagonists (Demerouti\& Bakker, 2011; Schaufeli\&Taris, 2014).

The gap in the understanding of collective work engagement in the different studies carried out to date opens up avenues for research due to the scarce and fragmented results that result in lack of theoretical integration. So, while some researchers have clearly focused on the individual employee (e.g., Llorens, Bakker, Schaufeli, \&Salanova, 2006), others have focused purely on the level of the organization (e.g., Harter, Schmidt, \& Hayes, 2002). Fewer studies have covered the topic of team work engagement, which is surprising given the explanatory potential of team-level engagement as an intermediate level of analysis that helps to comprehend how individual work engagement may turn into organizational work engagement (Salanova, Agut, \&Peiró, 2005; Schaufeli\&Salanova, 2011). Therefore, the main goal of this $\mathrm{PhD}$ project lies in the study of team work engagement, to go deeper into the notion of work engagement as a collective phenomenon, and to discuss the implications for organizations and the teams that comprise them.

\section{Research questions}

The above-mentioned goal can be separated into several steps and various research questions, which will be answered by means of the different chapters that make up this thesis. The research questions (RQ) are the result of a review of the literature, as included in the first chapter of this dissertation, and are focused on theoretical and practical implications. In this theoretical review an overview of the concept of team work engagement, theories and measurement tools, as well as its drivers and outcomes for work teams, was conducted. Throughout the theoretical review the gaps in the literature were pointed out and were the focus of detailed attention in the empirical chapters of the current thesis project.

The JD-R model (Demerouti et al., 2001), with its various extensions, has been the most widely applied in the study of work engagement. In fact, the theoretical 


\section{Introduction}

development of the model has always been linked to the prediction and understanding of work engagement (Bakker \&Demerouti, 2008; Schaufeli\& Bakker, 2004). This research front has been mostly limited to individual work engagement, although some papers have indicated that it is possible to conceptualize work engagement at the team level (Bakker, van Emmerik, \&Euwema, 2006; Salanova et al., 2005). As a result, recent reviews of the JD-R model call for papers to go deeper into their multilevel perspective to provide further development on the model (Demerouti\& Bakker, 2011; Schaufeli\&Taris, 2014). Therefore, the first chapter of this thesis was aimed at extending the JD-R model by including job demands and job resources at the organizational level over and above testing for individual level predictors. This constituted research question 1 :

\section{RQ1: How can the JD-R Model be extended to include organization-level demands and resources using a multilevel approach?}

Research has also pointed out that work engagement can spread and be transmitted to others. The transmission of work engagement occurs between life domains (from work to family and family to work; Bakker \&Xanthopoulou, 2009) or among work colleagues (Bakker, Schaufeli, Demerouti, \&Euwema, 2006). Bakker and colleagues (2009) identified several conditions for the "contagion" of engagement at work. These conditions are team climate, frequency of interaction, empathy, susceptibility to infection, and similarity among team members. Although suggestive, this study did not delve into the mechanisms involved in the different conditions of contagion. At this point, the next research question and main goal of this thesis was set out: how do conditions of contagion promote the transmission of work engagement from one employee to another employee working in the same work team? Conclusions on this topic could provide new insights on how to promote the positive contagion of work engagement in organizations. Special attention was given to the condition of similarity, since it may provide implications for the study of diversity in job settings, 


\section{Introduction}

where similarity in personal and work characteristics are objective indicators that serve as emotional referents between co-workers. Therefore:

\section{RQ2: How can work engagement spread among individuals working in teams through similarity following a positive emotional contagion process?}

The measurement of team work engagement is another area for further research. The literature on individual work engagement is clearly led by the use of the UWES questionnaire (Schaufeli\& Bakker, 2003). In fact, $83 \%$ of the articles published on work engagement made use of this scale (Schaufeli\&Salanova, 2011). This questionnaire consists of 17 items covering the three inner dimensions of work engagement: vigor (6 items), dedication (5 items), and absorption ( 6 items). The UWES questionnaire also has a short form that comprises 9 items (Schaufeli, Bakker, \&Salanova, 2006). Both forms are available in two different versions (i.e., employees and students) in 24 languages and are available online at www.schaufeli.com. The dissemination of this measurement tool has led the UWES questionnaire to become the most widely applied scale in the evaluation of work engagement in academia (Schaufeli\& Bakker, 2010). However, the specific requirements of the study of collective constructs such as team work engagement make it necessary to adapt existing questionnaires to obtain reliable and valid conclusions (Chen, Mathieu, \&Bliese, 2000). The rationale for this need can be summarized in two points: firstly, the referents of the items have to focus on the collective level of analysis under study (i.e., the team); and secondly, the scale requires validation using the average of the team, that is, using aggregated perceptions. Hence, a key goal in this PhD thesis was to test and adapt the UWES questionnaire for its use in the measurement of team work engagement. A valid and reliable tool for assessing the construct would allow us to inquire further into the antecedents and consequences of team work engagement. Thus, this constituted research question number 3 : 
Introduction

\section{RQ3: Can a reliable and valid assessment tool be developed to measure team work engagement?}

Exploring the drivers and outcomes of team work engagement constituted the fourth main objective of this thesis. The few studies available to date point to organizational resources as antecedents of engagement at the team level of analysis (Salanova et al., 2005). Moreover, previous research shows that team-level work engagement is positively related to: task performance of students working in groups (Salanova, Llorens, Cifre, Martínez, \&Schaufeli, 2003); extra-role performance, customer loyalty, and service quality (Gracia, Salanova, Grau, \&Cifre, 2012; Salanova et al., 2005); affect and positive collective efficacy beliefs (Salanova, Llorens, \&Schaufeli, 2011); and individual work engagement (Bakker et al., 2006; Tims, Bakker, Derks, \& van Rhenen, 2013). The goal of the following empirical chapter of this dissertation was to clarify the mediating role of team work engagement between resources and performance in teams using an objective measure of performance, i.e., as assessed by the supervisor. This constituted research question number 4 :

\section{RQ4: Does team work engagement mediate between social resources and performance in teams using an objective measure of performance?}

Finally, we aimed to frame team work engagement within a broader context: the organization as a whole. Although there are a few empirical articles on this or related topics, those that do exist made use of other perspectives of work engagement (i.e., employee engagement; Richardson \& West, 2010) introduced in the seminal paper by Kahn (1990). The study of organization-level engagement emerged from studies conducted based on business and consultancy firm research (Harter et al., 2002) and were driven with an impetus in business administration (e.g., Van Rooy, Whitman, Hart, \&Caleo, 2011). Efforts have been made to combine the different levels of analysis involved in work engagement within an organizational context (e.g., Pugh \& Dietz, 


\section{Introduction}

2008), although more research is needed in the quest for a model of work engagement that integrates different levels of analysis. Thus, the goal of the last chapter was to bring together organizational-level research with a clear connotation of business management and administration, and a team work engagement perspective clearly influenced by an occupational health perspective. This constituted research question number 5:

RQ5: Is it possible to develop a multilevel model of team work engagement in relation to drivers (i.e., human resource practices and resources), outcomes (i.e., team and organizational performance), and related constructs (i.e., organizational affective commitment)?

\section{Specific research objectives: Thesis planning}

The main goal of this $\mathrm{PhD}$ project is to study team work engagement, to go deeper into the notion of work engagement as a collective phenomenon, and to discuss the implications for organizations and the teams that comprise them. This main goal was separated into several steps and specific goals. First, a theoretical and conceptual chapter was presented. The aim of this chapter was to contextualize this research project within the framework of the existing literature and to point out its main sources and starting points. This review identified the knowledge gaps that constitute the research questions of this $\mathrm{PhD}$ project. The content of the empirical chapters, and its specific goal and hypotheses are summarized in the following paragraphs.

In Chapter 2 (empirical study \#1) research question 1 was addressed by focusing on the role of organizational demands and resources over individual demands and resources, introducing a multilevel perspective on the JD-R Model of burnout and work engagement. The role of acute demands and proactive coping was tested at the individual level as well as organizational demands and social support at the organizational level in relation to the core dimensions of burnout (i.e., emotional 
Introduction

exhaustion and cynicism) and work engagement (i.e., vigor and dedication). Job demands (acute and organizational demands) were expected to be positively related to burnout and negatively related to work engagement. The opposite associations were expected with resources (proactive coping and social support) in relation to burnout and work engagement. Furthermore, proactive coping strategies were expected to moderate the relationship between acute demands and burnout and work engagement. This study implemented hierarchical linear modeling in a very specific context: firefighters working in rescue teams dealing with emergency situations. This also provided further insights on the conceptualization of these two constructs as opposing indicators of well-being at work.

In Chapter 3 (empirical study \#2) conclusions were provided in alignment with research question number 2 . In this empirical study, the conditions of transmission of work engagement within organizations were analyzed, more specifically, in the condition of similarity between members who are working in the same team. Then, convergence in a shared state of team work engagement was regressed onto a measure of objective similarity between the team members in terms of gender and years of experience. Similarity in terms of both gender and company tenure were expected to be positively related to convergence in a shared state of team work engagement. The goal of this study was to go into detail in the process of positive contagion of team work engagement that results from the daily interaction of employees working in work teams. The importance of this approach lies in the theoretical implications for the contagion process based on the Emotional Contagion Theory (Hatfield et al., 1994) and the practical implications for the human resource management of diversity within companies. In short, the aim of this study was to gain a further understanding of how individual work engagement turns into a collective workrelated positive state, shared by all team members. 


\section{Introduction}

In Chapter 4 (empirical study \#3) a factorial validation of a questionnaire measuring team work engagement was tested. This chapter addressed research question 3. The assessment tools that were available, mainly based on the UWES questionnaire, were validated for use in specific studies and, although they had shown good internal consistencies, no specific study has explicitly addressed their construct validity. This was a requirement for the effective measurement of team work engagement due to the specific requirements of collective constructs: first, the items were required to follow a referent-shift consensus model (Chan, 1998), where the referent is changed and items are targeted toward collective perceptions (i.e., the team); and second, the scores were aggregated in the form of the average levels of team work engagement, and not only theoretically justified so as to be representative of the work engagement within the team. It was hypothesized that a Team Work Engagement Scale would show adequate factorial validity using confirmatory factor analysis, and that it would replicate the trifactorial structure of work engagement at the team level of analysis (i.e., team work vigor, team work dedication, and team work absorption).

Chapter 5 (empirical study \#4) deals with the mediating role of team work engagement between team social resources and team performance. This study sought to answer research question 4 , by testing the mediating role of team work engagement in a motivational process leading to team performance, as suggested by the JD-R Model. Team work engagement was expected to fully mediate the relationship between the social resources within the team, and the actual performance of the team. This process was tested using Structural Equation Modeling (SEM), given the multiple components of the constructs under analysis: team social resources (i.e., coordination, teamwork, and supportive team climate), team work engagement (i.e., team work vigor, team work dedication, and team work absorption), and team performance (i.e., in-role and extra-role performance) as assessed by the immediate supervisor of the team. 


\section{Introduction}

Chapter 6 (empirical study \#5) is focused on team work engagement in relation to organizational affective commitment as included in a wider organizational context. In this chapter research question 5 was addressed. In this study, a multilevel model of team work engagement was proposed, based on the Healthy and Resilient Organizations model (HERO; Salanova, Llorens, Cifre, \&Martínez, 2012) and focused on the cross-level relationships between teams and organizations. A set of healthy organizational practices and resources (i.e., organizational practices and team coordination) were expected to be positively related to organizational affective commitment and team work engagement, which in turn were expected to be related to higher positive outcomes for both the team (i.e., higher performance as rated by the teams) and the organization (i.e., higher customer loyalty as rated by the customers). Furthermore, the multilevel mediation effects of organizational affective commitment and team work engagement were also included in the analysis. In sum, this chapter integrates team work engagement in a wider organizational context with practical implications for human resource management and performance in companies.

Finally, in Chapter 7, the findings obtained through all this series of studies are summarized, integrated, and discussed. This chapter attempted to integrate all the results and findings from the individual chapters in order to present the final contribution of this dissertation to the understanding of team work engagement. Theoretical and practical implications for theory building and human resource management are also discussed. Moreover, the strengths and weaknesses of this research in relation to future challenges and possible research avenues are also pointed out.

\section{Final note}

As employees, we would not be able to comprehend happiness without regard for those around us. Thus, given the amount of hours we spend at work, our well-being in the workplace is very often determined by those with whom we interact every day. 


\section{Introduction}

Thus, we influence the well-being of our colleagues and supervisors, but in turn they play a crucial role in our own levels of work engagement, and so we constitute a source for the work engagement of others, and vice versa. At the end of the process, this influences the energy, dedication, and absorption with which we engage in work tasks, and these are transferred to our team colleagues to become team work engagement.

In this thesis project an insight into team work engagement was offered, linking work engagement with employees with a shared state of engagement in which engaged employees become resources for other members of the organization. All throughout this thesis project it is argued that this alternative view in the study of work engagement can contribute to the well-being and effectiveness of work teams and organizations. We hope to provide the various organizational stakeholders (employees, unions, prevention professionals, human resource managers, supervisors, and managers) with new insights into improving the welfare of teams by taking a positive perspective. 


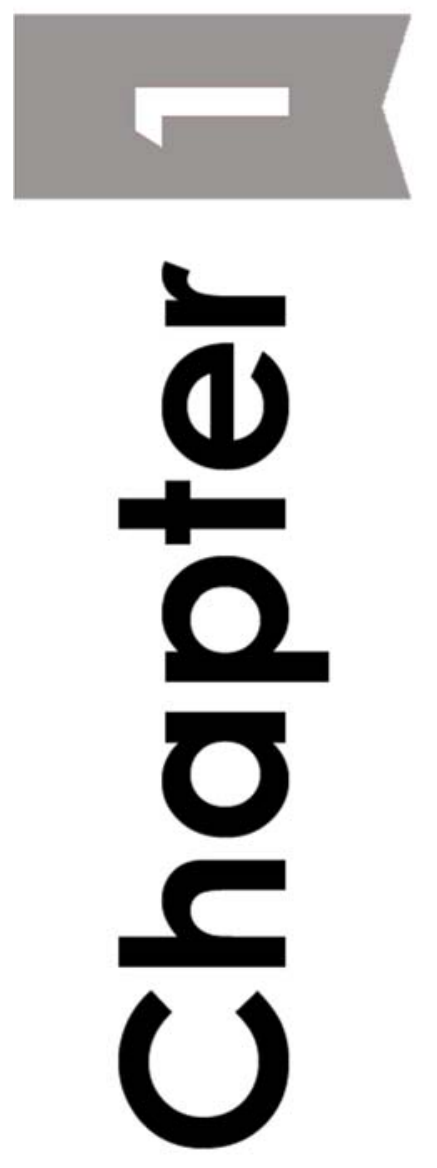


The Pursue of an Engaged Team:

\author{
The State-of-the-art in \\ Team Work Engagement
}




\section{Chapter 1}

\section{The pursue of an engaged team: the state-of-the-art in team}

\section{work engagement}

Over the centuries, work has become a cornerstone in our lives. It is very difficult to imagine a modern social order in which work is not a crucial aspect of human behavior. Given the time and effort we spend at work, there are clearly occasions when it makes us engage in unexpected and challenging circumstances while also offering moments of enjoyment. Furthermore, work in modern organizations is not performed in isolation but is based on work teams due to an enormous amount of information exchange, highly qualified and skilled individuals, and a changing working environment (Muchinsky, 2007). Work teams show a high degree of interdependence, which makes them capable of coping with ambiguous and uncertain situations within a group of competent and well-trained employees. Interdependence and mutually shared responsibility are defining properties that enable work teams to achieve the required outcomes (Cohen \& Bailey, 1997). In this process, work engagement may play a crucial role as social resources promote the vigor, dedication and absorption of employees, which transfer to the rest of the team members, thus contributing to achieve team duties. If we analyze how work engagement can be explained in the context of teams, several questions arise: What are the main theoretical models covering work engagement nowadays and how do they frame work engagement from a collective point-of-view? Is it possible to spread and share an affective-motivational state such as work engagement? How can we define and measure a shared state of team work engagement? What do we know about it? How does it emerge in the context of work organizations? 


\section{Chapter}

In this theoretical review an overview of the state-of-the-art in team work engagement is provided, highlighting the main streams of research in team work engagement. The goal is to identify what aspects require further investigation, and how they are developed in this thesis dissertation in particular. First, emphasis will be given to the definition and measurement of team work engagement. In the following section, the stress will be on the theories that can help us understand how work engagement can spread and be shared among different employees, namely, the emotional contagion theory. Then, the JD-R Model is discussed as the most widely used theoretical model to understand work engagement along with new multilevel models, such as the HERO Model. Next, the discussion takes a deeper look into the most relevant papers in order to develop what the state-of-the-art is in team work engagement, namely, how the extant literature agrees — or not — on the terminology, the operationalization, and the compositional models underlying team work engagement. Drivers and outcomes of the construct will be stressed at the end of this subsection. Finally, team work engagement will be framed within the organizational context and attention paid to the need for a multilevel model of work engagement.

\section{Team work engagement: Definition and measurement}

In this dissertation we build upon Schaufeli and colleagues' definition of work engagement as "a positive, fulfilling, work-related state of mind that is characterized by vigor, dedication, and absorption" (Schaufeli, Salanova, González-Romá, \& Bakker, 2002, p. 72). This seminal definition refers specifically to individuals. However, based on its inner dimensions, work engagement is also related to people with whom the employees carry out their daily duties. For example, a vigorous employee is persistent against difficulties and is thus able to motivate the rest of the team members to achieve team duties. A dedicated employee feels emotionally attached to the task at hand. This provides the employee with a sense of meaning that leads him or her to publicly 


\section{Chapter}

express joy and pride toward his or her work. Finally, absorbed employees feel fully engrossed with the task they are carrying out, which can provide a great deal of focus and concentration when engaging in a team task. These overt behaviors can be transmitted from one employee to another (Hatfield, Cacciopo, \&Rapson, 1994), and they are the basis for the definition that is used throughout this doctoral thesis. Therefore, team work engagement is defined as "a positive, fulfilling, work-related and shared psychological state characterized by team work vigor, dedication and absorption which emerges from the interaction and shared experiences of the members of a work team" (Torrente, Salanova, Llorens, \&Schaufeli, 2012, p. 107; see Chapter 5). Throughout this theoretical review we will stick to the term "team work engagement".

The definition and operationalization of team work engagement is closely related to the way research approaches and assesses the construct. Previous studies on work engagement provided support for the psychometric quality of the instrument used to assess the construct: the Utrecht Work Engagement Scale (UWES; Schaufeli et al., 2002). This scale is the most widely used tool to measure work engagement. A recent search on PsycINFO showed that $83 \%$ of scholarly articles about engagement used this questionnaire (Schaufeli\&Salanova, 2011). The UWES is composed of seventeen items measuring vigor (six items), dedication (five items), and absorption (six items) with a Likert-type scale ranging from 0 'never' to 6 'always'. The UWES has been translated into 24 languages (December, 2013). Different research using Confirmatory Factor Analysis (CFA) has provided evidence for the factorial validity of this instrument for testing work engagement in different occupations, such as workers in the tourism sector (Salanova, Agut, \&Peiró, 2005), ICT workers (Llorens, Schaufeli, Bakker, \&Salanova, 2007; Salanova\&Llorens, 2009), health care workers, educators, white- and blue-collar workers (Seppälä et al., 2009), university students working in groups (Llorens et al., 2006, 2007), and secondary school teachers (Salanova et al., 


\section{Chapter}

2010), as well as across different countries (for a review, see Schaufeli\& Bakker, 2010).

A further step in the measurement of work engagement was the shift toward the construction of a cross-nationally validated, 9-item version of the UWES scale (Schaufeli, Bakker, \&Salanova, 2006). By using CFA techniques, this revised scale was distributed in three dimensions: vigor (3 items), dedication (3 items), and absorption (3 items), with a Likert-type scale ranging from 0 'never' to 6 'always'. This short work engagement scale has also been cross-nationally validated in a large dataset with a wide range of occupations from ten different countries (Schaufeli et al., 2006). Thus the scientific literature provides an adequate measurement tool to assess work engagement. However, this use is limited to the individual level in the workplace: each individual answers the UWES by thinking about his/her personal perception of this experience.

Whereas individual work engagement has been widely studied using the UWES questionnaire, the measurement of team work engagement is a topic that remains uncovered. Although labeled as "collective engagement", Salanova and colleagues (2003) were the first scholars to propose a measure of team work engagement. However, this measure was applied to a sample of university students working in groups. The resulting adapted scale was composed of eighteen items distributed in three dimensions: collective vigor (seven items), collective dedication (four items), and collective absorption (seven items) using a Likert-type scale ranging from 0 'never' to 6 'always'. The focus of this measure was on the task (i.e., task engagement) and not on work (i.e., work engagement) as a whole (Schaufeli\&Salanova, 2011). This paper was the first attempt to address the factorial structure of this collective scale and served as a guideline for future research (e.g., Gracia, Salanova, Grau, \&Cifre, 2012; Salanova et al., 2005; Salanova, Llorens, \&Schaufeli, 2011). Despite the fact that these studies represented an important step toward achieving a validated measure of team work engagement, there is a lack of studies that analyze the factorial validity of this scale 


\section{Chapter}

following the requirements of a referent-shift consensus model: (1) assessment at the targeted level of analysis (i.e., changing the referent from "I" to "We"; Chan, 1998) to refer specifically to the shared state of team work engagement, and (2) justification of aggregation to the targeted level in terms of consensus and consistency through aggregation indices (Bliese, 2000). In Chapter 4, a proposed Team Work Engagement Scale is tested and built upon the UWES questionnaire. The chapter also presents the rationale for this adapted scale and its factorial validation based on its multilevel characteristics.

\section{Classic and new theoretical models in the study of team work engagement}

The Job Demands-Resources Model (JD-R Model; Demerouti, Bakker, Nachreiner, \&Schaufeli, 2001) is the most widely applied theoretical framework in the study of work engagement (Schaufeli\&Taris, 2014). The JD-R Model describes two different job characteristics in the workplace: job demands and job resources. Job demands are physical, social, or organizational characteristics of the job with which the employee is confronted, and require some effort to be accomplished. Employees' physical or emotional energy may end up being depleted or diminished in the process of dealing with job demands (Sonnentag, Mojza, Demerouti, \& Bakker, 2012). On the other hand, job resources involve a broad variety of physical, psychological, social or organizational aspects of the job that display three different characteristics: (1) they stimulate growth, development, and learning in workers; (2) they reduce the effect of job demands and its associated costs; and (3) they are functional in achieving work goals. As a consequence, job resources are not only necessary to cope with job demands, but they also play an important role in the work context in their own right.

Following the JD-R Model, both job demands and job resources have differential effects on work engagement (Bakker \&Demerouti, 2007). Job demands produce fatigue 


\section{Chapter}

and reduce energy while threatening a positive identification with one's work role, thus being positively related to employee burnout. On the positive side, job resources restore employees' energy and help them to deal with job demands successfully, thus promoting involvement and identification with one's job, i.e., engaging the work force. At the same time, job resources may reduce job demands, or the perception of their influence, which also leads to a negative relation with burnout being proposed (Schaufeli\& Bakker, 2004). Although in the JD-R Model both job demands are resources that include organizationallevel characteristics of the job, they have rarely been conceptualized at the appropriate level of analysis. In fact, recent reviews have commented on the importance of integrating the model into a multilevel framework in order to address the complexity of organizational phenomena and go deeper into development of the theory (Demerouti\& Bakker, 2011; Hakanen\&Roodt, 2010; Schaufeli\&Taris, 2014). In Chapter 2, the JD-R Model will be applied to a multilevel framework for team work engagement by testing the role of organizational demands and resources. Furthermore, in Chapter 5, the role of team work engagement as a mediator between social resources and objective performance in teams is tested by proposing that the motivational process of the JD-R Model may function at the team level of analysis.

In order to overcome the limitations and increase the applicability of the JD-R model in multilevel settings as opposed to focusing on individuals, other theoretical approaches for the study of well-being in work organizations have appeared. The HERO Model (HEalthy\& Resilient Organizations Model, Salanova, 2008, 2009; Salanova et al., 2012)

is a heuristic model that draws upon the notion of healthy organizations as "organizations that make systematic, planned, and proactive efforts to improve employees' and organizational processes and outcomes" (Salanova et al., 2012, p.788). HEROs are defined by three interrelated components: (1) Healthy organizational resources and practices, which refers to task resources (e.g., autonomy, feedback, variety), social resources (e.g., good leadership, social support, team working), and organizational practices (e.g., information and communication, career 


\section{Chapter}

and skill development, and organizational well-being); (2) healthy employees, concerning engaged and committed employees who are efficacious and resilient at work, and conduct their duties in a climate of trust with optimism and hope toward the future; and (3) healthy organizational outcomes, which refers to high quality services and products, as well as to improvements in organizational reputation by establishing positive relations with the environment, the community, and the rest of the stakeholders. Like the JD-R Model, the HERO model highlights the antecedents and consequences of individual work engagement. However, the impetus is given to the role of collective antecedents, states and outcomes required for a company to succeed in line with organizational objectives. As core shared states within the healthy employees component of the HERO Model, work engagement (e.g., Acosta, Salanova, \&Llorens, 2012; Hakanen, Perhoniemi, \&Toppinen-Tanner, 2008; Schaufeli\& Bakker, 2004; Xanthopoulou, Bakker, Demerouti, \&Schaufeli, 2009) and organizational commitment (e.g., Gong, Law, Chang, \&Xin, 2009; Schmidt \&Diestel, 2012; Taylor, Bedeian, \&Kluemper, 2012) are argued to play a mediatory role between the resources provided by the organization (i.e., the healthy organizational resources and practices component) and the actual performance of the firm (i.e., the healthy organizational outcomes component). Consequently, work engagement is expected to increase the performance of organizations at different levels of analysis. In the present dissertation, we build upon the HERO Model to provide an integration of team work engagement in the context of the organizations and in relation to organizational affective commitment in order to overcome the limitations of the JD-R Model (Chapter 6).

\section{The positive emotional contagion of work engagement}

Emotional contagion theory attempts to explain how different people are able to share and express the same emotional state (Hatfield, Rapson, \& Le, 2009). This theory posits that emotions can spread from individual to individual. The contagion of 


\section{Chapter}

emotions is triggered on the basis of our ability to empathize with the experiences of others (Barsade, 2002). Emotional contagion processes also seem to be present in the positive contagion of work engagement. Work engagement involves a number of behaviors such as the display of the expression of emotions and emotionally-charged verbalizations that can be appraised by team members and thus promote an emergent shared perception of work engagement (Bakker et al., 2006). For example, a vigorous employee is persistent against difficulties and is thus able to motivate the rest of the team members to achieve team duties. A dedicated employee feels emotionally attached to the task at hand. This provides the employee with a sense of meaning that leads him or her to publicly express joy and pride toward his or her work. Finally, absorbed employees feel fully engrossed with the task they are carrying out, which can provide a great deal of focus and concentration when engaging in a team task. These overt behaviors are perceived by others and may also have an effect on the levels of work engagement of the rest of the team members and represent the composition linkages between individual and our proposed conceptualization of team work engagement. In fact, the ability to perceive and regulate emotions has been identified as an antecedent of work engagement (Schaufeli, 2012a) and other positive emotions (van Gelderen, Konijn, \& Bakker, 2011). Previous research has tried to comprehend these mechanisms and how they work in the transmission of work engagement between couples (Bakker, Demerouti, \&Schaufeli, 2005; Sanz-Vergel, RodríguezMuñoz, Bakker, \&Demerouti, 2012), as well as within work teams (Bakker, van Emmerik, \&Euwema, 2006).

The studies available today have shown there are five conditions that facilitate the positive contagion of emotions: frequency of interaction, empathy, susceptibility to contagion, climate, and similarity (Bakker, Westman, \& Van Emmerik, 2009). By interacting more frequently, a team member is exposed to the emotional expressions of the team more times, thus making him or her more likely to converge emotionally (Bakker \&Schaufeli, 2000; Bakker \&Xanthopoulou, 2009). As regards empathy, if a 


\section{Chapter}

team member is more capable of putting him or herself in the other's shoes, it will be easier for him or her to feel the same way (Bakker \&Demerouti, 2009; Westman\&Vinokur, 1998). Susceptibility to contagion refers to the openness to capture the emotions of others, which increases the chances of contagion (Bakker, Schaufeli, Sixma, \&Bosveld, 2001). Team climate is also related to emotional contagion, as it considers the effect of other characteristics that are shared by all the members of the team. For example, a climate of cohesion among co-workers facilitates the transmission of positive emotions and prevents the undesirable effects of spreading negative emotions (Westman, Etzion, \& Chen, 2009). Concerning similarity, a worker may take another team member as an emotional referent if he or she feels identified with the other person. In uncertain situations in which the appropriate emotion is unclear, an evaluation of the emotional expressions of our colleagues helps us to decide what emotion is the proper one (Bakker, Westman, \&Schaufeli, 2007). Therefore, in job settings it becomes particularly relevant to assess the conditions for emotional contagion in order to promote desirable emotional shared states such as team work engagement. In Chapter 3 , we addressed how similarity between team members influences the spread and sharing of a team work engagement state, and the implications for diversity within organizations.

\section{What we know about team work engagement}

The number of papers available focusing on team work engagement is scarce, although some conclusions can still be drawn. Our search identified ten empirical studies addressing team work engagement, its drivers and outcomes, or team-level drivers and outcomes of individual work engagement. These papers are classified in Table 1 according to the terminology applied to refer to a shared state of team work engagement, the operationalization of the construct along with the level of assessment and the level of analysis involved, and the drivers and outcomes of team work engagement analyzed. At 
Chapter

first sight, the table shows that in the extant literature on team work engagement, there is no consensus on the way that scholars refer to team work engagement. Furthermore, the mismatch between the level of assessment and the level of the analysis of team work engagement is not the exception but the common rule, which results in confusion as to how to operationalize the concept. At the end of this subsection, we will focus our attention on the main drivers and outcomes acknowledged throughout this body of research. 
Table 1. Classification of the scientific literature on team work engagement presented in chronological order.

\begin{tabular}{|c|c|c|c|c|c|c|}
\hline Article & Term & $\begin{array}{c}\text { Level of } \\
\text { assessment }\end{array}$ & $\begin{array}{l}\text { Level of } \\
\text { analysis }\end{array}$ & Operationalization & Drivers & Outcomes \\
\hline $\begin{array}{l}\text { Harter et al. } \\
(2002)\end{array}$ & $\begin{array}{l}\text { Employee } \\
\text { engagement }\end{array}$ & Individual & Team & Aggregation & - & $\begin{array}{lr}\text { Customer } & \text { satisfaction-loyalty, } \\
\text { profitability, } & \text { productivity, } \\
\text { turnover, safety, performance }\end{array}$ \\
\hline $\begin{array}{l}\text { Salanova et al. } \\
(2003)\end{array}$ & $\begin{array}{l}\text { Collective } \\
\text { engagement }\end{array}$ & Team & Individual & Aggregation & $\begin{array}{l}\text { Perceived collective efficacy, } \\
\text { time pressure, group } \\
\text { communication system }\end{array}$ & - \\
\hline $\begin{array}{l}\text { Salanova et al. } \\
(2005)\end{array}$ & $\begin{array}{l}\text { Work } \\
\text { engagement }\end{array}$ & Individual & Team & Aggregation & Organizational resources & $\begin{array}{l}\text { Service climate, employee } \\
\text { performance }\end{array}$ \\
\hline $\begin{array}{l}\text { Bakker et al. } \\
(2006)\end{array}$ & $\begin{array}{l}\text { Team-level } \\
\text { engagement }\end{array}$ & Individual & Team & $\begin{array}{l}\% \text { of engaged } \\
\text { employees }\end{array}$ & - & $\begin{array}{l}\text { Individual burnout and work } \\
\text { engagement core dimensions }\end{array}$ \\
\hline $\begin{array}{l}\text { Hakanen et al. } \\
(2008)^{\star}\end{array}$ & $\begin{array}{l}\text { Work } \\
\text { engagement }\end{array}$ & Individual & Individual & - & Job resources & $\begin{array}{l}\text { Personal initiative, work-unit } \\
\text { innovativeness }\end{array}$ \\
\hline $\begin{array}{l}\text { Xanthopoulou et } \\
\text { al. }(2009)^{*}\end{array}$ & $\begin{array}{l}\text { Work } \\
\text { engagement }\end{array}$ & Individual & Individual & - & $\begin{array}{l}\text { Self-efficacy, organizational- } \\
\text { based self-esteem, optimism }\end{array}$ & Financial returns \\
\hline $\begin{array}{l}\text { Salanova et al. } \\
(2011)\end{array}$ & $\begin{array}{l}\text { Task collective } \\
\text { engagement }\end{array}$ & Team & Individual & Aggregation & $\begin{array}{l}\text { Collective efficacy beliefs, } \\
\text { positive affect }\end{array}$ & - \\
\hline $\begin{array}{l}\text { Gracia et al. } \\
(2012)\end{array}$ & $\begin{array}{l}\text { Collective work } \\
\text { engagement }\end{array}$ & Individual & Team & Aggregation & Organizational facilitators & $\begin{array}{l}\text { Relational service competence, } \\
\text { service quality }\end{array}$ \\
\hline $\begin{array}{l}\text { Acosta et al. } \\
(2012)\end{array}$ & $\begin{array}{l}\text { Team work } \\
\text { engagement }\end{array}$ & Team & Team & Aggregation & $\begin{array}{l}\text { Organizational practices, } \\
\text { organizational trust }\end{array}$ & - \\
\hline $\begin{array}{l}\text { Tims et al. } \\
(2013)\end{array}$ & $\begin{array}{l}\text { Team work } \\
\text { engagement }\end{array}$ & Team & Team & Aggregation & Team job crafting & $\begin{array}{l}\text { Team performance, individual } \\
\text { work engagement }\end{array}$ \\
\hline
\end{tabular}

*These studies only included collective outcomes of individual work engagement. 


\section{Chapter}

\subsection{Terminology and assessment}

In all cases, the studies under analysis depart from distinct ways of labeling and assessing team work engagement. For example, Harter, Schmidt, and Hayes (2002) focused on employee engagement at the business-unit level of analysis by building upon Kahn's (1990) seminal paper and using the $Q^{12}$ questionnaire. In contrast, the rest of the papers follow the conceptualization of work engagement developed by Schaufeli and colleagues using the UWES questionnaire (Schaufeli et al., 2002). Although the UWES approach is taking the lead as a measurement tool for the construct, there is confusion regarding the most convenient label for the term. In fact, almost every author has developed their own terminology to dub a shared state of work engagement, such as: "employee engagement" (Harter et al., 2002); "collective engagement" (Salanova et al., 2003); merely "work engagement" (Salanova et al., 2005); "team-level engagement" (Bakker et al., 2006); "task collective engagement" (Salanova et al., 2011); "collective work engagement" (Gracia et al., 2012); and, following Torrente, Salanova, Llorens, and Schaufeli (2012, see Chapter 4 in this dissertation), "team work engagement" (Acosta et al., 2012; Tims et al., 2013). Coherently, Hakanen et al.'s (2008) and Xanthopoulou et al.'s (2009) papers stuck to the term "work engagement" as they focus on work engagement at the individual level of analysis. The wide range of terms applied to the concept of team work engagement not only hamper understanding between scholars and practitioners, but also denotes disagreement in the underlying compositional model.

\subsection{Operationalization of team work engagement}

As was the case for the labeling of the construct, many differences exist in terms of how the literature on team work engagement operationalizes and frames this construct and its multilevel nature. This has deep implications when it comes to developing a successful conceptualization of team work engagement. As a construct allocated within teams emerging from the interaction and shared experiences of the team members, 


\section{Chapter}

team work engagement follows a referent-shift consensus model (Chan, 1998). In a referent-shift consensus model, higher-level constructs are composed by consensus among the lower-level units, although they are conceptually distinct, that is: the product of an emergent process. In this case, team constructs may have a similar structure to that of their individual counterpart, but they are expected to present some different functional properties (e.g., by showing a different pattern of relations with job demands, job resources, and outcomes) (Kozlowski \& Klein, 2002). Underlying a referent-shift consensus model there is the assumption that a collective phenomenon may not exist without consensus among the team members. In other words, one will not be dealing with individual perceptions of team-level work engagement, but with team work engagement as a differentiated construct. Thus, the successful operationalization of team work engagement using a referent-shift consensus model also requires a theory that accounts for its spread and sharing within teams.

As presented before (see section 3 in this theoretical review), the emotional contagion theory (Hatfield et al., 1994) provides the foundations for the positive contagion of team work engagement and the composite linkages connecting individual work engagement to the emergence of a shared state of team work engagement. Furthermore, a construct that is based on a referent-shift consensus model has two more requirements, namely it must: (1) be assessed at the targeted level of analysis (i.e., changing the referent from "I" to a collective form referring to the team; Chan, 1998), and (2) justify aggregation to the targeted level in terms of consensus and consistency through aggregation indices (Bliese, 2000). Therefore, the studies under analysis can also be classified in terms of the level of assessment (individual vs. team) and the level of analysis (individual vs. team) implied.

Salanova et al. $(2003,2011)$ assessed team work engagement at the team level (i.e., the referent was the team), however, their analyses were based on individual data. That is, they conducted the analysis using individual perceptions of team work engagement. In contrast, four papers chose completely the opposite perspective. In 


\section{Chapter}

these papers, researchers assessed work engagement at the individual level, but aggregated these individual data into averaged (i.e., aggregated) measures for the team. This means that these authors followed a direct consensus model (Chan, 1998). In direct consensus models the meaning of team work engagement relies purely on the consensus among team members without referring to the team. In this group of papers, it is worth noting that Bakker et al. (2006) took a totally different perspective and conceptualized team work engagement as the percentage of engaged employees working in the same team. Only in two papers (Acosta et al., 2012; Tims et al., 2013) was team work engagement both assessed and analyzed at the team level of analysis following Torrente et al. (2012; see Chapter 4). Therefore, a referent-shift consensus model was applied with the team as a referent and aggregation was justified using both consensus and consistency indices. All in all, results require further refinement using a common compositional model that would allow findings to be replicated and compared. We suggest that the use of a referent-shift consensus model would be preferred, as it allows for an integrated and better understanding of team work engagement in a multilevel context.

\subsection{Drivers and outcomes of team work engagement}

In this subsection, the main findings of the literature under analysis in terms of drivers and outcomes of team work engagement will be described. Papers are presented in chronological order. Harter et al. (2002) used a dataset consisting of 7939 business units in 36 companies to analyze the patterns of correlations between employee engagement (measured by the $\mathrm{Q}^{12}$ questionnaire, which mainly taps job satisfaction and a resourceful environment) and business outcomes (i.e., customer satisfaction, productivity, profit, employee turnover, and accidents). These authors found consistent evidence for the positive association between employee engagement and business outcomes across the companies under study. 


\section{Chapter}

Salanova et al. (2003) conducted a laboratory study in which 143 students were randomly distributed into 28 groups and were asked to work in either face-to-face or online chat interaction. Time pressure was balanced in both sets of groups. Results confirmed the moderating role of perceived collective efficacy over team work engagement. Although performance was included in this study, it was not tested directly in relation to team work engagement. In another paper, Salanova et al. (2005) applied SEM using aggregated data from 114 teams of hotel and restaurant employees and 1140 customers, and showed that organizational resources (i.e., training, autonomy, and technology) may act as drivers of team work engagement, which in turn is related to service climate and employee performance. Bakker et al. (2006) conducted a multilevel study in 2229 constabulary officers working in 85 teams using hierarchical linear modeling. Results indicated that team work engagement was positively related to individual-level work engagement.

Despite not testing team work engagement, two papers are worth discussing due to their implications for team and business-unit performance. In a longitudinal two-wave design using individual data, Hakanen, Perhoniemi, and Toppinen-Tanner (2008) found that higher individual work engagement led to higher personal initiative, which in turn increased individual perceptions of team-level innovativeness. Following a different perspective, Xanthopoulou, Bakker, Demerouti, and Schaufeli (2009) conducted a diary study on two shifts of two branches of a fast-food restaurant. Results showed that daylevel work engagement was positively related to objective financial returns at the end of the day. Financial returns were disaggregated for employees working on a given day and shift on the basis of the total amount of money earned within a particular shift that was reported by the supervisors of each branch.

In another study investigating the concept of team work engagement, Salanova et al. (2011) conducted a set of two studies to test the effect of efficacy beliefs over work engagement indirectly through the influence on positive affect. In study 2 , the authors developed a three-wave laboratory experiment on gain spirals between 


\section{Chapter}

collective efficacy beliefs, positive affect (i.e., comfort, enthusiasm, and satisfaction), and team work engagement. Longitudinal SEM in a sample of 100 university students working in groups confirms a positive spiral between the constructs under study. In fact, collective efficacy beliefs increased over time due to the influence of positive affect and team work engagement. Furthermore, enthusiasm - an active affect — showed the strongest relationship with team work engagement.

More recently, Gracia et al. (2012) analyzed data from 107 service-oriented units, aggregated from 615 service workers and 2165 customers. Applying SEM, these researchers showed that organizational facilitators (i.e., technical support, training, and autonomy) are related to team work engagement and relational service competence, which play a mediating role between organizational facilitators and service quality. As afforded by the organization, these resources provide the teams with skills, time scheduling and tools to fulfill their tasks and overcome the difficulties they find in the process. In the end, this may result in less stress and more energy, dedication and absorption at work that turns into better relational service competence and service quality as assessed by the customers.

In another study, Acosta et al. (2012) tested drivers of team work engagement in 518 employees nested within a heterogeneous sample of 55 teams. These scholars conducted a SEM to test the mediating role of organizational trust (i.e., vertical trust) between organizational practices and team work engagement (i.e., team work vigor, and team work dedication). Results indicated that vertical trust fully mediated the relationship between the practices implemented by the organization and team work engagement. These findings pointed out that the more the team members trust their supervisors and top managers, the higher the team work engagement with the task was within the teams.

Finally, another paper covering drivers of team-level engagement is Tims and colleagues' paper (2013) on team-level job crafting as an aggregated construct. These scholars found that in optimally designed (i.e., crafted) work environments work teams 


\section{Chapter}

have sufficient job resources and challenging work demands, which makes employees working in teams more likely to remain engaged in the collective task. Team work engagement was found to be positively related to individual work engagement, and to team performance as perceived by the employees.

All in all, the classification of the extant scientific literature on team work engagement is driven by studies using the UWES questionnaire, but there is a lack of agreement on the appropriate term to describe it. The main cause of this lack of consensus seems to be the confusion on how the construct is operationalized in terms of level of measurement and level of analysis, and thus in the underlying compositional model. Moreover, the number of studies is not large enough to enable integration of the results. Although this is a preliminary statement, researchers are assuming a homology of processes and mechanisms underlying both individual and team work engagement. Although scarce in number, taken together, these studies provide evidence for the positive relation between work engagement and valuable outcomes for employees working in teams and for the organizations as a whole. In the current dissertation, we provided a referent-shifted measure with justified aggregation (Chapter 4) and analyzed the drivers and outcomes of team work engagement at the target level of analysis (i.e., teams, Chapter 5 and 6). These chapters will provide a fine-grained tool for assessing team work engagement and a test of their empirical relationships that will contribute to the conceptualization of team work engagement following a referent-shift consensus model. In Chapter 5 and 6 , team work engagement will be related to drivers and outcomes at the team and organizational level of analysis, respectively.

\section{The need to build upon a multilevel model of team work engagement}

Although teams carry out their assigned duties, they are not beyond the influence of the wider organizational context in which they are embedded. Therefore, teams and 


\section{Chapter}

their performance benefit from human resource practices and also coexist with other general affective states within the organization (Gardner, Wright, \& Moynihan, 2011). Some scholars have addressed what strategies and practices can be implemented by the organization in order to achieve higher levels of work engagement within companies (Llorens, Salanova, Torrente, \& Acosta, 2013; Salanova, Llorens, Acosta, \& Torrente, 2013). Some examples include: work training and career management (Salanova et al., 2005; Schaufeli, 2014; Schaufeli\&Salanova, 2010), fairness and employee development and training (Gruman\& Saks, 2011), perceived ethical citizenship as a form of corporate social responsibility (Lin, 2010), or information and communication practices (Mone\& London, 2009). The notion of team work engagement is of practical value here as interventions and human resource practices oriented toward teams or business units are easy to implement at a lower cost (Schneider, Macey, Barbera, \& Young, 2010).

Further benefits for team performance may result when teams are embedded in an organizational environment that promotes a strong sense of commitment toward the organization (Salanova et al., 2012). Organizational affective commitment and team work engagement are socially construed following a similar contagion mechanism of emotions (Gardner, Wright, \& Moynihan, 2011). Furthermore, the notion of collective affective commitment bears some similarity with the notion of team work engagement, especially in the case of the dedication component, in which both refer to a strong sense of involvement and identification. This conceptual and nomological overlapping, however, does not allow for a clear differentiation of the constructs (Hallberg\&Schaufeli, 2006; Macey \& Schneider, 2008; Meyer, Gagné, \&Parfyonova, 2010). Hence, several authors have addressed their conceptualization as different states while identifying differences in the pattern of associations between them and with key organizational outcomes. For example, in a meta-analysis conducted by Newman, Joseph, and Hulin (2010) work engagement and organizational commitment showed modest correlations with an overlap of $15-29 \%$. Furthermore, another meta- 


\section{Chapter}

analysis showed that work engagement predicts in-role and extra-role performance after controlling for three job attitudes, including job satisfaction, job involvement, and organizational commitment (Christian, Garza, \& Slaughter, 2011).

One step further in distinguishing between the two states concerns both the foci and the sources, that is, the targets of, and motives for, organizational commitment in relation to job performance, respectively (Becker, Billings, Eveleth, \& Gilbert, 1996). In this line of reasoning, Schaufeli and Salanova (2011) drew attention to the need to consider the most suitable level of analysis for a proper conceptualization of collective work engagement and related collective states, such as organizational affective commitment. Thus, although both phenomena may play similar roles as mediating states related to antecedents (i.e., healthy organizational practices and resources) and outcomes (e.g., performance), the two constructs are better allocated at different levels of analysis within the organization (Macey \& Schneider, 2008). This view is coherent with the principle of compatibility (Ajzen, 2005), by which collective constructs should be studied in relation to other collective constructs.

The development of a multilevel model of team work engagement may provide a better understanding of collective work engagement within the wider organizational context. This would also allow for a clearer differentiation between work engagement and organizational commitment in terms of level of analysis. In the last empirical paper of this dissertation (Chapter 6) we propose a model of team work engagement in relation to human resource practices and organizational affective commitment. This approach accounts for the multilevel nature of work engagement not only at the team level of analysis but within the context of the entire organization (Demerouti\& Bakker, 2011; Schaufeli, 2012; Schaufeli\&Taris, 2014). 


\section{Chapter}

\section{Conclusion}

In conclusion, throughout this theoretical review we have highlighted several issues that deserved further attention in order to comprehend the emergence, mechanisms, and processes involved in team work engagement. These are gaps in the current literature on the topic and were translated into the specific goals of the present dissertation. For the time being, the lack of studies on team work engagement do not allow the integration of results into a clear model that enables its comprehension in terms of drivers, outcomes, and the process of emergence from individual employees to become a collective phenomenon. Moreover, the above-mentioned studies depart from very different perspectives on measuring, labeling, and conceptualizing the concept in terms of level of measurement and analysis. This confusion arises in a moment where new and classic models on work engagement call for further attention on the multilevel processes involved in work organizations. In this context, gathering further knowledge on team work engagement may offer an intermediate level of study between individuals and organizations, and thus provide some common ground for a better understanding of work engagement and well-being in organizations. 


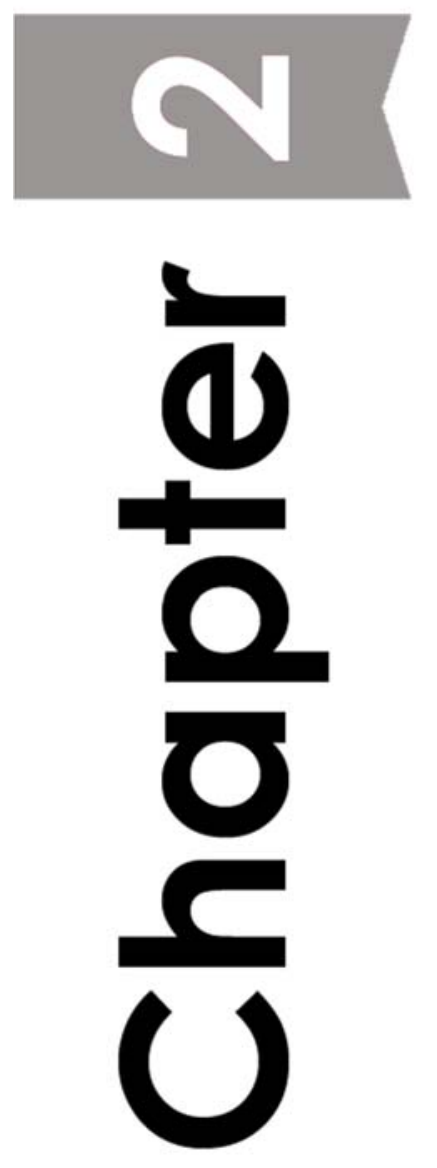




\section{Organizational Antecedents of}

\section{Burnout and Work Engagement:}

A Multilevel Study in Portuguese Firefighters' Brigades

This paper has been submitted as:

Torrente, P., Salanova, M., Llorens, S., Ângelo, R.P., \& Chambel, Ma.J. (2014). Organizational antecedents of burnout and work engagement: A multilevel study in Portuguese firefighters' brigades. Manuscript submitted. 


\section{Chapter 2}

\section{Organizational antecedents of burnout and work engagement: A multilevel study in Portuguese firefighters' brigades}

Many researchers will agree on the importance of taking care of well-being in the workplace by means of job demands and job resources. Although job demands are not necessarily negative, they do become stressors leading to chronic fatigue (Hakanen \& Roodt, 2010). This impairment process is especially consistent for the burnout syndrome, as work demands may deplete employees' energy and hinder their attachment to the organization (Schaufeli \& Bakker, 2004). Burnout is an important topic in work-related wellbeing that implies negative outcomes for both the individuals (e.g., depression; Maslach, Schaufeli, \& Leiter, 2001) and the organization (e.g., sickness absenteeism; Schaufeli, Bakker, \& van Rhenen, 2009). As a result, job-related burnout costs companies billions of dollars in terms of medical insurance and reduced productivity every year (Wall Street Journal, 2007). In contrast, job resources are intrinsically motivating for employees as they satisfy the basic human needs of competence, autonomy, and belongingness (Van den Broeck, De Witte, Lens, \& Vansteenkiste, 2008), and thus they have shown a consistent association with work engagement (Halbesleben, 2010). Resources are functional in achieving work goals and help to deal with work demands, thus promoting work engagement and, even more, preventing burnout, which some authors consider the antipode of work engagement (Schaufeli, Salanova, González-Romá, \& Bakker, 2002). The consequences of work engagement are allocated both at the individual level (e.g., performance and health; Shirom, Toker, Berliner, Shapira, \& Melamed, 2008) and at the organizational level (e.g., customer loyalty and service climate; Salanova, Agut, \& Peiró, 


\section{Chapter}

2005). In fact, companies with engaged employees may benefit from $\$ 80,000$ to $\$ 120,000$ more in monthly revenues and sales than less engaged organizations (Harter, Schmidt, \& Hayes, 2002).

One of the most widely applied theoretical models for both burnout and work engagement is the Job Demands-Resources Model (JD-R Model; Demerouti, Bakker, Nachreiner, \& Schaufeli, 2001). This model highlights job demands and job resources as the main antecedents of well-being at work. Recent reviews on the JD-R Model call for further research on multilevel processes in order to address the complexity of organizational phenomena and go deeper into theoretical development (Demerouti \& Bakker, 2011; Schaufeli 2012; Schaufeli \& Taris, 2014). In this context, it becomes important to differentiate between demands and resources at the unit level of analysis. Organization-level demands are shared demands that are common to all employees working in the same work unit. Similarly, organizational resources are developed within organizations. These involve actions taken by the work unit colleagues (i.e., social support) or practices implemented by the organization as represented by the CEOs or immediate supervisors (e.g., human resource practices). In the current study, we test a JD-R Model of occupational well-being in firefighters taking a cross-level perspective by including organizational demands and resources as shared, contextual characteristics of fire brigades that may have an influence on individual predictors of well-being.

Unlike employees working in profit organizations, firefighters' mission is to protect citizens' lives in emergency situations and so they therefore deal with demands and require particular resources that may influence their levels of burnout and work engagement in a very specific manner. Firefighters are expected to tackle risky situations that involve emergency fires, but they are also specially trained and prepared to save lives in extremely harsh situations (Patri, Pietrantoni, \& Cicognani, 2010). They need to be physically and psychologically able, and to keep themselves in excellent health to be able 


\section{Chapter 2}

to cope with the requirements of the job, and even more so given the intermittence of their work. In fact, unpredictable emergency tasks occur in between periods of full readiness for action (Kalimo, Lehtonen, Daleva, \& Juorinka, 1980). In these emergency situations they are exposed to a wide range of occupational demands that involve environmental stressors such as noise, poor lighting or extreme temperatures during shift and night work (Åkerstedt, 1990); traumatic stress derived from their role as help providers (Fullerton, McCarroll, Ursano, \& Wright, 1992); and organizational stressors such as situations where they are understaffed (McLeod \& Cooper, 1992). The implications of burnout and work engagement for firefighters have often been neglected in the literature, and even more so as regards the understanding of the conditions that foster well-being and not only prevent malfunctioning (Ben, Scotti, Chen, \& Fortson, 2006). The current study looks deeper into the role of both individual- and organization-level demands and resources for burnout and work engagement in firefighters developing their work in the context of fire brigades.

\section{Burnout and work engagement in the context of the Job- Demands Resources Model}

A dual perspective of well-being at work that includes both negative psychological states (i.e., burnout) and positive psychological states (i.e., work engagement) contributes to a more accurate understanding of the motives and emotions in job settings (George, 2011). The burnout syndrome is a "prolonged response to chronic emotional and interpersonal stressors on the job, and is defined by the three dimensions of exhaustion, cynicism, and professional inefficacy" (Maslach et al., 2001, p.397). On the positive side of well-being at work, work engagement is regarded as the positive pole of burnout (González-Romá, Schaufeli, Bakker, \& Lloret, 2008). First conceptualized by Kahn (1990), work engagement is a "positive, work-related state of mind, that is characterized by vigor, 


\section{Chapter}

dedication and absorption" (Schaufeli et al., 2002, p.74). Burnout and work engagement have been regarded as contrastingstates that mediate between opposing processes leading to health impairment (i.e., burnout) and work motivation (i.e., work engagement) (Schaufeli \& Bakker, 2004). Furthermore, the core dimensions of burnout and work engagement stand at the opposite ends of two different continua, namely, activation and identification (Schaufeli et al., 2008). At the activation pole, emotional exhaustion involves the depletion of emotional resources and thus the employee feels fatigued and emotionally drained, while vigor refers to feeling persistent against difficulties as well as energetic, strong, and devoted to his/her task. The identification pole relates to cynicism and dedication. Cynicism involves indifference or a distant attitude toward one's job or toward whom one works with, while dedication refers to being emotionally attached to the task at hand, which provides the employee with a sense of meaning and purpose toward his or her work.

Emotional exhaustion and cynicism constitute the core of the burnout syndrome (Green, Walkey, \& Taylor, 1991), a lack of professional efficacy being a consequence of it (García, Llorens, Cifre, \& Salanova, 2006). As a counterpart of the core dimensions of burnout, vigor and dedication are considered the core dimensions of work engagement (Schaufeli et al., 2002), absorption being a plausible consequence of it (Schaufeli, Taris, \& Van Rhenen, 2008). In the current study we have included the core dimensions of burnout (i.e., emotional exhaustion and cynicism) and work engagement (i.e., vigor and dedication). The rationale for the perspective taken in this study is twofold. Firstly, this is coherent with the idea of offering an integrative picture of emotional states in organizations by including both the negative (i.e., burnout) and positive (i.e., work engagement) indicators of psychological well-being at work (George, 2011). Secondly, based on the JD$\mathrm{R}$ Model, the study provides a closer examination of the antecedents of the separate dimensions of burnout and work engagement (Bakker \& Leiter, 2010). Focusing on the 


\section{Chapter 2}

single core dimensions of burnout and work engagement as dependent variables addresses the call for the conceptual development of burnout and work engagement based on their inner core components by taking into account differential patterns of relationships of their core dimensions with antecedents and/or consequences (Demerouti, Mostert, \& Bakker, 2010; Lorente, Salanova, Martínez, \& Schaufeli, 2006).

The JD-R Model (Demerouti, Bakker, Nachreiner, \& Schaufeli, 2001) is one of the most widely applied theoretical frameworks in the study of burnout and work engagement. The JD-R Model describes two different job characteristics in the workplace: job demands and job resources. Job demands are physical, social, or organizational characteristics of the job with which the employee is confronted, and that require an effort to be accomplished. One's physical or emotional energy may become depleted in the process of dealing with job demands (Sonnentag, Mojza, Demerouti, \& Bakker, 2012). On the other hand, job resources are aspects of the job (i.e., physical, psychological, social, or organizational) that facilitate work goal achievement, reduce job demands, and ease personal development and growth (Demerouti et al., 2001).

Following the JD-R Model, both job demands and job resources have differential effects on burnout and work engagement, respectively (Bakker \& Demerouti, 2007). Job demands produce fatigue and reduce energy while threatening a positive identification with one's work role, thus being positively related to employee burnout. On the positive side, job resources restore employees' energy and help them to deal with job demands successfully, thus promoting involvement and identification with one's job, i.e., engaging the workforce. At the same time, job resources may reduce job demands, or the perception of their influence, which also leads to the proposal of a negative relation with burnout (Schaufeli \& Bakker, 2004). Although in the JD-R Model both job demands and resources include organizational-level characteristics of the job, they have rarely been 


\section{Chapter}

conceptualized at a higher higher-order level of analysis in relation to burnout and work engagement (Hakanen \& Roodt, 2010; Schaufeli \& Taris, 2014).

\section{Acute demands and proactive coping strategies: Firefighter- level hypotheses}

Firefighters experience threatening work conditions that influence their well-being due to cumulative exposure in their daily work life (Chamberlin \& Green, 2010). Firefighter personnel intervene in incidents that involve severe injuries, life-threatening circumstances, and death, which are potentially traumatic events for them (Halpern, Gurevich, Schwartz, \& Brazeau, 2009). Hence, firefighters are exposed to very intense stressors for short periods of time, which thus become acute demands due to the intermittent nature of their work (Kalimo et al., 1980). The specificity of emergency situations is common to police, ambulance, and firefighting personnel, with the potential to lead them to become secondary victims of trauma and even to exhibit symptoms similar to those experienced by direct victims (Genest, Levine, Ramsden, \& Swanson, 1990; Raphael \& Meldrum, 1993). Adverse work conditions have consequences for the wellbeing and readiness for action of personnel, which may be largely reflected in their effectiveness. For example, Tuker, Sinclair, and Thomas (2005) showed that increased quantitative overload and less predictability were associated to a decrease in soldiers' well-being (i.e., higher depression and lower job satisfaction) and readiness for action (i.e., lower morale).

In the context of firefighters, acute demands are "unusual situations that hinder the responsiveness of the firefighter and lead to strong emotional reactions" (Ângelo, 2010; p.45). In emergency and ambulatory workers, these unexpected events may result in higher stress, usually combined with negative emotions and feelings of despair and 


\section{Chapter 2}

poignancy (Halpern et al., 2009). A conscious effort to deal with negative affect may result in energy depletion as the firefighter is required to actively confront these demands as part of his or her job (Gailliot et al., 2007). As a consequence, exposure to these demands may, in the long run, lead to emotional exhaustion (i.e., feeling emotionally drained and fatigued), and less vigor (i.e., feeling less vigorous and energetic during the required tasks and missions). This provides an explanation of why employees under strain invest in recovery activities in order to achieve an adequate level of psychological detachment from work (Sonnentag \& Jelden, 2009). In a more dysfunctional process aimed at preventing negative emotional reactions to acute demands, however, employees might develop cynical attitudes (i.e., psychological distance from one's job or the people with whom one is related at work), and diminish their levels of dedication (i.e., becoming less enthusiastic about and inspired by work). Therefore, we expect that:

Hypothesis 1a: Acute individual demands are positively related to burnout (i.e., emotional exhaustion and cynicism) and negatively related to work engagement (i.e., vigor and dedication). 


\section{Level 2: Fire brigade level} Level 1: Firefighter leve

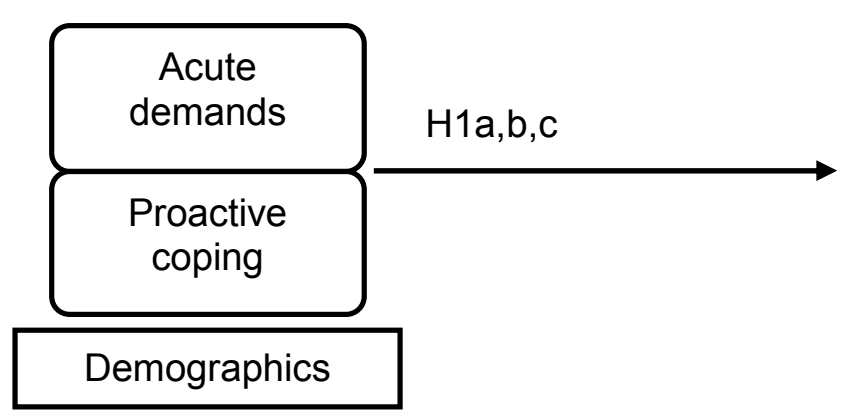

Psychological well-being

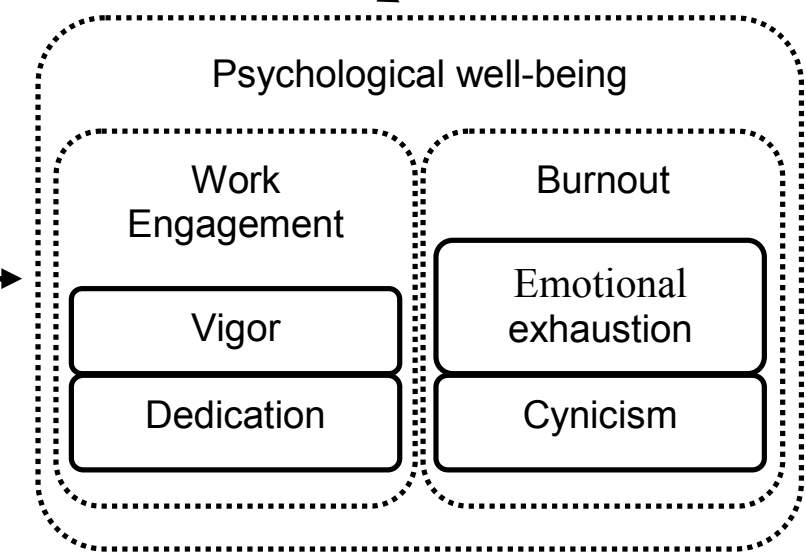

Figure 1. Research model involving individual firefighter-level predictors (H1a,b,c), and organizational fire brigade-level predictors (H2a,b, cross-level hypotheses). 


\section{Chapter 2}

Demanding work environments such as those experienced by firefighting personnel require suitable strategies that contribute to their well-being. Coping strategies are cognitive or behavioral efforts carried out to deal with demands that tax or exceed the personal resources of an individual (Lazarus \& Folkman, 1984). Thus, coping strategies alleviate emotional distress caused by overwhelming events that are perceived as harmful, threatening, or uncontrollable. As an intrinsic part of a firefighter's job, they depend on unexpected events that are common to other emergency and help-providing personnel and which can threaten their well-being (Bakker \& Williams, 2001; Bennett, Williams, Page, Hood, Woollard, \& Vetter, 2005; Cornell, Beaton, Murphy, Johnson, \& Pike, 1999). Following this rationale, the notion of proactive coping strategies suggests that firefighters may benefit from looking at unexpected events as challenges and self-promoting opportunities (Schwarzer, 2000).

Proactive coping strategies are defined as "an effort to build up general resources that facilitate promotion toward challenging goals and personal growth" (Schwarzer, 2001; p.406). Compared with other types of coping, a proactive coping style is more focused on future events that are perceived as self-promoting, thus helping to overcome their negative consequences (Schwarzer, 2000). Examples of this specific type of coping strategies include arranging resources to be used in an optimal way, realistic goal setting and appraisal of future events, and effective use of performance feedback (Sohl \& Moyer, 2009). Employees that deal with recurrent and unpredictable emergency situations may benefit from making use of a proactive coping style as they may perceive themselves to be more capable of successfully meeting their goals (Jex, Bliese, Buzzell, \& Primeau, 2001) or may take active steps to cope with stressors on their own or with other colleagues (Bakker, Schaufeli, Leiter, \& Taris, 2008). Apart from this expected, direct positive effect on psychological well-being at work (i.e., decreasing burnout and increasing work engagement), we can expect an indirect, positive effect of proactive coping as a moderator 


\section{Chapter}

of work demands. By definition, coping strategies are conscious efforts in which individuals engage when the expected circumstances overcome the resources they have at hand (Schaufeli, 2001). Hence, these strategies are oriented toward reducing the impact of demands. In the case of firefighting personnel, proactive coping strategies may buffer the negative effect of acute demands on firefighters' psychological well-being. Although scarcely researched in this specific population, previous literature suggests that well-being at work may benefit (i.e., less burnout and more work engagement) from applying proactive coping strategies as a means of dealing with highly demanding situations that have potentially harmful effects (e.g., Lewin \& Sager, 2009; Yip, Rowlinson, \& Siu, 2008). Therefore, we expect that:

Hypothesis 1b: Proactive coping strategies are negatively related to burnout (i.e., emotional exhaustion and cynicism) and positively related to work engagement (i.e., vigor and dedication).

Hypothesis 1c: Proactive coping strategies moderate the association between acute demands and both burnout and work engagement. Therefore, proactive coping strategies will buffer the positive relation between acute demands and burnout (i.e., emotional exhaustion and cynicism) and the negative relation between acute demands and work engagement (i.e., vigor and dedication) so that it will become weaker.

\section{Organization-level demands and social support: Brigade-level hypotheses}

Stress among firefighter personnel is not only caused by individual characteristics or demands that are only allocated at the individual firefighter level. Fire brigades consist of 


\section{Chapter 2}

direct command and control hierarchies, have clear goals, and are functionally organized so as to be able to fulfill their duties collectively. Because of the high level of coordination required to complete their tasks successfully during emergency situations involving fires and the like, firefighters share common experiences, values, knowledge, and perspectives in order to understand organizational events and interpret organization-level demands. In this context, organization-level demands are unit or organizational characteristics that require sustained mental effort, and hence are associated with physiological or psychological costs (Demerouti et al., 2001). Organization-level demands refer to the term shared stressor as an organizational characteristic shared by all the members of a working unit that may have a negative impact on individual well-being (Ostroff, 1993).

The distinctiveness of organization-level demands over other types of demands, suggests that the JD-R Model is built upon the notion of a cross-level theory (Rousseau, 1985). This means that contextual factors (i.e., shared stressors at the organizational level) may have predictive power over individual experiences (i.e., individual well-being), that is, contextual factors constitute a top-down process (Bliese, 2000). In fact, the outcomes of shared stressors may include direct effects on the levels of stress experienced by individuals, their productivity, and their levels of well-being (Bliese \& Jex, 2002). In cross-level theories, the constructs under analysis need to be aggregated and allocated at the target level of analysis (i.e., unit, platoon, organization) since collective constructs involve a different meaning from those of their person-level counterparts (e.g., Bliese \& Halverson, 1996).

Furthermore, research in multilevel contexts requires the implementation of a multilevel methodology that takes non-independence into account (Kreft \& Deleuw, 1998). In the context of this study, non-independence refers to a common amount of variance between firefighters due to their grouping in the same fire brigades, where they are subjected to similar organization-level demands. The presence of organization-level 


\section{Chapter}

demands makes the specific context in which these workers carry out their job more stressing. Examples of organization-level demands in the firefighters' context are: use of inadequate or impaired equipment or technology, understaffed situations, excessive overwork or double-shifts due to a lack of proper work scheduling, misleading information or incorrect reports about emergency scenarios, and coordination with other rescue forces. Along with unpredictable emergency situations, they have to deal with organization-level demands that affect the whole fire brigade and are beyond their individual control, which puts more strain on firefighters with all the associated costs (Hurrell, 1995). Research on the JD-R Model has rarely tackled the context of firefighter personnel. However, previous research has highlighted the role of organizational demands on employee well-being. For example, Demerouti et al. (2001) found that shift work was related to higher levels of exhaustion as well as the resulting interferences affecting work-family balance (Bakker, Demerouti, \& Euwema, 2005; Baker, Demerouti, \& Verbeke, 2004; Martinussen, Richardsen, \& Burke, 2007). Bakker, Demerouti, Taris, Schaufeli, and Schreurs (2003) suggest that problems with planning (e.g., sudden changes in the work schedule) are a shared stressor that has been shown to deplete energy in the form of emotional exhaustion. These authors also consider physical work overload (including work environment characteristics and lack of adequate materials or technology) as a predictor of exhaustion and lack of energy at work. All these demands are belong to the entire organizational context, since they fall under the usual responsibilities taken by the supervisors or those with the greatest responsibility within fire brigades. Therefore, we expect that:

Hypothesis 2a: Organization-level demands are positively related to burnout (i.e., emotional exhaustion and cynicism) and negatively related to work engagement (i.e., vigor and dedication). 


\section{Chapter 2}

As stated before, organization-level demands become shared stressors within the fire brigades. Similarly, we propose that social support becomes a shared social resource. Therefore, organizational resources could be defined as actions taken by the immediate supervisor (e.g., social support from supervisors) or practices implemented by the organization as represented by the CEOs or main representatives (e.g., human resource practices). Social support from supervisors and human resource practices are examples of organizational resources that are provided by the organization and thus follow a top-down process: they are developed by middle managers or the head of the unit and are implemented to benefit all the individuals within the organization. However, unlike organization-level demands, organizational resources may emerge from the patterns of interactions among employees in the form of a bottom-up process (Bliese, 2000). Social support may become a distinguishable characteristic of an organization through several mechanisms. For instance, supportive behavior in the form of extra-role behavior (e.g., helping a colleague during a work overload) may be perpetuated through reciprocity (Lu, 1997). When an employee is grateful for the help received, he or she can try to reciprocate by helping the aider sometime in the future. Furthermore, organizations can develop their own norms of supportive behavior by reinforcing extra-role performance and teamwork and/or punishing individualistic behavior. This generates a climate for more cohesive relationships that influences the behavior of individuals (Hammer, Saksvik, Nytro, Torvatn, \& Bayazit, 2004).

Social support has been widely studied within the context of the JD-R Model although with an emphasis on its being an individual resource, that is, in the form of individual perceptions of social support. This approach has neglected the collective nature of this resource at the unit or organization level. Bakker et al. (2005) supported the relation between social support from colleagues with less emotional exhaustion and cynicism and more professional efficacy. Similarly, Bakker et al. (2003) reported that social support was 


\section{Chapter}

related to a decrease in cynicism and inefficacy beliefs. Some studies also relate social support to less disengagement from work (e.g., Bakker et al., 2004) or higher levels of work engagement (Halbesleben, 2010). Following the JD-R Model (Demerouti et al., 2001), social support is a social resource due to its being functional in achieving work goals by enabling back-up behaviors (Allen \& Grisaffe, 2001), reducing job demands and the associated physiological and psychological costs since individuals provide each other with support that may reduce the strain experience and mitigate perceived stressors (Greenglass, Ficksenbaum, \& Burke, 1996; Viswesvaran, Sánchez, \& Fischer, 1999), and stimulating personal growth and development by nurturing social relationships (Schaufeli \& Salanova, 2008, 2010). Therefore, we expect that:

Hypothesis $2 \mathrm{~b}$ : Social support from colleagues is negatively related to burnout (i.e., emotional exhaustion and cynicism) and positively related to work engagement (i.e., vigor and dedication).

\section{The current study}

In the current study we applied the JD-R Model in order to test the association of predictors at both the individual (i.e., acute demands and proactive coping) and organization levels of analysis (i.e., organization-level demands and social support). Each relationship was tested for the two core dimensions of burnout (i.e., emotional exhaustion and cynicism) and the two core dimensions of work engagement (i.e., vigor and dedication). We expect the pattern of relationships that arises for the burnout dimensions to be similar to the work engagement dimensions. Furthermore, although previous research on organizational demands and resources provided a rationale for expecting a significant relation with burnout and work engagement, they did not follow the 
methodological and conceptual tenets of cross-level theories. This limitation was addressed by conducting the current study within a multilevel framework.

\section{Method}

\section{Participants and procedure}

Data were gathered by means of a protocol between the University of Lisbon Organizational Psychology Department and the Portuguese Government's Firefighting Agency. Altogether, 2,025 rescue mission firefighters from every district in Portugal (18 in all) were invited to participate. Each firefighter received a questionnaire, instructions on how to fill it out, and return envelopes ( $80 \%$ response rate). The sample was composed of 1,610 firefighters from 70 fire brigades in Portugal. Out of all the questionnaires handed back, 1,487 (92\%) were complete and usable for subsequent analyses. The mean age was 35.2 years ( $S D=9.1$ years), $98 \%$ were male, and the average number of years' experience was 13.7 years $(S D=8.2$ years). The type of firefighter was also taken into account (39\% volunteers, $38 \%$ professional, and 23\% municipals). Firefighters were nested within 70 fire brigades, with a mean brigade size of $21.2(S D=20.6)$. A comparison of the sample characteristics with those of the population (in accordance with Government Agency records) revealed no differences in age, gender or years of firefighting experience. Data was gathered in compliance with the APA Ethical principles.

\section{Measures}

Acute and organization-level demands were measured through the Portuguese Rescue Mission Firefighters - Professional Demands Scale (Ângelo, 2010). Scale items 


\section{Chapter}

reflect two underlying dimensions, each measured with six items: acute demands (e.g., 'Scenarios of multi-trauma- 3 or more victims with serious injuries'; $\alpha=.74$ ) and organization-level demands (e.g., 'Lacking human resources to deal with an occurrence'; $\alpha=.74$ ). Items were scored on a five-point scale ranging from 1 (rarely) to 5 (very often).

Social support from colleagues. Social support from colleagues was measured through the Job Content Questionnaire (Karasek, 1985). Social support from colleagues was measured with five items (e.g., 'People I work with are competent in doing their jobs'; $\alpha=.83)$. Participants were asked to indicate the extent to which they agreed with each statement on a four-point scale ranging from 1 (strongly disagree) to 4 (strongly agree).

Proactive copingwas measured with five items (e.g., 'After attaining a goal, I look for another, more challenging one'; $\alpha=.71$ ) from theProactive Coping Inventory (Greenglass, Schwarzer, \& Taubert, 1999). Participants were asked to indicate the extent to which each statement characterizes them on a four-point scale ranging from 0 (never) to 4 (always).

Burnout was measured using the two core dimensions, i.e., emotional exhaustion and cynicism subscales of the Maslach Burnout Inventory-General Survey (MBI-GS; Schaufeli, Leiter, Maslach, \& Jackson, 1996). Emotional exhaustionwas measured with five items (e.g., 'I feel emotionally drained from my job'; $\alpha=.89$ ), and cynicismwith five items (e.g., 'I doubt the significance of my work'). However, the inspection of factor loadings in the results of the CFA hinted at the elimination of two items from the cynicism scale, due to low factor loadings (i.e., 'When I am working I do not like to be bothered with other things' and 'I have become more cynical about whether my work contributes anything'), as referred to in previous literature (e.g., Bakker, Emmerik, \& Riet, 2008). Thus, with three items, the Cronbach's alpha of the cynicism scale was .76. Participants were asked to rate the frequency of each statement on a seven-point scale ranging from 0 (never) to 6 (every day). 


\section{Chapter 2}

Work engagement was measured using the two core dimensions, i.e., vigor and dedication subscales of the Utrecht Work Engagement Scale general version (Schaufeli, Salanova, González-Romá, \& Bakker, 2002). Vigor was measured with six items (e.g., 'At my job, I feel strong and vigorous'; $\alpha=.75$ ), and dedicationwith five items (e.g., 'I am enthusiastic about my job'; $\alpha=.81$ ). Participants were asked to rate the frequency of each statement on a seven-point scale ranging from 0 (never) to 6 (every day).

Control variables.In addition to typical demographic variables (i.e., gender, age, and education), specific firefighter variables were also assessed, namely rank in the force, and years of experience as a firefighter, since previous research has shown that they influence well-being in this work population (Bacharach, Bamberger, \& Doveh, 2008; Baker \& Williams, 2001; Ben et al., 2006; Regehr \& Bober, 2005). Fire brigade size was also included as a control variable due to dispersion on the current sample at the fire brigade level $(S D=20.57)$.

\section{Statistical analyses}

\section{Aggregation indices.}

Organization-level demands and social support from colleagues were included as predictors at the second fire-brigade level of analysis. Firefighters' agreement was assessed using a twofold approach: following a consistency-based approach, both ICC 1 and $\mathrm{ICC}_{2}$ indices were calculated. Although there is no fixed cut-off point for ICC, a value of .01 might be considered a small effect, a value of .10 might be considered a medium effect, and values above .25 might be considered a large effect (Lebreton \& Senter, 2008; Murphy \& Myors, 1998). For the $\mathrm{ICC}_{2}$, values greater than .60 support aggregation (Glick, 1985). The Average Deviation Index ( $A D_{M(J)}$; Burke, Finkelstein, \& Dusig, 1999) was computed following a consensus-based approach, whereby fire-brigade agreement was 


\section{Chapter}

concluded when $A D_{M(J)}$ was equal to or less than 1 (Burke et al., 1999). Finally, Analyses of Variance (ANOVA) were computed in order to ascertain whether there was significant between-group discrimination for the measures.

$I C C_{1}, I C C_{2}$ and $A D_{M(J)}$ indices ranged from .10 to .16 , from .70 to .77 , and from .30 to .52 , respectively. One-way ANOVA results showed statistically significant betweengroup discrimination for organization-level demands, $F(69,1417)=3.30, p<.001$; and social support from colleagues, $F(69,1417)=3.43, p<.001$. By implication, there was a significant degree of between-group discrimination, and therefore the validity of organization-level demands and social support was supported. In conclusion, overall aggregation results indicated within-group agreement in the fire brigades so that firefighters' perceptions can be aggregated.

\section{Testing the adequacy of hierarchical linear modelling.}

ICC was also computed for the case of the dependent variables of the study, that is, the core dimensions of burnout (i.e., emotional exhaustion and cynicism) and the core dimensions of work engagement (i.e., vigor and dedication). In this case, ICC is interpreted as a measure of non-independence, and tests the percentage of variance explained by the aggregated fire-brigade level on the dependent variables, thereby indicating the adequacy of testing hierarchical linear models (Bliese, 2000).

Non-independence ICC was calculated by conducting an ANOVA model within the general hierarchical linear modeling procedure, which allows the variance to be partitioned for the levels involved in the analyses (Hox, 2010). ICC results for the dependent variables ranged from .02 to .09 . Although there is no general rule of thumb, results resemble those reported by Bliese (2000) with data gathered from the army, which ranged from .05 to 20 . For each outcome variable, variability across the 70 fire brigadeintercepts was also examined based on results for the random part in the baseline model. Significant random 


\section{Chapter 2}

level-2 intercept coefficients indicate that there is enough variability to include organizational level predictors. Wald's $t$ tests for the level-2 intercept coefficients were significant for emotional exhaustion $\left(\tau_{00}=0.21 ; p<.001\right)$, cynicism $\left(\tau_{00}=0.09 ; p<.001\right)$, vigor $\left(\tau_{00}=0.02 ; p=.05\right)$, and dedication $\left(\tau_{00}=0.01 ; p<.05\right)$. Hence, fire brigades differed in terms of intercepts for the dependent variables, thereby allowing tests for cross-level hypotheses.

\section{Hierarchical linear models.}

In order to test hypotheses, we conducted hierarchical linear modeling (also known as random coefficient modeling; Gavin \& Hofmann, 2002) using LISREL 8.8 (Jöreskog \& Sörbom, 2006). Three different hierarchical linear models were tested in a step-by-step approach using maximum likelihood. First, we implemented a random-coefficient regression model (Model 1) in which random coefficients for intercepts and slopes are allowed to fluctuate freely in the baseline equation. Individual-level predictors (i.e., individual-level control variables as well as acute demands and proactive coping) are also included in the equation. This model provides tests of Hypotheses $1 \mathrm{a}$ and $1 \mathrm{~b}$ (main effects), and 1c (interaction effect). The second model, or intercepts-as-outcomes model (Model 2), included fire brigade predictors in the level 2 equation for the intercept (i.e., fire brigade control variables as well as organization-level demands and social support from colleagues). This model allows cross-level effects as stated in Hypotheses $2 a$ and $2 b$ to be tested. This procedure was repeated for each of the four dependent variables, namely emotional exhaustion, cynicism, vigor, and dedication.

\section{Centering predictors.}

For the random-coefficient regression model, individual predictors were grandmean centered and their intercepts and slopes were allowed to vary across the fire brigades. Under grand-mean centering, the variance in the intercept term is an adjusted 


\section{Chapter}

estimator of the between-groups variance in the outcomes as it controls for the individual predictors (Hofmann, Griffin, \& Gavin, 2000). For the second model, involving tests of cross-level relationships, fire brigade predictors were also grand-mean centered as this facilitates model estimation (Bliese, 2002) and alleviates estimation problems at the aggregated level of analysis (Hofmann \& Gavin, 1998).

\section{Results}

\section{Descriptives}

Means, standard deviations, internal consistencies, and correlations among the variables in the study are presented in Table 1. As expected, the core dimensions of work engagement (i.e., vigor and dedication) were positively and significantly interrelated, $r=.84$, $p<.001$. Similarly, the core dimensions of burnout (i.e., emotional exhaustion and cynicism) were positively and significantly related, $r=.61, p<.001$. Acute demands were significantly related to organizational demands, $r=.56, p<.001$, whereas proactive coping was not significantly related to support from colleagues, $r=.01, p>.05$. 


\section{Chapter}

\section{Table 1}

Means, standard deviations, Cronbach's alphas, and intercorrelations among the study variables

\begin{tabular}{|c|c|c|c|c|c|c|c|c|c|c|c|}
\hline Variables & M & SD & 1 & 2 & 3 & 4 & 5 & 6 & 7 & 8 & 9 \\
\hline 1. Acute demands & 2.66 & .65 & $(.74)$ & $.32^{\star * *}$ & .04 & $-.10^{\star \star \star}$ & $-.69^{* \star *}$ & $.20 * * \star$ & $.10^{\star * *}$ & -.04 & .00 \\
\hline 2. Org.-level demands & 2.37 & .70 & $.56^{\star \star \star}$ & $(.74)$ & .04 & $-.32^{\star \star *}$ & $-.47^{\star \star *}$ & $.27^{\star \star \star}$ & $.26^{\star \star \star}$ & $-.18^{\star \star *}$ & $-.18^{\star \star \star}$ \\
\hline 3. Proactive coping & 3.33 & .43 & -.04 & $.15^{\star \star \star}$ & $(.71)$ & .04 & -.02 & $-.11^{* * *}$ & $-.16^{* * *}$ & $.31^{* * *}$ & $.28^{* * *}$ \\
\hline 4. Colleague's support & 2.99 & .47 & $-.52^{* * *}$ & $-.59^{* * *}$ & .01 & $(.83)$ & $.56^{* * *}$ & $-.13^{* * *}$ & $-.17^{* * *}$ & $.22^{\star \star *}$ & $.25^{\star * *}$ \\
\hline 5. Size of fire brigade & 21.24 & 20.57 & $-.33^{* * *}$ & $-.17^{* * *}$ & -.01 & .03 & $(-)$ & $-.56^{* * *}$ & $-.33^{* * *}$ & $.11^{* * *}$ & $.05^{*}$ \\
\hline 6. Emotional exhaustion & 2.25 & 1.52 & $.69^{* * *}$ & $.60^{\star * *}$ & -.01 & $-.58^{* * *}$ & $-.21^{\star * *}$ & $(.89)$ & $.49^{* * *}$ & $-.29^{\star \star *}$ & $-.26^{\star * *}$ \\
\hline 7. Cynicism & .93 & 1.30 & $.46^{* * *}$ & $.54^{\star \star \star}$ & $-.06^{*}$ & $-.47^{\star \star *}$ & $-.10^{\star \star *}$ & $.61^{* * *}$ & $(.76)$ & $-.31^{* * *}$ & $-.39^{* * *}$ \\
\hline 8. Vigor & 4.93 & .87 & $-.16^{\star * *}$ & $-.35^{\star * *}$ & $.23^{* * *}$ & $.32^{* * *}$ & .03 & $-.40^{* * *}$ & $-.55^{\star \star *}$ & $(.75)$ & $.74^{\star * *}$ \\
\hline 9. Dedication & 5.35 & .76 & $-.12^{* * *}$ & $-.35^{\star * *}$ & $.11^{* * *}$ & $.24^{\star * *}$ & .01 & $-.36^{\star * *}$ & $-.47^{* * *}$ & $.84^{\star * *}$ & $(.81)$ \\
\hline
\end{tabular}

Note. Cronbach's alphas over the main diagonal. Intercorrelations are presented at the individual level (below the main diagonal; $\mathrm{n}=1487$ ) and at the fire brigade level (above the main diagonal; $k=70$ ).

${ }^{*} p<.05 .{ }^{* *} p<.01 .{ }^{* * *} p<.001$ 


\section{Chapter}

\section{Hierarchical regression analyses}

\section{Tests of individual drivers of firefighter's burnout and work engagement.}

Hypotheses $1 \mathrm{a}$ and $1 \mathrm{~b}$ addressed the main effects at the individual firefighter level of analysis. Following Hypothesis 1a, acute demands were expected to be positively related to the core dimensions of burnout (i.e., emotional exhaustion and cynicism) and negatively related to the core dimensions of work engagement (i.e., vigor and dedication), whereas, based on Hypothesis $1 \mathrm{~b}$, proactive coping strategies were expected to be negatively related to the core dimensions of burnout and positively related to the core dimensions of work engagement. Table 2 and 3 include results for the hierarchical linear models predicting burnout and work engagement, respectively. Model 1 includes results for Hypotheses $1 \mathrm{a}$ and $1 \mathrm{~b}$ since only firefighter-level predictors were included in the equation along with individual level control variables (i.e., general demographics and specific control variables). 


\section{Table 2}

Results for the hierarchical linear models predicting Emotional Exhaustionand Cynicism

\begin{tabular}{|c|c|c|c|c|}
\hline \multirow[b]{2}{*}{ Parameters } & \multicolumn{2}{|c|}{ Emotional Exhaustion } & \multicolumn{2}{|c|}{ Cynicism } \\
\hline & Model 1 & Model 2 & Model 1 & Model 2 \\
\hline Intercept & $3.53^{* * *}(0.43)$ & $3.28^{* * *}(0.42)$ & $1.02^{* *}(0.37)$ & $0.83^{*}(0.37)$ \\
\hline \multicolumn{5}{|l|}{ Level 1 (firefighters) } \\
\hline Type of firefighter & $-0.23^{*}(0.09)$ & $-0.08(0.11)$ & $-0.09(0.07)$ & $-0.02(0.09)$ \\
\hline Gender & $-0.01(0.16)$ & $0.02(0.16)$ & $0.28^{*}(0.14)$ & $0.29 *(0.14)$ \\
\hline Age & $-0.02^{*}(0.01)$ & $-0.02^{*}(0.01)$ & $-0.01^{*}(0.01)$ & $-0.01^{*}(0.01)$ \\
\hline Education & $-0.08(0.05)$ & $-0.08(0.05)$ & $-0.03(0.03)$ & $-0.02(0.05)$ \\
\hline Rank in the force & $-0.04(0.04)$ & $-0.04(0.04)$ & $0.02 *(0.01)$ & $-0.03(0.03)$ \\
\hline Years of experience & $0.02 *(0.01)$ & $0.02 *(0.01)$ & $0.01(0.06)$ & $0.02^{*}(0.01)$ \\
\hline Acute demands (AD) & $0.31^{* * *}(0.06)$ & $0.29^{* * *}(0.06)$ & $0.14^{*}(0.06)$ & $0.11^{*}(0.06)$ \\
\hline Proactive coping (PC) & $-0.43^{* * *}(0.09)$ & $-0.44^{* * *}(0.09)$ & $-0.53^{* * *}(0.08)$ & $-0.53^{* * *}(0.08)$ \\
\hline$A D x P C$ & $-0.11(0.15)$ & $-0.13(0.15)$ & $0.03(0.13)$ & $0.01(0.13)$ \\
\hline \multicolumn{5}{|l|}{ Level 2 (fire brigades) } \\
\hline Fire brigade size & & $-0.00(0.00)$ & & $-0.00(0.00)$ \\
\hline Org.-level demands & & $0.78^{* *}(0.24)$ & & $0.77^{* * *}(0.21)$ \\
\hline Colleagues' support & & $-0.39(0.37)$ & & $-0.37(0.31)$ \\
\hline
\end{tabular}

Note. Standard errors are in parentheses.

${ }^{*} p<.05 .{ }^{* *} p<.01 .{ }^{* * *} p<.001$. 


\section{Chapter}

\section{Table 3}

Results for the hierarchical linear models predicting Vigor and Dedication

\begin{tabular}{|c|c|c|c|c|}
\hline \multirow[b]{2}{*}{ Parameters } & \multicolumn{2}{|c|}{ Vigor } & \multicolumn{2}{|c|}{ Dedication } \\
\hline & Model 1 & Model 2 & Model 1 & Model 2 \\
\hline Intercept & $4.73^{\star \star \star}(0.24)$ & $4.86^{* * *}(0.24)$ & $5.32^{* \star *}(0.21)$ & $5.42^{* * *}(0.21)$ \\
\hline \multicolumn{5}{|l|}{ Level 1 (firefighters) } \\
\hline Type of firefighter & $-0.02(0.04)$ & $-0.08(0.05)$ & $-0.04(0.04)$ & $-0.10(0.05)^{\star}$ \\
\hline Gender & $0.03(0.09)$ & $0.01(0.09)$ & $-0.01(0.08)$ & $-0.03(0.08)$ \\
\hline Age & $0.01^{* *}(0.00)$ & $0.01^{* *}(0.00)$ & $0.12^{\star *}(0.00)$ & $0.01^{* *}(0.00)$ \\
\hline Education & $-0.07^{*}(0.03)$ & $-0.06^{*}(0.03)$ & $-0.06^{*}(0.03)$ & $-0.06^{*}(0.03)$ \\
\hline Rank in the force & $0.05^{\star}(0.02)$ & $0.05^{*}(0.02)$ & $0.01(0.02)$ & $0.02(0.02)$ \\
\hline Years of experience & $-0.01^{*}(0.01)$ & $-0.01^{*}(0.01)$ & $-0.01 *(0.01)$ & $-0.01^{*}(0.00)$ \\
\hline Acute demands (AD) & $-0.08^{*}(0.04)$ & $-0.06(0.04)$ & $-0.02(0.03)$ & $-0.00(0.03)$ \\
\hline Proactive coping (PC) & $0.67^{\star \star \star}(0.05)$ & $0.67^{* \star *}(0.05)$ & $0.54^{\star \star \star}(0.05)$ & $0.54^{* \star *}(0.05)$ \\
\hline$A D x P C$ & $0.25^{\star \star}(0.09)$ & $.25^{\star *}(0.09)$ & $-0.01(0.08)$ & $-0.00(0.08)$ \\
\hline \multicolumn{5}{|l|}{ Level 2 (fire brigades) } \\
\hline Fire brigade size & & $0.01(0.02)$ & & $0.00(0.00)$ \\
\hline Org.-level demands & & $-0.28^{*}(0.12)$ & & $-0.30^{\star \star}(0.11)$ \\
\hline Colleagues' support & & $0.31(0.18)$ & & $0.13(0.17)$ \\
\hline
\end{tabular}

Note. Standard errors are in parentheses.

${ }^{*} p<.05 .{ }^{* *} p<.01 .{ }^{* * *} p<.001$. 


\section{Chapter 2}

Following Hypothesis $1 \mathrm{a}$, acute individual demands were expected to be positively related to burnout and negatively related to work engagement. Acute demands were positively and significantly related to both burnout dimensions $(\beta=.31, p<0.001$, and $\beta=.14, \quad p<0.05$, for emotional exhaustion and cynicism, respectively). In turn, acute demands were negatively and significantly related to vigor $(\beta=-.08, p<0.05)$, whereas they were not related to dedication $(\beta=-.02, p>0.05)$. Thus, results provided partial support for Hypothesis 1a. Acute demands were related to emotional exhaustion, cynicism, and vigor, but they were not related to dedication.

Following Hypothesis $1 \mathrm{~b}$, proactive coping strategies were expected to be negatively related to burnout and positively related to work engagement. Results showed that proactive coping strategies were negatively and significantly related to the burnout dimensions $(\beta=-.43, p<0.001$, and $\beta=-.53, p<0.001$, for emotional exhaustion and cynicism, respectively). For the case of work engagement, proactive coping strategies were positively and significantly related to both work engagement dimensions $(\beta=.67$, $p<0.001$, and $\beta=.54, p<0.001$, for vigor and dedication, respectively). Thus, results provided support for Hypothesis 1b. Proactive coping strategies were negatively related to burnout and positively related to work engagement.

Hypothesis $1 \mathrm{c}$ addressed the interaction effect at the individual firefighter level of analysis. This same hypothesis stated that proactive coping strategies will moderate the relationship between acute demands and burnout and work engagement. Therefore, the depleting effect of acute demands would be buffered by proactive coping strategies. Results are included in Table 2 and 3 for burnout and work engagement core dimensions, respectively. Results showed that proactive coping strategies were a positive and significant moderator in the case of vigor $(\beta=.25, p<0.01)$. This interaction effect was not significant for the case of dedication, and for the core dimensions of burnout, emotional exhaustion, and cynicism. Hence, proactive coping strategies moderated the effect of 


\section{Chapter}

acute demands on the firefighters' vigor, so that acute demands were not depleting energy for those firefighters who were high in proactive coping strategies. Figure 2 depicts the interaction effect of proactive coping strategies in the relationship between acute demands and vigor.

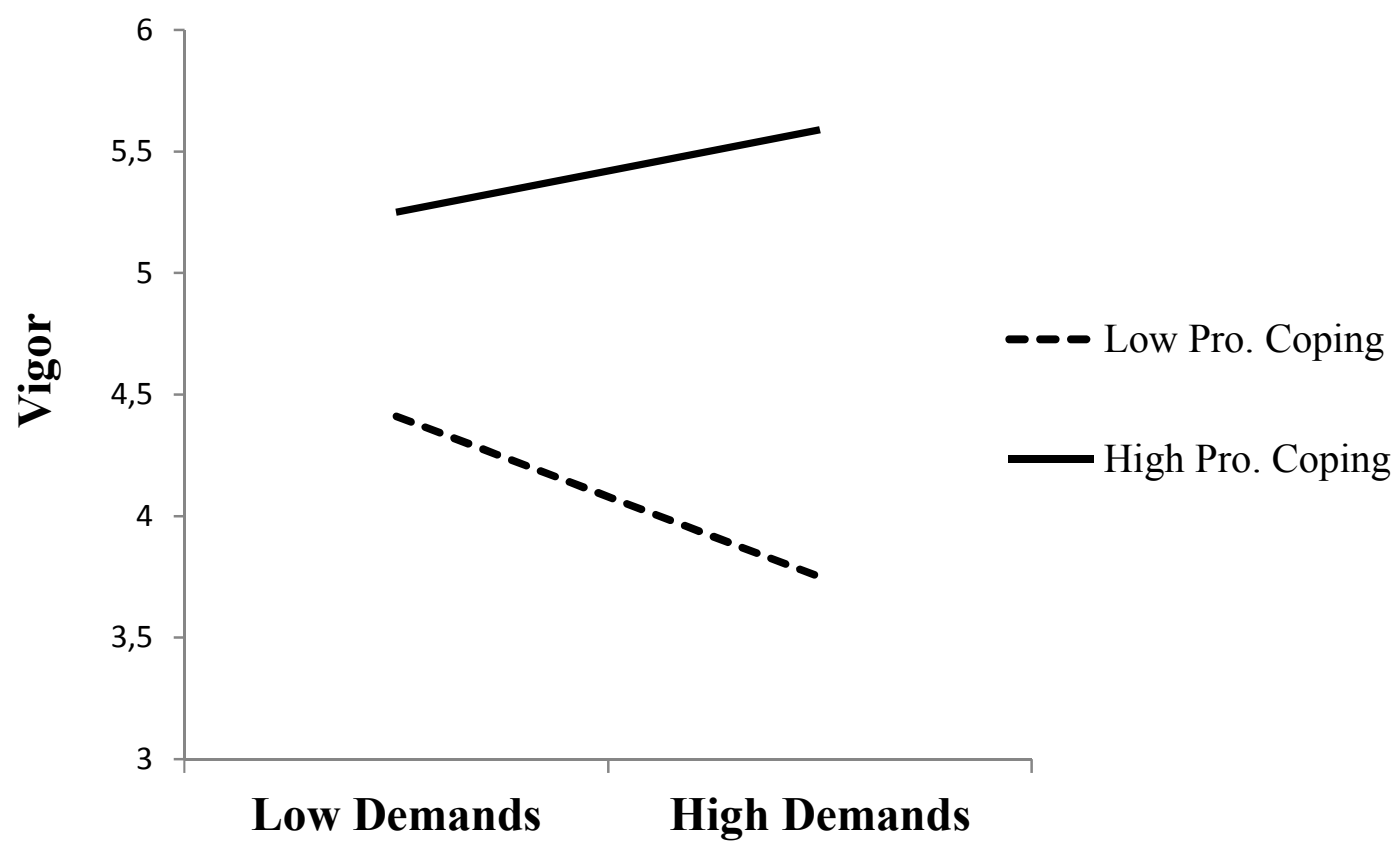

Figure 2. Interaction effect of proactive coping over the relationship between acute demands and vigor.

In order to assess the relative importance of individual level predictors over each outcome, we also calculated the proportion of explained variance (Snijders \& Bosker, 1999). To compute these estimates, first we computed the random-coefficient regression model (model 2) fixing slopes for the individual level predictors. Then we compared the resulting variance estimates with the ones from the ANOVA baseline model. The proportions of explained variance for the outcome variables were $5 \%$ (emotional exhaustion), 4\% (cynicism), 11\% (vigor), and 9\% (dedication). 


\section{Chapter 2}

\section{Tests of organizational drivers of firefighters' burnout and work engagement.}

Hypotheses $2 a$ and $2 b$ dealt with predictors at the organizational, fire brigade level of analysis. Fire brigade size was included as a control variable (see Table 2 and 3 for results on burnout and work engagement, respectively). Model 2 yields results for Hypotheses $2 a$ and $2 b$ since it includes organizational-level variables in order to test for cross-level effects. Following Hypothesis 2a, organization-level demands were expected to be positively related to burnout and negatively related to work engagement, above individual drivers (i.e., acute demands and proactive coping strategies). Results show that organization-level demands were positively and significantly related to both burnout dimensions $(\beta=.78, p<0.01$, and $\beta=.77, p<0.001$, for emotional exhaustion and cynicism, respectively). For the case of work engagement, results indicate that these demands were negatively related to both work engagement dimensions $(\beta=-.28, p<0.05$ and $\beta=-.30$, $p<0.01$, for vigor and dedication, respectively). Hence, results provided support for Hypothesis 2a.

Following Hypothesis 2b, social support from colleagues was negatively related to burnout and positively related to work engagement. Results showed that, unexpectedly, social support from colleagues was not significantly related to burnout $(\beta=-.39, p>0.05$, and $\beta=-.37, p>0.05$, for emotional exhaustion and cynicism, respectively). Similarly, social support from colleagues was not significantly related to the two work engagement dimensions $(\beta=.31, p>0.05$, and $\beta=.13, p>0.05$, for vigor and dedication, respectively). Thus, Hypothesis $2 b$ was not supported.

The proportion of explained variance was also calculated for each outcome for Model 2 as compared with a model including only firefighter-level predictors (Model 1). The proportions of explained variance between fire brigades (level-2 variance) due to Model 2 were $45 \%$ (emotional exhaustion), 43\% (cynicism), 60\% (vigor), and 50\% (dedication). 


\section{Chapter}

\section{Discussion}

Using the JD-R Model as a theoretical framework, in the present study we analyzed the relationship between organization-level demands and resources, and individual wellbeing (i.e., burnout and work engagement) over and above the relationship of individual drivers (i.e., acute demands and proactive coping strategies) in a sample of Portuguese rescue mission firefighters. Furthermore, we explored the moderating role of proactive coping on the relation between acute demands and individual well-being. Results indicated that proactive coping was related to lower burnout and higher work engagement, whereas acute demands were related to higher burnout and lower work engagement (but only for vigor). Moreover, proactive coping moderated the relationship between acute demands and vigor. Finally, organization-level demands were related to higher burnout and lower work engagement whereas, unexpectedly, social support from colleagues was not related to firefighters' well-being. The results have practical and theoretical implications that are discussed below.

\section{Theoretical implications}

In light of the results, further refinement and suggestions for improvements to the JD-R are presented. First, it is necessary to foster a multilevel perspective of this model through a suitable conceptualization of demands and resources at the appropriate level of analysis (Bliese \& Jex, 2002). Although many articles have tested the role of various types of organizational demands and resources previously (e.g., Bakker \& Demerouti, 2007), an adequate conceptualization to a higher level of analysis may show different relationships to those found when measuring and analyzing demands and resources at the individual level (Hox, 2010). Based on the seminal work of Demerouti et al. (2001), we proposed a 


\section{Chapter 2}

definition and conceptualization of organizational demands and resources based on the different processes involved in turning these organizational characteristics into either a shared-stressor or a shared-resource. That is, in the current context, organization-level demands are fire brigade characteristics that put a similar level of strain on all the firefighting personnel, whereas organizational resources can either be part of systematic organization planning (e.g., human resource practices) or emerge from the interaction and shared experiences of the employees (e.g., social support). Thus, while organizational demands constitute a top-down process, organizational resources may turn into either a top-down process or a bottom-up process (Bliese, 2000). Hence, following a multilevel approach would help to refine the results obtained so far by the extensive body of literature that has emerged in the last decade that has the JD-R as the underlying theoretical model (Hakanen \& Roodt, 2010).

At the individual level of analysis, acute demands showed a significant positive relation with firefighters' emotional exhaustion and cynicism, while they were negatively and significantly related to firefighters' vigor, but not related to dedication. Although these findings fully supported previous research on the burnout syndrome, the role of firefighters' acute demands over work engagement differed depending on the dimension involved. Thus, although acute demands became hindrance demands depleting employees' vigor (an energetic and behavioral component of work engagement; Crawford, LePine, \& Rich, 2010), they showed no effect on dedication (an emotional dimension of affective attachment toward work). A rationale for this finding may be found in the specific characteristics of the job of firefighters and their role as providers of help, which endows this work population with a strong sense of purpose and meaning toward their job (Fullerton et al., 1992). In fact, in the current sample, firefighters showed a very high average level of dedication $(X=5.35, S D=.76)$ and, in contrast at the other extreme, a very 


\section{Chapter}

low level of cynicism $(X=.93, S D=1.30)$. This finding supports the view of a detailed analysis of work engagement by exploring different antecedents and outcomes for its inner components (Bakker \& Leiter, 2010).

Nevertheless, contrary to expectations, social support was not significantly related to any of the four dimensions of psychological well-being included in the current study. This unexpected finding may be due to the type of relationships that exist in an organizational structure such as fire brigades. Firefighters develop their work in a paramilitary structure and command chain that may yield the salience of coercitive leadership and threaten for punishments instead of promoting the display of supportive behaviors. Furthermore, firefighting is a male-dominated occupation. In these job settings, males feel more effective when taking an avoidance strategy from adverse situations in daily work (Long \& Gessaroli, 1989), whereas women reported seeking social support as more effective (Greenglass, Burke, \& Konarski, 1998). Therefore, in these environments the emotional aspect of work may be granted little importance or employees may develop rules of emotional expression that punish behaviors (i.e., asking for social support) that do not correspond to their expected social role (González-Morales, Rodríguez, \& Peiró, 2010). In fact, the same non-significant result between social support and individual well-being has been found previously in the context of firefighters. Regehr, Hill, Knott, and Sault (2003) compared new recruits in the first week of employment and following a 10-week training period with experienced firefighters. In their discussion of results, the authors suggested that opportunities for promotion are limited which breeds competition within tasks more than cooperation and support. 


\section{Chapter 2}

\section{Limitations and future research}

A major limitation of this study is its cross-sectional nature. This approach cannot determine cause and effect relationships between variables. However, in line with current recommendations in this field, the relations under study did not rely on a single level of analysis but incorporated predictors and covariates at the fire brigade level of analysis. This decision contributed to the expansion of the JD-R Model following a multilevel perspective (Demerouti \& Bakker, 2011; Schaufeli \& Taris, 2014). Moreover, we also made use of subjective measures of well-being obtained through self-report questionnaires that were filled out by the firefighters themselves. We took this approach because our focus of interest was on the employees' perceptions about their workplace and how these perceptions affect their subjective psychological well-being. In addition, we conducted the analyses in a wide sample of firefighters from all the districts of Portugal. So, although we made use of a convenience sample, the representativeness of the answers was maximized and suggested the results could be generalized for this occupational sample.

The current results provide some insight into the processes involved in firefighters' well-being, but future research may fine-tune our conclusions. Diary studies are a suitable methodology for gathering detailed information on response time, subjective well-being, or actual well-being through psychophysiological indicators (Oerlemans \& Bakker, 2013). Moreover, as firefighters work mainly in the form of action teams (Hollenbeck, Beersma, \& Schouten, 2012), hence, a team-level analysis of the tasks conducted by professionals in emergency situations is highly recommended. A collective point-of-view analyzing work in the context of teams would provide detailed information on the social determinants of wellbeing in the form of both burnout (González-Morales, Peiró, Rodríguez, \& Bliese, 2012) or work engagement (Torrente, Salanova, Llorens, \& Schaufeli, 2012). 


\section{Chapter}

\section{Practical implications}

Psychological well-being not only depends on the actions taken by the firefighters themselves but also on all the practices and policies that the organization may implement (Schaufeli \& Salanova, 2010). Although the effect of acute demands is inherent to firefighters' duties, the development of a proactive coping style may be beneficial for future emergency events. Proactive coping can be trained through interventions focused on effective management of stress (Shimazu, Umanodan, \& Schaufeli, 2006), as well as interventions aimed at improving goal setting and resource accumulation before the stressful situation arises (Sohl \& Moyer, 2009). The accumulation of resources can lead to positive spirals between well-being and job resources to cope with future stressors (Salanova, Llorens, \& Schaufeli, 2011).

Organization-level demands can be influenced by human resource managers within each fire brigade. Those in charge should ensure employees are provided with proper tools and equipment, and assign firefighters with sufficient training to meet the demands required by the complexity and range of the mission. Coordination with other security forces is also a task of the coordinators or managers of the brigade, and is a source of stress detected in this investigation. All these tasks are not under the control of most firefighters, as they are pushed to focus their full attention on the action at hand, and they thus develop a feeling of lack of control that works at the expense of their psychosocial well-being. The organizational context is a crucial factor in enhancing the possibility of developing interventions that focus on both the individual and the organization as a whole following the conclusions drawn in this study. 


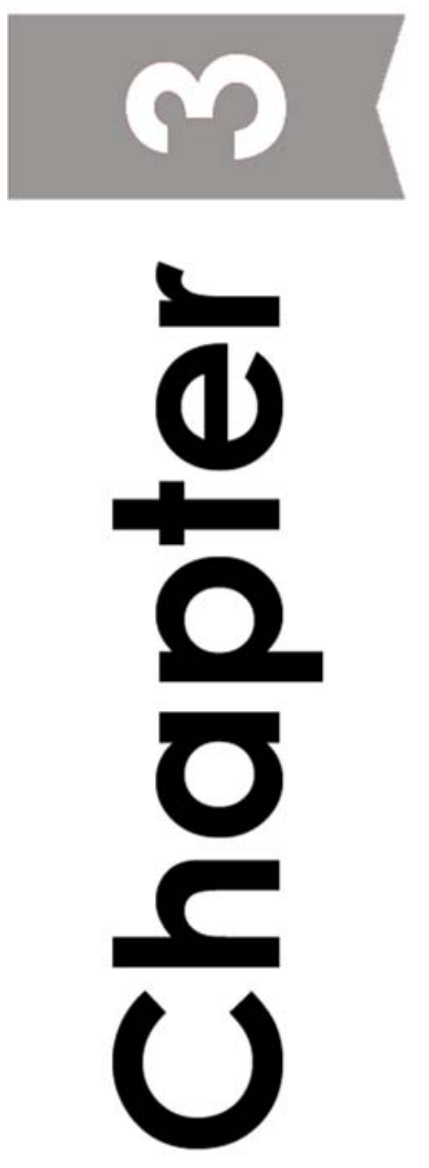




\title{
Spreading Engagement:
}

\author{
On the Role of Similarity in the \\ Positive Contagion of Team Work \\ Engagement
}

This paper has been published as:

Torrente, P., Salanova, M., \& Llorens, S. (2014). Spreading engagement: On the role of similarity in the positive contagion of team work engagement. Journal of Work and Organizational Psychology, 29, 153-159. 


\section{Chapter 3}

\section{Spreading engagement: On the Role of Similarity in the Positive Contagion of Team Work Engagement}

Being engaged and passionate about one's own work has been one of the most popular topics in Work \& Organizational Psychology over the past decade (Bakker \&Leiter, 2010). The pursuit of further knowledge in this topic has yielded a number of contributions addressing what causes work engagement (e.g., Schaufeli, Bakker, \& van Rhenen, 2009), how it is measured (e.g., Schaufeli, Bakker, \&Salanova, 2006), and its consequences (e.g., Torrente, Salanova, Llorens, \&Schaufeli, 2012). Although some studies have already examined, and supported, the contagion of work engagement among employees (Bakker \&Xanthopoulou, 2009; Bakker, Demerouti, \&Verbeke, 2004; Bakker, van Emmerik, \&Euwema, 2006), the role of similarity in the spread and sharing of work engagement among employees has been largely neglected in the work engagement literature (Bakker, Westman, \& van Emmerik, 2009; Schaufeli, 2012).

Focusing on the behavioral consequences of work engagement, engaged employees invest an extra amount of energy, persistence, and dedication in their duties, which is transferred to the job setting and may therefore be appraised and shared by other employees working in the same team (Salanova, Agut, \&Peiró, 2005) in a kind of contagion or positive infection of affect. As many organizations are functionally structured around work teams nowadays, this positive contagion process involves key implications in terms of promoting a shared state of work engagement within teams. The novelty of this study lies in the fact that it takes a diversity management perspective, thereby analyzing how similarity among employees in terms of demographics, such as gender and company tenure, could be related with sharing desirable states such as team work engagement, which emerges from team work engagement perceptions held by the team members. Although these perceptions are 


\section{Chapter}

spread through their interactions and shared experiences, throughout the paper we will refer to just team work engagement for the sake of consistency in the usage of terminology and space-saving. Hence, the aim of this study is to analyze the role of similarity in the convergence in a shared state of work engagement based on emotional contagion theory (Hatfield, Cacioppo, \&Rapson, 1994).

\section{Team work engagement and contagion mechanisms}

Work engagement is a positive, fulfilling, work-related state of mind that is characterized by vigor, dedication, and absorption (Salanova, Schaufeli, Llorens, Peiró, \&Grau, 2000; Schaufeli, Salanova, González-Romá, \& Bakker, 2002). Work engagement involves a number of behaviors such as the display of emotions expression and emotionallycharged verbalizations that can be appraised by team members and thus promote an emergent shared perception of work engagement (Bakker et al., 2006). For example, a vigorous employee is persistent against difficulties and is thus able to motivate the rest of the team members to achieve team duties. Moreover, a dedicated employee feels emotionally attached to the task at hand. This provides the employee with a sense of meaning that leads him or her to express joy and pride toward his or her work. Finally, absorbed employees feel fully engrossed with the task they are carrying out, which can provide a great deal of focus and concentration when engaging in a team task. Coherent with this contagion mechanism, team work engagement has been defined as "a positive, fulfilling, work-related and shared psychological state characterized by team work vigor, dedication and absorption which emerges from the interaction and shared experiences of the members of a work team" (Torrente et al., 2012; p.107). The rationale behind this definition and the proposed underlying contagion mechanism of work engagement is rooted in the tenets of emotional contagion theory.

Emotional contagion theory attempts to explain how different people are able to share and express the same emotional state (Hatfield, Rapson, \& Le, 2009). This theory posits that 


\section{Chapter}

emotions can spread from individual to individual. The contagion of emotions is triggered consciously based on our ability to empathize with the experiences of others (Barsade, 2002). For instance, using different occupational samples Totterdell, Kellett, Teuchmann, and Briner (1998) proved that there is a link between individual emotions and those experienced by the team itself. Furthermore, contextual factors such as team size may influence emotional convergence. Since teams with a higher number of members require a higher number of interactions to achieve a consensus on a shared affect (Bakker et al., 2009), the spread and sharing of emotions within teams may become weaker (Bowers, Pharmer, \& Salas, 2000). These influences model emotional contagion processes and raise the question as to what conditions are required for emotional transmission between individuals.

\section{Similarity: An antecedent for the positive contagion of work engagement}

Previous research has pointed out similarity as one condition enabling the emotional contagion process to begin (Bakker et al., 2009). That is, a worker may take another team member as an emotional referent if he or she feels identified with the other person or if he or she feels similar to that person (Bakker, Westman, \&Schaufeli, 2007). In this context, similarity refers to specific characteristics such as, for example, sex, race, nationality, or job seniority that are shared by the members of a work team. Similarity, then, differs from related concepts in the field such as group identification, understood as the members' identification with an interacting group (Henry, Arrow, \&Carini, 1999).

Members of teams are likely to form impressions on the basis of team members' outstanding physical characteristics (Fiske \&Neuberg, 1990). Those who possess similar individual characteristics and attitudes will be perceived as such and, hence, they will be attracted to one another (Byrne, 1971). In that sense, similarity in terms of gender is related to stronger friendship ties and more cohesive relationships (Lincoln \& Miller, 1979). As a result, there is an increase in the frequency of positive and meaningful interactions in the 


\section{Chapter}

workplace (Mehra, Kilduff, \& Brass, 1998), which is likely to increase team work engagement (Torrente et al., 2012). Thus, we expect that:

Hypothesis 1: Similarity among the team members in terms of gender will be positively related to convergence in team work engagement.

Further support for the role of similarity on the contagion of team work engagement is provided by social identity (Tajfel\& Turner, 1986) and self-categorization theories (Turner, 1987). Several scholars (Tajfel\& Turner, 1986; Turner, 1987) suggested that individuals tend to categorize themselves and those around them in groups, making use of dimensions that are personally meaningful. These dimensions include categories that are based on salient demographic and organizational-related variables such as company tenure. Similarly experienced employees share many job-related aspects such as motives to work (Kooij, De Lange, Jansen, Kanfer, \&Dikkers, 2011), job demands (Johnson, Mermin, \&Resseger, 2011), social stereotyping by others (Pothuma\& Campion, 2009), and even common characteristics that belong to the non-work domain such as non-work demands (Baltes\& Young, 2007). These similarities may enact categorization processes that take the form of exhibiting bias in favor of similar members (Tsui\& O'Reilly, 1989) as well as employees' responding more favorably to contexts where there is a greater proportion of similar members (Tsui\&Gutek, 1999). In consequence, team members are likely to conform to norms of emotional and behavioral expression toward the team duties. Emotional and behavioral expressions of work engagement within the team take the form of a similar level of work engagement being spread and shared within the team. Thus, we expect that:

Hypothesis 2: Similarity among the team members in terms of years of seniority in the organization will be positively related to convergence in team work engagement.

In conclusion, the aim of this study is to analyze the role of similarity among the members of work teams in terms of gender and company tenure, as associated with the convergence in a shared state of work engagement within teams. 


\section{Method}

\section{Participants and procedure}

The sample comprised 694 employees nested within 161 teams from 80 Spanish organizations. The sample was composed of a heterogeneous group of organizations: $21 \%$ industry (manufacturing activities), 17\% commerce, 16\% hotels and restaurants, 10\% entertainment activities, $8 \%$ education, $7 \%$ consultancies and assistance, $7 \%$ technical maintenance, $6 \%$ construction, $4 \%$ health care, and $4 \%$ others.

Organizations were invited to join the project and were offered a final report containing the most relevant results of the study in order to promote commitment with the research study throughout the whole process. A preliminary interview was conducted with a key agent within the organization (administrator, human resources manager or risk prevention technician), who helped to identify the teams in their organizations. Only teams with just one immediate supervisor were included in the analysis. After the company had agreed to participate in the study, researchers administered questionnaires to the participants, who took part in the study voluntarily. The full questionnaire required about 30 minutes to be filled out, but the scales used in this study could be completed in about 5 minutes. The questionnaires were then put into sealed envelopes and collected by the researchers themselves in order to maximize the confidentiality of the answers.

\section{Measures}

Demographic variables were assessed by gender and company tenure. Gender was a dichotomous variable (Female="1", Male="2"). Company tenure was a continuous variable that considered the number of years spent working in the organization. The demographic variables section was reduced to avoid biases arising from employees' perceiving a lack of anonymity in their answers as well as to ensure questionnaire fulfillment. Based on the work 


\section{Chapter}

of Harrison and Klein (2007), we developed objective measures of team similarity using Blau's index (Blau, 1977) for gender and standard deviation for company tenure.

Team work engagement was assessed by 18 items validated for the Spanish population by Salanova, Llorens, Cifre, Martínez, and Schaufeli (2003) and included in the HERO Questionnaire (Salanova, Llorens, Cifre, \&Martínez, 2012). In accordance with the aims of the study, the referent of this scale was the team. In line with prior research (Bakker et al., 2006; Salanova et al., 2012; Schaufeli\& Bakker, 2010; Schaufeli et al., 2006), we focused on overall engagement, and thus created a composite measure based on its three components $(\alpha=.91)$ : team work vigor (seven items, e.g., "While working, my team feels full of energy"), team work dedication (five items, e.g., "My team feels very motivated to do a good job"), and team work absorption (seven items, e.g., "My team feels happy when we are engrossed in the task"). Participants responded using a seven-point, Likert-type scale ranging from 0 (never) to 6 (always). Convergence in terms of team work engagement was operationalized using standard deviation (Harrison \& Klein, 2007). Intraclass correlation coefficients $\left(I C C_{1}\right.$ and $\left.I C C_{2}\right)$ were calculated for this variable. Results for these indices $\left(I C C_{1}\right.$ $=.20$, and $\mathrm{ICC}_{2}=.53$ ) suggested variation at the organizations level of the average level of team work engagement within teams.

Team size (i.e., number of team members) was included as a control variable since, in accordance with previous research (Bowers et al., 2000), the number of interactions required to share a common emotional state is likely to be higher in large teams.

Furthermore, in order to empirically assess the preliminary team distribution yielded by the key agent, we used three items from the Teamworking scale (included in the HERO Questionnaire: "My team has well-defined work goals", "In my team, innovative and creative ideas are accepted", and "My team consists of people with appropriate and complementary expertise"). Participants also responded using a seven-point Likert-type scale ranging from 0 (never) to 6 (always). The pooled within-teams mean for teamworking in this sample was $4.80(\mathrm{SD}=.83)$. This means that, on average, participants within teams were from "quite" to "very frequently" involved in actual teamworking. 


\section{Data analyses}

Descriptive statistics of the study variables were calculated. As teams were nested within a higher-order grouping variable (i.e., organizations), we conducted the analysis using hierarchical linear modeling (Hofmann, Griffin,\& Gavin, 2000). This methodology allowed us to control for the variability due to differences between organizations.

Following the categorization of composition models offered by Bliese (2000), similarity research might be included in the so-called compilation models. Compilation models make use of individual-level data to develop and operationalize measures of team constructs that may be completely different in their meaning and interpretation. As the levels of the two constructs are neither functional nor structurally related, aggregation indices (of reliability and non-independence) tend to be irrelevant (Bliese, 2000).

Similarity (as the opposite of diversity) can be measured making use of dispersion indices (Harrison \& Klein, 2007). For the measurement of gender (dichotomous variable), we developed a measure of variety within the team. When conducting variety research, members differ from one another qualitatively, on a categorical attribute (i.e., gender), and also in the extent to which they spread across the number of categories involved in the analysis (Harrison \& Klein, 2007). The degree to which team members are similar in a given category may be operationalized using Blau's index (1977):

$$
\text { Blau's index }=1-\sum\left[n_{k}\left(n_{k}-1\right) /(n(n-1))\right]
$$

In this equation, $n$ is the team size, and $n_{k}$ is the frequency of team members in the $k$ th category. Blau's index is the most common measure for diversity as variety (Bunderson \& Sutcliffe, 2002). This measure was initially developed by Simpson (1949), and to be able to use it to assess diversity within teams, sampling is performed from a finite population yielding the equation given above. As regards its interpretation, the higher the value of Blau's index, the lower the similarity within the team in terms of gender.

Concerning the second independent variable, similarity in terms of company tenure takes the form of separation. Separation studies propose that team members differ from one 


\section{Chapter}

another in their allocation along a continuous attribute or characteristic. Following Harrison and Klein (2007), separation is operationalized using standard deviation (SD):

$$
\mathrm{SD}=\sqrt{\left[\sum\left(X_{i}-\bar{X}\right)^{2} / n\right]}
$$

Standard deviation has the advantage that the resulting values are given in the same interval-level metric as the original attribute. The higher the SD is, the lower the similarity within the team will be.

Therefore, Blau's index and SDs were operationalized as a measure of similarity among team members (Schneider, Salvaggio, \&Subirats, 2002). Convergence in terms of team work engagement (i.e., the dependent variable) also involved the use of a continuous scale. So SD was used to assess convergence in team work engagement. In the same vein as in the case of company tenure, the higher the SD for team work engagement is, the lower the similarity within the team will be. Standard deviations of team work engagement within teams were regressed onto Blau's index for gender as well as onto standard deviations of company tenure. LISREL 8.8 (Jöreskog\&Sörbom, 2006) was used to conduct the analyses.

\section{Results}

\section{Hierarchical linear models}

Table 1 shows means, standard deviations, and intercorrelations among the study variables. Table 2 shows the results of testing the research hypotheses. As regards Hypothesis 1, results for this hypothesis showed that similarity in gender was positive and significantly related to convergence in team work engagement $(\beta=.21, p<.05)$. Thus, the more similar teams are in terms of gender, regardless of whether they are mostly composed of men or women, the higher the convergence will be in terms of team work engagement. Consequently, results confirmed Hypothesis 1. 


\section{Table 1}

Means, standard deviations, and intercorrelations at the team level $(n=161)$

\begin{tabular}{lccccccccc}
\hline Variables & Mean & SD & 1 & 2 & 3 & 4 & 5 & 6 & 7 \\
\hline 1. Gender & 1.53 & .42 & - & $-.17^{*}$ & -.04 & -.05 & -.07 & -.17 & .03 \\
2. Company tenure & 6.68 & 4.94 & - & -.03 & .06 & .12 & .12 & .07 \\
3. Team size & 4.37 & 2.13 & & - & -.07 & -.13 & -.10 & -.03 \\
4. Team work engagement & 4.47 & .59 & & & $(.91)$ & $.89^{* * *}$ & $.93^{* * *}$ & $.89^{* * *}$ \\
5. Team work vigor & 4.43 & .57 & & & & $(.81)$ & $.78^{* * *}$ & $.67^{* * *}$ \\
6. Team work dedication & 4.82 & .71 & & & & & $(.87)$ & $.74^{* * *}$ \\
7. Team work absorption & 4.13 & .66 & & & & & & & $(.80)$ \\
\hline
\end{tabular}

Note. Cronbach's Alphas are in parentheses.

$$
{ }^{*} p<.05 ;{ }^{* *} p<.01
$$

\section{Table 2}

Results for the hierarchical linear models $(n=161)$

\begin{tabular}{ll}
\hline Parameters & Estimators \\
\hline Gender & $.40^{* * *}(.07)$ \\
Intercept & $.04^{* * *}(.01)$ \\
Team size & $.21^{*}(.09)$ \\
Gender's Blau & \\
$\quad$ Random part & $.01(.01)$ \\
Level 2 & $.10^{* * *}(.02)$ \\
Level 1 & \\
Company tenure & $.45^{* * *}(.07)$ \\
Intercept & $.06^{* * *}(.01)$ \\
Team size & $-.02^{*}(.01)$ \\
SD for company tenure & \\
$\quad$ Random part & $.00(.01)$ \\
Level 1 & $.08^{* * *}(.01)$ \\
Level 2
\end{tabular}

Note. Standard errors are in parentheses.

$$
{ }^{*} p<.05 ;{ }^{* * *} p<.001 .
$$




\section{Chapter}

Results for Hypothesis 2 showed that, unexpectedly, similarity in company tenure was significant but negatively related to convergence in team work engagement $(\beta=-.02, p<.05)$. Thus, the less similar teams are in terms of company tenure, the higher the convergence will be in terms of team work engagement. Consequently, Hypothesis 2 received support in the opposite direction.

\section{Further analyses}

Further analyses were conducted dividing the work teams in three different groups and then, conducting the analyses in each of them. The first group of teams considered those that had no agreement in their level of team work engagement. For a 7-point Likert type scale and coherently with other consensus-based indices of agreement that are interpretable in the original metric of the scale (Lebreton\&Senter, 2008), we included teams that showed 1 SD or higher among the team work engagement within the team. From the remaining teams, we selected the teams for the second and third group of work teams. In the second group, work teams with 1 SD under the pooled averaged level of team work engagement were included. Then, this group considered teams with agreement in a low level of team work engagement within the team. Finally, in the third group, work teams with 1 SD over the pooled averaged level of team work engagement were included. Then, this group considered teams with agreement in a high level of team work engagement within the team. The analyses were conducted for 17,25 , and 24 teams, respectively using Restricted Maximum Likelihood. Results indicated that there were no differences depending on the group of teams involved in the analysis with provided support for the robustness of the main results. 


\section{Chapter 3}

\section{Discussion}

The aim of this study was to analyze the role of similarity in the convergence within a shared state of work engagement based on emotional contagion theory. Similarity among the team members in terms of gender and company tenure was expected to be positively related to convergence in team work engagement within teams. Results provided support in the case of gender, so that the greater the similarity in gender within work teams is, the greater the convergence between the team members in team work engagement will be. Results were significant, although in the opposite direction for the case of company tenure. The novelty of the current study lies in the similarity perspective taken to explore the positive contagion of work engagement within a heterogeneous sample of actual work teams, which has implications for theory development and human resources management.

\section{Theoretical implications}

Findings provided mixed support for similarity as one of the main sources of emotional contagion theory (Hatfield et al., 1994). Emotional contagion seems to occur more easily within teams in which most of the members are of the same gender, thus yielding support to similarity as a source of emotional contagion within teams (Bakker et al., 2009). This finding also links to research on relational demography that points out that dissimilarity in terms of gender is related to higher emotional conflict, and thus to reduced cohesiveness (Pelled, 1996), which may hinder the contagion of positive emotions within teams (Totterdell et al., 1998).

Team members were more similar in their shared state of work engagement when there was a greater imbalance in terms of company between the team members. This may be explained by taking into account structural group characteristics that hinder the natural tendency of similar individuals to approach one another within the team, such as status. For example, Chattopadhyay, Tluchowska, and George (2004) showed how low-status group 


\section{Chapter}

members may seek identity-affirmation by approaching and affiliating with high-status members, even if they pertain to different groups. Thus, the imbalance in company tenure will result in a tendency to converge in a shared state of team work engagement.

As an alternative explanation, people with less company tenure and is usually less socialized and tend to require support and assistance from a more experienced team member (e.g., by answering questions or offering to help with formal procedures). The interactions with tenured employees provide the newcomers not only with information (Ostroff\& Kozlowski, 1992), but also with social support (Bauer, Morrison, \&Callister, 1998). Hence, based on these interactions, some members are more likely to achieve a positive shared state of team work engagement as they interact very frequently at an early stage within the organization.

Concerning our control variable, previous studies controlled for the influence of team size on the average team scores of work engagement concluding that the number of team members did not influence the average, team-level engagement levels (Bakker et al., 2006).In contrast with previous research though, our current findings suggest that team size did play a role in the convergence of team work engagement. The effect of team size on emotional convergence can be explained by the fact that the number of emotional referents is lower and, thus, in-group identification and similarity processes are more easily promoted (Cunningham \&Chelladurai, 2004). As a consequence, it is conceivable that members of smaller work teams were more likely to enjoy a higher quality group experience and wellbeing (Aubé, Rousseau, \& Tremblay, 2011), which may be related to an increase in the display of observable expressions of team work engagement (Torrente et al., 2012).

With regard to work engagement theory, previous research has tried to further elaborate the construct by taking a look at the measure, as well as the drivers and outcomes of work engagement at the team level of analysis (e.g., Torrente et al., 2012). In contrast, the current study delved into the underlying mechanisms of contagion, based on the role of similarity (Bakker et al., 2009). Similarity processes boosting the contagion of team work engagement are highly dependent on the specific variable under study, as similarity in terms 


\section{Chapter}

of gender was related to convergence in team work engagement, whereas similarity in terms of company tenure was inversely related. The findings broaden the application of emotional contagion theory to explain the emergence of a shared state of team work engagement.

\section{Practical implications}

Research on similarity has traditionally considered diversity management in organizations as a desirable characteristic of teams with positive outcomes for them, such as creativity (Jassawalla\&Sashittal, 1999) and group performance (Hauptman \&Hirji, 1996). However, Cunningham and Chelladurai (2004) already noticed the double-edged effects of diversity, which also led to increased employee stress (Keller, 2001) and less cohesion (Ancona\& Caldwell, 1992). Likewise, similarity in terms of gender presents a comparable counter-intuitive effect as gender diversity has been related to higher performance (Barney, 1991). Based on the current study, however, the more similar the employees were in terms of gender, the more capable of sharing a positive common state of team work engagement they were. At this point, a practical advice consists of getting a balance between the positive and negative effects of similarity by means of developing cohesiveness among the team members. This may be achieved by promoting being kind to others (e.g., designating a "kindness day"), sharing good news through the habitual communication channels within the team, nurturing social relationships (e.g., socializing during work breaks or planning outdoor activities), and expressing gratitude (e.g., reinforcing expressions of gratitude through rolemodeling; Schaufeli\&Salanova, 2010).

Following Bakker et al. (2009), positive contagion may also be fostered by means of promoting social resources (e.g., a supportive team climate, coordination, and teamwork), which may ease team work engagement (Torrente et al., 2012). Following this rationale, the organization may implement practices aimed at increasing trust within teams and with the whole organization (Acosta, Salanova, \&Llorens, 2012; Salanova, Llorens, Acosta, \& Torrente, 2013). Furthermore, organizations may carry out training and instruction in 


\section{Chapter}

empathy as a competence to increase meaningful, supportive interactions between team members, as well as between members and supervisors (Schaufeli\&Salanova, 2010).

The findings have also posited that dissimilarity in terms of company tenure could enhance convergence in terms of team work engagement. An example of this kind of asymmetry is the relation between an experienced worker and a new team member who he or she is helping. These behaviors are mainly performed by leaders or supervisors trying to increase the skills of their subordinates in a specific task, and providing them with social support (Bauer et al., 1998). As they interact frequently as a requirement for the training process, both mentor and mentees are exposed to emotional displays (e.g., facial expressions or positive comments on the task at hand), thus making the emergence of a shared state of work engagement more likely (Sy, Côté, \& Saavedra, 2005). Team leaders are a salient source of information in daily work, so it seems necessary to train them to promote positive states within their team, as this will create a shared state with beneficial effects for all the members (Nielsen, Randall, Yarker, \& Brenner, 2008). Following this reasoning, a transformational leadership style that promotes contact with employees and getting involved with their needs and well-being is expected to enhance positive emotional contagion (Cruz, Salanova, \&Martínez, 2013).

In sum, the current findings present implications for practical purposes stressing a condition that may remain hidden and requires awareness on behalf of managers and supervisors: similarity characteristics that ease team work engagement convergence. This may result critical, but at the same time more easily managed, during the first stages of team formation or when implementing team cohesion practices (Harrison, Price, \& Bell, 1998). Having said so, the management of diversity has deep ethical issues associated that may not be demeaned (Treviño\& Brown, 2004). Taking all together, managers and supervisors may set the stage for a smooth and fluid spreading of team work engagement at work beyond taking measures to maximize its averaged levels. 


\section{Limitations and further research}

The current research was aimed at analyzing similarity as a condition for team members to show convergence in team work engagement. We developed objective measures of team similarity to test their association with a shared state of work engagement within teams. Nevertheless, the analysis of the contagion process itself fell beyond the scope of this work. Future studies may further analyze under what conditions this process is triggered and how it evolves over time in order to maximize the effect of a shared state of team work engagement. Experimental studies are encouraged, as they can be designed to zoom in on specific processes and disentangle causal relations over time. Indeed, time especially may also exert an influence on the process, as for the case of newly-formed teams, in which there is no adequate level of cohesiveness (e.g., Harrison et al., 1998). Another line of research may look further into the combination of different members' attributes and the resulting subgroup divisions in the positive contagion of team work engagement and its convergence in work teams by taking a faultline perspective of diversity (Horwitz\&Horwitz, 2007, Lau \&Murnighan, 1998) or team processes (e.g., Marks, Mathiew\&Zaccaro, 2001). Further knowledge on the relationship between convergence and average levels of team work engagement may provide fruitful avenues for research connecting with previous literature on the topic (Bakker et al., 2006; Torrente et al., 2012).

Recent research points out the importance of studying both positive and negative emotions in the workplace simultaneously, so as to be able to draw conclusions aimed at integrating the role of both positive and negative states into organizational behavior (George, 2011). Thus, future studies may want to consider the analysis of positive and negative workrelated shared states, which would make it possible to draw practical recommendations from a more holistic and comprehensive point of view in the debate on emotional contagion at work. 


\section{Chapter}

\section{Final note}

The current study aimed to establish similarity as a bridge in terms of demographics and a shared state of team work engagement within teams. Findings provided mixed support for our hypotheses, which accounts for the complexity of understanding positive contagion of work engagement between members of the same work team. This perspective opens up future avenues of research, and highlights the desirability of building teams composed of employees that are not only highly but also similarly engaged, which can be achieved by spreading engagement. 


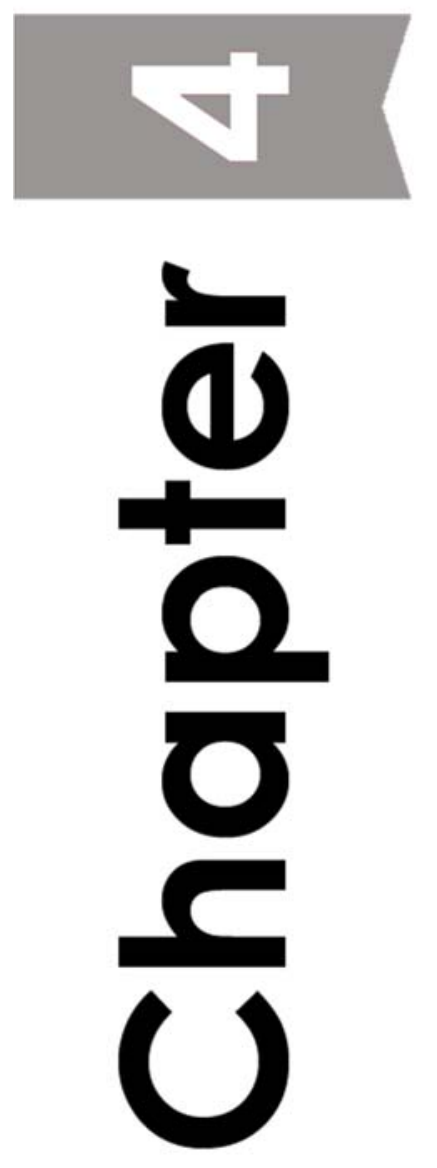




\section{From "l" to "We":}

\section{The Factorial Validity of a Team} Work Engagement Scale

This paper has been published as:

Torrente, P., Salanova, M., Llorens, S., \&Schaufeli, W.B. (2013). From Ito We: The factorial validity of a Team Work Engagement Scale. In J. Neves\& S.P. Gonçalves (Eds.), Occupational Health Psychology: From burnout to well-being (pp. 333-355). Rosemead, CA: Scientific \& Academic Publishing. 


\section{Chapter 4}

\section{From "l" to "We": The Factorial Validity of a Team Work Engagement Scale}

The study of work engagement is a core topic in Occupational Health Psychology (Salanova\&Schaufeli, 2009). Work engagement is a persistent affective-cognitive workrelated state characterized by vigor, dedication and absorption which has been related with many key outcomes, such as performance and financial returns (Bakker \&Leiter, 2010). Despite its relevance, the vast majority of scholars have focused on measuring work engagement at the individual level and have not paid much attention to groups and teams. This is even more remarkable if we consider that teams play a crucial role in achieving efficiency and competitiveness in modern organizations (Hodson, 1997). Different scholars have shown the importance of teams to increase innovation (Edmondson, 2002), efficiency (Cohen \& Bailey, 1997), and productivity (Salanova, Llorens, Cifre, Martínez, \&Schaufeli, 2003).

However, there is very little research based on teams and well-being, especially on work engagement, at the team level (Simpson, 2009; Whitman, Van Rooy, \&Viswesvaran, 2010). Work engagement has proven its relevance in many job settings but findings have only focused on the individual level of analysis, despite the development of several theoretical frameworks focusing on higher-order levels of analysis. This is the case of the HEalthy\& Resilient Organization Model (HERO; Salanova, Llorens, Cifre, \&Martínez, 2010), which states that healthy organizational practices (e.g., job and social resources and healthy organizational strategies), healthy employees (e.g., team work engagement) and healthy outcomes (e.g., excellence in products and services) interact with each other to constitute healthy and resilient organizations at higher-order levels, such as teams and organizations. 


\section{Chapter}

One reason for the lack of research on work engagement in teams is that no consensus about the measurement of team work engagement has been reached. Salanova et al. (2003) were the first scholars to propose a measure of collective work engagement. However, so far this measure has only been validated in a sample of university students working in groups, but not in employees working in teams. In addition, the focus of work engagement in this measure was on the task and not on work as a whole. Although some papers have tried to tackle this limitation in the past, in the current study we go one step further. Specifically, the objective of the study is to test the validity of a team work engagement scale using aggregated data at the workunit level.

\section{Work engagement: The concept and its measurement}

Work engagement has traditionally been described as "a positive, fulfilling, workrelated state of mind that is characterized by vigor, dedication, and absorption" (Schaufeli, Salanova, González-Romá, \& Bakker, 2002). Vigor refers to the willingness to invest effort in one's work, being persistent in the face of difficulties, and exhibiting high levels of energy and mental resilience while working. Dedication refers to particularly strong work involvement and identification with one's job. The final dimension of engagement, absorption, denotes being fully concentrated and engrossed in one's work, whereby time passes quickly and one has difficulties with detaching oneself from work. This three-dimensional structure of work engagement (i.e., vigor, dedication, and absorption) has been confirmed in a vast amount of research in different contexts: among students (Salanova, Schaufeli, Martínez, \&Bresó, 2009), Information and Communication Technology (ICT) workers (Llorens, Bakker, Schaufeli, \&Salanova, 2006), teachers (Hakanen, Bakker, \&Schaufeli, 2006), secondary school teachers, and students working in groups (Salanova, Llorens, \&Schaufeli, in press), among others. Moreover, a number of studies evidence the positive consequences of 


\section{Chapter}

generating engagement at work. Engaged workers display more proactive behavior (Salanova\&Schaufeli, 2008), perform better (Bakker, Demerouti, \&Verbeke, 2004), obtain higher objective financial returns for the business (Xanthopoulou, Bakker, Demerouti, \&Schaufeli, 2007), and show less sickness absenteeism (Schaufeli, Bakker, \& Van Rhenen, 2009). All in all, these studies provide evidence for the relevance of enhancing work engagement at work.

Previous studies on work engagement provided support for the psychometric quality of the instrument used to assess the construct: the Utrecht Work Engagement Scale (UWES; Schaufeli et al., 2002). This scale is the most widely used instrument to measure work engagement. A recent search on PsycINFO (June 2010) showed that $83 \%$ of scholarly articles about engagement used this questionnaire (Schaufeli\&Salanova, 2011). The UWES is composed of seventeen items measuring vigor (six items), dedication (five items) and absorption (six items) with a Likert-type scale ranging from 0 'never' to 6 'always'. Different research using Confirmatory Factor Analysis (CFA) provided evidence for the structural validity of this instrument for testing work engagement in different occupations, such as workers in the tourism sector (Salanova, Agut\&Peiró, 2005), ICT workers (Llorens, Schaufeli, Bakker, \&Salanova, 2007; Salanova\&Llorens, 2009), health care workers, educators, white- and blue-collar workers (Seppälä et al., 2009), university students working in groups (Llorens et al., 2006, 2007), and secondary school teachers (Salanova et al., 2010), as well as across different countries (for a review, see Schaufeli\& Bakker, 2010).

A further step in the measurement of work engagement was the shift toward the construction of a cross-nationally validated, 9-item version of the UWES scale (Schaufeli, Bakker, \&Salanova, 2006). By using CFA techniques, this development led to a short 9-item scale distributed in three dimensions: vigor (3 items), dedication (3 items) and absorption ( 3 items) with a Likert-type scale ranging from 0 'never' to 6 'always'. This short work engagement scale has also been cross-nationally validated in 


\section{Chapter}

a large dataset with a wide range of occupations from ten different countries (Schaufeli et al., 2006).

All in all, the scientific literature provides an adequate and consistent concept of work engagement and also validated instruments (i.e., the original and the short version of the UWES) to measure work engagement across different contexts (e.g., students, teachers, ICT users). However, this use is limited to the individual level in the workplace: each individual answers the UWES by thinking about his/her personal perception of this experience. Consequently, the measurement of work engagement at higher-order levels of analysis (e.g., organizational, team level) remains virtually uncovered. The current study attempts to bridge this gap in the literature.

\section{Team work engagement: The concept and the measurement}

In line with the original definition by Schaufeli et al. (2002), team work engagement is conceptualized as a positive, fulfilling, work-related shared-state that is characterized by team work vigor, dedication, and absorption which emerges from the interaction and shared experiences of the members of a work team. In fact, social psychology offers a large number of studies showing how common beliefs and affective experiences arise among people working together and who, in addition, tend to show similar cognitive and behavioral patterns (González-Romá, Peiró, Subirats, \&Mañas, 2000), feel collective emotions (Barsade, 2002), share collective efficacy (Bandura, 2001) or share job strain (Semmer, Zapf, \& Greif, 1996).

There are essentially two reasons for these collective phenomena, which can be summarized as: team members can affect each others' moods (implicit processes) and are likely to share many experiences, as they are all part of the same work place (explicit processes) (Ilies, Wagner, \&Morgeson, 2007). This rationale can also be applied to work engagement by considering emotional contagion as the main potential mechanism (Bakker, Demerouti, \&Schaufeli, 2005). Thus, team work engagement 


\section{Chapter}

arises from consensus on the perceptions of team members who are able to share a common idea on how the team expresses vigor, dedication and absorption. Since team work engagement is also expected to maintain an isomorphic structure across different levels of analysis, a reference-shift consensus model has to be applied to model work engagement at the team level. This aggregation model uses the aggregate from team members who have been asked to rate team properties directly, thereby shifting the referent from "l" to "we". The use of an aggregation index is required, since it is necessary to provide statistical support to consider that a consensus about the construct exists (Chen, Mathieu, \&Bliese, 2004).

Several studies have shown a significant relationship between work engagement measured at the collective level, and organizational and team outcomes. A metaanalytic study by Harter, Schmidt and Hayes (2002) revealed that engagement positively predicts business-unit outcomes. Furthermore, Salanova et al. (2003) observed a sample of students working in groups and concluded that collective work engagement increases the levels of task performance (when collective efficacy is high). Salanova et al. (2005) also used a sample of 114 service employees from hotel front desks and restaurants to prove that work engagement relates to service climate, which in turn predicts employee performance, all of which was measured at the collective level. Llorens et al. (2007) recruited a sample of students working in groups to show that collective work engagement generates the perception of job resources (i.e., control) and efficacy beliefs in gain cycles using a two-wave longitudinal design. Finally, Salanova et al. (in press), again in students working in groups, showed that activity engagement (i.e., work and task) increases collective positive affect (i.e., comfort, enthusiasm, satisfaction) and collective efficacy by means of positive spirals using a three-wave longitudinal design.

As far as we know, work engagement at the collective level (i.e., the group is the referent of work engagement although it is assessed by individuals) was tested for the first time using a collective version of the UWES in a sample of students working in 


\section{Chapter}

groups (Salanova et al., 2003). The resulting adapted scale was composed of eighteen items distributed in three dimensions: collective vigor (seven items), collective dedication (four items) and collective absorption (seven items) using a Likert-type scale ranging from 0 'never' to 6 'always'. A first attempt to confirm the factorial structure of this collective scale was made by Salanova et al. (2005). The results revealed that a model for collective vigor, collective dedication and collective absorption fit the data well. Further support for the collective questionnaire of work engagement was included in the validation paper of the HERO Questionnaire (Salanova et al., 2010), which revealed the factorial structure of team work engagement using second-order factor analyses in a sample of small and medium-sized enterprises (SMEs).

Despite the fact that these studies represented an important step toward achieving a validated measure of team work engagement, an important critique should be carried out: despite having the team as a referent, team work engagement has not yet been tested by considering aggregated data at the team level instead of using individual perceptions of the construct. This study intends to fill this void in the literature.

\section{The current study}

The objective of our study is to test, for the first time, the factorial structure of a team work engagement scale by aggregating data at the team level. Specifically, we test the three-factor structure of team work engagement (i.e., team work vigor, team work dedication and team work absorption) by considering the aggregation of team members' perceptions. At this point, we expect the three-factor structure of the Team Work Engagement Scale to fit the data better than a one-factor model. 


\section{Method}

\section{Sample and procedure}

The sample consisted of 511 employees nested within 54 work units from 12 Spanish SMEs. Response rate was $58 \%$. Of these employees, $81 \%$ of the SMEs belonged to the services sector, $11 \%$ to industry, and $8 \%$ to construction sectors. Other data included the fact that $53 \%$ were women, $71 \%$ had a tenured contract, $17 \%$ were self-employed, and $12 \%$ had a temporary contract. The average tenure in their current job was 4 years $(S D=3.47), 7$ years working in the same company $(S D=5.58)$ and 10 years working in general $(S D=7.67)$. Finally, work-units had an average team size of 9.46 members $(S D=9)$.

After the company had agreed to participate in the study, questionnaires were administered to the different team members, who were asked to participate voluntarily. The whole questionnaire required about 30 minutes to be filled out (the engagement questionnaire only 5 minutes). According to Feldman (1988), the accommodation period that the new worker needs to settle into his job and the organization is three or four months (i.e., the encounter stage). Thus, in order to prevent bias, only workers who had been working in the same company for more than six months were considered for the analyses. Confidentiality and anonymity of the answers were guaranteed.

\section{Measures}

The Team Work Engagement Scale was assessed by eighteen items from the collective work engagement scale, as included in the HERO questionnaire (Salanova et al., 2010). These items were reworded from their original collective version in Salanova et al. (2003) so that they could be used in work teams (see Appendixes section). Specifically, team work engagement also considered three dimensions: team work 


\section{Chapter}

vigor (seven items; e.g., 'During the task, my team feels full of energy'; alpha = .80); team work dedication (four items; e.g., 'My team is enthusiastic about the task'; alpha = .91), and team work absorption (seven items; e.g., 'When my team is working, we forget everything else around us'; alpha $=.86$ ). Thus, internal consistencies for the three dimensions achieved the cut-off point of .70 (Nunnally\& Bernstein, 1994). Respondents answered by using a 7-point Likert-type scale ranging from 0 'nothing' to 6 'always'.

\section{Data analyses}

Firstly, we calculated the internal consistencies (Cronbach's $\alpha$ ) for the individual data. Secondly, since the team work engagement items were measured at the team level, we computed the interrater agreement at team level for each item from each scale (Chen et al., 2004). To do so, we used a consensus-based approach by computing the Average Deviation Index $\left(A D_{M(J)}\right.$; Burke, Finkelstein, \&Dusig, 1999). Then, the Average Deviation Indices of the scales $\left(A D_{M(J)}\right)$ were computed by averaging the values for their corresponding items $\left(A D_{M(j)}\right)$. Accordingly, team agreement was concluded when $A D_{M(J)}$ were equal to or less than 1 (Burke et al., 1999). Moreover, Analyses of Variance (ANOVA) were computed in order to ascertain whether there was an adequate between-units differentiation on average scales (i.e., vigor, dedication, and absorption) to support the validity of the measure. Thirdly, we computed the descriptive statistics and intercorrelations among the aggregated items at the team level. Fourthly, the AMOS 18.0 software application (Analysis of MOment Structures; Arbuckle, 1997) was used to implement the different CFA in order to test the factorial structure of the team work engagement scale. Two plausible models for the 18-item scale of team work engagement were compared: M1, the one-factor model, in which all the items loaded on a single latent factor; and M2, a three-factor model in 


\section{Chapter}

which items loaded on the specific team work engagement dimensions: team work vigor, team work dedication, and team work absorption.

We assessed two absolute goodness-of-fit indices to evaluate the goodness-offit of the models: (1) the $X^{2}$ goodness-of-fit statistic; and (2)the Root Mean Square Error of Approximation (RMSEA). The $X^{2}$ goodness-of-fit index is sensitive to sample size, so the use of relative goodness-of-fit measures is recommended (Bentler, 1990). In consequence, four relative goodness-of-fit indices were used: (1) the Comparative Fit Index (CFI); (2) the Normed Fit Index (NFI); (3) the Tucker-Lewis Index (TLI, also called the Non-Normed Fit Index); and (4) the Incremental Fit Index (IFI). For RMSEA, values smaller than .05 were considered to indicate an excellent fit, whereas values greater than .1 led to model rejection (Brown \&Cudeck, 1993). For the relative fit indices, values greater than .90 were indicative of a good fit (Hu \&Bentler, 1999). In order to compare non-nested models, the Akaike Information Criterion (AIC) was also requested in the analyses. The lower the AIC is, the better the model fits to the data (Akaike, 1987).

\section{Results}

\section{Descriptive analyses and aggregation}

Table 1 shows the Cronbach a's (at the individual level), means, standard deviations and intercorrelations of the three dimensions (eighteen items) of team work engagement aggregated at the work-unit level. Thus, based on the aggregated data $(\mathrm{N}=54)$, the $A D_{\mathrm{M}(\mathrm{J})}$ indices were $.73(S D=.24), .66(S D=.31)$, and $.84(S D=.26)$ for team work vigor, team work dedication and team work absorption, respectively. Since an $A D_{M(J)}$ value equal to or less than 1 indicated an adequate level of agreement, these results provided support to consider that within-group agreement in the study's workunits was adequate to aggregate unit members' perceptions to the work-unit level 


\section{Chapter}

(Burke et al., 1999). We also tested a one-way ANOVA to ascertain whether there was an adequate between-units differentiation in the scales (i.e., vigor, dedication, and absorption) to support the validity of the measure. Results for the three team work engagement dimensions were: $F(53,452)=2.89, F(53,452)=2.81$, and $F(53$, $451)=2.96$, respectively $(p<.001)$. Therefore there was a significant degree of between-unit discrimination, which supported the validity of the three aggregated dimensions of team work engagement (i.e., vigor, dedication, and absorption). Regarding the correlations at the team level $(N=54)$, the patterns of the intercorrelations among team work vigor, team work dedication and team work absorption with the aggregated data show that the variables correlated positively and significantly with each other. 


\section{Table 1}

Means, standard deviations (SD), and intercorrelations of team work vigor, team work dedication, and team work absorption for the aggregated scales $(N=54)$ and Cronbach's $\alpha(N=511)$

\begin{tabular}{|c|c|c|c|c|c|c|c|}
\hline \multirow[b]{2}{*}{ Variables } & \multicolumn{2}{|c|}{ 18-item Scale } & \multicolumn{2}{|c|}{ 9-item Scale } & \multirow[b]{2}{*}{1} & \multirow[b]{2}{*}{2} & \multirow[b]{2}{*}{3} \\
\hline & Mean & SD & Mean & SD & & & \\
\hline 1. Vigor & 4.40 & .54 & 4.43 & .57 & $.86 / .80$ & $.88^{* * *}$ & $.74^{* * *}$ \\
\hline 2. Dedication & 4.77 & .59 & 4.67 & .64 & $.84^{* * *}$ & $.91 / .91$ & $.79^{\star * *}$ \\
\hline 3. Absorption & 4.04 & .58 & 4.17 & .72 & $.67^{* \star *}$ & $.75^{\star \star *}$ & $.86 / .87$ \\
\hline
\end{tabular}

Notes.Cronbach a's at the individual level (for the 18-item/9-item scales) on the diagonal $(\mathrm{N}=511)$;

Correlations for the 9-item scale below the diagonal; ${ }^{* * *} p<.001$. 


\section{Chapter}

\section{Confirmatory factor analyses for the team work engagement scale}

For the CFA, we used the aggregated database $(\mathrm{N}=54)$ that considered 511 employees nested within 54 work units from 12 SMEs; consequently, the aggregated items at the work-unit level for the team work engagement vigor, team work dedication and team work absorption were considered to be observed variables. Meanwhile, team work vigor, team work dedication and team work absorption were considered to be latent variables. Table 2 provides the results of the CFA conducted to test the team work engagement structure by aggregating the data at the work-unit level. The findings of these analyses indicate that the three-factor team work engagement model (M2) with correlated factors and no cross-loadings fitted the data better than M1 [Delta $\left.\chi^{2}(3)=30.886, p<.001\right]$

However, M1 and M2 models testing the fit for the 18-item scale did not showed adequate goodness-of-fit indices and did not, therefore, support the consideration of factorial validity for this scale to measure team work engagement at the aggregated level. Since low factor loadings also suggested unsound items in the original collective scale, an item-reduction procedure was applied to deal with these unexpected findings. The procedure for the reduction of the original 18-item scale consisted in removing the items with the lowest factor loadings. A similar procedure can be found in the field within an Exploratory Factor Analysis framework (Schaufeli, Shimazu, \&Taris, 2009). For the team work vigor scale, items 2, 3, 4 and 7 were left out of the model. The same procedure was applied for team work dedication and item 8 was removed. Finally, items $13,14,17$ and 18 were removed for the team work absorption scale.

Consequently, a revised version (nine items) of the Team Work Engagement Scale was obtained. This revised 9-item version considered the three inner dimensions of team work engagement: team work vigor (three items), team work dedication (three items), and team work absorption (three items) (see Appendix 1 for the final items). Then, a revised model $\left(M 2_{R}\right)$ was tested. $M 2_{R}$ fitted the data with all the fit indices 


\section{Chapter}

satisfying the criteria, and with the RMSEA index close to the criterion value of .10. Since the original three-factor 18-item model (M2), and the original one-factor 18-item model (M1) has fewer items and they are not nested within $M 2_{R}$, the comparison between these models was made by means of the AIC. This index indicated that $M 2_{R}$ showed a better fit to the data as compared with the original models. Finally, $M 2_{R}$ was also compared to $\mathrm{M} 2_{\mathrm{Alt}}$; that is, an alternative model which assumes that the nine items of the Team Work Engagement Scale load on a one-factor model. Once again, the Chisquare tests between $M 2_{R}$ and $M 2_{A l t}$ supported the superiority of $M 2_{R}$ [Delta $\chi^{2}(3)=$ 22.23, $p<.001]$. Thus, the revised three-factor scale (nine items) for team work engagement $\left(M 2_{R}\right)$ was the most parsimonious scale and the one which offered the best goodness-of-fit indicators. This final model was completed as shown in Figure 1. Firstly, it is important to note that all the items loaded significantly on the intended latent factors: team work vigor, team work dedication, and team work absorption. An inspection of output revealed that all the indicators of team work vigor had loadings on the intended latent factor which were higher than .70. Furthermore, the loadings of team work dedication and team work absorption indicators were higher than .80 and .81 , respectively. Moreover, with this final model, the covariances among the three dimensions of team work engagement were higher than .79. 


\section{Chapter}

\section{Table 2}

Fit Indices of the CFA for the team work engagement scale $(N=54)$

\begin{tabular}{|c|c|c|c|c|c|c|c|c|c|c|c|c|c|c|c|}
\hline Models & $\chi^{2}$ & $d f$ & RMSEA & $\mathrm{CFI}$ & $\mathrm{NFI}$ & TLI & IFI & $\mathrm{AIC}$ & $\Delta \chi^{2}$ & $\Delta d f$ & $\triangle \mathrm{RMSEA}$ & $\Delta \mathrm{CFI}$ & $\Delta \mathrm{NFI}$ & $\Delta \mathrm{TLI}$ & $\Delta \mathrm{IFI}$ \\
\hline M1 & 342.739 & 135 & .170 & .732 & .630 & .696 & .738 & 414.739 & & & & & & & \\
\hline M2 & 311.853 & 132 & .160 & .768 & .664 & .731 & .774 & 389.853 & & & & & & & \\
\hline Diff. M2-M1 & & & & & & & & & $30.886^{\star * *}$ & 3 & .010 & .036 & .034 & .035 & .036 \\
\hline$M 2_{R}$ & 37.624 & 24 & .103 & .962 & .905 & .943 & .963 & 79.624 & & & & & & & \\
\hline M2Alt & 59.854 & 27 & .152 & .909 & .849 & .878 & .911 & 95.854 & & & & & & & \\
\hline Diff. M2Alt $-M 2_{R}$ & & & & & & & & & $22.23^{* * *}$ & 3 & .049 & .053 & .056 & .065 & .052 \\
\hline
\end{tabular}

Notes. $\chi^{2}=$ Chi-square, $\mathrm{df}=$ degrees of freedom; RMSEA = Root Mean Square Error of Approximation; CFI = Comparative Fit Index; NFI = Normed Fit Index; $\mathrm{TLI}=$ Tucker-Lewis Index; IFI = Incremental Fit Index; ${ }^{* *} p<.001$. For a description of the models, see text. 


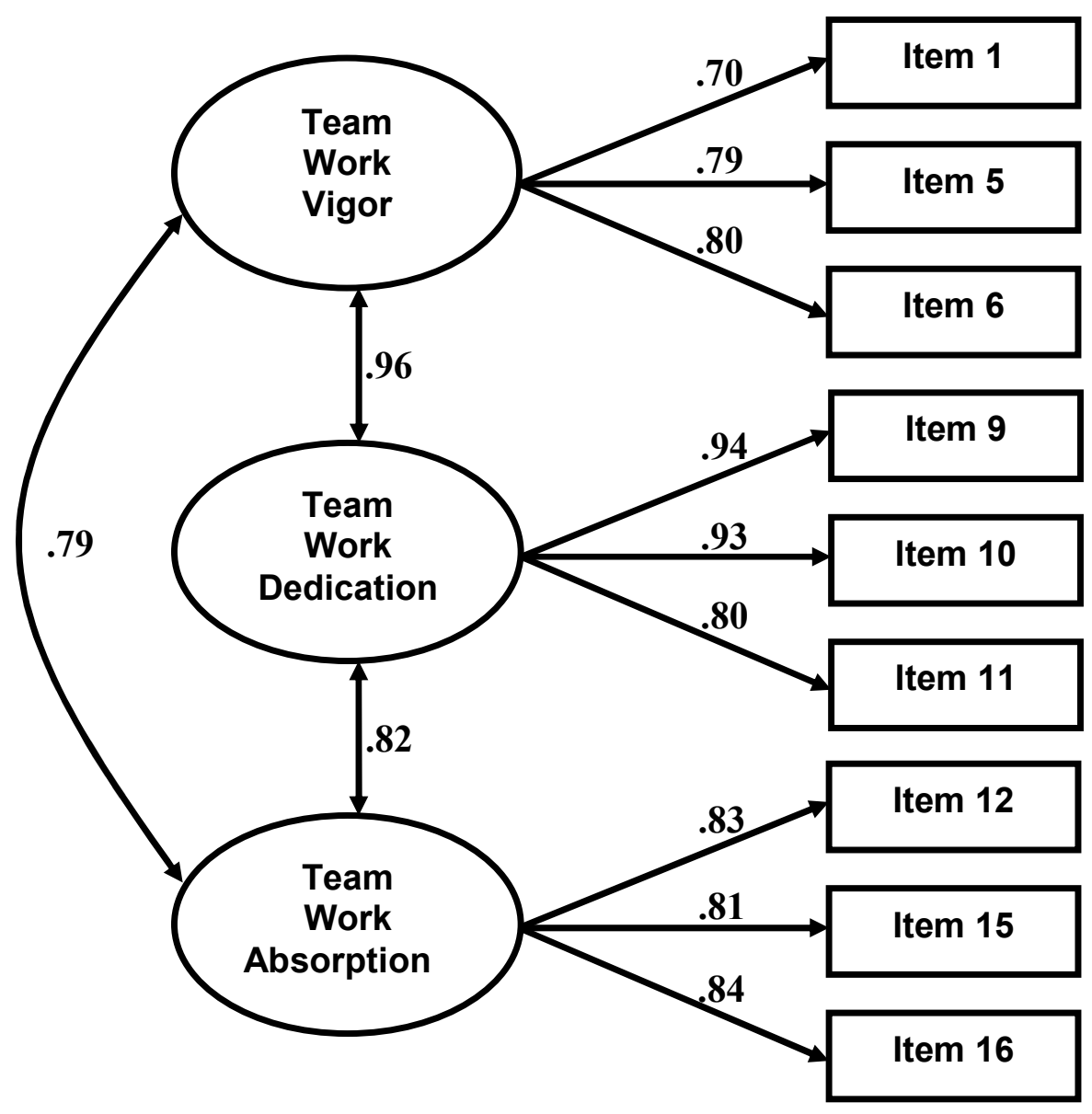

Figure 1. Path diagram for the final Team Work Engagement Scale. All factor loadings and covariances are significant at $p<.001$.

Internal consistencies and descriptive analyses of this 9-item version of the Team Work Engagement are shown in Table 1. Internal consistencies for the revised three team work engagement dimensions achieved the cut-off point of .70 (Nunnally\& Bernstein, 1994). The patterns of the intercorrelations among team work vigor, team work dedication, and team work absorption with aggregated data also showed that variables correlated positively and significantly with each other. 


\section{Chapter}

\section{Discussion}

The objective of our study was to test, for the first time, the factorial structure of a team work engagement scale by aggregating data at the team level. Specifically, we tested the three-factor structure of team work engagement (i.e., team work vigor, team work dedication, and team work absorption) by considering team members' aggregated perceptions of work engagement. Since statistical support for reference-shift consensus models is required (Chen et al., 2004), items were aggregated from team members' perceptions using the $A D_{\mathrm{M}(\mathrm{j})}$ index. We expected the three-factor structure of the Team Work Engagement Scale to fit the data better than a one-factor model.

The results of the CFA analyses with the aggregated data at work-unit level revealed that the three original scales from the team work engagement scale did not fit the data. In consequence, an acceptable degree of factorial validity for the original 18item scale was not achieved. This unexpected result could be due to a mismatch between the level of measurement and the level of analysis when conducting previous CFA. Since earlier research did not aggregate team members' perceptions to test the factorial validity of team work engagement, the level of analysis was not in accordance with the level of measurement, thus leading to invalid results. To deal with this finding, we carried out an item-reduction procedure. After the item-reduction procedure (removing the items with the lowest factor loadings) the three-dimension original scale (eighteen items) was reduced to nine items: three items each for team work vigor, team work dedication, and team work absorption with good internal consistencies. This revised three-factor 9-item model fitted data significantly better than both the original three-factor 18-item model and a one-factor model (with eighteen items and with nine items), which assumes that items load on a common single factor.

More specifically, this three-factor structure of team work engagement tested at the work-unit level reflects the three inner dimensions of work engagement that had previously been found in different samples at the individual level (e.g., Bakker 


\section{Chapter}

\&Demerouti, 2008; Schaufeli et al., 2006). As a whole, the CFA: (1) confirm the expected three-factor structure of team work engagement (vigor, dedication and absorption) when they are tested at the team level with nine items using aggregated data, and (2) offer a validated scale with which to test work engagement in teams. Consequently, the results support the consideration that the main study objective has been attained.

However, since the three dimensions of team work engagement are highly intercorrelated (ranging from .79 to .96), an overall measure of team work engagement could be derived from averaging the final nine items of the revised scale. This conclusion was also drawn by Schaufeli et al. (2006) from the individual point of view when reducing the original UWES questionnaire to a shorter version. Several differences appear when comparing the nine items which emerged in the abovementioned validation paper against the nine items obtained in the current study.

Regarding the vigor dimension, Schaufeli et al. (2006) included an item (“When I get up in the morning, I feel like going to work") that was left out of the team version. This item refers to a behavioral-energetic state that is purely individual and which it is difficult to have a shared perception about within the team. Concerning the dedication dimension, two items have no clear team counterpart ("My job inspires me" and "I am proud of the work that I do"). One reason for this difference can be found in the nature of the construct to which they refer. Inspiration and pride are more cognitive than affective or motivational in nature, and it is thus more difficult for them to be shared by all team members. In contrast, the team counterparts of these items (see items \#10 and \#11 in Appendix 1) focus on enjoyment and motivation, which are more related to explicit behavior, which in turn is more capable of affecting team members' perceptions of team work dedication. Finally, differences are less pronounced in the absorption dimension, since all items refer to being fully concentrated on work. 


\section{Chapter}

\section{Limitations and further research}

The main limitation of this study is the use of a convenience sample. However, it is a wide sample, including different team groups from different enterprises which belong to different economic sectors. A further step in this line of research must also consider the factorial validation of this scale in a wide range of occupations, along with multi-group comparisons and cross-cultural studies, as they will lead to fruitful contributions to the factorial invariance of the measure of team work engagement by aggregated data.

More research on the content validity of team work engagement is also needed by testing its antecedents and consequences as well as its underlying contagion processes. Following recent theoretical frameworks which focus on the collective level, as is the case of the HERO Model, will help to provide a deeper understanding of how to boost team work engagement in organizations (Salanova et al., 2010). Multilevel techniques are also recommended in order to look for cross-level relationships involving this construct. Furthermore, relevant variables in organizational research may display different effects from one dimension to another, so greater detail is needed when team work engagement measures are considered. Comparing both individual work engagement and its team-level counterpart in the same sample is also encouraged. Following Chen et al. (2004), these papers foster the validity of multilevel constructs and lead to a greater understanding of how they evolve as part of wider psychosocial processes within organizations.

\section{Theoretical and practical implications}

The current study presents important theoretical and practical implications. First, the results corroborate and extend the three-factor structure of work engagement to team work engagement by using aggregated data at the team level. Hence, a step forward has been taken toward confirming the relevance of this construct in higher- 


\section{Chapter}

order levels within organizations, i.e., the work-unit level. This finding evidences the isomorphism of the work engagement measure at different levels of analysis. This fact reinforces the idea that underlying processes such as emotional contagion could be playing a key role in how team members share a common perception about team work engagement that arises from individual perceptions of the construct (Bakker et al., 2005). Second, a revised and shorter scale with only nine items leads to a more parsimonious understanding of the construct. With this 9-item team work engagement scale practitioners gain not only from the advantage of using a shorter work engagement measure that applies to work teams but also from the possibility of acquiring a better understanding of well-being at work in highly interdependent job settings.

\section{Final note}

To sum up, this research has led to the development of a team work engagement scale that can be applied to teams. The three-factor model of work engagement has been replicated at the team level, which encourages us to consider the isomorphism of this construct at a higher-order level of analysis. This team-oriented instrument enhances future research into well-being in teams for scholars, and is also a new specific tool for information within organizations. Thus, by changing the focus from "I" to "we", a huge amount of rich and useful information about the topic of work engagement becomes available. 



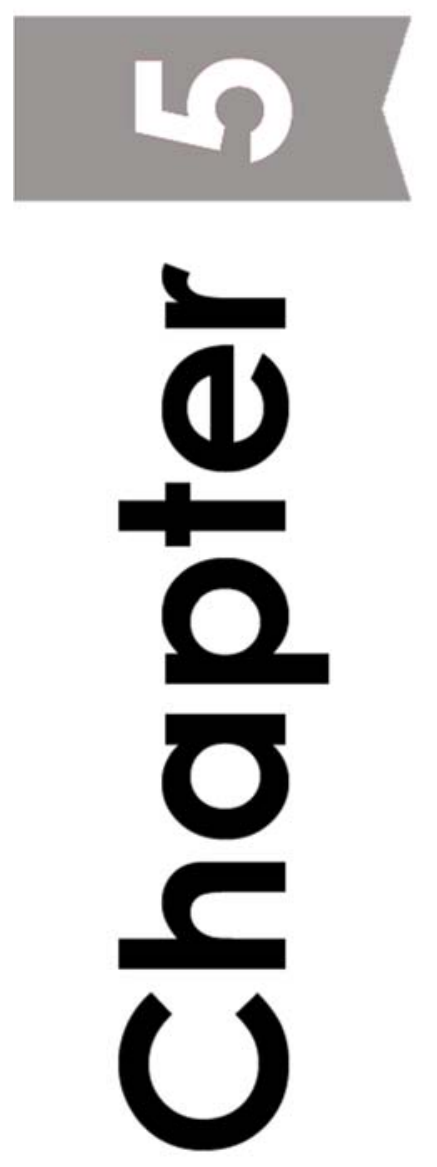




\section{Teams Make It Work:}

\section{How Team Work Engagement}

Mediates Between Social

Resources and Performance in

Teams

This paper has been published as:

Torrente, P., Salanova, M., Llorens, S., \&Schaufeli, W.B. (2012). Teams make it work: How team work engagement mediates between social resources and performance in teams. Psicothema, 24, 106-112. 


\section{Chapter 5}

\section{Teams Make It Work: How Team Work Engagement Mediates Between Social Resources and Performance in Teams}

The study of work engagement has become a popular topic since the turn of the century. Work engagement is a positive affective-motivational and work-related psychological state characterized by vigor, dedication and absorption (Schaufeli, Salanova, González-Romá, \& Bakker, 2002). Despite its relevance in work settings, the vast majority of scholars have focused on work engagement at the individual level, thus ignoring the role of teams (Richardson \& West, 2010). This is even more remarkable if we consider that teams play a crucial role in employee health and wellbeing (Wilson, DeJoy, Vandenberg, Richardson, \& McGrath, 2004), and productivity (Salanova, Llorens, Cifre, Martínez, \&Schaufeli, 2003). In order to fill this gap, this study analyzes the role of team work engagement as a mediator between social resources and team performance, as assessed by the team supervisor, using aggregated data at the team level of analysis.

\section{The theoretical background: the Job Demands-Resources Model}

The Job Demands-Resources (JD-R) Model(Bakker \&Demerouti, 2007; Demerouti, Bakker, Nachreiner, \&Schaufeli, 2001) is a heuristic and parsimonious model that posits how two sets of employees' working conditions (i.e., job demands and job resources) relate with their psychosocial health and well-being, which in turn are associated with several employee and organizational outcomes (Llorens, Bakker, Schaufeli, \&Salanova, 2006). The JD-R model has been successfully studied in different countries as well as in different occupations such as white-collar workers 


\section{Chapter}

(Schaufeli\& Bakker, 2004) and blue-collar workers (Bakker, Demerouti, De Boer, \&Schaufeli, 2003).

The JD-R Model assumes two independent processes in order to explain the impact of job demands and job resources on various work-related outcomes. The health-impairment or erosion process posits that the presence of chronic job demands consumes energy and effort, and may therefore undermine employee health and wellbeing and lead to burnout, which in turn can lead to an increase in psychological and somatic complaints (Hakanen, Bakker, \&Schaufeli, 2006). In contrast, the motivational process posits that job resources foster employees' motivation and induce positive emotions, as is the case for work engagement. Next, this affective-motivational state may lead to positive results for the organization, such as a decrease in turnover intention (Schaufeli\& Bakker, 2004) and sickness absence (Schaufeli, Bakker, \& Van Rhenen, 2009).

The erosion process of the JD-R Model has also been tested at the team level of analysis by Bakker, Van Emmerik and Van Riet (2008), whose results showed the mediating role of burnout between job demands and resources on the one hand and performance on the other. However, despite the fact that work engagement plays a mediating role in the motivational process at the individual level of analysis by linking resources to outcomes (Llorens et al., 2006), the positive path of the JD-R Model remains to be tested at the collective, team level. In order to analyze whether engaged teams are also better-performing teams, we include the aggregated perceptions of team social resources and team work engagement as well as the supervisor-rated team performance. Following the JD-R Model, social resources may constitute the starting point of a virtuous process. 


\section{The role of team social resources}

According to the JD-R Model(Demerouti et al., 2001, p. 501), job resources are defined as "those physical, psychological, social, or organizational aspects of the job that may do any of the following: (a) be functional in achieving work goals; (b) reduce job demands at the associated physiological and psychological costs; (c) stimulate personal growth and development". Previous research shows that social resources can influence work engagement at the individual level. For instance, teachers with high levels of social resources (i.e., innovative climate, supervisor support, and supportive social climate) experience more work engagement than teachers with low levels of such resources (Hakanen et al., 2006). Longitudinal research has also supported this relationship, as illustrated by Schaufeli and colleagues (2009), who examined a Dutch telecom company and found that social support predicted work engagement over a period of one year, controlling for baseline-level engagement. Recent team-level research also revealed that social phenomena, such as vertical trust (Acosta, Salanova, \&Llorens, in press) or healthy organizational practices that include team social resources (Salanova, Llorens, Cifre, \&Martínez, 2011), have a positive relationship with work engagement at the team level.

Although previous research suggests that a relationship exists among social resources and work engagement, two issues remain problematic: (1) social resources have been tested together with employee and organizational level variables, i.e., including variables from different levels of analysis in the same structural model, and (2) to date the relationship between social resources and work engagement has only been tested at the individual level, and not at the team level. Therefore, in the current study social resources are considered at the team level in order to explore their relationship with team work engagement and team performance as rated by the supervisor. 


\section{Chapter}

\section{Team work engagement}

Work engagement has traditionally been described as "a positive, fulfilling, workrelated state of mind that is characterized by vigor, dedication, and absorption" (Schaufeli et al., 2002, p. 72). Vigor suggests a willingness to invest high levels of energy and mental resilience while working. Dedication refers to a particularly strong work involvement and identification with one's job. Finally, absorption denotes being fully concentrated and engrossed in one's work.

To date work engagement has been studied mainly at the individual level (e.g., Llorens et al., 2006, 2007), but it may also exist as a collective psychosocial construct. The fact that people who work together experience collective emotions (Barsade, 2002) may also be applied to work engagement. For instance, Bakker, van Emmerik and Euwema (2006) identified emotional contagion as the main crossover mechanism behind the emergence of a shared psychological state such as team work engagement. Thus, we conceptualize team work engagement as a positive, fulfilling, work-related and shared psychological state characterized by team work vigor, dedication and absorption which emerges from the interaction and shared experiences of the members of a work team (Salanova et al., 2003).

Previous research has shown that collective work engagement increases: (1) task performance of students working in groups (Salanova et al., 2003), (2) service climate in service employees (Salanova, Agut, \&Peiró, 2005), (3) collective positive affect and collective efficacy beliefs (Salanova, Llorens, \&Schaufeli, 2011), and (4) individual-level work engagement (Bakker et al., 2006). However, as far as we know, no study has explored the relationship between team work engagement and team-level performance, with the team as a referent and not the individual employee. One of the innovations of the present study is that team performance is not reported by individuals but is assessed by their immediate supervisor. 


\section{Team performance: The supervisor point of view}

According to Goodman and Svyantek (1999), in-role and extra-role performance are related to task and contextual performance, respectively. Specifically, task performance includes activities that are related to the formal job. On the other hand, contextual performance refers to actions that exceed what the employee is prescribed to do, e.g., helping others or voluntary overtime. Hence, considering both complementary types of job performance provides a comprehensive picture of employees' performance.

Different scholars have confirmed the positive relationship between employees' well-being and job performance at the individual level. For instance, Schaufeli, Taris and Bakker (2006) concluded that engaged employees show more in-role and extrarole performance in a broad range of companies and occupations. Furthermore, in another recent study in a fast-food restaurant (Xanthopoulou, Bakker, Demerouti, \&Schaufeli, 2009) engaged employees managed to accomplish higher objective financial returns for the business. This relationship has also been found at the team level. For example, Salanova et al. (2011) showed that a set of indicators for healthy employees (i.e., collective efficacy, work engagement and resilience) had a positive association with various outcomes (i.e., performance and commitment).

\section{The current study}

Based on the JD-R Model (Demerouti et al., 2001), our hypothesis is thatteam work engagement (i.e., team work vigor, team work dedication, and team work absorption) fully mediates the relationship between social resources (i.e., supportive team climate, coordination and teamwork) and the supervisor's rating of performance in teams (i.e., in-role and extra-role performance; see Figure 1). 


\section{Chapter}

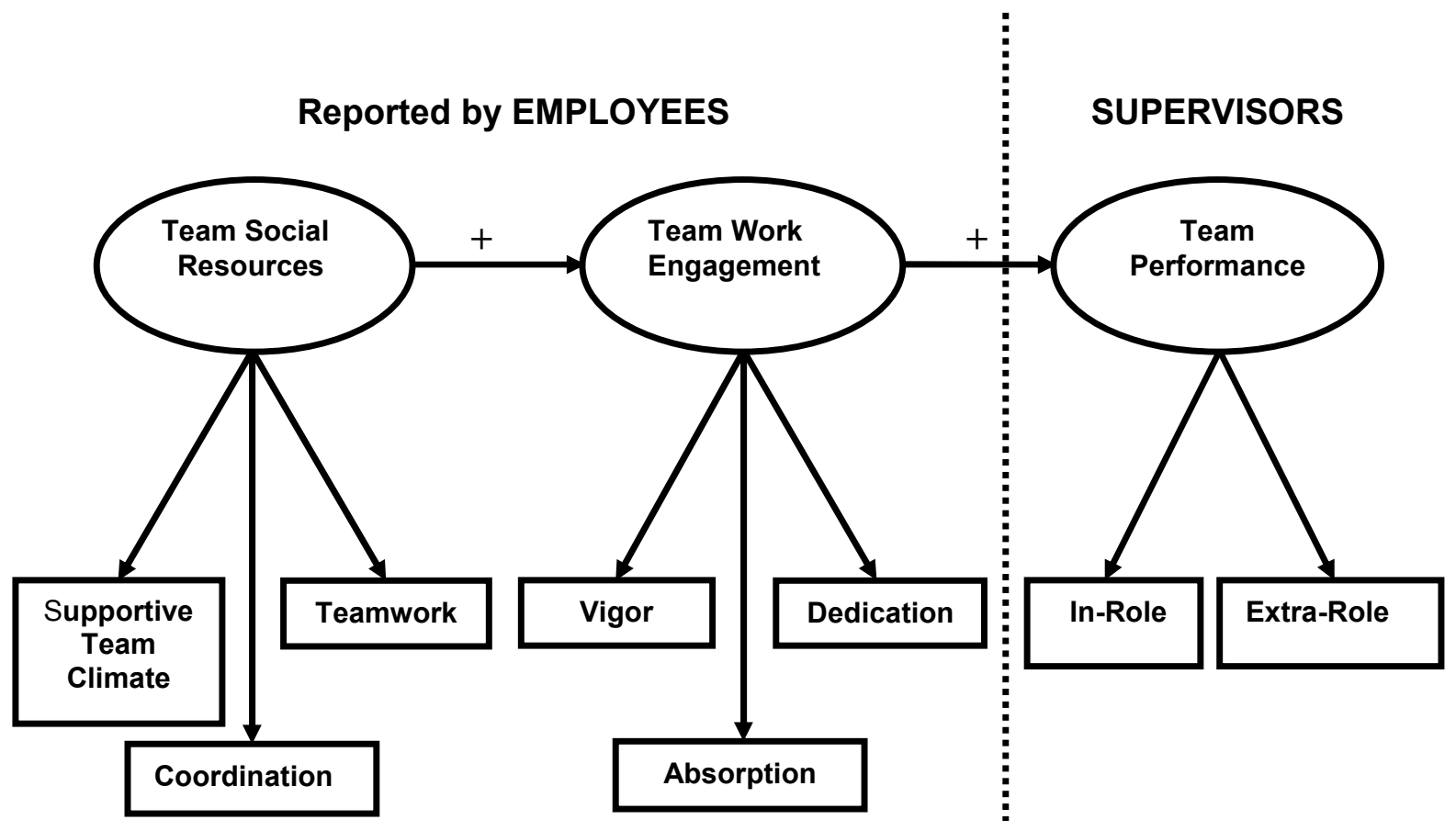

Figure 1. Proposed Fully Mediated Model.

\section{Method}

\section{Sample and procedure}

A convenience sample consisting of 533 employees (average response rate $58 \%$ ) nested within 62 teams (with 62 team supervisors; average response rate $76 \%$ ) from 13 enterprises was used in the study. Of the total number, $82 \%$ worked in the service sector, $10 \%$ in industry, and $8 \%$ in construction. Moreover, $54 \%$ were women, $70 \%$ had a tenured contract, $16 \%$ were self-employed, and $14 \%$ had a temporary contract. The average job tenure was 4.39 years $(S D=3.47)$ and the average tenure in the company was 6.6 years $(S D=5.54)$. Regarding the supervisors, $52 \%$ were male, $82 \%$ had a tenured contract, $13 \%$ were self-employed, and $5 \%$ had a temporary contract. The average job tenure was 6.25 years $(S D=4.95)$ and the average tenure in 


\section{Chapter}

the company was 13.94 years $(S D=5.88)$. Finally, teams had an average of almost nine members $(M=8.6, S D=8.7)$.

After reaching an agreement about the company's participation in the study, questionnaires were administered to the participants, who were asked to take part voluntarily. Teams with more than one supervisor were not included in the data analysis. To lead respondents' attention away from the individual level to the team level, all items focused on team perceptions as stipulated in the HERO (HEalthy and Resilient Organizations) questionnaire (Salanova et al., 2011). The confidentiality of the answers was guaranteed.

\section{Measures from employees}

Team social resources were assessed by nine items in three different scales: supportive team climate (three items; e.g., 'In my team, constructive criticism is rewarded'; alpha = .76), coordination (three items; e.g., 'My team is wellcoordinated';alpha = .79), and teamwork (three items; e.g., 'My team has well-defined work goals';alpha $=.75)$. Respondents answered using a 7-point Likert-type scale ranging from 0 (never) to 6 (always).

Team work engagement was assessed by nine items validated for aggregated data at the team level by Torrente, Salanova, Llorens and Schaufeli (in press). Specifically, we tested three dimensions: team work vigor (three items; e.g., 'While working, my team feels full of energy'; alpha = .76), team work dedication (three items; e.g., 'My team is enthusiastic about the task'; alpha $=.84$ ), and team work absorption (three items; e.g., 'While working, we forget everything else around us'; alpha $=.75$ ). Respondents answered using a 7-point Likert-type scale ranging from 0 (never) to 6 (always). 


\section{Chapter}

\section{Measures from supervisors}

Team performance was assessed by six items adapted from the Goodman and Svyantek scale (1999). Two different scales were considered: in-role performance (three items; e.g.,'The team that I supervise achieves its work goals'; alpha $=.82$ ) and extra-role performance (three items; e.g., 'In the team that I superviseemployees help each other when somebody is overloaded'; alpha $=.72$ ). The supervisors answered using a 7-point Likert-type scale ranging from 0 (totally disagree) to 6 (totally agree).

\section{Data analyses}

Firstly, the Harman's single factor test (e.g., Podsakoff, MacKenzie, Lee, \&Podsakoff, 2003) was carried out using AMOS 18.0 (Arbuckle, 2009) for the variables assessed by the employees. Secondly, the agreement of employee perceptions in teams was checked using various indices: following a consistency-based approach, both $I C C_{1}$ and $I C C_{2}$ indices were calculated. Values greater than .12 for $I C C_{1}$ indicate an adequate level of within-unit agreement (James, 1982). For the $\mathrm{ICC}_{2}$, values greater than .60 support aggregation (Glick, 1985). From a consensus-based approach, the Average Deviation Index was computed $\left(A D_{M(J)}\right.$; Burke, Finkelstein, \&Dusig, 1999), whereby team agreement was concluded when $A D_{M(J)}$ was equal to or less than 1 (Burke et al., 1999). Finally, Analyses of Variance (ANOVA) were computed in order to ascertain whether there was significant between-group discrimination for the measures. Thirdly, we computed descriptive statistics and intercorrelations among the variables at the individual and the aggregated levels. Finally, AMOS 18.0 (Arbuckle, 2009) was used to implement Structural Equation Modeling (SEM) using the maximum likelihood estimation method. Three competitive models were compared: $\mathrm{M} 0$, the independence model; M1, the fully mediated model; and M2, the partially mediated model.

Two absolute goodness-of-fit indices were assessed: (1) the $X^{2}$ goodness-of-fit statistic; and (2)the Root Mean Square Error of Approximation (RMSEA). The 


\section{Chapter}

$X^{2}$ goodness-of-fit index is sensitive to sample size and so the use of relative goodnessof-fit measures is recommended (Bentler, 1990). Accordingly, four relative goodnessof-fit indices were used: (1) the Normed Fit Index (NFI); (2) the Tucker-Lewis Index (TLI); and (3) the Incremental Fit Index (IFI). Values smaller than .05 are indicative of an excellent fit for RMSEA (Brown \&Cudeck, 1993) and values higher than .95 are indicative of an excellent fit for the relative indices (Hoyle, 1995). Finally, we computed the Akaike Information Criterion (AIC; Akaike, 1987) to compare competing non-nested models; the lower the AIC index, the better the fit is.

\section{Results}

\section{Descriptive and aggregation analyses}

Firstly, the results of the Harman's single factor test (e.g., Podsakoff et al., 2003) revealed a poor fit to the data: $\chi^{2}(9)=46.398, \mathrm{RMSEA}=.261, \mathrm{NFI}=.820$, $\mathrm{TLI}=.744, \mathrm{IFI}=.850$. Results also showed that the model considering two latent factors (i.e., team social resources and team work engagement) fit the data well: $\chi^{2}(8)=5.499$, RMSEA $=.000, \mathrm{NFI}=.979, \mathrm{TLI}=1.019$, and $\mathrm{IFI}=1.010$. The difference between both models is also significant in favor of the model with two latent factors, Delta $X^{2}(1)=40.899, p<.001$. Consequently, common method variance is not a serious deficiency in these data.

Table 1 shows means, standard deviations, intercorrelations, and aggregation indices of all the study variables. $I C C_{1}, I C C_{2}$ and $A D_{M(J)}$ indices ranged from .12 to .28, from .54 to .77 , and from .64 to 1.13 , respectively. Results for these indices were modest in the case of $A D_{M(J)}$ for supportive team climate $\left(A D_{M(J)}=1.13\right)$ and of $I C C_{2}$ for team work vigor $\left(\mathrm{ICC}_{2}=.54\right)$. However, one-way ANOVA results showed statistically significant between-group discrimination for supportive team climate, $F(61,465)=3.66$, $p<.001$; coordination, $F(58,461)=3.02, p<.001$; teamwork, $F(61,468)=4.30, p<$ 


\section{Chapter}

.001 ; team work vigor, $F(61,471)=2.19, p<.001$; team work dedication, $F(61,471)=$ 2.68, $p<.001$; and team work absorption, $F(61,471)=2.96, p<.001$. By implication, there was a significant degree of between-group discrimination, and therefore the validity of team social resources and the three dimensions of team work engagement was supported. In conclusion, overall aggregation results indicated within-group agreement in the teams so that unit members' perceptions can be aggregated.

Further analyses were conducted in order to control for the influence of interorganizational variability in the study variables. Intraclass Correlation Coefficients (ICCs) were calculated by testing an intercept-only model using a multilevel methodology (Hox, 2002). ICCs for the study variables ranged from .002 to .14. Thus, it was concluded that there were no extreme differences between organizations that could be biasing the results.

Finally, as expected the work engagement dimensions were positively interrelated (mean $r=.74$ ) and positively related to team social resources (mean $r=$ $.54)$ at the team level. Regarding the intercorrelations between employee and supervisor variables, teamwork, coordination, team work vigor, and team work absorption were significantly related to in-role performance (mean $r=.27$ ). In-role and extra-role performance were also significantly interrelated $(r=.68)$. 


\section{Chapter}

\section{Table 1}

Means, standard deviations, intercorrelations, and aggregation indices for the study variables

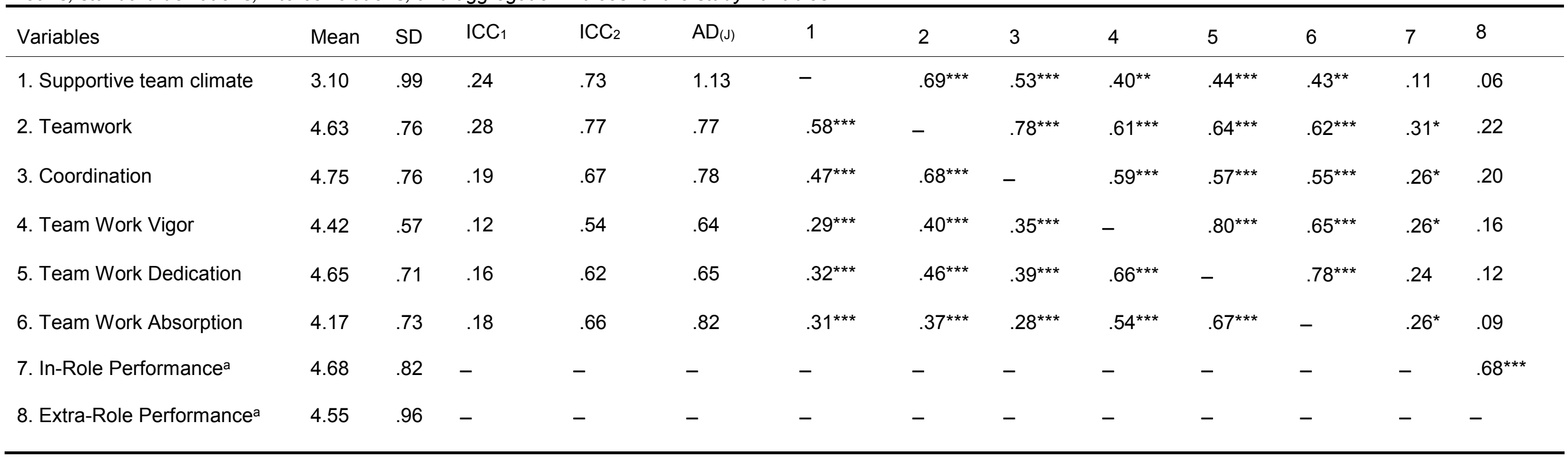

Notes.Intercorrelations are presented at the individual-level (below the diagonal) and at the team-level (above the diagonal). aReported by the supervisors.

${ }^{*} p<.05 ;{ }^{* *} p<.01 ;{ }^{* *} p<.001$ 


\section{Chapter}

\section{Model fit: Structural equation modeling}

To compute SEM, we used the aggregated database that included team social resources and team work engagement as well as the supervisor's team performance rating $(\mathrm{N}=62)$. Table 2 shows the results of the SEM analysis indicating that the proposed fully mediated model fits the data well, with all fit indices satisfying their corresponding criteria. The chi-square difference test between M1 (the Fully Mediated model) and M0 (the Independence Model) shows a significant difference between the two models in favor of M1, Delta $\chi^{2}(10)=297.24, p<.001$. The chi-square difference test between M1 (the Fully Mediated Model) and M2 (the Partially Mediated Model) shows a non-significant difference between the two models, Delta $\chi^{2}(1)=1.83$, ns, which is to be interpreted in favor of the most parsimonious one, namely M1. On comparing all models, M1 was the model that showed the lowest AIC value.

\section{Table 2}

\begin{tabular}{ccccccccccc}
\hline Models & $\chi^{2}$ & $d f$ & RMSEA & NFI & TLI & IFI & AIC & $\Delta \chi^{2}$ & $\Delta d f$ & $\Delta$ AIC \\
\hline M0 & 307.07 & 28 & .40 & .00 & .00 & .00 & 323.07 & & & \\
M1 & 11.66 & 19 & .00 & .96 & 1.04 & 1.03 & 45.66 & & & \\
$\Delta$ M0-M1 & & & & & & & & $295.41^{* * *}$ & 9 & 277.42 \\
M2 & 9.83 & 18 & .00 & .97 & 1.05 & 1.03 & 45.83 & & & \\
$\Delta \mathrm{M} 2-\mathrm{M} 1$ & & & & & & & & $1.83 n s$ & 1 & .17 \\
\hline
\end{tabular}

Notes. $\chi^{2}=$ Chi-square; $\mathrm{df}=$ degrees of freedom;RMSEA $=$ Root Mean Square Error of Approximation; NFI = Normed Fit Index; TLI = Tucker-Lewis Index; IFI = Incremental Fit Index; AIC = Akaike Information Criterion .

${ }^{* * *} p<.001 ; n s=$ non-significant. 


\section{Chapter}

To assess the mediation effect, the Sobel test (Sobel, 1988) was conducted, which showed non-significant results (Sobelt $=0.36, p=.72$ ). However, further analyses were conducted using the approach developed by Baron and Kenny (1986): (1) team social resources were positively and significantly related to the supervisor's perception of team performance $(\beta=.33, p<.05)$; (2) team work engagement was positively and significantly related to the supervisor's perception of team performance $(\beta=.29, p<.05)$; and finally, (3) the relationship between team social resources and team performance became non-significant $(\beta=.28, p=.117)$ when team work engagement was introduced. The fact that the relationship between team social resources and team performance became non-significant suggests that team work engagement mediated the relationship between team social resources and team performance. Mediation was also tested by comparing the chi-square statistic of the partially mediated model (M2) with a third model constraining the path from team work engagement to team performance (M3) to the unstandardized coefficient of this path in M1 (for an application see Salanova et al., 2005). M3 fit the data with all goodness-of-fit indices meeting the criteria but the chi-square difference between M2 and M3 was not significant. Therefore, the influence of team social resources on team performance was mediated by team work engagement.

In conclusion, previous results using SEM and mediation analyses provide some evidence for M1, that is, the fully mediated model. The final model is depicted in Figure 2. As expected, team social resources have a positive and significant influence on team work engagement $(\beta=.73, p<.001)$, which in turn is positively and significantly associated with team performance $(\beta=.29, p<.05)$. It is interesting to note that team social resources explain $53 \%$ of the variance in team work engagement $\left(R^{2}=.53\right)$, and that this in turn accounts for $8.4 \%$ of the variance in team performance $\left(R^{2}=.08\right)$. 
Reported by EMPLOYEES

\section{SUPERVISORS}

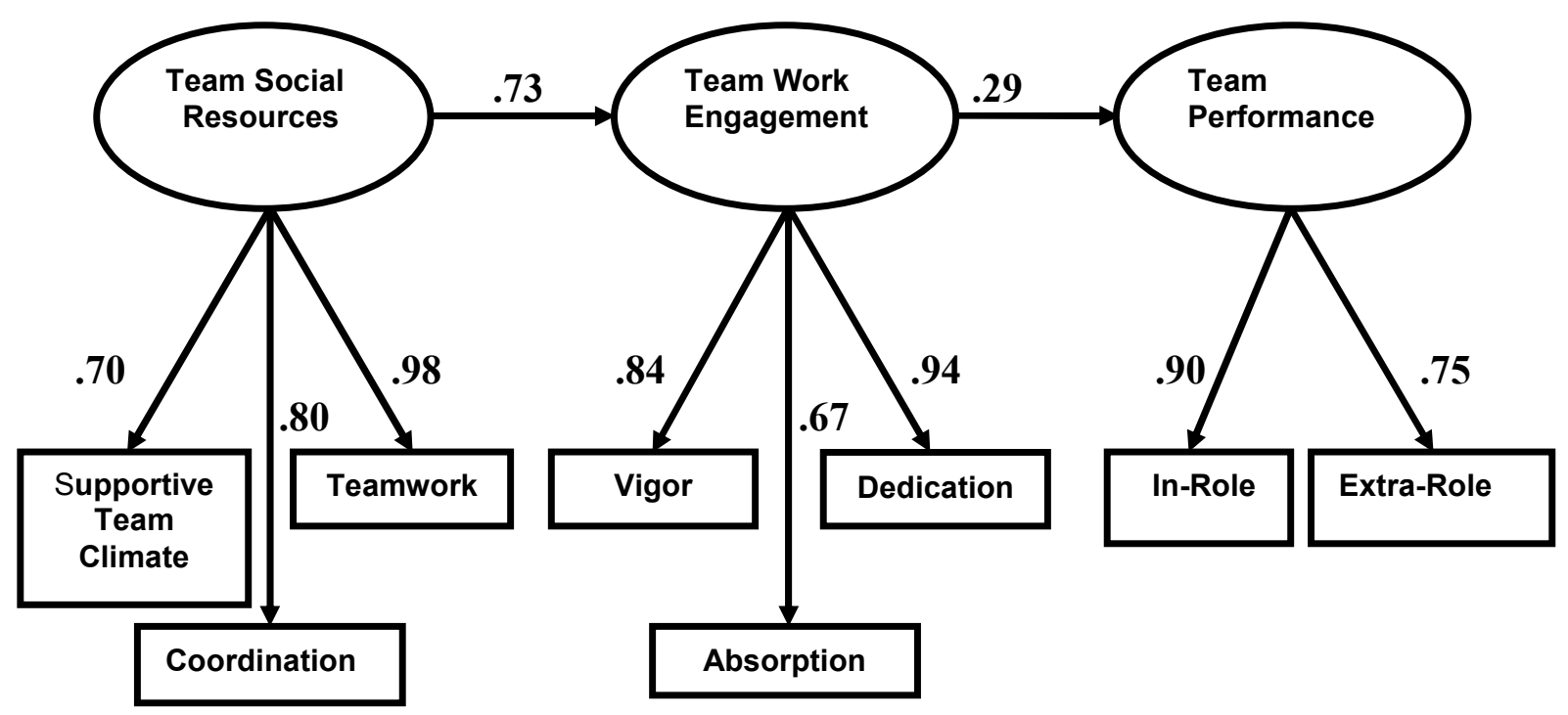

Figure 2. The final model with standardized coefficients $(N=62)$. All coefficients are significant at $p<.001$, except for the path between team work engagement and team performance, which is significant at $p<.05$.

\section{Discussion}

Based on the JD-R Model (Demerouti et al., 2001), we hypothesized that team work engagement mediates the relationship between social resources of the team and performance, as measured by the supervisor's rating. Results suggest that team social resources are positively related to a commonly shared psychological state, namely team work engagement, which is in turn related to team performance. 


\section{Theoretical and practical implications}

At the theoretical level, the present study extends current knowledge about the key role of team work engagement in the process by linking team social resources and the supervisor's view of team performance. The JD-R Model receives support from the findings since they provide evidence of its theoretical validity to explain team-level processes. The underlying motivational process is also reinforced as team work engagement is observed to be a meaningful team well-being construct that mediates the impact of social resources on performance in teams. At the same time, the three inner components of team work engagement have been replicated at the team level, which enhances the validity of the three-factor model of work engagement.

As suggested by previous research, emotional contagion could be considered the fundamental underpinning process explaining how team members share a common idea about a team property such as team work engagement. This rationale could be applied to team social resources and team work engagement, since these constructs were aggregated from individual perceptions of team properties. Although the underlying crossover mechanism has not been revealed by our findings, we assume that emotional contagion could be the explanatory mechanism that is responsible for employee agreement - a prerequisite to be aggregated. Team social resources may trigger emotional contagion of team work engagement among employees through offering a pool of shared experiences. Embedded within the organizational environment, this common background (e.g., a supportive team climate, need for coordination and task interdependence within team working) can elicit the functioning of interactive processes between individuals at work. At this point, employees dispose of a shared scenario to interact both consciously and unconsciously in order to influence each other reciprocally and trigger the emergence of a positive shared state, as is the case of team work engagement (Bakker et al., 2006). 


\section{Chapter}

With regard to practical implications, results can be used as recommendations following the advice offered previously from the individual perspective of work engagement (Schaufeli\& Bakker, 2004), but which go deeper into the idea of fostering team-based resources. When teams are the main work structure in a given organization, promoting team-oriented policies will be the most efficient management behavior. Thus, the findings in the present study warn organizations of the need to take care of team social resources if positive consequences regarding employees and outcomes are desired. Therefore, engaged teams will provide enterprises with a unique competitive advantage (Macey \& Schneider, 2008).

Specifically, results show the relevance of organizations promoting a supportive team climate, coordination and team working in order to build more vigorous, dedicated and absorbed teams, which in turn will enhance their performance at work. Promoting a climate of psychological safety and rewarding constructive criticism as well as dealing with interpersonal problems in such a way that the supervisor is perceived as caring for his/her subordinates are approaches that are capable of fostering a supportive team climate. Coordination can be fostered by ensuring the existence of appropriate channels of communication among the team members. This will make it easier for the team to accomplish its goals while avoiding an additional source of stress that would lead to poor team performance. Lastly, recruiting and selecting applicants who complement team skills and considering the introduction of team-based retribution according to performance would help to boost team working. In general, conclusions derived from the results provide empirical evidence of previous recommendations on how to intervene so as to increase work engagement by focusing on social interactions (Schaufeli\&Salanova, 2010).

Another practical implication is related to the relevant voice of supervisors. Obviously, the team leader plays a key role in increasing social team resources so that the team not only feels engaged, but also performs better. Our research shows that in doing so, good team leaders should be both considerate (i.e., improve the 


\section{Chapter}

psychological team climate) and task-oriented (i.e., set clear goals and coordinate the efforts of team-members).

\section{Limitations and further research}

The present study has several limitations. The first one is that a convenience sample was used, which might compromise the generalizability of the results. However, it is a rather heterogeneous sample, including different teams from different enterprises. Secondly, the data was obtained by self-report measures, which might have caused common method bias. However, data were used from different sources, employees and supervisors. Furthermore, the Harman's single factor test suggested that common method bias is not very likely. Thirdly, two aggregation indices (i.e., $\mathrm{ICC}_{2}$ for team work vigor, and $A D_{(\mathrm{J})}$ for supportive team climate), although close to their cutoff values, did not reach the criteria to support aggregation. Although indices of this kind are based on arbitrary rules-of-thumb, these results could be compromising the validity of the team-level measures for these variables in some way. Conducting multilevel confirmatory factor analyses is also encouraged, as this methodology would enhance the multilevel validation of the work engagement measure at different levels of analysis. Finally, the present study is cross-sectional in nature. Although team performance was rated by the immediate supervisor, who is an independent informant, it is not possible to reach decisive conclusions about the causation between the variables included in the model. To deal with this limitation, further research might use longitudinal techniques that would uncover causal paths. The knowledge that emerged using two or more data waves would enhance the validity of the JD-R Model as a useful model of intervention also at the collective, team level, as well as offering a thorough comprehension of the crossover processes involved. Furthermore, reversed and reciprocal relationships could be tested to explore the existence of positive cycles and spirals between the variables analyzed and other key variables such as collective 
Chapter

efficacy beliefs. The use of a multilevel methodology would also be highly recommended to explore cross-level relationships with enterprise-level variables that could be influencing and promoting work engagement within teams, as is the case of Human Resources Management practices. By so doing, we really will be ensuring that teams make it work. 


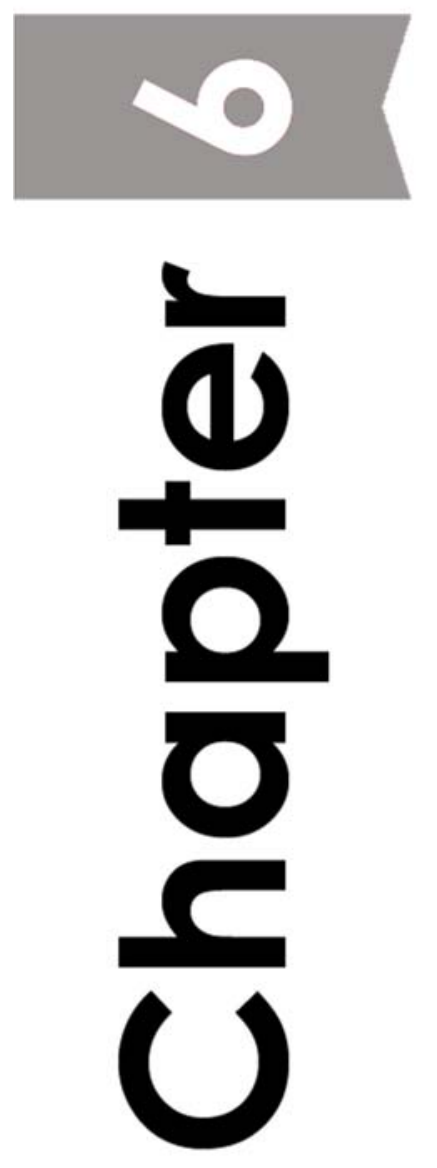




\section{Committing the Engaged:}

\section{A Multilevel Mediation Modelof \\ Team Work Engagement and \\ Organizational Affective \\ Commitment}

This paper has been submitted as:

Torrente, P., Salanova, M., Llorens, S., \&Schaufeli, W.B. (2014). Committing the engaged: A multilevel mediation model of team work engagement and organizational affective commitment. Manuscript submitted. 


\section{Chapter 6}

\section{Committing the engaged: A multilevel mediation model of team work engagement and organizational affective commitment}

Since the turn of the century, research has focused increasingly more on the concept of work engagement (Schaufeli\& Bakker, 2010). Recently, the influence of the social context within companies has led to the study of work engagement in the form of team work engagement (Salanova, Llorens, Cifre, \&Martínez, 2012; Torrente, Salanova, Llorens, \&Schaufeli, 2012). Teams and their performance may benefit from human resource practices and thus coexist with a wider state of organizational commitment (Gardner, Wright, \& Moynihan, 2011). Given the confusion that exists in the literature when conceptualizing and distinguishing team work engagement and organizational commitment (e.g., Macey \& Schneider, 2008), their relation with antecedents and outcomes at different levels of analysis results in a topic of special interest in research.

In order to fulfill their duties, teams have to rely on the resources provided by the organization. Teams are flexible and capable of adapting to many different circumstances, as they rely on the competences and experiences of each of their members. Furthermore, an invigorated, dedicated and absorbed (i.e., engaged) team is expected to take full advantage of the resources provided by the organization in order to achieve higher productivity. Work teams enhance, for example, innovation (Edmondson, 2002), and efficiency and competitiveness (Cohen \& Bailey, 1997; Hodson, 1997). Further benefits may result when teams are embedded in an organizational environment that promotes a strong sense of commitment toward the organization (Salanova et al., 2012). In this paper we build upon the notion of team 


\section{Chapter}

work engagement and organizational affective commitment, testing its role as a mediator between the resources and practices that are implemented and the desired outcomes at the team and organizational levels of analysis.

\section{The general framework: the HERO (Healthy \& Resilient Organization) Model}

The HERO Model (Salanova, 2008; 2009; Salanova et al., 2012; see Figure 1) is a heuristic model that draws upon the notion of healthy organizations as "organizations that make systematic, planned, and proactive efforts to improve employees' and organizational processes and outcomes" (Salanova et al., 2012, p.788). HEROs are defined by three interrelated components: (1) Healthy organizational resources and practices, which refers to task resources (e.g., autonomy, feedback, variety), social resources (e.g., good leadership, social support, team working), and organizational practices (e.g., information and communication, career and skill development, and organizational well-being); (2) The healthy employees component, concerning engaged and committed employees who are efficacious and resilient at work, and conduct their duties in a climate of trust with optimism and hope toward the future; and (3) The healthy organizational outcomes component, which refers to high quality services and products, and to improve the image of the organization by establishing positive relations with the environment, the community, and the rest of the stakeholders. The HERO model stresses the role played by collective phenomena in understanding the collective antecedents and outcomes required for a company to succeed in line with organizational objectives. As core shared states within the healthy employees component of the HERO Model, work engagement (e.g., Hakanen, Perhoniemi, \&Toppinen-Tanner, 2008; Schaufeli\& Bakker, 2004; Xanthopoulou, Bakker, Demerouti, \&Schaufeli, 2009) and organizational commitment (e.g., Gong, Law, Chang, \&Xin, 2009; Schmidt \&Diestel, 2012; Taylor, 


\section{Chapter}

Bedeian, \&Kluemper, 2012) are argued to play a mediation role between making use of the resources provided by the organization (i.e., the healthy organizational resources and practices component) and the actual performance of the firm (i.e., the healthy organizational outcomes component).

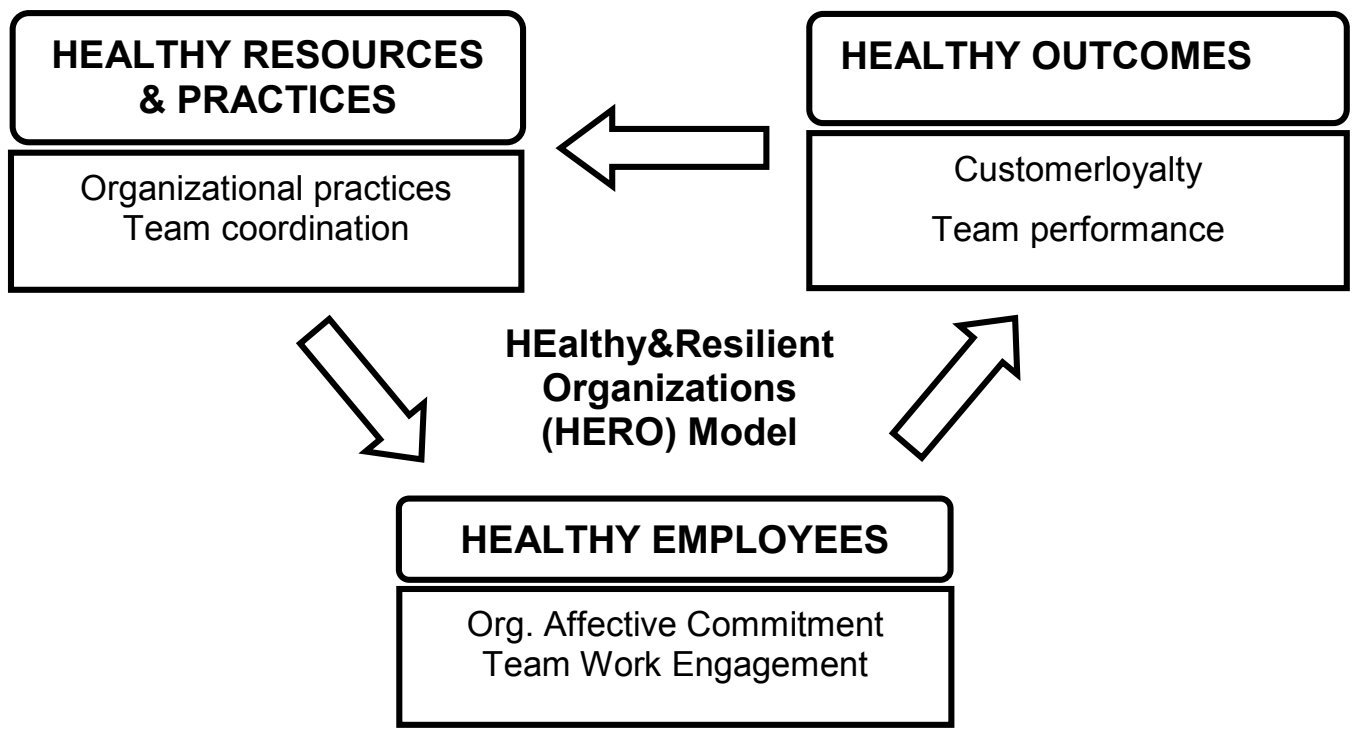

Figure 1. The HERO model.

\section{Team work engagement}

Based on the HERO Model, work engagement remains at the core of the healthy employees component, as an indicator of teams' well-being in work organizations. To date, work engagement has been studied mainly at the individual level (Schaufeli, Salanova, González-Romá, \& Bakker, 2002), but it may also exist as a collective, psychosocial construct. As team members interact on a daily basis they influence each other, being susceptible to positive emotional contagion in terms of work engagement spreading among workers (Bakker, Demerouti, \&Schaufeli, 2005; Bakker, van Emmerik, \&Euwema, 2006). Emotional contagion theory (Hatfield, Cacioppo, \&Rapson, 1994) posits that people have the innate, inner tendency to mimic facial expressions, postures, and emotions thus synchronizing physically and emotionally 


\section{Chapter}

with each other (Bavelas, Black, Lemery, \&Mullett, 1987). Furthermore, during the socialization process employees develop norms of emotional expression that are appropriate in a given context, which in turn may have an effect in expressing similar affective states. Following this rationale, Torrente, Salanova, and Llorens (2013) found that similarity in terms of demographics made employees working in the same work team more likely to share a similar level of team work engagement, thereby arguing for the positive emotional contagion process among employees.

Team work engagement is "a positive, fulfilling, work-related and shared psychological state characterized by team work vigor, dedication and absorption which emerges from the interaction and shared experiences of the members of a work team" (Torrente et al., 2012, p.110). Team work engagement involves a number of behaviors such as emotional expressions and emotionally-charged verbalizations that can be appraised by team members and, hence, promote a shared perception of work engagement (Bakker et al., 2006). For example, a vigorous employee is persistent against difficulties as he/she feels strong and devoted to his/her job thus being able to motivate the rest of the team members to carry out team duties. A dedicated employee feels emotionally attached to the task at hand. This provides the employee with a sense of meaning and purpose that is expressed in the form of joy and pride toward his or her work. Finally, absorbed employees feel fully engrossed with the task they are carrying out, which can provide them with a great deal of focus and concentration when interacting with the rest of the team members.

\section{Organizational affective commitment}

Organizational commitment is a psychological state that accounts for the employees' positive relation with the organization, thus making them more likely to remain with their current employer (Allen \& Meyer, 1990; 1996). Following these authors, organizational commitment involves three components: (1) normative 


\section{Chapter}

commitment, (2) continuance commitment, and (3) affective commitment. However, recent research on the three-component model of commitment suggests that only affective commitment, expressed through emotional attachment and identification toward the organization, is in fact actual organizational commitment. In contrast, normative and continuance commitment are attitudes regarding specific forms of behavior, that is, staying on at or leaving the organization, respectively (Solinger, van Olffen, \& Roe, 2008). Many scholars (e.g., Meyer, Becker, \&Vandenberghe, 2004; Vandenberghe, Bentein, \&Stinglhamber, 2004) suggest that affective commitment is the component that shows a closer association with performance, low turnover, and high job satisfaction (Meyer, Stanley, Herscovitch, \&Topolnytsky, 2002; Riketta, 2002).

Collective affective commitment is "a shared mindset and a shared psychological state among a delimited collective of individuals regarding their employer typified by feelings of loyalty and a desire to invest mental and physical energy in helping the organization achieve its goals" (Gardner et al., 2011, p.318). Gardner and colleagues (2011) built upon Barsade's work (2002) on emotional contagion to suggest that interaction among members promotes the existence of a shared state of affective commitment by spreading from the more committed employees to the rest of the team members. These interactions and the resulting shared affect create congruent group norms of committed behavior (Morgeson\& Hofmann, 1999).

Organizational affective commitment and team work engagement are socially construed following a contagion mechanism of emotions. The notion of collective affective commitment bears some similarity to the notion of team work engagement, especially in the case of the dedication component, in which both refer to a strong sense of involvement and identification. This overlapping does not allow for a clear differentiation of the constructs (Meyer, Gagné, \&Parfyonova, 2010), which has been addressed in a search for a differentiation in terms of antecedents and consequences (e.g., Hallberg\&Schaufeli, 2006). One step further in distinguishing between the two states concerns both the foci and the sources, that is, the targets of, and motives for, 


\section{Chapter}

organizational commitment in its relation to job performance, respectively (Becker, Billings, Eveleth, \& Gilbert, 1996). In this line of reasoning, Schaufeli and Salanova (2011) drew attention to the need of considering the adequate level of analysis for a proper conceptualization of collective work engagement and related collective states, such as organizational affective commitment. Thus, although both phenomena may play similar roles as mediating states related to antecedents (i.e., healthy organizational practices and resources) and outcomes (e.g., performance), the two constructs are better allocated at different levels of analysis within the organization (Macey \& Schneider, 2008). This view is coherent with the principle of compatibility (Ajzen, 2005), by which collective constructs should be studied in relation to other collective constructs.

\section{The team-level process: The role of team work engagement}

Previous research indicates that social resources may act as antecedents of work engagement (Salanova et al., 2012). These resources are social in nature and are related through the interaction and interdependence among the team members. For instance, Hakanen, Bakker, and Schaufeli (2006) showed that teachers with higher levels of social resources (i.e., innovative climate, supervisor support, and supportive social climate) experienced higher work engagement than teachers with low levels of such resources. Longitudinal research has also confirmed this relation, as illustrated by Schaufeli, Bakker, and Van Rhenen (2009), who found that social support predicted work engagement over a period of one year in a sample of telecom managers.

In the current study, we focused on team coordination as a crucial process in team work (Salas, Stagl, \& Burke, 2004). Team coordination involves "(a) the combination of disparate team-member actions and effort, and (b) temporal entrainment (i.e., linked rhythms) and action synchronization in the combination process" (Kozlowski \& Bell, 2003, p.95). Team coordination is a social resource of 


\section{Chapter}

practical value within the organizational context as a key resource in the fulfillment of team duties that may be improved by the immediate supervisor (Kozlowski \&llgen, 2010). Job resources are defined as "those physical, psychological, social, or organizational aspects of the job that may do any of the following: (a) be functional in achieving work goals; (b) reduce job demands at the associated physiological and psychological costs; (c) stimulate personal growth and development" (Demerouti, Bakker, Nachreiner, \&Schaufeli, 2001, p. 501). Following this rationale, team coordination may be considered a social resource that is positively related to team work engagement, since: a) it helps to resolve interpersonal, task or process conflicts, and helps to maintain relations over time (Jehn\& Shah, 1997); b) it enables the exchange of the required information and reduces the strain and demands associated to uncertainty arising from events that may overwhelm the competence of a single team member (Cramton\& Orvis, 2003); and c) it allows the team to learn and develop by means of knowledge sharing and identification with the team (Lounamaa\& March, 1987). Thus, proper team coordination is likely to promote a shared state of work engagement as the team members are able to allocate and invest all their energy in the team task. So, the team will perceive that they are taking part in a unique, common task that is full of purpose and meaning, and thus feel emotionally attached to its duties, whereby the team becomes totally engrossed in the work process (Torrente et al., 2012). Accordingly, the following hypothesis was formulated:

Hypothesis 1: Team coordination is positively related to team work engagement.

As shown by the outcomes of the hypothesized model, work engagement is an important predictor of job performance (Demerouti\&Cropanzano, 2010). Previous research shows that team-level work engagement is positively related to (1) task performance of students working in groups (Salanova, Llorens, Cifre, Martínez, \&Schaufeli, 2003); (2) extra-role performance and customer loyalty (Salanova, Agut, 


\section{Chapter}

\&Peiró, 2005) and service quality through relational service competence (Gracia, Salanova, Grau, \&Cifre, 2013) in service employees; and (3) in-role and extra-role team performance as assessed by the immediate supervisor (Torrente et al., 2012). Engaged work teams are composed of employees that act as resources for the rest of the team members, thus enabling the team to be persistent in the face of difficulties, and keeping the team members involved in the current task together with a sense of being absorbed in the process. Therefore, we argue that a shared state of team work engagement is associated to higher performance regarding the collective, team duties. Hence, we expect that:

Hypothesis 2: Team work engagement is positively related to team performance.

\section{Contextual influences in team work engagement and team performance}

Healthy organizational practices are "planned human resource deployments and activities intended to enable an organization to achieve its goals" (Wright \& McMahan, 1992, p. 298). Healthy organizational practices are connected to work engagement, as enacting an engaged workforce is a source of competitive advantage not easily imitated by other companies (Macey \& Schneider, 2008). Very few studies have dealt with the relation between healthy organizational practices and work engagement. Previous research indicates that several different human resource management practices are associated to work engagement: work training and career management (Salanova et al., 2005; Schaufeli\&Salanova, 2010), fairness and employee development and training (Gruman\& Saks, 2011), perceived ethical citizenship as a form of corporate social responsibility (Lin, 2010), or information and communication (Mone\& London, 2009). However, none of these studies have specifically addressed the relation between healthy organizational practices and work engagement at the 


\section{Chapter}

team level, as coherent with the idea of team-based organizations (Cohen \& Bailey, 1997). Hence, we expect that:

Hypothesis 3: Healthy organizational practices are positively related to team work engagement.

Even if team work plays a role in promoting team performance, organizational affective commitment may exert a unique influence on team-level performance. Traditionally, organizational commitment was linked to many outcomes such as turnover, job satisfaction and/or performance following an individual point-of-view (Mathieu \&Zajac, 1990). Meyer, Paunonen, Gellatly, Goffin, and Jackson (1989) found that affective commitment was positively related with job performance. Coherently, organizational affective commitment as an emotional identification and attachment targeted toward the organization was related to organization-level performance (Conway \&Briner, 2012). An affectively committed workforce may benefit performance in team-based organizations. That is to say, team goals may be easily accomplished if the team members are driven by the shared feeling that the fulfillment of organizational goals is part of the team goals. In this case, the team would be more likely to exert an extra effort in carrying out its duties. Hence, we expect that:

Hypothesis 4: Organizational affective commitment is positively related to team performance.

\section{Organizational-level hypotheses: The role of organizational affective}

\section{commitment}

Human resource management may shape and set the stage for an organization with committed employees (Kozlowski \& Klein, 2000; Meyer et al., 2002). Although scarce in number, several studies do argue in favor of this association at the organizational level of analysis. For example, Agarwala (2003) explored and confirmed the positive association between innovative human resource practices and 


\section{Chapter}

organizational commitment. Furthermore, Gardner et al. (2011) showed that an increase in motivating and empowering human resources practices was positively related to increased organizational affective commitment. These findings suggest that, if the organization implements healthy organizational practices, employees are more likely to feel psychologically attached to it. As employees perceive that the organization is taking care of them and fulfilling their needs, they reciprocate the company by fully involving themselves in the needs of the organization. This mechanism is coherent with previous studies on the fulfillment of the psychological contract (Rousseau, 1995), that is, as employees perceive that the employer fulfills their expectations, they invest in addressing the needs of their current organization (Fortinha, Chambel, \& de Cuyper, 2012; Lopes \&Chambel, 2012). Hence, we expect that:

Hypothesis 5: Healthy organizational practices are positively related to organizational affective commitment.

Following current conceptualizations, the relation between organizational affective commitment and customer ratings of performance has been acknowledged from the very beginning (Allen \&Grisaffe, 2001). However, as pointed out by Conway and Briner (2012), research on organizational commitment is still scarce at the aggregated, company level, and even more so in relation with customer ratings that have an influence on the results of the organization as a whole. Customers' loyalty is a key value for organizations, as it refers to the customer's behavioral intentions to return to an establishment and buy products or services (Swan \& Oliver, 1989). This relation has implications for repurchasing behavior and for mouth-to-ear recommendations which satisfied customers may engage in (Oliver, 1997). Results on this relation, although scarce, indicate that organizational affective commitment in employees is related to reduced customer complaints as well as with lower average queuing time for the customers (Conway \&Briner, 2012). Several mechanisms may serve to explain this relation. Committed employees identify themselves with their colleagues within the 


\section{Chapter}

organization, which, based on social identity (Tajfel\& Turner, 1986) and selfcategorization (Turner, 1987) theories, is the basis for social and personal self-esteem. This sense of belonging enacts prosocial and helping behavior toward the rest of the members, thereby preventing delay and promoting performance through, for example, back-up behaviors that ensure fulfillment of customers' demands (Allen \&Grisaffe, 2001). Therefore, affectively-committed employees seem to satisfy customers' demands in a shorter period of time, which, in turn, may positively influence future repurchasing intention on the part of the customers.

Hypothesis 6: Organizational affective commitment will be positively related to customer loyalty as perceived by customers.

\section{The current study}

In the current study, we rely upon the tenets of the HERO Model in order to test the role of team work engagement and organizational affective commitment between team social resources and team performance, as well as between organizational practices and customer loyalty. Following a multilevel perspective, the hypothesized multilevel model includes team work engagement and organizational affective commitment, allocated at the team and organizational level of analysis, respectively. The proposed model is an attempt to shed light on the collective affective states within the organizational setting that may play a role in team-level outcomes using two different sources of information: employees and customer-rated performance. The research model is shown in Figure 2. 


\section{Chapter}

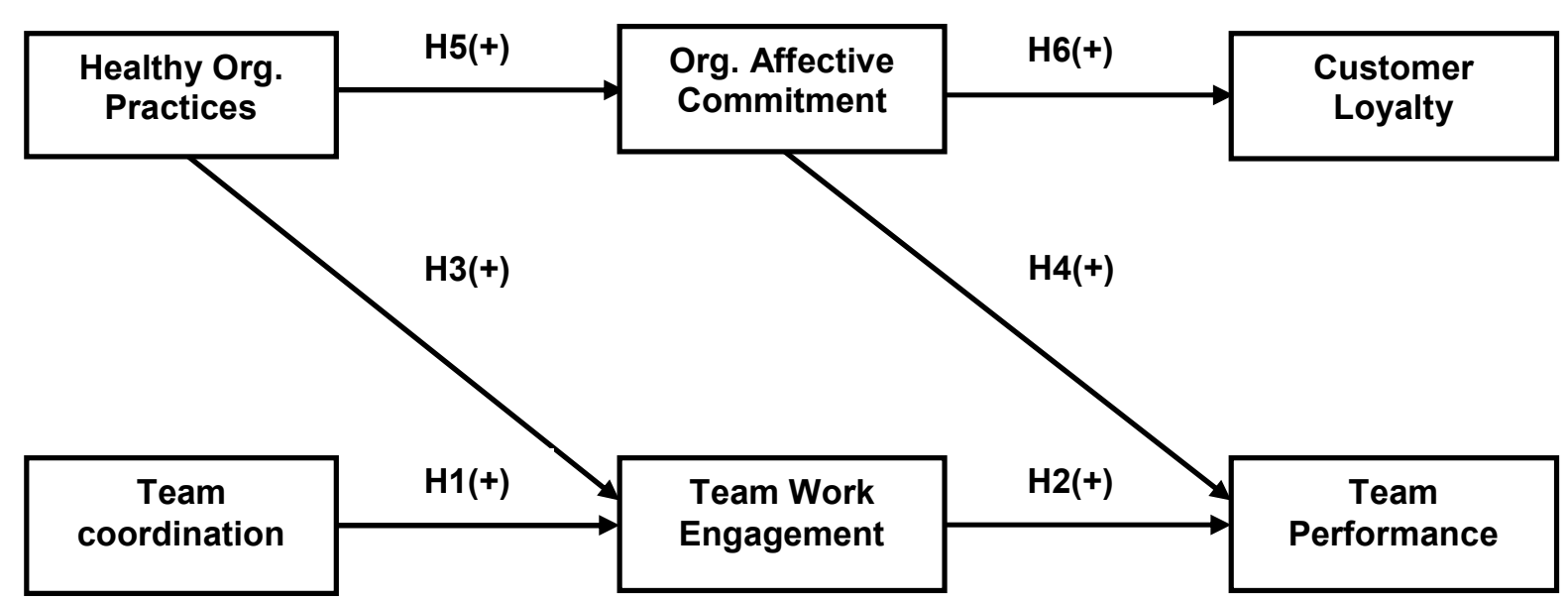

Figure 2.Research model.

\section{Method}

\section{Sample and procedure}

The study was conducted on a convenience sample that consisted of 948 employees nested within 187 teams and their 2,349 customers. Of the employees, $56 \%$ were women, $85 \%$ had a tenured contract, $13 \%$ had a temporary contract, and $2 \%$ were self-employed. The average tenure in the company was 6.93 years $(S D=6.57)$. Finally, on average, teams had 5 members $(M=5.14, S D=4.58)$ and organizations had 26 employees $(M=26.23, S D=30.25)$. Enterprises also differed in terms of economic sector: $90 \%$ belonged to the service sector, $7 \%$ industry, and $3 \%$ construction. The customers who participated in the study were mostly regular customers $(82 \%)$.

The company's participation in the study was arranged with the Human Resource Manager or with the person with the highest responsibility in the organization, who were approached directly via telephone and email. As the study was dealing with teams nested within enterprises, the people from the participant organizations informed the researchers about the actual teams that composed the organization in a preliminary interview. They were also encouraged to ensure that these teams were identified in 


\section{Chapter}

terms of the actual daily interaction of the team members, who had common goals and worked under just one immediate supervisor. Participants voluntarily completed a selfreport questionnaire focusing on perceptions of collective phenomena at the organization and team level of analysis. Only workers with more than six months' organizational tenure were considered for the analyses in order to ensure that the study only included employees who are familiar with the actual functioning within the organizations. The questionnaires were placed in sealed envelopes and collected by the researchers themselves or by an impartial contact within the enterprise. These procedures were implemented in order to maximize the confidentiality of the answers. The researchers gathered customers' data by administering the questionnaire in the work centers or by phone when the former strategy was not possible. The customers' questionnaire took approximately five minutes to fill out.

\section{Measures and aggregation indices}

Measures in this study involved three team-level variables (i.e., team coordination, team work engagement, and team performance) and three organizational-level variables (i.e., healthy organizational practices, organizational affective commitment, and customer loyalty) from two different sources of information (i.e., employees and customers). All the scales used in this study were included in the HERO Questionnaire (Salanova et al., 2012) and included a 7-point Likert-type scale ranging from 0 (never) to 6 (always).

Team coordination was assessed by three self-construed items and validated in Salanova et al. (2012). An example of an item is "My team is well-coordinated" $(\alpha=.77)$.

Team work engagement was assessed by nine items validated by Torrente, Salanova, Llorens, and Schaufeli (2013), shortened and reworded so that it could be used for aggregated data at the collective level of analysis. In line with prior research (Bakker et al., 2006; Schaufeli\& Bakker, 2010; Schaufeli, Bakker, \&Salanova, 2006), 


\section{Chapter}

we focused on overall engagement, and thus created a composite measure based on its three components $(\alpha=.89)$.

Team performance was assessed by six items adapted from the Goodman and Svyantek scale (1999). Both scales were combined taking into account the high teamlevel correlation $(\rho=.72, p<.001)$, as well as with the aim of providing a straight view of performance behaviors within teams $(\alpha=.83)$.

The Healthy organizational practices scale was adapted from the ERCOVA (Valencian Community Responsible Enterprise) European Project (2004), and validated by Salanova et al. (2012; e.g., "This organization takes care of employees' well-being and quality of life"; $\alpha=.91)$. The scale was composed of nine items covering eight organizational practices: information and communication (two items), social corporate responsibility, mobbing, inequity, work-family conflict, career development, skills' development, and well-being. We conducted a Principal Component Analysis (PCA; Jolliffe, 2002) to ensure that the items were part of the same principal component. Results for the PCA showed that only one component was accounting for the $58 \%$ of the total variance. These individual perceptions were aggregated from the team to the organizational level of analysis to represent the shared perception of teams toward the healthy organizational practices implemented by the whole organization.

Organizational affective commitment was assessed by three items (e.g., "In my team we really feel as if this organization's problems are our own"; $\alpha=.80$ ). This scale was adapted from Allen and Meyer's Commitment Scale (1990).

Customer loyalty was assessed by two items adapted from Martínez-Tur, Ramos, Peiró, and Buades (2001): "In the future I will recommend this service to others"; $\alpha=.87)$

Three control variables were also included in the analyses: team size, organizational size, and economic sector (1: Services, 2: Industry, and 3: Construction). Team size and organizational size were included as a control variable since, according to previous research (Bowers, Pharmer, \& Salas, 2000), the number 


\section{Chapter}

of interactions required to share a common emotional state is likely to be higher in large teams. Economic sector was included as a control variable, since the organizations involved in the study differed in terms of the products and/or services they provided.

Using two different approaches, ICC and $A D_{M(J)}$ indices were calculated for the variables in order to assess interrater reliability and interrater agreement, respectively. Although there is no fixed cut-off point for ICC, a value of .01 might be considered a small effect, a value of .10 might be considered a medium effect, and values above .25 might be considered a large effect (see Murphy \&Myors, 1998). The Average Deviation Index $\left(A D_{M(J)}\right)$ was computed whereby it was concluded that there was agreement among team members when this index was equal to, or less than, 1 for a 7 -point Likerttype scale (Burke, Finkelstein, \&Dusig, 1999). Analyses of Variance (ANOVA) were also computed in order to ascertain whether there was significant between-group discrimination for the measures. Results for the interrater reliability index indicated that ICCs ranged from .09 to .44 . Except for the variable team coordination, which showed a small effect $(I C C=.09)$, the rest of the variables showed a medium to large grouping effect on their corresponding level of analysis. In the case of the interrater agreement index, Average Deviation indices ranged from .50 to .79. Furthermore, ANOVA results showed significant coefficients for all the variables involved in the study $(p<.001)$, which indicates that the scales discriminated significantly among the teams and organizations. All in all, we may conclude that the results supported the aggregation of measures.

\section{Statistical analyses}

\section{Adequacy of hierarchical linear modeling.}

Intraclass Correlation Coefficient, or ICC, is also interpreted as a measure of nonindependence, as it tests the percentage of variance explained by contextual variables 


\section{Chapter}

(Bliese, 2000). Therefore, the higher the ICC is, the higher the amount of variability that can be accounted for by variables at the higher-level of analysis (i.e., the organization) will be.

\section{Testing of hypotheses.}

Hypotheses 1 to 4 were tested using hierarchical linear modeling or random coefficient modeling (Gavin \& Hofmann, 2002). The same approach was applied to both dependent variables (i.e., team work engagement and team performance). The models were tested following a step-by-step approach using maximum likelihood as implemented by LISREL 8.8 (Jöreskog\&Sörbom, 2006). First, we developed a randomcoefficient regression model (Model 1), in which random coefficients were freed to allow them to vary between organizations. A team-level control variable (i.e., team size) and covariates were included in the model equation. This model provided tests of lower-level covariates while taking into account the nesting structure of the data as well as controlling for lower-level control variables. Thus, this model allows Hypotheses 1 and 2 to be tested. The second model, or intercepts-as-outcomes model (Model 2), included organizational-level controls and predictors in the equation for the intercept. In the present study, this model makes it possible to test the effect of organizational level variables over and above the effect of lower-level predictors and covariates, while also controlling for higher-level covariates. Thus, this model allows Hypotheses 3 and 4 to be tested. The remaining hypotheses, i.e., Hypotheses 5 and 6 , were tested using regression analyses with the OLS estimation method and centering procedure.

\section{Centering predictors.}

For the random-coefficient regression model, team-level variables were centered in order to avoid multicollinearity between variables and to obtain unbiased estimators. Under grand-mean centering, the variance in the intercept term is an adjusted estimator of the variance between organizations, thus making it easier to interpret 


\section{Chapter}

(Hofmann, Griffin, \& Gavin, 2000). For the second model, involving tests of cross-level relationships, organizational-level variables were also grand-mean centered because this facilitates general model estimation as it occurs in multivariate regression (Bliese, 2002). Grand-mean centering also deals with multicollinearity, since it reduces the correlation between intercept and slope estimates across the higher level of analysis (Hofmann \& Gavin, 1998). Furthermore, team-level predictors were group-mean centered in the second model to yield an unbiased estimate for the within-group slope. Therefore, results are more accurate when testing cross-level effects (Hofmann \& Gavin, 1998).

\section{Results}

\section{Descriptives, internal consistencies, and intercorrelations}

Means, standard deviations, internal consistencies and intercorrelations among the variables in the study are presented in Table 1 . All variables showed positive and significant intercorrelations except for customer loyalty. Team size was negatively related to team coordination at the team level $(r=-.16, p<.05)$, whereas it was positively related to organizational size at the company level $(r=.59, p<.001)$. At the team level of analysis, organizational size was negatively related to team performance $(r=-.15$, $p<.05)$, healthy organizational practices $(r=-.20, p<.01)$, and organizational affective commitment $(r=-.16, p<.05)$, but positively related to customer loyalty $(r=.37, p<.001)$ and team size $(r=.32, p<.001)$. Finally, economic sector was positively related to customer loyalty $(r=.23, p<.01)$, and negatively related to organizational size $(r=-.24$, $p<.01)$ at the team level of analysis. 


\section{Chapter}

\section{Table 1}

Means, standard deviations, internal consistencies, and intercorrelations among the study variables

\begin{tabular}{|c|c|c|c|c|c|c|c|c|c|c|c|c|}
\hline Variables & M & SD & ICC & $A D_{M(J)}$ & 1 & 2 & 3 & 4 & 5 & 6 & 7 & 8 \\
\hline 1. Team coordination & 4.71 & .79 & .09 & .74 & $(.77)$ & $.54^{* *}$ & $.52^{* *}$ & $.54^{* *}$ & $.37^{*}$ & .16 & -.18 & -.14 \\
\hline 2. Team work engagement & 4.50 & .67 & .15 & .71 & $.52^{* * *}$ & $(.89)$ & $.63^{* * *}$ & $.56^{* *}$ & $.79^{* * *}$ & .25 & .03 & -.18 \\
\hline 3. Team performance & 4.87 & .60 & .39 & .69 & $.58^{* * *}$ & $.58^{* * *}$ & $(.83)$ & $.53^{* *}$ & $.57^{\star *}$ & .02 & -.07 & -.15 \\
\hline 4. Healthy Org. Practices & 3.31 & 1.02 & .44 & .72 & $.49^{* * *}$ & $.50^{* * *}$ & $.39^{* * *}$ & $(.91)$ & $.57^{* *}$ & .16 & .05 & -.1 \\
\hline 5. Org. Affect. Commitment & 4.51 & .82 & .32 & .50 & $.35^{* * *}$ & $.74^{* * *}$ & $.42^{* * *}$ & $.48^{* * *}$ & $(.80)$ & .27 & -.10 & -.30 \\
\hline 6. Customer Loyalty & 5.00 & .60 & .11 & .79 & .05 & .07 & -.12 & .00 & .12 & $(.87)$ & -.20 & .05 \\
\hline 7. Team size & 5.00 & 4.56 & - & - & $-.16^{*}$ & -.11 & -.04 & -.08 & -.11 & .02 & - & $.59^{* * *}$ \\
\hline 8. Organizational size & 51.20 & 46.88 & - & - & -.08 & -.11 & $-.15^{\star}$ & $-.20^{\star *}$ & $-.16^{*}$ & $.37^{\star * \star}$ & $.32^{* * *}$ & - \\
\hline
\end{tabular}

Note. Correlations presented at the team level (below the main diagonal; $N=187$ ) and at the company level (above the main diagonal; $\mathrm{n}=34$ ).

${ }^{*} p<.05 ;{ }^{* *} p<.01 ;{ }^{* * *} p<.001$ 


\section{Hierarchical regression analyses}

A baseline model was computed to evaluate non-independence ICC. This model is used within the general hierarchical linear modeling procedure as a comparison model as well as to evaluate the percentage of variance for the levels involved in the analyses (Hox, 2010). Results for non-independence ICCs for team work engagement and team performance were .23 and .14 , respectively. Although there is no general rule of thumb, results are higher than the median value of .12 reported by James (1982) for a number of studies included in his review.

Results concerning the testing of Hypotheses 1 to 4 using hierarchical regression analyses are displayed in Table 2. Hypothesis 1 stated that team coordination is positively related to team work engagement. As expected, team coordination was positively and significantly related to team work engagement $(\beta=.39, \quad p<.001)$. Hypothesis 2 stated that team work engagement is positively related to team performance. As expected, team work engagement was positively and significantly related to team performance $(\beta=.51, p<.001)$. Therefore, results confirmed Hypotheses 1 and 2. 
Chapter

Table 2

Results for the multilevel models

\begin{tabular}{|c|c|c|}
\hline Parameters & Model 1 & Model 2 \\
\hline & \multicolumn{2}{|c|}{ Team work engagement } \\
\hline Intercept & $4.84^{* * *}(0.06)$ & $4.53^{* * *}(0.06)$ \\
\hline \multicolumn{3}{|l|}{ Level 1 (teams) } \\
\hline Team size & $-0.01(0.01)$ & $-0.01(0.01)$ \\
\hline Team coordination & $0.39^{* * *}(0.06)$ & $0.36^{* * *}(0.06)$ \\
\hline \multicolumn{3}{|l|}{ Level 2 (organizations) } \\
\hline Economic sector & & $-0.04(0.12)$ \\
\hline Organizational size & & $-0.00(0.00)$ \\
\hline \multirow[t]{2}{*}{ Healthy Org. Practices } & & $0.33^{\star \star \star}(0.08)$ \\
\hline & \multicolumn{2}{|c|}{ Team performance } \\
\hline Intercept & $4.89^{* * *}(0.05)$ & $3.50^{* * \star}(0.44)$ \\
\hline \multicolumn{3}{|l|}{ Level 1 (teams) } \\
\hline Team size & $0.01(0.01)$ & $0.01(0.01)$ \\
\hline Team Work Engagement & $0.51^{* * *}(0.06)$ & $0.53^{* * *}(0.06)$ \\
\hline \multicolumn{3}{|l|}{ Level 2 (organizations) } \\
\hline Economic sector & & $-0.15(0.10)$ \\
\hline Organizational size & & $-0.00(0.00)$ \\
\hline Org. Affect. Commitment & & $0.31^{* * *}(0.10)$ \\
\hline
\end{tabular}

Note. Standard errors are in parentheses.

${ }^{*} p<.05 ;{ }^{* *} p<.01 ;{ }^{* * *} p<.001$.

In order to assess the relative importance of team coordination on team work engagement, we also calculated the proportion of explained variance (Snijders\&Bosker, 1999). To compute this proportion, first we computed the randomcoefficient regression model (model 1), fixing slopes for team coordination. We then compared the resulting variance estimates with those of the baseline model. Team 


\section{Chapter}

coordination accounted for $23 \%$ of variance for team work engagement whereas the proportion of explained variance for team work engagement over team performances was $31 \%$.

Hypothesis 3 tested the cross-level effect of healthy organizational practices on team work engagement over and above the association between team coordination and team work engagement. As expected, healthy organizational practices were positively and significantly related to team work engagement $(\beta=.24, \quad p<.05)$. Hypothesis 4 tested the cross-level effect of organizational affective commitment on team performance over and above team work engagement. As expected, organizational affective commitment was positively and significantly related to team performance $(\beta=.31, p<.01)$. Hence, results confirmed Hypotheses 3 and 4 .

The proportion of variance explained by level-2 predictors was also calculated for model 2 with fixed slopes as compared with the baseline model. Results indicate that healthy organizational practices accounted for $20 \%$ of variance for team work engagement, whereas the proportion of explained variance for organizational affective commitment over team performance was $22 \%$.

Results concerning the test of Hypotheses 5 and 6 using regression analyses are displayed in Table 3. Hypothesis 5 posited that healthy organizational practices were positively related to organizational affective commitment. As expected, healthy organizational practices positively and significantly predicted organizational affective commitment $(\beta=.49, \quad p<.001)$. Hypothesis 6 posited that organizational affective commitment is positively related to customer loyalty. As expected, organizational affective commitment was positively and significantly associated with customer loyalty $(\beta=.27, p<.001)$. Healthy organizational practices accounted for $31 \%$ of the variance in organizational affective commitment, whereas organizational affective commitment accounted for $30 \%$ of the variance in customer loyalty. Thus, results confirmed Hypotheses 5 and 6. 
Chapter

Table 3

Results for the regression analyses

\begin{tabular}{lccc}
\hline Variables & B & SE B & $\beta$ \\
\hline \multicolumn{1}{c}{ Organizational Affective Commitment } \\
Intercept & & & \\
Healthy Org. Practices & 4.51 & 0.3 & $* * *$ \\
Organizational Size & 0.40 & 0.05 & $0.49^{* * *}$ \\
Economic Sector & -0.00 & 0.00 & $-0.21^{* *}$ \\
F & 0.13 & 0.07 & 0.11 \\
& & & $28.50^{* * *}$ \\
& & Customer Loyalty & \\
Intercept & & & $.27^{* * *}$ \\
Org. Affect Commitment & 4.99 & .04 & $.51^{* * *}$ \\
Organizational Size & .32 & .08 & $.30^{* * *}$ \\
Economic Sector & .01 & .01 & $26.47^{* * *}$ \\
F & .43 & .09 & \\
\hline
\end{tabular}

${ }^{* * *} p<.001$.

\section{Tests of mediation.}

As teams were nested within organizations, testing the mediating effect of team work engagement using traditional procedures will result in biased coefficients, as argued by Zhang, Zyphur, and Preacher (2009). Therefore, we followed the procedure recommended by these authors to test mediation effects in multilevel contexts. As demonstrated by the authors, mediation effects can be erroneously estimated when the within- and the between-group effects differ in magnitude. Thus, although single-level mediation models can also be tested using the traditional Sobel test (Sobel, 1992), caution should be taken. In the current study, we tested the hierarchical models as described in Zhang et al. (2009), that is, by group-mean centering the predictors for each model and including the mean in the level-2 intercept equation (dubbed CWC(M) 


\section{Chapter}

or centered within context with reintroduction of the subtracted means). Once each coefficient had been obtained from the models, mediation was tested using the Sobel test (Sobel, 1992). Results indicated that team work engagement was significantly mediating the relation between team coordination and team performance (Sobel $Z=3.32, p<.001)$.

Unlike the previous mediation effect, the mediating role of organizational affective commitment between healthy organizational practices and customer loyalty was unbiased, since organizations were not nested within a higher order level variable. Thus, this mediation effect was tested following the Sobel test for mediation. Results indicated that organizational affective commitment did not mediate this relation (Sobel $Z=1.08, p>.05)$

Further mediation analyses were conducted in order to test the mediating role of team work engagement and organizational affective commitment between healthy organizational practices and team performance. The mediating role of team work engagement involved a 2-1-1 model, as stated by Zhang et al. (2009). Multilevel mediation models of this type are susceptible to bias when CWC(M) is not applied. So predictors in each model were group-mean centered and then the means were reintroduced in the level-2 intercept equation. Results showed that team work engagement was significantly mediating the relation between healthy organizational practices and team performance (Sobel $Z=3.83, p<.001$ ).

In order to compare the mediating roles of team work engagement with organizational affective commitment in the association between healthy organizational practices and team performance, further mediation models were tested. Organizational affective commitment is a level-2 mediator within a 2-2-1 model framework (Zhang et al., 2009). Mediation in these types of models does not require the inclusion of CWC(M) because the associations between the antecedent and the outcome and between the mediator and the outcome are all at the higher level (i.e., level 2). This means that no level-1 relations interfere with the estimation of level 2 mediation effects. 


\section{Chapter}

Results indicated that organizational affective commitment was not a significant mediator between healthy organizational practices and team performance (Sobel $Z=1.18, p>.05)$

\section{Discussion}

In this study we addressed a comprehensive multilevel model of the antecedents and consequences of team work engagement and organizational affective commitment, as they involve cross-level links between the team- and the organizational-level of analysis. Specifically, the findings provided a detailed focus on the multilevel mechanisms by which organizations influence multiple-level goals through shared affective states that emphasize a collective, multilevel perspective. Results are summarized in Figure 3.

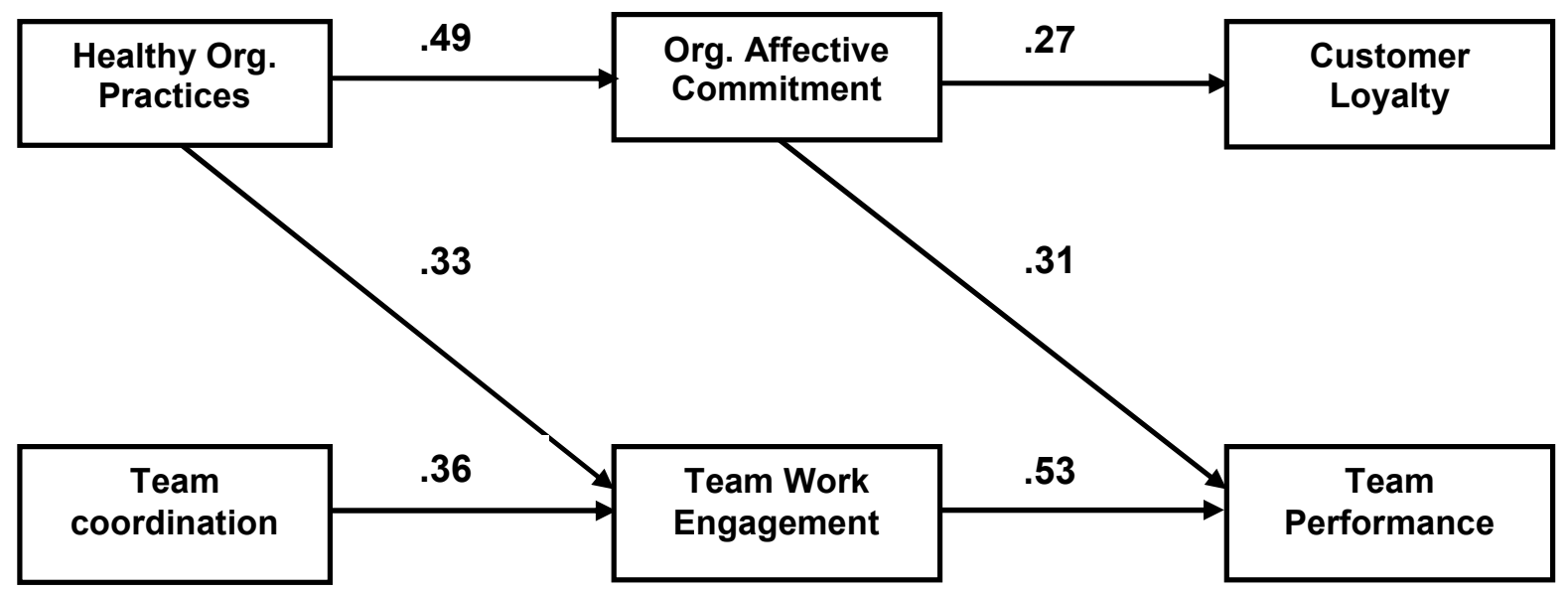

Figure 3. Final model.

All coefficients are significant at $p<.001$. 


\section{Theoretical implications}

First, team coordination was related to higher team work engagement, which argues in favor of coordination as a social resource. This finding extends the pool of resources considered by theoretical models that aim to determine key team antecedents of work engagement by following a collective point of view. This is the case of the HERO Model (Salanova et al., 2012), which emphasizes the role of collective phenomena, built up on shared, socially-construed perceptions within organizations. As an alternative, team coordination falls under the umbrella of job resources included in the JD-R Model (Demerouti et al., 2001) in relation to work engagement. However, its scope is mostly limited to the individual level of analysis (Demerouti\& Bakker, 2011).

As stated above, team work engagement and organizational affective commitment bear some similarities in terms of contagion mechanisms. However, findings provide further discussion on the rationale that accounts for the sharing of perceptions of collective states. As noted in previous research on emotions within work organizations, emotions spread among team members (Brief \& Weiss, 2002). Although in the current study we controlled for team size and organizational size, concerns about the intensity of emotional convergence may arise. In this line of reasoning, convergence may become weaker in larger teams (Bowers et al., 2000). Thus, a higher number of team members requires a higher number of interactions to achieve a consensus on a shared affect due to the less intense communication among its members (Bakker, Westman, \& van Emmerik, 2009). Previous research has pointed out that team size plays a role in team work engagement convergence, thus making a team more likely to exhibit a similar level of team work engagement (Torrente et al., in press). However, current findings indicated that this relation did not have an influence on average levels of team work engagement. In conclusion, unit size (i.e., teams or organizations) is negatively related to the emotional convergence of team work 


\section{Chapter}

engagement, whereas it shows no significant relation with average levels of team work engagement.

To achieve consensus in a general organizational state of affective commitment, we might assume that each member had a certain degree of exchange with the rest of his or her colleagues throughout the entire organization. Agreement on the perceptions about the emergent construct is required among the team members to argue in favor of the validity of the construct as well as a theoretical mechanism that accounts for the sharing of perceptions (Bliese, 2000; Chan, 1998). However, this might not be the case in every organization, so team members are not always required to exchange information with the rest of their colleagues on a daily basis. Even if the organizations under study showed an adequate level of consistency and consensus in a shared state of organizational affective commitment, we may argue that convergence processes other than emotional contagion might be playing their role. In fact, some other work group characteristics that promote emotional convergence within teams have been reported in the literature (Brief \& Weiss, 2002). These authors pointed out mood regulation norms as an underlying process that accounts for the sharing of emotions and moods in the workplace. Following this rationale, implicit or explicit norms for mood regulation might be playing their role in higher level phenomena such as organizational affective commitment at the organizational level of analysis. This view is coherent with the definition and explanatory mechanisms for organizational affective commitment that stresses the importance of both emotional contagion and the development of group norms of committed behavior (Gardner et al., 2011).

Findings suggested that engaged teams exerted greater efforts at work in terms of both in- and extra-role performance. Work engagement has been more usually linked to extra-role performance, as it enacts further efforts and behaviors not strictly required in the fulfillment of the work role (e.g., Schaufeli\&Salanova, 2010). This notwithstanding, we argue that team work engagement provides the team with a qualitative improvement in in-role performance. This process may be achieved by 


\section{Chapter}

means of back-up behaviors displayed within the team. This is the case when one employee provides feedback to reduce errors, suggests optimization methods to reduce time-consuming team tasks, and takes care to ensure that the team has access to tools, materials and technology (Porter, 2005).

In this study, we explored the link between organizational affective commitment and customer loyalty, understood as a behavioral intention to repurchase the service or product provided by the organization (Swan \& Oliver, 1989). An organization made up of committed employees is more capable of building a positive attitude toward the organization, which may increase the chances of this translating into actual repurchasing behavior. The mechanism behind this association could be related to customer-oriented behaviors that are displayed within committed organizations (Allen \&Grisaffe, 2001). Customer-oriented behaviors involve a wide set of actions that are aimed at, for instance: reducing unpleasant emotions due to delay or extra queuing time in service delivery (Conway \&Briner, 2012), easing cooperation among the employees to fulfill customer's needs (Hoffman \& Kelley, 2004), or engaging in conversation topics that are relevant to their customers (Netemeyer, Heilman, \&Maxham, 2012).

Mediation findings suggest that team work engagement mediates the relation between team coordination and team performance, and between healthy organizational practices and team performance. Meanwhile, organizational affective commitment was not mediating the association between healthy organizational practices and customer loyalty. This unexpected finding might be due to the influence of other organizationallevel variables. In that sense, Gavino, Wayne, and Erdogan (2012) proposed that organizational support may play a role between human resource management practices and organizational affective commitment. These authors suggest that employees may have access to healthy organizational practices provided by the organization and, nonetheless, perceive that the organization is not supportive enough toward the team. However, many other variables have been suggested as playing a 


\section{Chapter}

role in this process such as the perceptions of organizational equity and/or organizational politics (Chen \&Indartono, 2011), organizational trust (Acosta, Salanova, \&Llorens, 2012), and organizational justice (Ertürk, 2007). Even more, organizational affective commitment was not a mediator in the association between healthy organizational practices and team performance. This finding provides support for a process in which engaged teams translate healthy organizational practices into proper team performance. In contrast, a shared state of organizational affective commitment toward the organization may promote team performance in addition to team work engagement, but does not seem to be an organizational characteristic modulating the association of healthy organizational practices with team performance.

\section{Practical implications}

Managers in charge of human resource practices may boost performance at different levels, thus having an influence on team work engagement and organizational affective commitment. Hence, teams' well-being benefits from resources provided to coordinate properly within a context where this process is conducted in line with organizational goals (i.e., information and communication, and social corporate responsibility), preventing hindrance demands (i.e., mobbing, inequity, and work-family conflict), as well as promoting team amplition (i.e., career and skills' development, and well-being).

Our findings provided support for current views on positive organizational practices (Llorens, Salanova, Torrente, \& Acosta, 2013; Salanova, Llorens, Acosta, \& Torrente, 2013). In line with the focus and scope of this research, we draw upon the value of collective interventions, as they may result in further organizational benefits from a practical standpoint (Schneider, Macey, Barbera, \& Young, 2010). Schaufeli and Salanova (2010) proposed a number of practices to increase work engagement: assessment and evaluation of employees, job (re)design, transformational leadership, 


\section{Chapter}

training, and career development. Among those, training and career development were included in this study and were positively related to team work engagement. These findings encourage policy-makers to implement team-focused practices to influence team work engagement.

Supervisors may play a crucial role in translating organizational practices into daily operations within teams. It is in their hands to ensure proper communication channels and the adequate flow of information within the team (Kozlowski \&llgen, 2006). Organizations that actively promote healthy organizational practices (e.g., by opening communication channels) may benefit from an increase in team-level resources such as team coordination (Osterman, 1995; Salanova et al., 2012). The combination of these two types of resources (team coordination and organizational practices), driven concurrently at both collective levels, might maximize their effectiveness. Both may then enact synergies that maximize the impact over the engagement of the team. In this sense, Mathieu, Gilson, and Ruddy (2006) indicated that upper-level management is responsible for coordinating actions across teams. Thus, as a different but important healthy practice, human resource management could contribute to within-team coordination as a prior step to coordinating across teams.

\section{Limitations and further research}

This study presents limitations that may turn into avenues for further research. Previous literature on emotional contagion acknowledged the role of the contagious leader or supervisor (Sy, Côté, \& Saavedra, 2005). Supervisors may also trigger emotional states within the teams and fine-tune their affective tone due to the relevance of their guidance and the information that they provide for team goalachievement. The inclusion of the role of the supervisor adds further complexity to the proposed model of the engagement/commitment interplay, while accounting for a key agent within the team. Transformational leadership is connected to work engagement 


\section{Chapter}

as transformational leaders are supportive and are expected to take care of the needs of their subordinates, thus enacting a virtuous circle in the positive contagion of work engagement and affective commitment (Avolio, Zhu, Koh, \& Bhatia, 2004; Tims, Bakker, \&Xanthopoulou, 2011). Therefore, though analyzing the role of the supervisor in the proposed model falls beyond the scope of this paper, it does open up future avenues of research in light of the current findings.

As previously suggested (Torrente et al., 2012), team coordination may increase team work engagement by enabling a proper communication flow among the team members. Nevertheless, the group dynamics literature has pointed out the complexity of coordination in previous studies (Arrow, McGrath, \&Bertahl, 2000). It also falls outside the scope of this paper to test coordination as a prerequisite for sharing emotions, that is, the actual positive contagion process of work engagement within the work team. This conception of team coordination has been linked to interpersonal mood induction, contagion theory and mood linkage (Totterdell, 2000). In this study, we built upon the conception of team coordination as a means of achieving higher performance through a shared state of team work engagement. Recent developments in the study of team dynamics allow for a more detailed look at the temporal patterns related to team coordination and its effects on the spread and positive contagion of team work engagement (Li \& Roe, 2012).

In this study we relied on teams' perceptions of healthy organizational practices implemented by Human Resource Management. We attempted to test how these practices were related to shared affective states displayed by the teams and by the organization as a whole. Further research may want to delve into the adequacy of looking for a universal set of practices, assess the contextual factors that affect the impact of Human Resource systems, or focus on the combinations and patterns of multiple Human Resource practices (Ostroff\& Bowen, 2002). The objective and direct assessment of the organizational practices implemented within the companies or the use of independent sources of information is also strongly recommended. The findings 


\section{Chapter}

suggest that a set of multiple healthy organizational practices seems positively associated with wide emotional shared states held at the team and organizational levels.

Furthermore, longitudinal studies are encouraged in order to disentangle possible causal paths among the study variables at the collective level of analysis. Although the present study was conducted following a cross-sectional perspective, the HERO Model posits that healthy organizational resources and practices, healthy employees, and healthy organizational outcomes are three different but interrelated components. The three core dimensions of the model are expected to contribute to resource caravans and produce positive gaining cycles and/or spirals (Salanova et al., 2012). The longitudinal perspective introduced by the model at the collective level may provide further knowledge on the relation of human resource management practices, organizational well-being, and performance over time.

\section{Final note}

Further refining of the model presented here is expected in the future, given the recent interest in multiple levels of analysis within the work engagement/commitment literature (e.g., Le Blanc \& González-Romá, 2012; Macey \& Schneider, 2008). However, underlying the proposed model is the allocation of work engagement and affective commitment within different nesting structures. The main purpose of this study was to offer a new perspective on the relation of collective states such as work engagement and organizational commitment as allocated on different levels of analysis. This study aspired to offer new insights for both work engagement and organizational commitment theory in a joint effort to commit the engaged. 



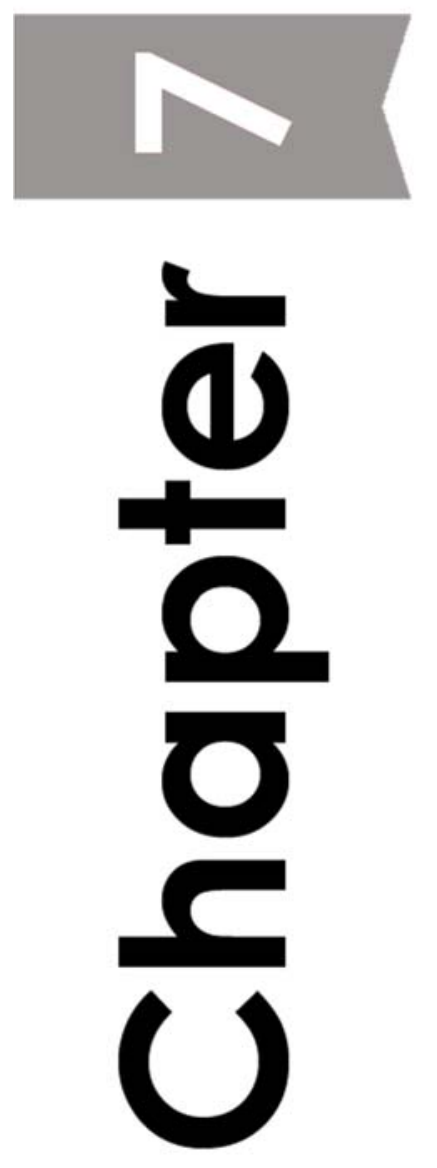




\section{Chapter}

\section{Chapter 7}

\section{General discussion}

The goal of this thesis project was to further our knowledge of team work engagement. A number of empirical studies have been conducted in order to address several points that arose from the theoretical review of work engagement (Chapter 1). First, the drivers of work engagement were analyzed in an attempt to take a multilevel perspective of the topic. To offer a complete picture of well-being at work, we included both work engagement and burnout as opposite poles, following the JD-R Model, and including cross-level relationships with organizational demands and resources (Chapter 2). Next, the focus was placed on the mechanisms underlying positive contagion of work engagement within teams. Emotional contagion theory was applied and special attention was paid to similarity among employees as a precondition for convergence in a shared state of work engagement within teams (Chapter 3). In the following chapter, a Team Work Engagement Scale was developed and validated based on the UWES questionnaire in order to tackle team work engagement (Chapter 4). This scale was applied to a set of work teams in order to test the mediating model of team work engagement between social resources and performance, as assessed by their immediate supervisor (Chapter 5). Finally, team work engagement was analyzed as embedded within organizations, and in relation to: (1) healthy organizational practices implemented by the companies, and (2) organizational affective commitment as a way of contributing to distinguish conceptually between the two collective states (Chapter 6). In the general dissertation, firstly the main results of the above-mentioned empirical studies are summarized, and then they are discussed in terms of their theoretical implications within the context of the specific research question stated in the theoretical review. Next, the practical implications and recommendations will be discussed. Finally, strengths, limitations and avenues for future research will be presented. 


\section{Main findings and theoretical implications}

The findings of this dissertation have implications for theory building and for the conceptual development of team work engagement. Implications for the mechanisms and processes that support the main theoretical frameworks that articulated the present thesis project will be discussed, namely: the JD-R Model, the HERO Model, and Emotional Contagion Theory. These implications will be enriched with alternative explanations for the unexpected results. In Figure 1, the relationships that were tested throughout this thesis in relation to team work engagement are summarized. Taken together, these findings may provide some support with which to build a preliminary model of team work engagement including multiple levels of analysis.

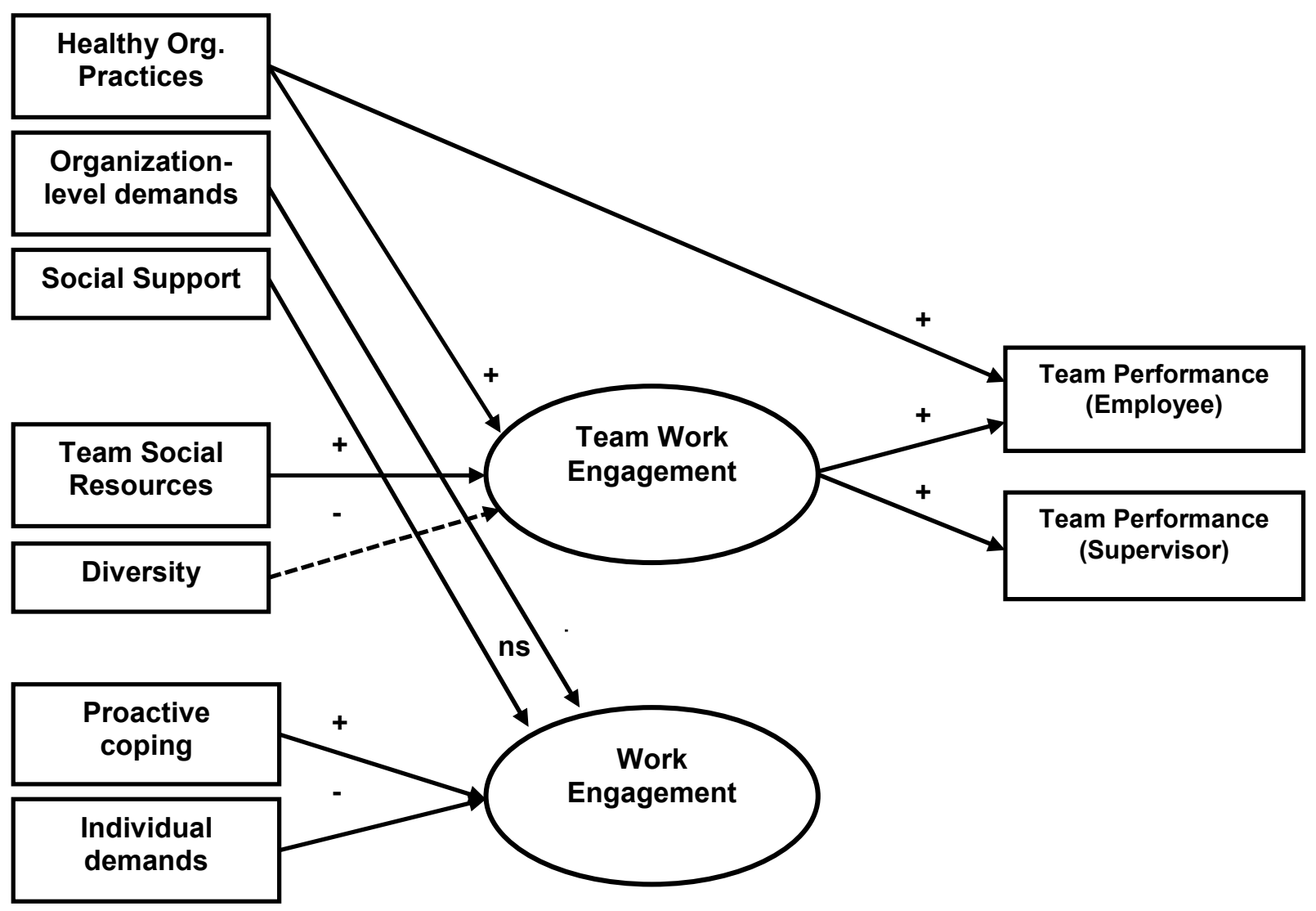

Figure 1. A model of team work engagement showing the relations tested in this thesis. Solid arrows indicate direct effects. Dotted arrows indicate the composition model involved in the analyses. Dashed arrows indicate a direct effect of diversity on convergence in team work engagement assessed in terms of dispersion. 


\section{Chapter}

\section{RQ1: How can the JD-R Model be extended to include organization-level demands and resources using a multilevel approach?}

Research question 1 was addressed in the first empirical study (Chapter 2), where it was hypothesized that individual-level demands and proactive coping were related to the core dimensions of burnout and work engagement. A cross-level association was also hypothesized. More specifically, organization-level demands and social support from colleagues (organization level) were expected to be related to burnout and work engagement (individual level). In the proposed research model, demands (i.e., individual and organizational) were expected to be negatively related to work engagement, whereas resources (i.e., individual and organizational) were expected to be positively related. The opposite pattern of relations was expected for the core dimensions of burnout. Results indicated that - as expected - individuallevel demands were positively related to emotional exhaustion and cynicism, and negatively related to vigor and dedication. The only exception to this set of results was the non-significant association between individual demands and dedication. Furthermore, proactive coping strategies were negatively and significantly associated with emotional exhaustion and cynicism, whereas they were positively and significantly related to vigor and dedication. Even more, results indicated that there was a significant moderation effect between proactive coping and individual-level demands, so that proactive coping buffered the negative relationship between individual-level demands and vigor. Results from the test of cross-level effects indicated that organization-level demands were positively and significantly related to emotional exhaustion and cynicism, whereas they were negatively and significantly related to vigor and dedication. However, we failed to find a significant relationship between social support and either work engagement or burnout in individual firefighters.

A number of conclusions can be drawn from this set of results for theory development and for comprehension of the psychological processes under study. The 


\section{Chapter}

JD-R Model (Demerouti, Bakker, Nachreiner, \& Schaufeli, 2001) posits that work engagement plays a crucial role in the motivational process of well-being at work (Schaufeli \& Bakker, 2004). The JD-R Model is a general, heuristic model stressing the importance of demands and resources in employee well-being. The wide array of papers that have followed this perspective was mostly restricted to individual work engagement, as presented in the theoretical review at the beginning of this thesis. In Chapter 1, individual-level demands (i.e., acute demands) and resources (i.e., proactive coping) were tested in relation to burnout and work engagement in a very specific occupational sample: a national sample of Portuguese firefighters. Emergency situations involve unpredictable situations that involve acute and highly stressful work environments that threaten the lives of both victims and workers (Bennett, Williams, Page, Hood, Woollard, \& Vetter, 2005). In consequence, employees suffer from strain that drains their energy, leading to resource depletion, which in the long run may turn into burnout (Taris, Leblanc, Schaufeli, \& Schreurs, 2005). In contrast, one may expect job demands to have the opposite effect on work engagement, undermining employees' willingness to invest energy and motivation in their work. Although this rationale accounted for the hypotheses that were put forward, job demands are not negative by definition (Hakanen \& Roodt, 2010), and some researchers have suggested the existence of a motivational effect of certain types of demands, dubbed challenge demands (Crawford, Lepine, \& Rich, 2005). This may provide an explanation for the non-significant effect of acute demands over work engagement. For some employees, acute demands may result in sensation seeking or in a sense of challenge and beating the odds. The self-selection bias is also a plausible explanation in this process, as firefighters entering the profession know that challenge and risk are characteristics of this occupation, which involves frequently having to deal with emergency situations (Ziliak \& McCloskey, 2008). 


\section{Chapter}

The role of organization-level demands and resources was also stressed in Chapter 1. Organization-level demands were conceptualized as shared demands that were common to all employees working in the same fire brigade (e.g., coordination with external stakeholders, or understaffed situations). The strain produced by organizationlevel demands is usually overcome through actions taken by the immediate supervisor or by practices implemented by the organization as represented by the CEOs or main representatives (e.g., human resource practices). The definition of organization-level demands enriches current definitions of demands in the JD-R Model for the specific case of demands allocated at the organization level of analysis (cf., Demerouti et al., 2001). Similarly, employees themselves can arrange their own organization-level resources to cope with organizational demands. Other forms of collective organizational resources may benefit work units, for instance, by crafting strategies taken by the teams (Tims, Bakker, Derks, \& van Rhenen, 2013). It was concluded that the main difference between organization-level demands and resources is the process that accounts for how these organizational characteristics become shared stressors or shared resources, respectively. Therefore, whereas organization-level demands display something like a snowball effect, influencing all the employees within the same organization in a similar way, organization-level resources can be provided by the organization and/or emerge from the interaction and daily experiences of the employees.

Nevertheless, social support showed a non-significant effect on burnout and work engagement. We propose that this unexpected finding may be due to the specific characteristics of the firefighting personnel. In fact, the same non-significant result has been found previously within the context of firefighters. Regehr, Hill, Knott, and Sault (2003) compared new recruits in the first week of employment with experienced firefighters. The authors suggested that opportunities for promotion are limited, which breeds competition within tasks rather than cooperation and support. Firefighters carry out their work in a paramilitary structure and command chain that may lead to the 
salience of coercive leadership and threats of punishments instead of promoting the display of supportive behaviors. Furthermore, firefighting is a male-dominant occupation. As males feel more effective when taking an avoidance strategy from adverse situations in daily work (Long \& Gessaroli, 1989), in these environments the emotional aspect of work can be of little importance, as seeking social support cannot correspond to their expected social role (González-Morales, Rodríguez, \& Peiró, 2010).

\section{RQ2: How can work engagement spread among individuals working in teams through similarity following a positive emotional contagion process?}

In the second empirical study (Chapter 3 ), it was hypothesized that similarity in terms of gender and company tenure was positively related to convergence in team work engagement among employees working in teams. Results indicated that, as expected, similarity in teams as regards gender was positively related to convergence in team work engagement. Nevertheless, contrary to our expectations, similarity in terms of company tenure was significant but negatively related to convergence in team work engagement. Thus, teams with members of the same gender were more likely to share a state of team work engagement. Unexpectedly, teams with more differences in terms of company tenure were also more prone to convergence in team work engagement.

This chapter adds to the scarce stream of research suggesting that contagion processes affect both the sharing of burnout and work engagement at work (Bakker et al., 2006). In Chapter 3 we took a closer look at the contagion process of work engagement based on similarity between employees working in the same team. Similarity in terms of gender and company tenure was significantly related to convergence in team work engagement, though results for company tenure were contrary to what was expected. This finding confirms that similarity acts as a precondition in achieving a shared state of team work engagement (Bakker et al., 


\section{Chapter}

2009). Although it does not mean that this is a necessary condition for contagion, it may promote the spread of a similar level of work engagement within teams. Therefore, teams that were more similar as regards the number of men or women showed a similar level of team work engagement. Gender-similar colleagues seem to act as emotional referents in work-related emotions given the stronger friendship ties and more cohesive relationships that they share (Lincoln \& Miller, 1979). In contrast, unexpectedly, teams that were more dissimilar in terms of company tenure showed a better convergence in terms of team work engagement. Experienced employees share motives to work, job demands, social stereotyping by others, or even characteristics that belong to the non-work domain, all of which can enact categorization processes that take the form of exhibiting bias in favor of similar members (Tsui \& O'Reilly, 1989). This rationale provided support to expect that similarity in terms of company tenure was related to convergence in team work engagement. However, experienced employees are usually involved in behaviors that support less experienced employees when it comes to solving problems or to contributing to a successful socialization which leads to a more intense interaction between them (Bauer, Morrison, \& Callister, 1998). This latter explanation was the one that received further support from the results.

In this paper, Chapter 3 , we also use the term positive contagion to refer to the process by which the work engagement of a given employee serves as a resource for the work engagement of his or her colleagues. Engaged employees invest an extra amount of energy, persistence, and dedication in their duties, which is transferred to the job setting. The behavioral consequences of work engagement (e.g., showing persistence against obstacles, expressing enthusiasm and pride during work duties, or losing track of time while working) may therefore be appraised and shared by other employees working in the same team. This process can be triggered by several mechanisms, the most simple of them being the frequency of interactions between people working together (Bakker, Westman, \& van Emmerik, 2009). In a more unconscious path, empathy has an influence on team work engagement contagion 


\section{Chapter}

through our innate tendency to mimic each other's gestures, body positions, and verbal expressions (Ilies et al., 2007).

\section{RQ3: Can a reliable and valid assessment tool be developed to measure team work engagement?}

In the third empirical study (Chapter 4), we developed a factorial validation of a Team Work Engagement measure based on the UWES questionnaire using aggregated date at the team-level of analysis. It was hypothesized that a three-factor structure - including team work vigor, team work dedication, and team work absorption - defined the construct of team work engagement in teams, as opposed to a one-factor structure with all the items loading on one general single factor of team work engagement. A three-factor model of team work engagement was compared with a model including just one single factor. As expected, the three-factor model showed a superior fit to the data, replicating the structure of the construct in the context of work teams. This finding provided support for the construct validity of work engagement across levels of analysis and offered a specific measurement tool of team work engagement for academic and applied purposes.

\section{RQ4: Does team work engagement mediate between social resources and performance in teams using an objective measure of performance?}

In the fourth empirical study (Chapter 5), it was hypothesized that team work engagement would play a mediating role between team social resources (i.e., supportive team climate, teamwork, and team coordination) and team performance (i.e., in-role and extra-role) as assessed by the immediate supervisor. Previous research on collective perceptions of work engagement did not consider the use of performance reports provided by the supervisor. The inclusion of performance as rated by the immediate supervisor in daily contact with the teams is a novelty of this study since it introduces an objective measure of performance in relation to team work engagement. Results indicated that team social resources were positively related to 


\section{Chapter}

team work engagement, which in turn was related to higher team performance. A fully mediating model fits better than a partial mediating model of team work engagement. Hence, it was concluded that social resources within teams have an influence on team performance through a collective, shared state of team work engagement. This finding provides support for the motivational process of the JD-R Model within teams, suggesting that homologous processes are functioning across levels of analysis having work engagement (i.e., individual level) and team work engagement (i.e., team level) as key mediating positive states. As far as we know, this was the first empirical paper to provide a definition along with an emergence model, and to test the role of a shared state of work engagement within teams, which constitutes the main novelty of this study. Furthermore, the stated processes provide support for the inclusion of a crosslevel perspective in the JD-R Model and may serve to integrate it into the HERO Model, given the stress in collective phenomena presented by the latter research model.

RQ5: Is it possible to develop a multilevel model of team work engagement in relation to drivers (i.e., human resource practices and resources), outcomes (i.e., team and organizational performance), and related constructs (i.e., organizational affective commitment)?

Last but not least, in the fifth empirical study (Chapter 6), a multilevel research model was proposed in which team work engagement was mediating between team coordination and team performance, and organizational affective commitment was mediating between healthy organizational practices and customer loyalty, as assessed by the customers. In this study we analyzed team work engagement as embedded within a wider organizational context. In this model, team work engagement was a shared state within teams that was enhanced by team coordination, a social resource that may help them cope with team demands. In turn, team work engagement was hypothesized to yield higher team performance, in this case rated by the actual team 


\section{Chapter}

members. Team work engagement coexists alongside other collective states that spread within organizations. In this case, we focus on organizational affective commitment, suggesting that it can be operationalized at the organization level and that it mediates between the practices implemented and the performance of the company. An objective measure of performance (i.e., customer loyalty) as assessed by the actual customers was introduced and supported the novelty and robustness of the design. Results indicated that team work engagement was playing a mediating role between team coordination and team performance. Furthermore, team work engagement was a multilevel mediator between healthy organizational practices and team performance, whereas organizational affective commitment was positively related to team performance, but it was not a significant multilevel mediator between healthy organizational practices and team performance. Furthermore, organizational affective commitment was not a mediator between healthy organizational practices and customer loyalty.

Thus, Chapter 5 provided further support for the assumptions of the HERO Model, as this research model aimed to address well-being at work from a collective point of view. In this empirical paper, a set of cross-level processes having team work engagement as a mediator was tested following a homology process (Chan, 1998). In contrast to Chapter 1 , this chapter sought to propose an explanatory mediating process between critical factors within companies that bring together both occupational health psychology and human resource management. In line with the tenets of the HERO Model, results suggested that a motivational process within teams exists that may be triggered by contextual aspects of work such as healthy organizational practices, supportive team climate, teamwork, and team coordination. These resources are associated to a collective state of work engagement within teams, which in turn may lead to higher in-role and extra-role team performance. 


\section{Chapter}

The findings of the current thesis have implications for the HERO Model (HEalthy and Resilient Organizations Model; Salanova, 2008, 2009; Salanova, Llorens, Cifre, \& Martínez, 2012). Although both the JD-R Model and the HERO Model are heuristic and depart from similar nomological networks, several differences may be highlighted. The HERO Model stresses the role of collective and positive resources, states, and outcomes that lie at the core of healthy and resilient organizations, whereas the JD-R Model focuses on individual well-being. In fact, the emphasis on collective phenomena, which is the cornerstone of the HERO Model, comes in a moment when calls for the development of a multilevel perspective in the JD-R Model are being made (Demerouti et al., 2001; Schaufeli, 2012a; Schaufeli \& Taris, 2014). In fact, the HERO Model posits that a general component, i.e., the healthy organizational resources and practices component includes: task resources (i.e., allocated at the individual level), social resources (i.e., at the team or work unit level), and organizational practices (i.e., at the organizational or business unit level).

In Chapter 6 team work engagement was integrated into a wider organizational context. Healthy organizational practices were associated with benefits in team work engagement, which can result in further benefits for team performance in addition to promoting other positive shared states within enterprises (i.e., organizational affective commitment). In line with this reasoning, the HERO Model stresses the importance of human management practices as drivers of employees' well-being. The findings in Chapter 6 provide support for the HERO Model by stressing the role of policymakers to engage work teams and groups of employees through practices (Schaufeli \& Salanova, $2008,2010)$, as we will discuss in the following section.

\section{Practical implications}

The findings of this dissertation project yielded some practical implications for organizations interested in promoting a shared state of team work engagement. In fact, 


\section{Chapter}

some of the initiatives to improve employee well-being are in the hands of the people with most responsibility in the enterprises. This was the conclusion reached in Chapter 2, where organization-level demands are planned and can be rearranged by the board of directors in each company or by the immediate supervisor as an intermediate in the command chain. Preventing organization-level demands serves three different purposes: (1) it compensates for the negative impact they may have on individual work engagement (Crawford et al., 2005), (2) it protects individual employees from experiencing symptoms of burnout (Demerouti et al., 2001), and (3) it acts as a shared stressor that affects employees in a similar manner, thereby reducing the possibility of a contagion of burnout among employees (González-Morales, Peiró, Rodríguez, \& Bliese, 2011). All in all, preventing organization-level demands will allow the expression of more positive emotions that could lead to shared states of work engagement (Salanova, Llorens, \& Schaufeli, 2011). Specifically, organizations can promote a shared state of team work engagement through the implementation of healthy organizational practices that tackle this collective state within teams directly. Therefore, three sets of practices showed the applicability as organizational resources in order to improve team work engagement by: ensuring that teams conduct their work in line with organizational goals (i.e., information and communication, and social corporate responsibility), preventing hindrance demands (i.e., mobbing, inequity, and work-family conflict), and promoting team amplition (i.e., career and skills' development, and wellbeing).

Another implication for work engagement in the organizational context regards the spreading of this positive state among individuals. This thesis suggests that co-workers may act as actual resources, reciprocally influencing each other's levels of work engagement through daily interaction and shared experiences. Therefore, employees are positive resources for the rest of the members of their team. This was shown through the precondition of similarity in the contagion process of team work 


\section{Chapter}

engagement. The need to pay attention to similarity processes within teams adds to the extant literature on diversity management introducing more complexity into this debate. Selection processes need to take care of the potential for influencing others into positive emotional states based on gender and company tenure. Findings showed that, as teams are composed of more members of the same gender, they are more likely to achieve a similar state of team work engagement. Nevertheless, ethical issues are present in this discussion as gender cannot become a source of discriminatory selection and recruitment processes. The complexity of this finding goes along with the debate about the advantages and disadvantages of similarity within teams for performance. Diverse teams are expected to show higher creativity and performance (Tsui \& Gutek, 1999). However, based on the findings of Chapter 2, we may expect lower performance as diversity hinders the transmission of team work engagement. Furthermore, teams that are made up of members with different company tenureare more prone to converge in a similar state of team work engagement. This suggests that socialization processes are not only playing a role in supporting and mentoring new employees, but also in shaping their emotions toward work within teams (Bauer, Morrison, \& Callister, 1998). Supervisors in mentoring processes for newcomers have the opportunity to motivate and increase those newcomers' levels of work engagement. Thus, the mentoring role has to be conducted by those who are more likely to connect with and transmit positive emotions to others. We could expect that empathic individuals who grasp colleagues' emotions more easily (Bakker et al., 2009) or extroverts who openly seek social interaction (Langelaan, Bakker, Schaufeli \& van Doornen, 2006) may well serve as positive socializers.

Another important practical implication raised by this thesis project is the measurement of team work engagement for research or applied purposes. To address our research questions a new Team Work Engagement Scale had to be developed and tested. This became a specific measurement tool that tackled the phenomenon under analysis and became an application of this thesis. As a shared state that focuses on 


\section{Chapter}

the team level of analysis the items refer to the individuals' perception of the level of work engagement within teams, as a group. These perceptions are then averaged aggregated - to achieve a reliable mean of the level of team work engagement within teams. It can also be informative of the differences and similarities between individual perceptions of team work engagement in terms of standard deviation or agreement (Brown \& Kozlowski, 1999). As a result, a team work engagement measurement tool was proposed building upon a work engagement questionnaire that has been widely validated across occupations including cross-national studies, namely the UWES (Utrecht Work Engagement scale; Schaufeli \& Bakker, 2003). Finally, a 9-item Team Work Engagement Scale was obtained for use in work teams. Furthermore, the factorial validity of the scales was tested, showing that the three-factor structure of work engagement was replicated at a higher level of analysis. This questionnaire allows for further research in the field and a more accurate analysis of work engagement within work teams in the organizational context.

Last but not least, the findings regarding the mediating role of team work engagement in teams are also worth mentioning. Team work engagement mediates a process in which organizational and team level resources increase the vigor, dedication, and absorption of team members, which in turn leads to higher productivity in terms of both in-role (i.e., the duties that are expected to be fulfilled by contract) and extra-role performance (i.e., helping other colleagues or taking action that improves the efficiency or image of the company). As discussed above, healthy organizational practices are organizational resources that are related to team work engagement. As another practical recommendation throughout these chapters, the importance of promoting team social resources was also stressed in the form of coordination, teamwork, and supportive team climate. Promoting a climate of psychological safety and rewarding constructive criticism as well as dealing with interpersonal problems foster a supportive team climate. Coordination can be fostered by ensuring the existence of appropriate channels of communication among the team members. 


\section{Chapter}

Finally, results suggest that recruiting and selecting applicants who complement team skills as well as considering the possibility of introducing team-based retribution according to performance would help to boost team working. This finding was replicated using two different types of performance appraisal information systems: the immediate supervisor as a source of objective information, and the employees themselves reporting on their own performance. Given that employees could be responding under the influence of desirability or that bias may exist due to common method variance, the use of supervisor perceptions provided support for the robustness of these set of results.

\section{Strengths of this thesis project}

The implications of this thesis project are supported by the approaches and techniques used throughout the chapters. In the following lines the main strengths of this thesis will be presented. First of all, using different theoretical approaches strengthened the findings and provided further refinement for the functioning of the proposed processes. The JD-R Model (Demerouti et al., 2001) provided the theoretical background for most of the proposed processes in terms of demands and resources in relation to burnout and work engagement. A related multilevel view of healthy organizational resources and practices was highlighted by the HERO Model (Salanova et al., 2012). This model provided the rationale for a collective view of positive states within enterprises and its relation with antecedents and outcomes. A theoretical strength of this dissertation project remains in its combining and integrating both theoretical frameworks through their applications to build a cross-level theory of work engagement. Moreover, we also applied emotional contagion theory (Hatfield et al., 1994), arguing for an explanatory mechanism for the spread and sharing of work engagement within teams. This theoretical approach was crucial for the 


\section{Chapter}

conceptualization of team work engagement, since it accounted for a transmission mechanism that helps to understand how individuals are able to feel a shared state of work engagement as a team, and not only as single individuals.

The Team Work Engagement Scale obtained in Chapter 4 was applied to different work populations and a heterogeneous sample of companies (i.e., services, industry, and construction) that allowed the hypotheses and research questions to be tested. Conclusions were also enriched by using data from two different countries: Portugal and Spain. This cross-national perspective supports the replicability of the findings. The use of multilevel analysis - or hierarchical linear modeling — required large samples to account for the nesting structures under analysis and the statistical assumptions underlying calculations. Moreover, sample sizes were adequate to allow for proper generalizability of results. Furthermore, the use of three different sources of information strengthened the conclusions for this set of studies. We made use of perceptions of employees, immediate supervisors (i.e., in-role and extra-role performance), and customers (i.e., customer loyalty). Taken together, all these strategies allowed for the robustness of results while also minimizing the impact of bias due to common method variance.

Another strength of this dissertation project is based on the wide array of methodological and statistical procedures applied to the analysis of data. The various research questions stated at the beginning of this thesis required the use of multiple techniques. In Chapter 3, the factorial validation of the questionnaire required the implementation of confirmatory factor analysis using data at the team level of analysis. In Chapter 4, we implemented structural equation modeling with aggregated data in teams. Due to the multilevel context in which this thesis was framed, the use of hierarchical lineal modeling was required. The multilevel relationships tested involved cross-level relationships between individuals nested within organizations (Chapter 1), individuals nested in teams (Chapter 2), and teams nested within organizations 


\section{Chapter}

(Chapter 5). The multilevel approach taken to study work engagement was one of the main innovations presented in this thesis.

\section{Limitations and further research}

The limitations of this thesis project open avenues of research in the field of team work engagement. The relationships tested in this dissertation followed a cross-level design. Cross-level designs imply variables that are measured synchronically and do not allow causation to be concluded. In order to build a preliminary model of team work engagement, we presented a series of studies using correlational data. Further finetuning of this model is required by making use of different waves of data. Longitudinal data can be gathered by two means, in the laboratory setting or in the actual organizational context. The laboratory setting seems the ideal context in which to study specific processes of contagion, social antecedents, and the consequences of team work engagement in a controlled environment. This context makes it easier to gather data at a lower cost than in the organizational context, as it does not interact with the usual daily activities of the employees. Laboratory designs are very well suited to the analysis of group formation processes involved in the socialization and engagement of newcomers in work teams (Hakanen \& Roodt, 2010). The periodicity of work audits attempt not to overwhelm employees with repetitive measurement of climate perceptions. Nevertheless, although more prolonged in time, obtaining longitudinal data in the job setting enables improvements to be achieved in ecological validity. This method allows cycles or spirals of positive resource caravans to be tested in actual work teams (Llorens, Schaufeli, Bakker, \& Salanova, 2007).

The Team Work Engagement Scale that resulted from Chapter 4 was tested for use in teams by means of aggregated date, which constitutes a first step in the validation of an assessment tool for a multilevel context (Chen, Mathieu, \& Bliese, 2005). However, further steps in the multilevel validation of this questionnaire would be 


\section{Chapter}

the simultaneous testing of scales at the targeted levels of analysis (e.g., individuals within teams nested within companies). This procedure allows for the proper discrimination of the scales not only between individuals, but also between teams - as is the case of team work engagement - , or between any other grouping variables (e.g., business units, organizations, or countries). In fact, further steps in multilevel validation of questionnaires are already going on for work engagement. For example, Breevaart, Bakker, Demerouti, and Hetland (2012) proposed a multilevel validation of the UWES questionnaire to test its ability to discriminate between two levels of analysis: between and within individuals (i.e., in different time frames). Results indicated that this questionnaire is a reliable and valid assessment tool for use in diary studies, that is, studies that are conducted in a multilevel context that stresses differences within individuals over short periods of time (e.g., hours or days; Oerlemans \& Bakker, 2013). A similar approach is encouraged for team work engagement by testing the validity of the proposed team work engagement scale between individuals and teams, and/or between teams and enterprises.

Although data from two different countries were included in this thesis project, testing the validity of its conclusions in other national contexts would help to attain further generalizability and robustness for the findings. In fact, an interesting avenue of research concerns cross-cultural studies (i.e., individualistic vs. collectivistic), studies in specific occupational samples, or countries. For example, it is known that Japan is the country that shows the lowest levels of work engagement among its working population in comparison with other countries (Shimazu, Miyanaka, \& Schaufeli, 2010). Replication of the current findings using different samples would strengthen the robustness of these results on team work engagement or would even yield a more thorough understanding of other intervening variables. The study of team work engagement in different contexts may also help to replicate the inner three-factorial structure of team work vigor, team work dedication, or team work absorption. For example, a recent paper validating a measure of team work engagement (Costa, 


\section{Chapter}

Passos, \& Bakker, 2014) failed to show that the construct is based on the three components of the original UWES scale. The differences between these findings and the chapter in this thesis enrich the field and provide a fruitful avenue of research in the search for the causes of these contradictory findings in the dimensions of team work engagement.

In the current thesis project, team work engagement was studied either as a latent factor (i.e., Chapter 5) or as a composite measure (i.e., Chapter 2, 3, 4, and 6). Thus, research on the specific dimensions of team work engagement can open interesting avenues of research, as has been suggested for individual work engagement (Bakker \& Leiter, 2010; Demerouti, Mostert, \& Bakker, 2010). Following our findings, further research on team work vigor, team work dedication, and team work absorption may help to gain a deeper understanding of the specific psychological processes involved. Although not elaborated in any depth, this idea was introduced by Bakker et al. (2006) to suggest that the vigor and absorption component of team-level engagement could follow an unconscious transmission mechanism. The opposite would be true for the process of contagion accounting for team work dedication that is suggested to be consciously transmitted through expressing feelings of enthusiasm for the team task, for instance. The study of the specific dimensions of well-being at work has received more attention among scholars researching into the burnout syndrome. In fact, some authors have even detected causation patterns between the dimensions of burnout, which suggests that a similar phenomenon may occur between the different dimensions of work engagement (Taris, Le Blanc, Schaufeli, \& Schreurs, 2005).

Comparing burnout and work engagement and their contagion processes over time opens interesting avenues for research both for theory development and process testing. The work of Baumeister and colleagues (Baumeister, Bratslavsky, Finkenauer, \& Vohs, 2001; Baumeister, Vohs, DeWall, \& Zhang, 2007) claimed that negative states and emotions have a stronger effect than positive ones. Framing these processes within the team work engagement context with employees working in teams, one could 


\section{Chapter}

expect that burnout individuals would have a stronger influence on the emotional tone of the team than engaged employees. Designs aimed at testing and understanding this research question may represent applications to generate team work engagement.

Finally, it is important that these findings result in applicable interventions that help to promote team work engagement within teams, which may lead to healthier organizations. In fact, collective interventions are cheaper as they reach the maximum number of employees with lower associated costs (Schneider, Macey, Barbera, \& Young, 2010), which is why investing in team work engagement may be more efficient than just focusing on individual work engagement within enterprises. Further research may translate these empirical results into practical, standardized interventions that are useful for the actual organizational context, which are the ultimate purpose of applied research.

\section{Final note}

This thesis project has attempted to shed light on the topic of team work engagement. The specific emergent properties and collective processes that remain at the core of team work engagement have been highlighted, unlike the more traditional perspective of studying individual work engagement. Some steps have been taken toward building a preliminary model of team work engagement, thereby encouraging future research and laying fertile ground for a growing interest in the field during the coming years. The future looks promising in terms of avenues of research for a topic that is worth developing further: staying engaged while being connected to others, thus building engaged work teams in healthy companies. 



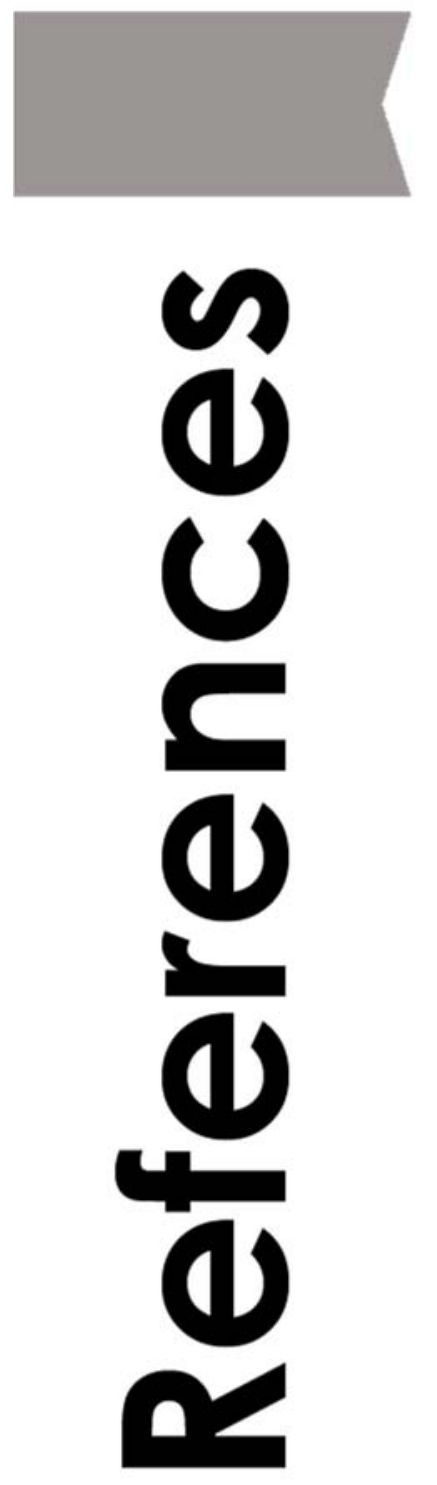




\section{References}

\section{References}

Acosta, H., Salanova, S., \& Llorens, S. (2012). How organizational practices predict team work engagement: The role of organizational trust [Special issue]. Ciencia \& Trabajo, 7-15.

Agarwala, T. (2003). Innovative human resource practices and organizational commitment: An empirical investigation. The International Journal of Human Resource Management, 14, 175-197.doi:10.1080/0958519021000029072

Ajzen, I. (2005). Attitudes, personality, and behavior. Milton Keynes, UK: Open University Press/McGraw-Hill.

Akaike, H. (1987). Factor analysis and AIC. Psychometrika, 52, 317-332.

Åkerstedt, T. (1990). Psychological and psychophysiological effects of shift work. Scandinavian Journal of Work, Environment and Health, 16, 67-73.doi: 10.5271/sjweh.1819

Alfes, K., Truss, K., Soane, E., Rees, C., \& Gatenby, M. (2010). Creating an Engaged Workforce (CIPD Research Report). London: Chartered Institute of Personnel and Development.

Allen, N.J., \& Grisaffe, D.B. (2001). Employee commitment to the organization and customer reactions: Mapping the linkages. Human Resource Management Review, 11, 209236.doi: 10.1016/S1053-4822(00)00049-8

Allen, N.J., \& Meyer, J.P. (1990).The measurement and antecedents of affective, continuance, and normative commitment. Journal of Occupational Psychology, 63, 1-18.doi: 0.1111/j.2044-8325.1990.tb00506.x

Allen, N.J., \& Meyer, J.P. (1996). Affective, continuance and normative commitment to the organization: An examination of construct validity. Journal of Vocational Behavior, 49, 252-276.doi: 10.1006/jvbe.1996.0043

Ancona, D.G., \&Caldwell, D.F. (1992). Demography and design: Predictors of new product team performance. Organization Science, 3, 321-341.doi:10.1287/orsc.3.3.321

Ângelo, R.-P. (2010). Psicologia da saúde ocupacional dos bombeiros portugueses: O papel das exigências e recursos profissionais na promoção do bem-estar psicológico [Occupational Health Psychology in Portuguese firefighters: The role of professional 
demands and resources in promoting psychological well-being] (Unpublished doctoral dissertation). University of Lisbon, Lisbon.

Arbuckle, J.L. (1997). Amos users' guide version 4.0. Chicago, IL: Smallwaters Corporation.

Arbuckle, J.L. (2009). Amos 18 Users' guide. Chicago, IL: SPSS.

Arrow, H., McGrath, J.E., \& Berdahl, J.L. (2000). Small groups as complex systems: Formation, coordination, development and adaptation. Thousand Oaks, CA: Sage.

Aubé, C., Rousseau, V., \&Tremblay, S. (2011). Team size and quality of group experience: The more the merrier? Group Dynamics, 15, 357-375.doi:10.1037/a0025400

Avolio, B.J., Zhu, W., Koh, W., \& Bhatia, P. (2004). Transformational leadership and organizational commitment: Mediating role of psychological empowerment and moderating role of structural distance. Journal of Organizational Behavior, 25, 951968.doi: 10.1002/job.283

Bacharach, S., Bamberger, P., \& Doveh, E. (2008). Firefighters, critical incidents, and drinking to cope: The adequacy of unit-level performance resources as a source of vulnerability and protection. Journal of Applied Psychology, 93, 155-169.doi: 10.1037/00219010.93.1.155

Baker, S., \& Williams, K. (2001). Short communication: Relation between social problemsolving appraisals, work stress and psychological distress in male firefighters. Stress and Health, 17, 219-229.doi: 10.1002/smi.901

Bakker, A.B., \& Demerouti, E. (2007). The Job Demands-Resources model: State of the art. Journal of Managerial Psychology, 22, 309-328.doi: 10.1108/02683940710733115

Bakker, A.B., \& Demerouti, E. (2008). Towards a model of work engagement. Career Development International, 13, 209-223.

Bakker, A.B., \& Demerouti, E. (2009). The crossover of work engagement between working couples: A closer look at the role of empathy. Journal of Managerial Psychology, 24, 220-236.doi: 10.1108/02683940910939313

Bakker, A.B., Demerouti, E., De Boer, E., \& Schaufeli, W.B. (2003). Job demands and job resources as predictors of absence duration and frequency. Journal of Vocational Behavior, 62, 341-356. 


\section{References}

Bakker, A.B., Demerouti, E., \& Euwema, M.C. (2005). Job resources buffer the impact of job demands on burnout. Journal of Occupational Health Psychology, 10, 170-180.doi: 10.1037/1076-8998.10.2.170

Bakker, A.B., Demerouti, E., \& Schaufeli, W.B. (2005). The crossover of burnout and work engagement among working couples. Human Relations, 58, 661-689.doi: $10.1177 / 0018726705055967$

Bakker, A.B., Demerouti, E., Taris, T., Schaufeli, W.B., \& Schreurs, P. (2003). A multi-group analysis of the Job Demands-Resources model in four home care organizations. International Journal of Stress Management, 10, 16-38.doi: 10.1037/1072-5245.10.1.16

Bakker, A.B., Demerouti, E., \& Verbeke, W. (2004). Using the Job Demands Resources model to predict burnout and performance. Human Resource Management, 43, 83-104.doi: 10.1002/hrm.20004

Bakker, A.B., \& Leiter, M.P. (2010). Where to go from here? Integration and future research on work engagement. In A.B. Bakker \& M.P. Leiter (Eds.), Work engagement: A handbook of essential theory and research (pp. 181-196). New York: Psychology Press.

Bakker, A.B., Schaufeli, W.B., Demerouti, E., \& Euwema, M.C. (2006). An organizational and social psychological perspective on burnout and work engagement. In M. Hewstone, H. Schut, J. de Wit, K. van den Bos, \& M. Stroebe (Eds.), The scope of social psychology: Theory and applications (pp. 229-252). Andover, UK: Psychology Press.

Bakker, A.B., Schaufeli, W.B., Leiter, M.P., \& Taris, T.W. (2008). Work engagement: An emerging concept in occupational health psychology. Work \& Stress, 22, 187-200.doi: $10.1080 / 02678370802393649$

Bakker, A.B., van Emmerik, H., \& Euwema, M.C. (2006). Crossover of burnout and engagement in work teams. Work and Occupations, 33, 464-489.doi:10.1177/0730888406291310

Bakker, A.B., van Emmerik, H., \& van Riet, P. (2008). How job demands, resources, and burnout predict objective performance: A constructive replication. Anxiety, Stress, and Coping, 21, 309-324.doi: 10.1080/10615800801958637

Bakker, A.B., Westman, M., \& Schaufeli, W.B. (2007). Crossover of burnout: An experimental design. European Journal of Work and Organizational Psychology, 16, 220239.doi:10.1080/13594320701218288 
Bakker, A.B., Westman, M., \& van Emmerik, H. (2009). Advancements in crossover theory. Journal of Managerial Psychology, 24, 206-219.doi:10.1108/02683940910939304

Bakker, A.B., \& Xanthopoulou, D. (2009). The crossover of daily work engagement: Test of an actor-partner interdependence model. Journal of Applied Psychology, 94, 1562-1571.

Baltes, B. B., \& Young, L. M. (2007).Aging and work/family issues. In K.S. Shultz \& G.A. Adams (Eds.), Aging and work in the $21^{\text {st }}$ century (pp.251-275). Mahwah, NJ: Lawrence Erlbaum Associates.

Bandura, A. (2001). Social cognitive theory: An agentic perspective. Annual Review of Psychology, 52, 1-26.

Barney, J.B. (2001). Resource-based theories of competitive advantage: A ten-year retrospective on the resource-based view. Journal of Management, 27, 643650.doi:10.1177/014920630102700602

Baron, R.M., \& Kenny, D.A. (1986). The moderator-mediator variable distinction in social psychological research: Conceptual, strategic and statistical considerations. Journal of Personality and Social Psychology, 51, 1173-1182.

Barsade, S. G. (2002). The ripple effect: Emotional contagion and its influence on group behavior. Administrative Science Quarterly, 47, 644-675.doi: 10.2307/3094912

Bauer, T.N., Morrison, E.W., \& Callister, R.R. (1998). Organizational socialization: A review and directions for future research. In G.R. Ferris (Ed.), Research in Personnel and Human Resources Management (pp. 149-214). Greenwich CT: JAI Press.

Baumeister, R.F., Bratslavsky, E., Finkenauer, C., \& Vohs, K.D. (2001). Bad is stronger than good. Review of General Psychology, 5, 323-370.doi: 10.1037//1089-2680.5.4.323

Baumeister, R.F., Vohs, K.D., DeWall, C.N., \& Zhang, L. (2007). How emotion shapes behavior: Feedback, anticipation, and reflection, rather than direct causation. Personality and Social Psychology Review, 11, 167-203.doi: 10.1177/1088868307301033.

Bavelas, J.B., Black, A., Lemery, C.R., \& Mullett, J. (1987). Motor mimicry as primitive empathy. In N. Eisenberg \& J. Strayer (Eds.), Empathy and its development (pp. 317-338). New York: Cambridge University Press. 


\section{References}

Becker, T.E., Billings, R.S., Eveleth, D.M., \& Gilbert, N.L. (1996). Foci and bases of employee commitment: Implications for job performance. Academy of Management Journal, 39, 464-482.doi: $10.2307 / 256788$

Ben, K.D., Scotti, J.R., Chen, Y., \& Fortson, B.L. (2006). Prevalence of posttraumatic stress disorder symptoms in firefighters. Work and Stress, 20, 37-48.doi: $10.1080 / 02678370600679512$

Bennett, P., Williams, Y., Page, N., Hood, K., Woollard, M., \& Vetter, N. (2005). Associations between organizational and incident factors and emotional distress in emergency ambulance personnel. British Journal of Clinical Psychology, 44, 215-226.doi: $10.1348 / 014466505 \times 29639$

Bentler, P.M. (1990). Comparative fit indexes in structural equation models. Psychological Bulletin, 107, 238-246.

Bhagwati, J. (2004). In defense of globalization. New York, NY: Oxford University Press.

Blau, P.M. (1977). Inequality and heterogeneity. New York: Free Press.

Bliese, P.D. (2000).Within-group agreement, non-independence, and reliability: Implications for data aggregation and analyses. In K.J. Klein \&S.W. Kozlowski (Eds.), Multilevel theory, research, and methods in organizations: Foundations, extensions, and new directions (pp. 349-381). San Francisco: Jossey-Bass.

Bliese, P.D. (2002). Multilevel random coefficient modeling in organizational research: Examples using SAS and S-PLUS. In F. Drasgow \& N. Schmitt (Eds.), Measuring and analyzing behavior in organizations (pp. 401-445). San Francisco, CA: Jossey-Bass.

Bliese, P.D., \& Halverson, R.R. (1996). Individual and nomothetic models of job stress: An examination of work hours, cohesion, and well-being. Journal of Applied Social Psychology, 26, 1171-1189.doi: 10.1111/j.1559-1816.1996.tb02291.x

Bliese, P.D., \& Jex, S.M. (2002). Incorporating a multi-level perspective into occupational stress research: Theoretical, methodological, and practical implications. Journal of Occupational Health Psychology, 7, 265-276.doi: 10.1016/S1479-3555(02)02006-1

Bowers, C.A., Pharmer, J.A., \& Salas, E. (2000). When member homogeneity is needed in work teams. Small Group Research, 31, 305-27.doi: 10.1177/104649640003100303 


\section{References}

Boyd, C.M., Bakker, A.B., Pignata, S., Winefield, A.H., Gillespie, N., \& Stough, C. (2011). A longitudinal test of the job demands-resources model among Australian university academics. Applied Psychology: An International Review, 60, 112-140.

Breevaart, K., Bakker, A.B., Demerouti, E., \& Hetland, J. (2012). The measurement of state work engagement: A multilevel factor analytic study. European Journal of Psychological Assessment, 28, 305-312.doi: 10.1027/1015-5759/a000111

Brief, A.P., \& Weiss, H. (2002). Organizational behavior: Affect in the workplace. Annual Review of Psychology, 53, 279-307.doi: 10.1146/annurev.psych.53.100901.135156

Brown, K.G., \& Kozlowski, S.W.J. (1999, April). Dispersion Theory: Moving beyond a dichotomous conceptualization of emergent organizational phenomena. Paper presented at the Fourteenth Annual Meeting of the Society of Industrial and Organizational Psychology, Atlanta, GA.

Browne, M. W., \& Cudeck, R. (1993). Alternative ways of assessing model fit. In K. A. Bollen \& J. S. Long (Eds.), Testing structural equation models (pp. 136-162). Newbury Park: Sage.

Buckingham, M., \& Coffman, C. (1999). First, break all the rules: What the world's greatest managers do differently. New York, NY: Simon \& Schuster.

Bunderson, J.S., \& Sutcliffe, K.M. (2002).Comparing alternatives conceptualizations of functional diversity in management teams: Process and performances effects. Academy of Management Journal, 45, 875-893.

Burke, N.J., Finkelstein, L.M., \& Dusig, M.S. (1999). On average deviation indices for estimating interrater agreement. Organizational Research Methods, 2, 4968.doi: $10.1177 / 109442819921004$

Byrne, D. (1971). The Attraction Paradigm. New York: Academic Press.

Campbell, L., \& Kashy, D.A. (2002). Estimating actor, partner, and interaction effects for dyadic data using PROC MIXED and HLM: A user-friendly guide. Personal Relationships, 9, 327-342.doi: 10.1111/1475-6811.00023 


\section{References}

Chamberlin, M., \& Green, H. (2010). Stress and coping strategies among firefighters and recruits. Journal of Loss and Trauma, 15, 548-560.doi: 10.1080/15325024.2010.519275

Chan, D. (1998). Functional relations among constructs in the same content domain at different levels of analysis: A typology of composition models. Journal of Applied Psychology, 83, 234-246.doi: 10.1037/0021-9010.83.2.234

Chattopadhyay, P., Tluchowska, M., \& George, E. (2004).Identifying the ingroup: A closer look at the influence of demographic dissimilarity on employee social identity. Academy of Management Review, 29, 180-202.

Chen, C.V., \& Indartono, S. (2011). Study of commitment antecedents: The dynamic point of view. Journal of Business Ethics, 103, 529-541.doi: 10.1007/s10551-011-0878-x

Chen, G., Mathieu, J. E., \& Bliese, P.D. (2004). A framework for conducting multilevel construct validation. In F. J. Yammarino \& F. Dansereau (Eds.), Research in multilevel issues: Multilevel issues in organizational behavior and processes (Vol. 3), pp. 273-303. Amsterdam: Elsevier.

Chen, G., Mathieu, J.E., \& Bliese, P.D. (2005). A framework for conducting multi-level construct validation. In K.J. Klein \& S.W.J. Kozlowski (Eds.), Multilevel theory, research, and methods in organizations: Foundations, extensions, and new directions (pp. 273-303). San Francisco, CA: Jossey-Bass.

Christian, M.S., Garza, A.S., \& Slaughter, J.E. (2011).Work engagement: A qualitative review and test of its relations with task and contextual performance. Personnel Psychology, 64, 89-136.

Cohen, S.G., \& Bailey, D.E. (1997). What makes teams work: Group effectiveness research from the shop floor to the executive suite.Journal of Management, 23, 239290.doi: $10.1177 / 014920639702300303$

Conway, N., \& Briner, R.B. (2012).Investigating the effect of collective organizational commitment on unit-level performance and absence. Journal of Occupational and Organizational Psychology, 85, 472-486.doi: 10.1111/j.2044-8325.2011.02051

Cooper, C.L., \& Cartwright, S. (1994). Healthy mind; Healthy organization - A proactive approach to occupational stress. Human Relations, 47, 455-471. 


\section{References}

Cornell, W., Beaton, R., Murphy, S., Johnson, C., \& Pike, K. (1999). Exposure to traumatic incidents and prevalence of posttraumatic stress symptomatology in urban firefighters in two countries. Journal of Occupational Health Psychology, 4, 131-141.doi: 10.1037/1076-8998.4.2.131

Costa, P., Passos, A.M., \& Bakker, A. (2014). Empirical validation of the team work engagement construct. Journal of Personnel Psychology, 13, 34-45.doi: 10.1027/1866-5888/a000102

Cramton, C.D., \& Orvis, K.L. (2003). Overcoming barriers to information sharing in virtual teams. In C.B. Gibson \& S.G. Cohen (Eds.), Virtual teams that work: Creating conditions for virtual team effectiveness (pp.214-230). San Francisco: Jossey-Bass.

Crawford, E.R., LePine, J.A., \& Rich, B.L. (2010). Linking job demands and resources to employee engagement and burnout: A theoretical extension and meta-analytic test. Journal of Applied Psychology, 95, 834-848.doi: 10.1037/a0019364

Cruz-Ortiz, V., Salanova, M., \& Martínez, I.M. (2013). Liderazgo transformacional y desempeño grupal: Unidos por el engagement grupal [Transformational leadership and team performance: Linked through team work engagement]. Revista de Psicología Social, 28, 183-196.

Cunningham, G., \& Chelladurai, P. (2004).Affective reactions to cross-functional teams: The impact of size, relative performance and common in-group identity. Group Dynamics: Theory, Research and Practice, 8, 83-97.doi:10.1037/1089-2699.8.2.83

Demerouti, E., \& Bakker, A.B. (2011). The Job Demands-Resources model: Challenges for future research. South African Journal of Industrial Psychology, 37, 1-9.doi: 10.4102/sajip.v37i2.974

Demerouti, E., \& Cropanzano, R. (2010). From thought to action: Employee work engagement and job performance. In A. Bakker \& M. Leiter (Eds.), Work engagement: Recent developments in theory and research (pp.147-163). New York: Psychology Press.

Demerouti, E., Bakker, A.B., Nachreiner, F., \& Schaufeli, W.B. (2001).The job demandsresources model of burnout. Journal of Applied Psychology, 86, 499-512.doi: $10.1108 / 02683940710733115$ 


\section{References}

Demerouti, E., Mostert, K., \& Bakker, A.B. (2010). Burnout and work engagement: A thorough investigation of the independency of both constructs. Journal of Occupational Health Psychology, 15, 209-222.

Edmondson, A. (2002). The local and variegated nature of learning in organizations: A grouplevel perspective. Organization Science, 13, 128-146.doi: 10.1287/orsc.13.2.128.530

ERCOVA European Project (2004). Retrieved January 12, 2010, from http://ec.europa.eu/employment_social/ECDB/equal/jsp/dpComplete_2070.htm.

Ertürk, A. (2007). Increasing organizational citizenship behaviors of Turkish academicians. Mediating role of trust in supervisor on the relationship between organizational justice and citizenship behaviors. Journal of Managerial Psychology, 22, 257-270.doi: $10.1108 / 02683940710733089$

Ertürk, A. (2007). Increasing organizational citizenship behaviors of Turkish academicians. Mediating role of trust in supervisor on the relationship between organizational justice and citizenship behaviors. Journal of Managerial Psychology, 22, 257-270.doi: $10.1108 / 02683940710733089$

Feldman, D.C. (1988). Managing careers in organization. Gleenview, IL: Scott, Foresman and Company.

Fiske, S.T., \& Neuberg, S.L. (1990). A continuum of impression formation, from category-based to individuating process: Influences of information and motivation of attention and interpretation. Advances in Experimental Social Psychology, 23, 1-74.

Fontinha, R., Chambel, M.J., \& De Cuyper, N. (2012). HR attributions and the dual commitment of outsourced IT workers. Personnel Review, 41, 832-848.doi: $10.1108 / 00483481211263773$

Fredrickson, B.L. (1998). What good are positive emotions? Review of General Psychology, 2, 300-319.

Fullerton, C.S., McCarroll, J.E., Ursano, R.J., \& Wright, K.M. (1992). Psychological responses of rescue workers: Fire fighters and trauma. American Journal of Orthopsychiatry, 61, 371378.doi: $10.1037 / \mathrm{h} 0079363$

Gailliot, M.T., Baumeister, R.F., DeWall, C.N., Maner, J.K., Plant, E.A., Tice, D.M.,... Schmeichel, B.J. (2007). Self-control relies on glucose as a limited energy source: 
Willpower is more than a metaphor. Journal of Personality and Social Psychology, 92, 325-336.doi: 10.1037/0022-3514.92.2.325

García, M., Llorens, S., Cifre, E., \& Salanova, M. (2006). Antecedentes afectivos de la autoeficacia docente: un modelo de relaciones estructurales [Affective antecedents of teacher self-efficacy: A structural equation model]. Revista de Educación, 339, 387-400.

Gardner, T.M., Wright, P.M., \& Moynihan, L.M. (2011). The impact of motivation, empowerment, and skill-enhancing practices on aggregate voluntary turnover: The mediating effect of collective affective commitment. Personnel Psychology, 64, 315-350.doi: 10.1111/j.1744-6570.2011.01212.x

Gavin, M.B., \& Hofmann, D.A. (2002). Using hierarchical linear modeling to investigate the moderating influence of leadership climate. Leadership Quarterly, 13, 15-33.doi: $10.1016 / \mathrm{S} 1048-9843(01) 00102-3$

Gavino, M., Wayne, S.J., \& Erdogan, B. (2012). Discretionary and transactional human resource practices and employee outcomes: The role of perceived organizational support. Human Resource Management, 51, 665-686.doi: 10.1002/hrm.21493

Genest, M., Levine, J., Ramsden, V., \& Swanson, R. (1990). The impact of providing help: Emergency workers and cardiopulmonary resuscitation attempts. Journal of Traumatic Stress, 3, 305-313.doi: 10.1007/BF00975153

George, J.M. (2011). Dual tuning: A minimum condition for understanding affect in organizations? Organizational Psychology Review, 1, 147-164.doi: $10.1177 / 2041386610390257$

Gilboa, S., Shirom, A., Fried, Y., \& Cooper, C. (2008). A meta-analysis of work demand stressors and job performance: Examining main and moderating effects. Personnel Psychology, 61, 227-271.doi: 10.1111/j.1744-6570.2008.00113.x

Glick, W.H. (1985). Conceptualizing and measuring organizational and psychological climate: Pitfalls in multilevel research. Academy of Management Review, 10, 601-616.doi: 10.5465/AMR. 1985.4279045

Gong, Y., Law, K., Chang, S., \& Xin, K.R. (2009). Human resources management and firm performance: The differential role of managerial affective and continuance commitment. Journal of Applied Psychology, 94, 263-275.doi: 10.1037/a0013116 


\section{References}

González-Morales, M.G., Peiró, J.M., Rodríguez, I., \& Bliese, P.D. (2012). Perceived collective burnout: A multilevel explanation of burnout. Anxiety Stress Coping, 25, 43-61.doi: 10.1080/10615806.2010.542808.

González-Morales, M.G., Peiró, J.M., Rodríguez, I., \& Bliese, P.D. (2011). Perceived collective burnout: A multilevel explanation of burnout. Anxiety, Stress \& Coping, 1-19.doi: $10.1080 / 10615806.2010 .542808$

González-Morales, M.G., Rodríguez I., \& Peiró, J.M. (2010). A longitudinal study of coping and gender in a female-dominated occupation: Predicting teachers' burnout. Journal of Occupational Health Psychology, 15, 29-44.doi: 10.1037/a0018232

González-Romá, V., Peiró, J.M., Subirats, M., \& Mañas, M.A. (2000). The validity of affective work team climates. In M. Vartiainen, F. Avallone, \& N. Anderson (Eds.), Innovative theories, tools and practices in work and organizational psychology (pp. 97-109). Göttingen, Germany: Hogrefe \& Huber.

González-Romá, V., Schaufeli, W.B., Bakker, A., \& Lloret, S. (2006). Burnout and engagement: Independent factors or opposite poles? Journal of Vocational Behavior, 68, 165-174.doi: 10.1016/j.jvb.2005.01.003

Goodman, S. A., \& Svyantek, D. (1999). Person-organization fit and contextual performance: Do shared values matter. Journal of Vocational Behavior, 55, 254-275.doi: 10.1006/jvbe.1998.1682

Gracia, E., Salanova, M., Grau, R., \& Cifre, E. (2012). How to enhance service quality through organizational facilitators, collective work engagement, and relational service competence. European Journal of Work and Organizational Psychology, 22, 4255.doi:10.1080/1359432X.2011.628793

Green, D.E., Walkey, F.H., \& Taylor, A.J.W. (1991). The three factor structure of the Maslach Burnout Inventory. Journal of Social Behavior and Personality, 6, 453-472.doi: 10.1016/j.ijnurstu.2009.03.004

Green, F. (2004). Why has work effort become more intense? Industrial Relations, 43, 709-741. Greenglass, E.R., Burke, R.J., \& Konarski, R. (1998). Components of burnout, resources and gender-related differences. Journal of Applied Social Psychology, 28, 1088-1106.doi: 10.1111/j.1559-1816.1998.tb01669.x 


\section{References}

Greenglass, E.R., Fiksenbaum, L., \& Burke, R.J. (1996). Components of social support, buffering effects and burnout: Implications for psychological functioning. Anxiety, Stress and Coping: An International Journal, 9, 185-197.doi: 10.1080/10615809608249401

Greenglass, E.R., Schwarzer, R., \& Taubert, S. (1999). The Proactive Coping Inventory (PCI): A multidimensional research instrument [Questionnaire]. Retrieved from: http://userpage.fuberlin.de/ health/greenpci.htm

Gruman, J.A., \& Saks, A.M. (2011). Performance management and employee engagement. Human Resource Management Review, 21, 123-136.doi. 10.1016/j.hrmr.2010.09.004

Hakanen, J., Bakker, A.B., \& Schaufeli, W.B. (2006). Burnout and work engagement among teachers. The Journal of School Psychology, 43, 495-513.doi: 10.1016/j.jsp.2005.11.001

Hakanen, J.J., Perhoniemi, R., \& Bakker, A.B. (in press). Crossover of exhaustion between dentists and dental nurses. Stress and Health.doi: 10.1002/smi.2498

Hakanen, J., Perhoniemi, R., \& Topinen-Tanner, S. (2008). Positive gain spirals at work: From job resources to work engagement, personal initiative and work-unit innovativeness. Journal of Vocational Behavior, 73, 78-91.doi: 10.1016/j.jvb.2008.01.003

Hakanen, J.J., \& Roodt, G. (2010). Using the job demands-resources model to predict engagement: Analysing a conceptual model. In A.B. Bakker \& M.P. Leiter (Eds.), Work engagement: A handbook of essential theory and research (pp. 85-101). New York, NY: Psychology Press.

Hakanen, J.J., Schaufeli, W.B., \& Ahola, K. (2008). The job demands-resources model: A three-year cross-lagged study of burnout, depression, commitment, and work engagement. Work and Stress, 22, 224-241.

Halbesleben, J.R.B. (2010). A meta-analysis of work engagement: Relationships with burnout, demands, resources, and consequences. In A.B. Bakker \& M.P. Leiter (Eds.), Work engagement: A handbook of essential theory and research (pp. 102-117). New York, NY: Psychology Press.

Halbesleben, J.R.B., \& Wheeler, A.R. (2008). The relative role of engagement and embeddedness in prediction job performance and turnover intention. Work and Stress, 22, 242-256. 


\section{References}

Hallberg, U., \& Schaufeli, W.B. (2006). "Same same" but different? Can work engagement be discriminated from job involvement and organizational commitment? European Psychologist, 11, 119-127.doi: 10.1027/1016-9040.11.2.119

Halpern, J., Gurevich, M., Schwartz, B., \& Brazeau, P. (2009). What makes an incident critical for ambulance workers? Emotional outcomes and implications for intervention. Work and Stress, 23, 173-189.doi: 10.1080/02678370903057317

Hammer, T. H., Saksvik, P. Ø., Nytro, K., Torvatn, H., \& Bayazit, M. (2004). Expanding the psychosocial work environment: Workplace norms and work-family conflict as correlates of stress and health. Journal of Occupational Health Psychology, 9, 83-97.doi: 10.1037/1076-8998.9.1.83

Hansez, I., \& Chmiel, N. (2010). Safety behavior: Job demands, job resources, and perceived management commitment to safety. Journal of Occupational Health Psychology, 15, 267-278.

Harrison, D.A., \& Klein, K.J. (2007). What's the difference? Diversity constructs as separation, variety, or disparity in organizations. Academy of Management Review, 32, 1199-1228.

Harrison, D.A., Price, K.H., \& Bell, M.P. (1998). Beyond relational demography: Time and the effect of surface- versus deep-level diversity on group cohesiveness. Academy of Management Journal, 41, 96-107.

Harter, J.K., Schmidt, F.L., \& Hayes, T.L. (2002). Business-unit-level relationship between employee satisfaction, employee engagement, and business outcomes: A metaanalysis. Journal of Applied Psychology, 87, 268-279.doi: 10.1037/0021-9010.87.2.268

Hatfield, E., Cacioppo, J., \& Rapson, R.L. (1994). Emotional contagion. New York: Cambridge University Press.

Hatfield, E., Rapson, R.L., \& Le, Y.L. (2009). Primitive emotional contagion: Recent research. In J. Decety, \& W. Ickes (Eds.), The social neuroscience of empathy (pp.19-30).Boston, MA: MIT Press.

Hauptman, O., \& Hirji, K.K. (1996). The influence of process concurrency on product outcomes in product development: An empirical study of crossfunctional teams. IEEE Transactions on Engineering Management, 43, 153-164. 


\section{References}

Henry, K.B., Arrow, H., \& Carini, B. (1999).A Tripartite Model of Group Identification: Theory and Measurement. Small Group Research,30, 558-581. doi:10.1177/104649649903000504

Hobfoll, S.E. (1989). Conservation of resources: A new attempt at conceptualizing stress. American Psychologist, 44, 513-524.

Hodson, R. (1997). Group relations at work: Solidarity, conflict, and relations with management. Work and Occupations, 24, 426-452.doi: 10.1177/0730888497024004003

Hofman, D.A., Griffin, M.A., \& Gavin, M.B. (2000). The application of hierarchical linear modeling to organizational research.In K.J. Klein \& S.W.J. Kozlowski (Eds.), Multilevel theory, research, and methods in organizations: Foundations, extensions, and new directions(pp. 467-511). San Francisco, CA: Jossey-Bass.

Hofmann, D.A., \& Gavin, M. (1998). Centering decisions in hierarchical linear models: Implications for research in organizations. Journal of Management, 24, 623641.doi: $10.1177 / 014920639802400504$

Hoffman, K.D., \& Kelley, S.W. (1994). The influence of service provider mood states on prosocial behaviors and service quality assessments. In C.W. Park, D.C. Smith (Eds.), AMA Winter Educator's Proceedings (pp.288-289). Chicago: American Marketing Association.

Hollenbeck, J.R., Beersma, B., \& Schouten, M.E. (2012). Beyond team types and taxonomies: A dimensional scaling conceptualization for team description. Academy of Management Review, 37, 82-106.doi: 10.1080/1359432X.2012.690399

Horwitz, S. K. \& Horwitz, I. B. (2007). The Effects of Team Diversity on Team Outcomes: A Meta-Analytic Review of Team Demography. Journal of Management, 33, 9871014.doi: $10.1177 / 0149206307308587$

Hox, J. (2002). Multilevel analyses: Techniques and applications. Mahwah, NJ: Erlbaum.

Hox, J.J. (2010). Multilevel analysis. Techniques and applications (2nd ed.). New York: Routledge.

Hu, L., \& Bentler, P. M. (1999). Cutoff criteria for fit indices in covariance structure analysis: Conventional criteria versus new alternatives. Structural Equation Modeling, 6, 1-55.

Hurrell, J.J. (1995). Police work, occupational stress and individual coping. Journal of Organisational Behaviour, 16, 27-28.doi: 10.1002/job.4030160105 


\section{References}

llies, R., Wagner, D.T., \& Morgeson, F.P. (2007). Explaining affective linkages in teams: individual differences in susceptibility to contagion and individualism-collectivism. Journal of Applied Psychology, 92, 1140-1148.doi: 10.1037/0021-9010.92.4.1140

James, L.R. (1982). Aggregation bias in estimates of perceptual agreement. Journal of Applied Psychology, 67, 219-229.doi: 10.1037/0021-9010.67.2.219

Jassawalla, A. R., \& Sashittal, H. C. (1999).Building collaborative cross-functional new product teams. Academy of Management Executive, 13, 50-63.

Jehn, K.A., \& Shah, P.P. (1997). Interpersonal relationships and task performance: An examination of mediation processes in friendship and acquaintance groups. Journal of Personality and Social Psychology, 72, 775-790.doi: 10.1037/0022-3514.72.4.775

Jex, S.M., Bliese, P.D., Buzzell, S., \& Primeau, J. (2001). The impact of self-efficacy on stressor-strain relations: coping style as an exploratory mechanism. Journal of Applied Psychology, 86, 401-409.doi: 10.1037/0021-9010.86.3.401

Johnson, R.W., Mermin, G.B.T., \& Resseger, M. (2011). Job demands and work ability at older ages. Journal of Aging and Social Policy, 23, 101-118.

Jolliffe, I.T. (2002). Principal component analysis. New York, NY: Springer-Verlag.

Jöreskog, K.G. \& Sörbom, D. (2006). LISREL 8.8 for Windows [Computer software]. Lincolnwood, IL: Scientific Software International, Inc.

Kahn, W.A. (1990). Psychological conditions of personal engagement and disengagement at work. The Academy of Management Journal, 33, 692-724.doi: 10.2307/256287

Kalimo, R., Lehtonen, A., Daleva, M., \& Kuorinka, I. (1980). Physiological and biochemical strain in firemen's work. Scandinavian Journal of Work, Environment and Health, 6, 179187.doi: $10.5271 /$ sjweh.2618

Karasek, R.A. (1985). Job Content Questionnaire and user's guide. Lowell: University of Massachusetts Lowell, Department of Work Environment.

Keller, R.T. (2001). Cross-functional project groups in research and new product development: Diversity, communications, job stress, and outcomes. Academy of Management Journal, 44, 547-555.doi:10.2307/3069369 


\section{References}

Kenny, D.A., \& Cook, W. (1999). Partner effects in relationship research: Conceptual issues, analytic difficulties, and illustrations. Personal Relationships, 6, 433-448.doi: 10.1111/j.1475-6811.1999.tb00202.x

Kooij, D.T.A.M., de Lange, A.H., Jansen, P.G.W., Kanfer, R., \& Dikkers, J.S.E. (2011). Age and work-related motives: Results of a meta-analysis. Journal of Organizational Behavior, 32, 197-225.doi:10.1002/job.665

Kozlowski, S.W.J., \& Bell, B.S. (2003). Work groups and teams in organizations. In W.C. Borman, D.R. Ilgen, \& R.J. Klimoski (Eds.), Handbook of psychology: Vol. 12. Industrial and organizational psychology (pp.333-375). London: Wiley.

Kozlowski, S.W.J., \& llgen, D.R. (2006). Enhancing the effectiveness of work groups and teams. Psychological Science in the Public Interest, 7, 77-124.doi: 10.1111/j.15291006.2006.00030.x

Kozlowski, S.W.J, \& Klein, K.J. (2000). A multilevel approach to theory and research in organizations: Contextual, temporal, and emergent processes. In K. J. Klein \& S. W. J. Kozlowski (Eds.), Multilevel theory, research, and methods in organizations: Foundations, extensions, and new directions (pp. 3-90). San Francisco, CA: Jossey-Bass.

Lau, D.C., \& Murnighan, J.K. (1998). Demographic diversity and faultlines: The compositional dynamics of organizational groups. Academy of Management Review, 23, 325-340.

Lazarus, R.S., \& Folkman, S. (1984). Stress appraisal and coping. New York, NY: Springer.

Le Blanc, P.M., \& González-Romá, V. (2012). A team level investigation of the relationship between Leader-Member Exchange (LMX) differentiation, and commitment and performance. The Leadership Quarterly, 23, 534-544.doi: 10.1016/j.leaqua.2011.12.006

LeBreton, J.M., \& Senter, J.L. (2007). Answers to 20 questions about interrater reliability and interrater agreement. Organizational Research Methods, 11, 815-852.doi: $10.1177 / 1094428106296642$

Lewin, J.E., \& Sager, J.K. (2009). An investigation of the influence of coping resources in salespersons' emotional exhaustion. Industrial Marketing Management, 38, 798-805.doi: 10.1016/j.indmarman.2008.02.013 


\section{References}

Li, J., \& Roe, R.A. (2012). Introducing an intrateam longitudinal approach to the study of team process dynamics. European Journal of Work and Organizational Psychology, 21, 718748.doi: 10.1080/1359432X.2012.660749

Lin, C.P. (2010). Modeling corporate citizenship, organizational trust, and work engagement based on attachment theory. Journal of Business Ethics, 94, 517-531.doi: $10.1007 / \mathrm{s} 10551-009-0279-6$

Lincoln, J.R., \& Miller, J. (1979).Work and friendship ties in organizations: A comparative analysis of relation networks. Administrative Science Quarterly, 24, 181-199.

Llorens, S., Bakker, A.B., Schaufeli, W.B., \& Salanova, M. (2006). Testing the robustness of the Job Demands-Resources model. International Journal of Stress Management, 13, 378391.

Llorens, S., Bakker, A.B., Schaufeli, W.B., \& Salanova, M. (2006). Testing the robustness of the job demands-resources model. International Journal of Stress Management, 13, 378391.

Llorens, S., Salanova, M., Torrente, P., \& Acosta, H. (2013). Interventions to Promote Healthy \& Resilient Organizations (HERO) from Positive Psychology. In G.F. Bauer and G.J. Jenny (Eds.), Concepts of salutogenic organizations and change: The logics behind organizational health intervention research (pp.91-106). London: Springer.

Llorens, S., Schaufeli, W.B., Bakker, A.B., \& Salanova, M. (2007). Does a positive gain spiral of resources, efficacy beliefs and engagement exist? Computers in Human Behavior, 23, 825-841.

Long, B.C., \& Gessaroli, M.C. (1989). The relationship between teacher stress and perceived coping effective- ness: Gender and marital differences. The Alberta Journal of Educational Research, 35, 308-324.

Lopes, S., \& Chambel, M.J. (2012). Reciprocity of temporary and permanent workers: an exploratory study in an industrial company. The Spanish journal of psychology, 15, 11631176.doi: 10.5209/rev_SJOP.2012.v15.n3.39405

Lorente, L., Salanova, M., Martínez, I., \& Schaufeli, W.B. (2008). Extension of the Job Demands-Resources model in the prediction of burnout and engagement among teachers over time. Psicothema, 20, 354-360. 
Lounamaa, P.H., \& March, J.G. (1987). Adaptive coordination of a learning team Management Science, 33, 107-123.doi: 10.1287/mnsc.33.1.107

Lu, L. (1997). Social support, reciprocity, and well-being. The Journal of Social Psychology, 137, 618-628.doi: 10.1080/00224549709595483

Lusa, S., Häkkänen, M., Luukkonen, R., \& Viikari-Juntura, E. (2002). Perceived physical work capacity, stress, sleep disturbance and occupational accidents among firefighters working during a strike. Work \& Stress, 16, 264-274.doi: 10.1080/02678370210163301

Macey, W.H., \& Schneider, B. (2008). The meaning of employee engagement. Industrial and Organizational Psychology, 1, 3-30.doi: 10.1111/j.1754-9434.2007.0002.x

MacLeod, D., \& Clarke, M. (2009). Engaging for success: enhancing performance through employee engagement. London: Office of Public Sector Information.

Mark, B., Hughes, L., Belyra, M., Chang, Y., Hofmann, D., Jones, C., \& Cacon, C. (2007). Does safety climate moderate the influence of staffing adequacy and work conditions on nurse injuries? Journal of Safety Research, 38, 431-446.

Marks, M.A., Mathieu, J.E., \& Zaccaro, S.J. (2001). A temporally based Framework and taxonomy of team processes. Academy Management Review, 26, 356-376.doi: $10.2307 / 259182$

Martínez-Tur, V., Ramos, J., Peiró, J.M., \& Buades, E. (2001).Relationships among perceived justice, customers' satisfaction, and behavioral intentions: The moderating role of gender. Psychological Reports, 88, 805-811.doi: 10.2466/pr0.2001.88.3.805

Martinussen, M., Richardsen, A.M., \& Burke, R.J. (2007). Job demands, job resources and burnout among police officers. Journal of Criminal Justice, 35, 239-249.doi: 10.1016/j.jcrimjus.2007.03.001

Maslach, C. (1976). Burned-out. Human Behavior, 5, 16-22.

Maslach, C., Schaufeli, W.B., \& Leiter, M.P. (2001). Job Burnout. Annual Review of Psychology, 52, 397-422.doi: 10.1146/annurev.psych.52.1.397

Mathieu, J.E., Gilson, L.L., \& Ruddy, T.R. (2006). Empowerment and team effectiveness: An empirical test of an integrated model. Journal of Applied Psychology, 91, 97108.doi: 10.1037/0021-9010.91.1.97 


\section{References}

Mathieu, J.E., \& Zajac, D.M. (1990).A review and meta-analysis of the antecedents, correlates, and consequences of organizational commitment. Psychological Bulletin, 108, 171194.doi: 10.1037/0033-2909.108.2.171

McLeod, J., \& Cooper, D. (1992). A Study of Stress and Support in the Staffordshire Fire and Rescue Service. Keele: Keele University Centre.

Mehra, A., Kilduff, M., \& Brass, D.J. (1998). At the margins: A distinctiveness approach to the social identity and social networks of underrepresented groups. Academy of Management Journal, 41, 441-452.doi:10.2307/257083

Meyer, J.P., Becker, T.E., \& Vandenberghe, C. (2004). Employee commitment and motivation: A conceptual analysis and integrative model. Journal of Applied Psychology, 89, 9911007.doi: $10.1037 / 0021-9010.89 .6 .991$

Meyer, J.P., Gagné, M., \& Parfyonova, N.M. (2010). Toward an evidence-based model of engagement: What we can learn from motivation and commitment research. In S. L. Albrecht (Ed.), Handbook of Employee Engagement: Perspectives, Issues, Research and Practice (pp.62-73).Cheltenham: Edward Elgar.

Meyer, J.P., Paunonen, S.V., Gellatly, I.R., Goffin, R.D., \& Jackson, D.N. (1989). Organizational commitment and job performance. It's the nature of the commitment that counts. Journal of Applied Psychology, 74, 152-156.doi: 10.1037/0021-9010.74.1.152

Meyer, J.P., Stanley, D.J., Herscovitch, L., \& Topolnytsky, L. (2002). Affective, continuance, and normative commitment to the organization: A meta-analysis of antecedents, correlates, and consequences. Journal of Vocational Behavior, 61, 20-52.doi: 10.1006/jvbe.2001.1842

Mone, E.M., \& London, M. (2009). Employee engagement through effective performance management: A manager's guide. NewYork: Routledge.

Morgeson, F.P., \& Hofmann, D.A. (1999). The structure and function of collective constructs: Implications for multilevel research and theory development. Academy of Management Review, 24, 249-265.doi: 10.5465/AMR.1999.1893935

Muchinsky, P. (2007). Psychology applied to work. Madrid: Thomson.

Murphy, K.R., \& Myors, B. (1998). Statistical power analysis: A simple and general model for traditional and modern hypothesis tests. Mahwah, NJ: Lawrence Erlbaum. 


\section{References}

Nahrgang, J.D., Morgeson, F.P., \& Hofmann, D.A. (2011). Safety at work: A Meta-analytic investigation of the link between job demands, job resources, burnout, engagement, and safety outcomes. Journal of Applied Psychology, 96, 71-94.

Netemeyer, R.G., Heilman, C.M., \& Maxham, J.G. (2012). Identification with the retail organization and customer-perceived employee similarity: Effects on customer spending. Journal of Applied Psychology, 97, 1049-1058.doi: 10.1037/a0028792

Nielsen, K., Randall, R., Yarker, J., \&Brenner, S.O. (2008). The effects of transformational leadership on followers' perceived work characteristics and psychological well-being: A longitudinal study. Work \& Stress, 22, 16-32.doi:10.1080/02678370801979430

Nunnally, J. C., \& Bernstein, I. H. (1994). Psychometric theory (3rd ed.). New York: McGrawHill.

Oerlemans, W.G.M., \& Bakker, A.B. (2013). Capturing the moment in the workplace: Two methods to study momentary subjective well-being. In A.B. Bakker (Ed.), Advances in Positive Organizational Psychology (Vol. 1; pp. 329-346). Bingley, UK: Emerald.

Oliver, R.L. (1997). Satisfaction: A behavioral perspective on the consumer. New York: McGraw-Hill.

Osterman, P. (1995). Work/family programs and the employment relationship. Administrative Science Quarterly, 40, 681-700.

Ostroff , C., \& Kozlowski, S.W.J. (1992). Organizational socialization as a learning process: The role of information acquisition. Personnel Psychology, 45, 849-874.doi:10.1111/j.17446570.1992.tb00971.x

Ostroff, C. (1993). Rater perceptions, satisfaction and performance ratings. Journal of Occupational and Organizational Psychology, 66, 345-356.doi: 10.1111/j.20448325.1993.tb00544.x

Ostroff, C., \& Bowen, D.E. (2000). Moving HR to a higher level: Human resource practices and organizational effectiveness. In K.J. Klein \& S.W.J. Kozlowski (Eds.), Multilevel theory, research, and methods in organizations: Foundations, extensions, and new directions (pp.211-266). San Francisco: Jossey-Bass.

Pelled, L.H. (1996). Relational demography and perceptions of group conflict and performance: A field investigation. International Journal of Conflict Management, 7, 230-246. 


\section{References}

Podsakoff, P.M., MacKenzie, S.B., Lee, J.Y.,\& Podsakoff, N.P. (2003). Common method biases in behavioral research: A critical review of the literature and recommended remedies. Journal of Applied Psychology, 88, 879-903.

Porter, C.O.L.H. (2005). Goal orientation: Effects on backing up behavior, performance, efficacy, and commitment in teams. Journal of Applied Psychology, 90, 811818.doi: 10.1037/0021-9010.90.4.811

Posthuma, R.A., \& Campion, M.A. (2009). Age stereotypes in the workplace: Common stereotypes, moderators, and future research directions. Journal of Management, 35, 158-188.doi:10.1177/0149206308318617

Prati, G., Pietrantoni, L., \& Cicognani, E. (2010). Self-efficacy moderates the relationship between stress appraisal and quality of life among rescue workers. Anxiety, Stress, and Coping, 23, 463-470.doi: 10.1080/10615800903431699

Prins, J., van der Heijden, F., Weebers, J., Bakker, A.B., van de Wiel, H., Jacobs, B., \& Gazendam-Donofrio, S. (2009). Burnout, engagement and resident physicians selfreported errors. Psychology, Health and Medicine, 14, 654-666.

Raphael, B., \& Meldrum, L. (1993). The evolution of mental health responses and research in Australian disasters. Journal of Traumatic Stress, 6, 65-89.doi: 10.1002/jts.2490060107

Regehr, C., \& Bober, T. (2005). In the line of fire: Trauma in the emergency services. New York, NY: Oxford University Press.

Reijseger, G., Schaufeli, W.B., Peeters, M.C.W., \& Taris, T.W. (2012). Ready, set, go! A model of the relation between work engagement and performance. In S.P. Gonçalves \& J.G. Neves (Eds.), Occupational Health Psychology: From burnout to well-being (pp. 289306). Scientific \& Academic Publishing: USA.

Richardson, J., \& West, M. A. (2010). Engaged work teams. In S. L. Albrecht (Ed.), Handbook of employee engagement. Perspectives, issues, research and practice. (pp. 323-340). Cheltenham, UK: Edward Elgar.

Riketta, M. (2002). Attitudinal organizational commitment and job performance: A meta analysis. Journal of Organizational Behavior, 23, 257-266.doi: 10.1002/job.141 
Rousseau, D.M. (1985). Issues of level in organizational research: multi-level and cross-level perspectives. In L.L. Cummings \& B.M. Staw (Eds.), Research in organizational behavior (pp.1-37). Greenwich, CT: JAI Press.

Rousseau, D.M. (1995). Psychological contracts in organizations: Understanding written and unwritten agreements. Thousand Oaks, CA: Sage.

Salanova, M. (2008). Organizaciones saludables y desarrollo de recursos humanos [Healthy organizations and human resources development]. Estudios Financieros, 303, 179-214.

Salanova, M. (2009). Organizaciones saludables, organizaciones resilientes [Healthy organizations, resilient organizations]. Gestión Práctica de Riesgos Laborales, 58, 18-23.

Salanova, M., Agut, S., \& Peiró, J.M. (2005). Linking organizational resources and work engagement to employee performance and customer loyalty: The mediation of service climate. Journal of Applied Psychology, 90, 1217-1227. doi:10.1037/00219010.90.6.1217

Salanova, M., \& Llorens, S. (2009). Exposure to information and communication technology and its relationship to work engagement. Revista de Trabajo y Ciencia, 32, 55-62.

Salanova, M., Llorens, S., Acosta, H., \& Torrente, P. (2013). Positive interventions in positive organizations. Terapia psicológica, 31, 101-113.doi: 10.4067/S071848082013000100010

Salanova, M., Llorens, S., Cifre, E., \& Martínez, I.M. (2012). We need a HERO! Towards a validation of the Healthy \& Resilient Organization (HERO) Model. Group \& Organization Management, 37, 785-822.doi: 10.1177/1059601112470405

Salanova, M., Llorens, S., Cifre, E., Martínez, I.M., \& Schaufeli, W.B. (2003). Perceived collective efficacy, subjective well-being and task performance among electronic work groups. Small Group Research, 34, 43-73.doi: 10.1177/1046496402239577

Salanova, M., Llorens, S., \& Schaufeli, W.B. (2011). Yes, I can, I feel good, and I just do it! On gain cycles and spirals of efficacy beliefs, affect, and engagement. Applied Psychology: An International Review, 60, 255-285.

Salanova, M., \& Schaufeli, W.B. (2008). A cross-national study of work engagement as a mediator between job resources and proactive behaviour. The International Journal of Human Resource Management, 19, 116-131. 


\section{References}

Salanova, M., \& Schaufeli, W.B. (2009). El engagement en el trabajo. Cuando el trabajo se convierte en pasión [Work engagement. When work turns into passion]. Madrid: Alianza.

Salanova, M., Schaufeli, W.B., Llorens, S., Peiró, J.M., \& Grau, R. (2000). Desde el 'burnout' al 'engagement': ¿Una nueva perspectiva? [From 'burnout' to'engagement': A new perspective?] Revista de Psicología del Trabajo y las Organizaciones, 16, 117-134.

Salanova, M., Schaufeli, W.B., Martinez, I., \& Bresó, E. (2009). How obstacles and facilitators predict academic performance: The mediating role of study burnout and engagement. Anxiety, Stress, \& Coping, 26, 1-18.

Salas, E., Stagl, K.C., \& Burke, C.S. (2004). 25 years of team effectiveness in organizations: Research themes and emerging needs. International Review of Industrial and Organizational Psychology, 19, 47-91.doi: 10.1002/0470013311.ch2

Sanz-Vergel, A.I., Rodriguez-Muñoz, A., Bakker, A.B., \& Demerouti, E. (2012). The daily spillover and crossover of emotional labor: Faking emotions at work and at home. Journal of Vocational Behavior, 81, 209-217.

Schaufeli, W.B. (2001). Coping with job stress. In N.J. Smelser \& P.B. Baltes (Eds.), The international encyclopedia of the social and behavioral sciences, 12 (pp. 7983-7987). Oxford, UK: Elsevier.

Schaufeli, W.B. (2012a). Work engagement: What do we know and where do we go? Romanian Journal of Applied Psychology, 14, 3-10.doi: 10.1037/0021-9010.90.6.1217

Schaufeli, W.B. (2012b). The measurement of work engagement. In R.R. Sinclair, M. Wang, \& L.E. Tetrick (Eds.), Research methods in occupational health psychology: Measurement, design, and data analysis (pp. 138-153). New York: Routledge.

Schaufeli, W.B. (2013). What is engagement? In C. Truss, K. Alfes, R. Delbridge, A. Shantz, \& E. Soane (Eds.), Employee Engagement in Theory and Practice (pp. 15-35). London: Routledge.

Schaufeli, W.B. (in press). Employee engagement. In Cooper, C.L. (Ed.), Wiley Encyclopedia of Management ( $3^{\text {rded.). }}$. Chichester, UK: Wiley. 


\section{References}

Schaufeli, W.B., \& Bakker, A.B. (2003). UWES-Utrecht Work Engagement Scale: Test manual (Unpublished manuscript). Department of Psychology, Utrecht University, Utrecht, The Netherlands.

Schaufeli, W.B., \& Bakker, A.B. (2004). Job demands, job resources, and their relationship with burnout and engagement: A multi-sample study. Journal of Organizational Behavior, 25, 293-315.doi: 10.1023/A:1015630930326

Schaufeli, W.B., \& Bakker, A.B. (2004). Job demands, job resources, and their relationship with burnout and engagement: A multi-sample study. Journal of Organizational Behavior, 25, 293-315.

Schaufeli, W.B., \& Bakker, A.B. (2010). Defining and measuring work engagement: Bringing clarity to the concept. In A. B. Bakker, \& M. P. Leiter (Eds.), Work engagement: $A$ handbook of essential theory and research (pp. 10-25). New York: Psychology Press.

Schaufeli, W.B., Bakker, A.B., \& Salanova, M. (2006). The measurement of work engagement with a short questionnaire: A cross-national study. Educational and Psychological Measurement, 66, 701-716.doi:10.1177/0013164405282471

Schaufeli, W.B., Bakker, A.B., \& van Rhenen, W. (2009). How changes in job demands and resources predict burnout, work engagement, and sickness absenteeism. Journal of Organizational Behavior, 30, 893-917.doi: 10.1002/job.595

Schaufeli, W.B., Leiter, M.P., \& Maslach, C. (2009). Burnout: Thirty-five years of research and practice. Career Development International, 14, 204-220.

Schaufeli, W.B., Leiter, M.P., Maslach, C., \& Jackson, S.E. (1996). Maslach Burnout InventoryGeneral Survey (MBI-GS). In C. Maslach, S.E. Jackson, \& M.P. Leiter (Eds.), MBI Manual (3rd ed.). Palo Alto, CA: Consulting Psychologists Press.

Schaufeli, W.B., \& Salanova, M. (2008). Enhancing work engagement through the management of human resources. In K. Naswall, J. Hellgren, \& M. Sverke (Eds.), The individual in the changing working life (pp. 380-404). Cambridge, UK: Cambridge University Press.

Schaufeli, W.B., \& Salanova, M. (2010). How to improve work engagement? In S. Albrecht (Ed.), The handbook of employee engagement: Perspectives, issues, research and practice (pp.399-415). Northampton, MA: Edwin Elgar. 


\section{References}

Schaufeli, W.B., \& Salanova, M. (2011). Work engagement: On how to better catch a slippery concept. European Journal of Work and Organizational Psychology, 20, 3946.doi:10.1080/1359432X.2010.515981

Schaufeli, W.B., Salanova, M., González-Romá, V., \& Bakker, A.B. (2002).The measurement of engagement and burnout: A two sample confirmatory factor analytic approach. Journal of Happiness Studies, 3, 71-92.doi: 10.1023/A:1015630930326

Schaufeli, W.B., Shimazu, A., \& Taris, T.W. (2009). Driven to work excessively hard: The evaluation of a two-factor measure of workaholism in the Netherlands and Japan. Cross-Cultural Research, 43, 320-348.

Schaufeli, W.B., \& Taris, T.W. (2014). A critical review of the Job Demands-Resources Model: Implications for improving work and health. In G. Bauer \& O. Hämmig (Eds), Bridging occupational, organizational and public health (pp. 43-68). Dordrecht: Springer.

Schaufeli, W.B., Taris, T.W., \& Bakker, A. (2006). Dr. Jekyll and Mr. Hide: On the differences between work engagement and workaholism. In R. J. Burke (Ed.), Research companion to working time and work addiction (pp. 193-217). Northhampton, UK: Edward Elgar.

Schaufeli, W.B., Taris, T.W., \& van Rhenen, W. (2008). Workaholism, burnout, and work engagement: Three of a kind or three different kinds of employee well-being? Applied Psychology: An International Review, 57, 173-203.doi: 10.1111/j.14640597.2007.00285.x

Schmidt, K.H., \& Diestel, S. (2012). The relation of self-control demands to job strain: The moderating role of organisational commitment. Applied Psychology: An International Review, 61, 479-497.doi: 10.1111/j.1464-0597.2011.00479.x

Schneider, B., Macey, W.H., Barbera, K.M., \& Young, S.A. (2010). The role of employee trust in understanding employee engagement. In S. L. Albrecht (Ed.), Handbook of Employee Engagement. Perspectives, Issues, Research and Practice(pp.159-173). Cheltenham: Edward Elgar Publishing.

Schneider, B., Salvaggio, A.N., \& Subirats, M. (2002). Climate strength: A new direction for climate research. Journal of Applied Psychology, 87, 220-229. doi:10.1037/00219010.87 .2 .220 
Schwarzer, R. (2000). Manage stress at work through preventive and proactive coping. In E.A. Locke (Ed.), The Blackwell handbook of principles of organizational behavior (pp. 342355). Oxford, England: Blackwell.

Schwarzer, R. (2001). Stress, resources, and proactive coping. Applied Psychology: An International Review, 50, 400-407.

Semmer, N., Zapf, D., \& Greif, S. (1996). Shared job strain: A new approach for assessing the validity of job stress measurements. Journal of Occupational and Organizational Psychology, 69, 293-310.

Seppälä, P., Mauno, S., Feldt, T., Hakanen, J., Kinnunen, U., Tolvanen, A., et al. (2009). The construct validity of the Utrecht Work Engagement Scale: Multisample and longitudinal evidence. Journal of Happiness Studies, 10, 459-481.

Shimazu, A., Kubota, K., Bakker, A.B., Demerouti, E., Shimada, K., \& Kawakami, N. (2013). Work-to-family conflict and family-to-work conflict among Japanese dual-earner couples with preschool children: A spillover-crossover perspective. Journal of Occupational Health, 55, 234-243.

Shimazu, A., Miyanaka, D., \& Schaufeli, W.B. (2010). Work engagement from a cultural perspective. In S. Albrecht (Ed.). The handbook of employee engagement: Perspectives, issues, research and practice (pp. 364-372). Northampton, MA: Edwin Elgar.

Shirom, A., Toker, S., Berliner, S., Shapira, I., \& Melamed, S. (2008). The effects of physical fitness and feeling vigorous on self-rated health. Health Psychology, 27, 567-575.doi: 10.1037/0278-6133.27.5.567

Shuck, B. (2011). Four emerging perspectives of employee engagement: An integrative literature review. Human Resource Development Review, 10, 304-328.

Simpson, E.H. (1949). Measurement of diversity. Nature, 163, 688.doi:10.1038/163688a0

Simpson, M. R. (2009). Engagement at work: A review of the literature. International Journal of Nursing Studies, 46, 1012-1024.

Snijders, T., \& Bosker, R. (1999). Multilevel analysis: An introduction to basic and advanced multilevel modeling. London: Sage. 


\section{References}

Sobel, M.E. (1982). Asymptotic confidence intervals for indirect effects in structural equation models. In S. Leinhardt (Ed.), Sociological methodology (pp.290-312). Washington, DC: American Sociological Association.

Sobel, M.E. (1988). Direct and indirect effects in linear structural equation models. In J. S.Long (Ed.), Common problems/proper solutions (pp. 46-64). Beverly Hills, CA: Sage.

Sohl, S.J., \& Moyer, A. (2009). Refining the conceptualization of a future-oriented selfregulatory behavior: Proactive coping. Personality and Individual Differences, 47, 139144.doi: 10.1016/j.paid.2009.02.013

Solinger, O.N., van Olffen, W., \& Roe, R.A. (2008). Beyond the three-component model of organizational commitment. Journal of Applied Psychology, 93, 7083.doi: $10.1037 / 0021-9010.93 .1 .70$

Sonnentag, S., \& Jelden, S. (2009). Job stressors and the pursuit of sport activities: A day-level perspective. Journal of Occupational Health Psychology, 14, 165-181.doi: 10.1037/a0014953

Sonnentag, S., Mojza, E.J., Demerouti, E., \& Bakker, A.B. (2012). Reciprocal relations between recovery and work engagement: The moderating role of job stressors. Journal of Applied Psychology, 97, 842-853.doi: 10.1037/a0028292

Sulea, C., Virga, D., Maricutoiu, L.P., Schaufeli, W.B., Zaborila, C., \& Sava, F.A. (2012). Work engagement as mediator between job characteristics and positive and negative extrarole behaviors. Career Development International, 17, 188-207.

Sutton, R.I. (1991). Maintaining norms about expressed emotions: The case of bill collectors. Administrative Science Quarterly, 36, 245-268.

Swan, J.E., \& Oliver, R.L. (1989). Post purchase communications by consumers. Journal of Retailing, 65, 516-533.

Sy, T., Côté, S., \& Saavedra, R. (2005). The contagious leader: Impact of the leader's mood on the mood of group members, group affective tone, and group processes. Journal of Applied Psychology, 90, 295-305.doi: 10.1037/0021-9010.90.2.295

Tajfel, H., \& Turner, J.C. (1986). The social identity theory of intergroup behavior. In S. Worchel \& L.W. Austin (Eds.), Thepsychology of intergroup relations (pp.7-24). Chicago: NelsonHall. 


\section{References}

Taris, T.W., Le Blanc, P., Schaufeli, W.B. \& Schreurs, P.J.G. (2005). Are there relationships between the dimensions of the Maslach Burnout Inventory? A review and two longitudinal tests. Work \& Stress, 19, 256-262.doi: 10.1080/02678370500270453

Taylor, S.G., Bedeian, A.G., \& Kluemper, D.H. (2012). Linking workplace incivility to citizenship performance: The combined effects of affective commitment and conscientiousness. Journal of Organizational Behavior, 33, 878-893.doi: 10.1002/job.773

Tims, M., Bakker, A.B., \& Xanthopoulou, D. (2011). Do transformational leaders enhance their followers' daily work engagement? The Leadership Quarterly, 22, 121-131.doi: 10.1016/j.leaqua.2010.12.011

Torrente, P., Salanova, M., \& Llorens, S. (2014). Spreading engagement: On the role of similarity in the positive contagion of team work engagement. Journal of Work and Organizational Psychology, 29, 153-159.

Torrente, P., Salanova, M., Llorens, S., \& Schaufeli, W.B. (2012). Teams make it work: How team work engagement mediates between social resources and performance in teams. Psicothema, 24, 106-112.

Torrente, P., Salanova, M., Llorens, S., \& Schaufeli, W.B. (2013). From I to We: The factorial validity of a Team Work Engagement Scale. In J. Neves \& S. P. Gonçalves (Eds.), Occupational Health Psychology: From burnout to well-being (pp.333-355). Rosemead, CA: Scientific \& Academic Publishing.

Totterdell, P. (2000). Catching moods and hitting runs: Mood linkage and subjective performance in professional sports teams. Journal of Applied Psychology, 83, 848859.doi: 10.1037/0021-9010.85.6.848

Totterdell, P., Kellett, S., Teuchmann, K., \& Briner, R.B. (1998). Evidence of mood linkage in groups. Journal of Personality and Social Psychology, 74, 15041515.doi:10.1037/0021-9010.85.6.848

Treviño, L.K., \& Brown, M.E. (2004).Managing to be ethical: Debunking five business ethics myths. The Academy of Management Executive, 18, 69-83.

Tsui, A.S., \& O’Reilly, C.A. (1989). Beyond simple demographic effects: The importance of relational demography in superior-subordinate dyads. Academy of Management Journal, 32, 402-423.doi:10.2307/256368 


\section{References}

Tsui, A.S., \&Gutek, B.A. (1999). Demographic differences in organizations: Current research and future directions. Lanham, MD: Lexington Books.

Turner, J.C. (1987). Rediscovering the social group: A self-categorization theory. Oxford, England: Blackwell Publishing.

Van Beek, I., Taris. T., \& Schaufeli, W.B. (2011). Workaholic and work engaged employees: Dead ringers or worlds apart? Journal of Occupational Health Psychology, 16, 468-482.

Van Den Broeck, A., Vansteenkiste, M., De Witte H., \& Lens, W. (2008). Explaining the relationships between job characteristics, burnout and engagement: The role of basic psychological need satisfaction. Work \& Stress, 22, 277-294.doi: $10.1080 / 02678370802393672$

Van Gelderen, B.R., Konijn, E.A., \& Bakker, A.B. (2011). Emotional labor among trainee police officers: The interpersonal role of positive emotions. The Journal of Positive Psychology, $6,163-172$.

Vandenberghe, C., Bentein, K., \& Stinglhamber, F. (2004). Affective commitment to the organization, supervisor, and work group: Antecedents and outcomes. Journal of Vocational Behaviour, 64, 47-71.doi: 10.1016/S0001-8791(03)00029-0

Viswesvaran, C., Sánchez, J.I., \& Fisher, J. (1999). The role of social support in the process of work stress: A meta-analysis. Journal of Vocational Behavior, 54, 314-334.

Wall Street Journal (2007, August 12). Wall Street looks for Fed rescue in the growing credit storm. Eastern Online Edition.

Whitman, D. S., Van Rooy, D. L., \& Viswesvaran, C. (2010). Satisfaction, citizenship behaviors, and performance in work units: a meta-analysis of collective construct relations. Personnel Psychology, 63, 41-81.

Wilson, M., Dejoy, D., Vandenberg, R., Richardson, H., \& McGrath, A. (2004). Work characteristics and employee health and well-being: Test of a model of healthy work organization. Journal of Occupational and Organizational Psychology, 77, 565-588.doi: $10.1348 / 0963179042596522$

Wright, P.M., \& McMahan, C.G. (1992). Theoretical perspectives for strategic human resource management. Journal of Management, 18, 295-320.doi: 10.1177/014920639201800205 
References

Xanthopoulou, D., Bakker, A.B., Demerouti, E., \& Schaufeli, W.B. (2009). Work engagement and financial returns: A diary study on the role of job and personal resources. Journal of $\begin{array}{llll}\text { Occupational and Organizational Psychology, } & \text { 82, }\end{array}$ 200.doi: 10.1348/096317908X285633

Yip, B., Rowlinson, S., \& Siu, O.L. (2009). Coping strategies as moderators in the relationship between role overload and burnout. Construction Management and Economics, 26, 871882.doi: $10.1080 / 01446190802213529$

Zhang, Z., Zyphur, M.J., \& Preacher, K.J. (2009). Testing multilevel mediation using hierarchical linear models: Problems and solutions. Organizational Research Methods, 12, 695719.doi: $10.1177 / 1094428108327450$

Ziliak, S.T., \& McCloskey, D.N. (2008). The cult of statistical significance: How the standard error costs us jobs, justice, and lives. Ann Harbor, MI: University of Michigan Press. 



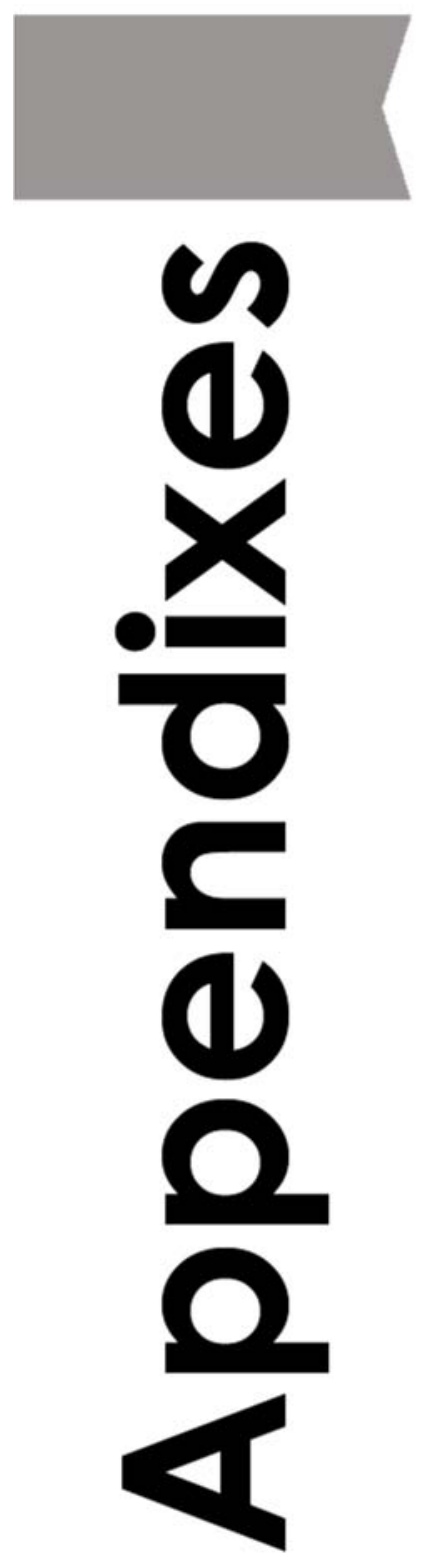




\section{Appendixes}

\section{Appendixes}

Appendix 1.Collective work engagement scale, as included in the HERO questionnaire

Vigor

1. During the task, my team feels full of energy*

2. My team can continue working for very long periods of time

3. My team keeps on working, even when things do not go well

4. Hard work is not much of an effort for my team

5. My team feels very persistent during the task ${ }^{*}$

6. My team feels strong and vigorous during the task*

7. When the task is finished, my team has quite some energy left for other activities

\section{Dedication}

8. My team is involved in the task

9. My team is enthusiastic about the job*

10. My team enjoys doing the task ${ }^{*}$

11. My team feels very motivated to do a good job*

\section{Absorption}

12. When my team is working, we forget everything else around us*

13. My team takes new initiatives

14. My team is immersed in the task

15. Time flies when my team is working ${ }^{*}$

16. My team feels happy when we are engrossed in the task ${ }^{*}$

17. It is difficult for the team to detach from the task

18. My team gets "carried away" by the task

Note: Items with asterisks were selected for the revised 9-item scale. 


\section{Appendix 2. Escala de engagement con el trabajo en equipos (Versión en Español)}

Vigor

1. Durante la realización del trabajo mi equipo se siente lleno de energía*

2. Mi equipo puede continuar trabajando durante largos períodos de tiempo

3. Mi equipo continua trabajando incluso cuando las cosas no van bien

4. Trabajar duro no supone demasiado esfuerzo para mi equipo

5. Mi equipo se siente muy persistente durante la realización del trabajo*

6. Mi equipo se siente fuerte y vigoroso durante la realización del trabajo*

7. Cuando el trabajo ha terminado mi equipo tiene suficiente energía para implicarse en otras actividades

\section{Dedication}

8. Mi equipo está implicado en la tarea

9. Mi equipo está entusiasmado con su propio trabajo*

10. Mi equipo disfruta realizando el trabajo*

11. Mi equipo está motivado por hacer un buen trabajo*

\section{Absorption}

12. Cuando mi equipo está trabajando olvida todo lo que pasa alrededor*

13. Mi equipo toma nuevas iniciativas

14. Mi equipo está inmerso en su trabajo

15. El tiempo 'pasa volando' cuando mi equipo está trabajando*

16. Mi equipo es feliz cuando estamos trabajando intensamente*

17. Es difícil para mi equipo desconectarse de la tarea

18. Mi equipo se ‘deja llevar’ por el trabajo

Nota: Los ítems con asterisco fueron seleccionados para la escala revisada de 9 ítems. 


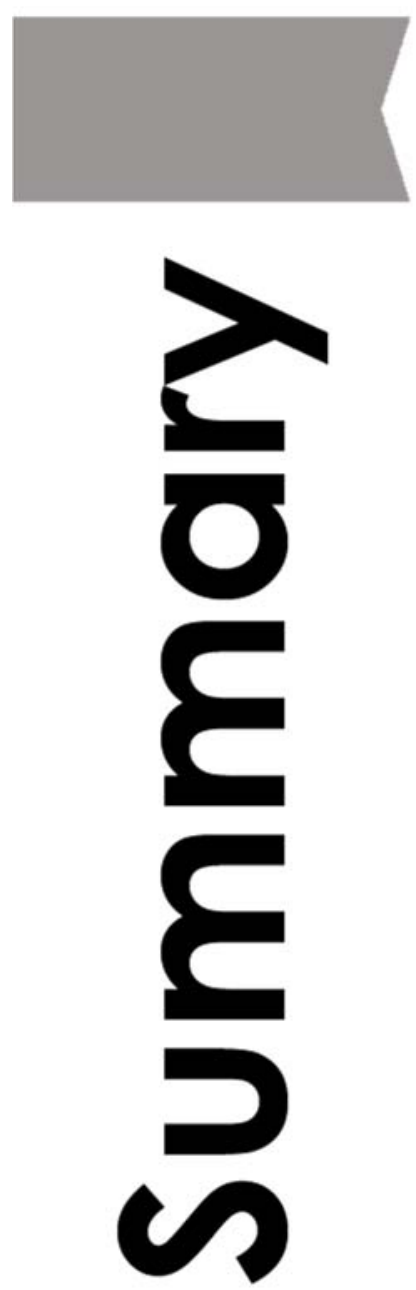


\section{Resumen (Summary)}

El objetivo de este proyecto de tesis es comprender y analizar los antecedentes, los procesos involucrados y los consecuentes del engagement con el trabajo en equipo (o teamworkengagement). Se ha presentado una serie de estudios empíricos que abordan las preguntas de investigación $(\mathrm{PI})$ que emergieron tras la revisión teórica (Capítulo 1). En primer lugar, se analizaron los antecedentes del engagement con el trabajo en equipo adoptando una perspectiva multinivel. Con el objetivo de ofrecer una panorámica completa del bienestar en el trabajo se incluyó incluimos tanto el engagement como el burnout como polos opuestos aunque interrelacionados en base al model de demandas-recursos laborales (JD-R Model). Este capítulo analiza las relaciones entre demandas y recursos laborales a nivel de individuos y organizaciones con el engagement y el burnout de los individuos (Capítulo 2). A continuación, se puso el foco en los mecanismos que subyacen al contagio positivo del engagement con el trabajo en equipos. Se prestó especial atención a la similitud entre los empleados como una condición previa para la convergencia en un estado compartido de engagement con el trabajo en equipo estableciendo las hipótesis en base a la teoría del contagio emocional (Capítulo 3). En el capítulo siguiente, se presenta y se valida una escala de engagement con el trabajo en equipo en base al cuestionario UWES, de amplísimo uso en la evaluación del engagement con el trabajo a nivel individual (Capítulo 4). Esta escala se administró a un conjunto de equipos de trabajo con el fin de probar un modelo de mediación del engagement con el trabajo en equipo entre los recursos sociales y una evaluación de desempeño por parte del supervisor inmediato lo que supone una medida objetiva del rendimiento laboral (Capítulo 5). Por último, se analizó en el engagement con el trabajo en equipos como estado compartido que funciona dentro de un contexto organizacional más amplio en base al modelo HERO y en relación con: (1) las prácticas organizacionales saludables implementadas por las 
empresas, y (2) el compromiso organizacional afectivo con el objetivo de distinguir conceptualmente entre ambos estados afectivos compartidos (Capítulo 6). En la discusión general se resumen los resultados de los estudios empíricos antes mencionados y, a continuación, se discuten en términos de sus implicaciones teóricas y prácticas para las preguntas de investigación. en el contexto de la cuestión específica de la investigación se señala en la revisión teórica. También se presentan las fortalezas, las limitaciones y las líneas de investigación futura (Capítulo 7). El presente texto es una traducción y adaptación al castellano de este último capítulo.

\section{Principales hallazgos e implicaciones teóricas}

Los resultados de esta tesis tienen implicaciones para el desarrollo de las teorías

utilizadas (esto es, modelo de demandas-recursos laborales, el modelo HERO y la teoría del contagio emocional). Estas implicaciones se verán enriquecidas con explicaciones alternativas para los resultados inesperados. En la Figura 1 se presentan gráficamente las relaciones que se han probado a lo largo de esta tesis. En conjunto, estos hallazgos proporcionan apoyos con los que construir un modelo preliminar de engagement con el trabajo en equipos a través de múltiples niveles de análisis. 
Summary

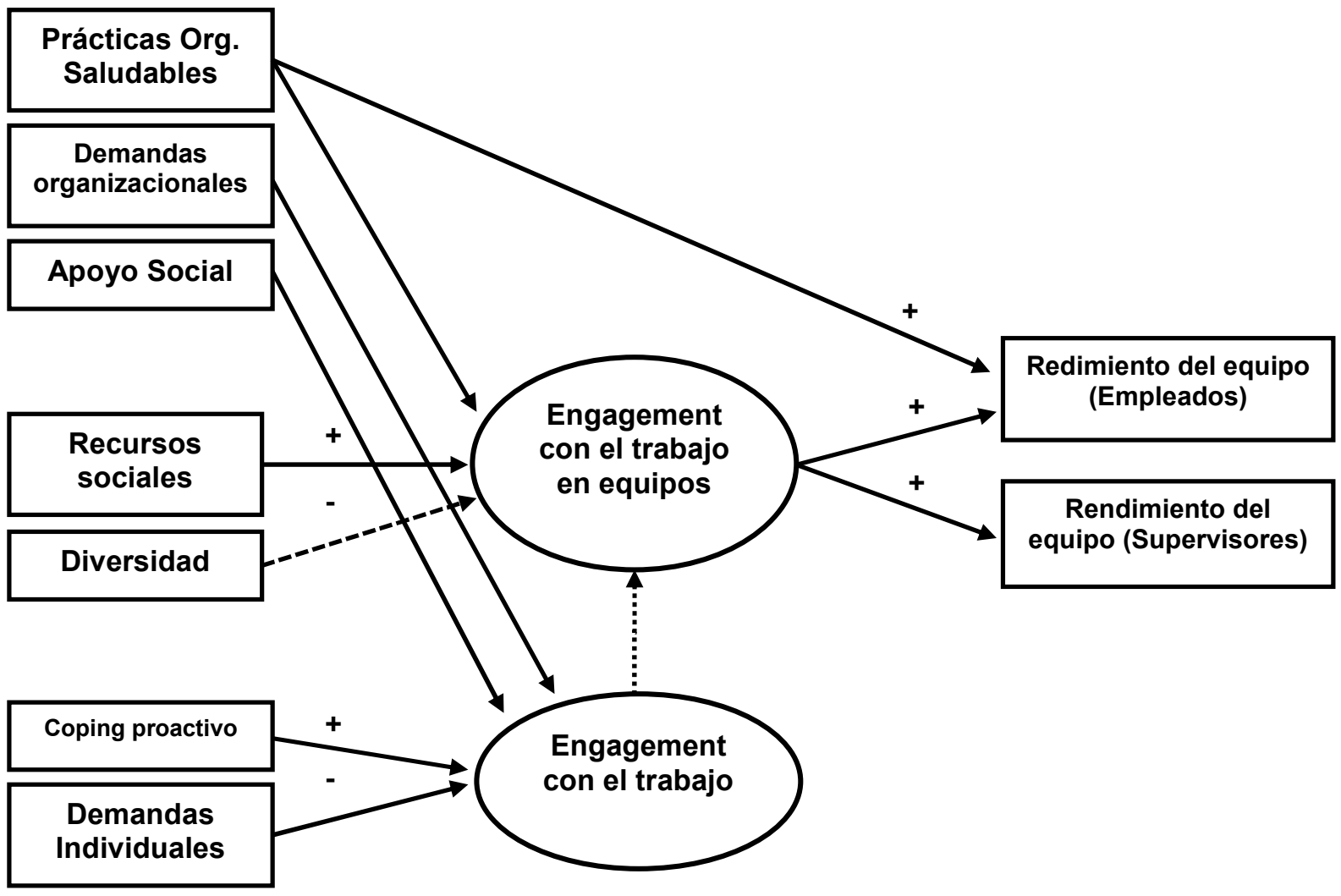

Figura 1. Modelo de engagement con el trabajo en equipos que muestra las relaciones analizadas en esta tesis. Las flechas sólidas indican efectos directos. La flecha de puntos indica el modelo de composición utilizado en los análisis. La flecha discontinua representa un efecto directo de la diversidad en la convergencia en el engagement con el trabajo en equipos en términos de dispersión.

PI1: ¿Cómo se puede extender el Modelo JD-R para incluir demandas $y$ recursos a nivel organizacional siguiendo una perspectiva multinivel?

El Capítulo 2 trata de dar respuesta a esta pregunta a través del primer estudio empírico de la presente tesis. En este estudio se planteó la hipótesis de que las demandas a nivel individual y el coping proactivo se relacionan con las dimensiones “corazón” del burnout y el engagement. Además se planteó una hipótesis transnivel. 
Más específicamente, se espera que las demandas a nivel organizacional y los recursos organizacionales (esto es, el apoyo social de los compañeros) estarán relacionadas con el burnout y el engagement a nivel individual. En el modelo de investigación propuesto, se espera que las demandas, individuales y organizacionales, se relacionen negativamente con el engagement, mientras que los recursos, individuales y organizacionales, se relacionen positivamente con el engagement. Se espera el patrón opuesto de relaciones entre las demandas y los recursos con las dimensiones "corazón" del burnout. Los resultados indicaron que - tal como se esperaba - tanto las demandas individuales como organizacionales se relacionan positivamente con el agotamiento emocional y el cinismo, y negativamente con el vigor y la dedicación. La única excepción a estos resultados se encuentra en la relación entre demandas individuales y dedicación, que no fue significativa. Además, las estrategias de coping proactivo se asocian de forma negativa y significativa con el agotamiento emocional y el cinismo, mientras que lo hacen positiva $y$ significativamente con el vigor y la dedicación. Los resultados también indican que el coping proactivo modula la relación negativa que existe entre las demandas a nivel individual y el vigor de los trabajadores. Los efectos transnivel puestos a prueba indican que las demandas organizacionales están positiva y significativamente relacionadas con el agotamiento emocional y el cinismo de los trabajadores, mientras que están negativa y significativamente relacionadas con el vigor y la dedicación. Sin embargo, en contra de lo esperado, la relación entre apoyo social de los compañeros con el engagement y el burnout no fue significativa.

A partir de este conjunto de resultados se pueden extraer diversas conclusiones que contribuyen al desarrollo teórico y a la comprensión de los procesos psicológicos estudiados. El modelo de demandas-recursos laborales (JD-R Model; Demerouti, Bakker, Nachreiner, \&Schaufeli, 2001) plantea que el engagement con el trabajo juega un papel crucial en el proceso motivacional de la salud en el trabajo (Schaufeli\&Bakker, 2004). El Modelo JD-R es un modelo heurístico y comprehensivo 


\section{Summary}

que destaca la importancia de las demandas y los recursos en el bienestar del empleado. En el Capítulo 1, las demandas (es decir, las demandas agudas) y los recursos individuales (es decir, el coping proactivo) se pusieron a prueba en relación con el burnout y el engagement con el trabajo en una muestra muy concreta: una muestra nacional de bomberos portugueses. Las situaciones de emergencia implican situaciones impredecibles que involucran entornos de trabajo exigentes y altamente estresantes que suponen una amenaza para la vida de las víctimas y de los propios trabajadores (Bennett, Williams, Page, Hood, Woollard, \&Vetter, 2005). En consecuencia, los empleados trabajan bajo presión lo que drena su energía y a largo plazo puede llevarles a desarrollar el síndrome de estar quemado con el trabajo (Taris, Leblanc, Schaufeli, \&Schreurs, 2005). Por el contrario, se puede esperar que las demandas del trabajo tengan el efecto contrario sobre el engagement, socavando la energía y motivación de los empleados. Aunque este razonamiento puede explicar las hipótesis que han sido presentadas, las demandas no son negativas por definición (Hakanen\&Roodt, 2010), es por ello que algunos investigadores han sugerido la existencia de un efecto motivacional de cierto tipo de demandas, conocidas como demandas reto (Crawford ,Lepine, \&Rich, 2005). Esto puede proporcionar una explicación alternativa para el efecto no significativo de las demandas agudas sobre la dedicación. Para algunos empleados, las demandas pueden resultar en la búsqueda de sensaciones o convertirse en un reto o un desafío para superarse a sí mismos. El sesgo de autoselección es también una explicación plausible en este proceso ya que los bomberos que acceden a esta profesión son conocedores de que estos retos son característicos de la profesión por lo que pueden estar accediendo las personas más preparadas y resistentes a los posibles efectos negativos de las demandas (Ziliak\&McCloskey, 2008).

En el Capítulo 1 también se destacó el papel de las demandas y los recursos a nivel de la organización. Las demandas organizacionales se conceptualizaron como demandas compartidas que son comunes a todos los empleados que trabajan en la 
misma brigada de incendios (por ejemplo, la coordinación con otras fuerzas de seguridad o la falta de recursos humanos para una salida de emergencia). La definición de demandas organizacionales enriquece la definición actual de demanda que incluye el Modelo JD-R especificando qué es una demanda organizacional como diferenciada a los otros tipos de demandas en cuanto a nivel de análisis (cf., Demerouti et al., 2001). Los efectos negativos de las demandas organizacionales se puede superar a través de medidas adoptadas por el supervisor inmediato o a través de prácticas promovidas por la organización desde la cúpula directiva (por ejemplo, en la forma de prácticas de recursos humanos). Sin embargo, los propios empleados pueden organizar sus propios recursos a nivel de la organización para hacer frente a estas demandas de la organización. Por ejemplo, los equipos de trabajo puede beneficiarse de organizarse para implementar cambios en el trabajo que les ayuden a trabajar de manera más saludable o eficiente (Tims, Bakker, Derks, \& van Rhenen, 2013). Se concluyó que la principal diferencia entre las demandas y los recursos organizacionales es el proceso que explica cómo estas características de la organización se convierten, respectivamente, en estrés o en recursos compartidos. Mientras que las demandas organizacionales muestran un efecto de bola de nieve, influyendo en todos los empleados de manera similar dentro de una misma organización; los recursos organizacionales pueden ser proporcionados por la organización y/o emerger de la propia interacción y de las experiencias cotidianas de los empleados.

Otro resultado inesperado tuvo que ver con la relación no significativa entre apoyo social de los compañeros sobre el burnout y el engagement. Este hallazgo puede ser debido a las características específicas de esta población ocupacional. De hecho, este mismo resultado no significativo ha sido encontrado previamente en el contexto de los bomberos. Regehr, Colina, Knott y Sault (2003) compararon a nuevos reclutas en la primera semana de trabajo con bomberos experimentados. Los autores sugieren que las oportunidades de ascenso son limitadas, lo que engendra la 


\section{Summary}

competencia dentro de las tareas en lugar de la cooperación y el apoyo. Los bomberos realizan su trabajo en una estricta estructura de jerarquía y de cadena de mando lo que puede ser caldo de cultivo para un liderazgo coercitivo o castigar en lugar de promover la expresión de conductas de apoyo social. Por otra parte, la lucha contra incendios es una ocupación predominantemente masculina. Dado que los hombres se sienten más eficaces cuando toma una estrategia de evitación durante las situaciones adversas del trabajo diario en comparación con las mujeres que buscan más el apoyo social (Long \&Gessaroli, 1989), en estos ambientes de trabajo el aspecto emocional puede ser minusvalorado dado que se percibe que la búsqueda de apoyo social no corresponde con su rol social esperado (González-Morales, Rodríguez, \&Peiró, 2010).

PI2: ¿Qué papel juega la similitud entre los miembros del equipo en el proceso de contagio positivo del engagement con el trabajo en equipos?

En el segundo estudio empírico (Capítulo 3), se planteó la hipótesis de que la similitud en términos de género y años de experiencia en la empresa se relacionan positivamente con la convergencia en un estado compartido en engagement con el trabajo entre empleados que trabajan en un mismo equipo. Los resultados indican que, tal como se esperaba, la similitud entre los miembros de los equipos en cuanto a género se relaciona positivamente con la convergencia en el engagement con el trabajo en equipo. Sin embargo, en contra de lo esperado, la similitud en cuanto a años de experiencia en la empresa está significativa pero negativamente relacionada con la convergencia en este mismo estado emocional. Por lo tanto, los equipos con miembros del mismo sexo son más propensos a compartir un estado de engagement con el trabajo en equipos. Por otro lado, los equipos de trabajo con más diferencias en cuanto a años de experiencia entre sus miembros, son los más propensos a la convergencia en términos de engagement.

En este capítulo se suma al escaso número de artículos que sugiere que los procesos de contagio influyen en la transmisión de un estado compartido de burnout y de engagement con el trabajo (Bakker et al., 2006). Este hallazgo confirma que la 
similitud actúa como una condición previa para lograr un estado compartido de engagement con el trabajo en equipos (Bakker et al., 2009). Aunque esto no significa que sea una condición necesaria para el contagio. De este estudio podemos deducir que los equipos que eran más similares en cuanto a número de hombres y mujeres mostraron un nivel similar de engagement con el trabajo en equipos. Los miembros de un mismo género parecen actuar como referentes emocionales en el contexto laboral, dados los fuertes lazos de amistad y relaciones más solidarias que comparten (Lincoln \& Miller, 1979). Por el contrario, de forma inesperada, los equipos con miembros más diferentes en cuanto a años de experiencia en la empresa mostraron una mayor convergencia en términos de engagement.

Los empleados experimentados comparten motivos, demandas laborales, estereotipos sociales por parte de otros, o incluso características personales y familiares relacionadas con su edad. Todo esto puede llevar a generar procesos de categorización que toman la forma de tener un sesgo a favor de los miembros similares (Tsui\&O'Reilly, 1989). Este razonamiento nos lleva a esperar que la similitud en cuanto a años de experiencia en la empresa está relacionado con la convergencia en un estado compartido de engagement con el trabajo en equipos. Sin embargo, los empleados con experiencia están a menudo involucrados en conductas de apoyo a otros empleados con menos experiencia y puede darse una interacción más intensa entre ellos a la hora de resolver problemas o para contribuir a una socialización exitosa (Bauer, Morrison, \&Callister, 1998). Esta última explicación parece ser la que recibió más apoyo de los resultados.

En este segundo artículo empírico también se utiliza el término contagio positivo para referirse al proceso por el cual el engagement con el trabajo de un trabajador se convierte en un recurso para el engagement con el trabajo de sus colaboradores. Los empleados comprometidos invierten una cantidad extra de energía, persistencia y dedicación en sus funciones que se transfiere al resto de empleados. Por tanto, las conductas visibles de engagement con el trabajo en equipo (por ejemplo, mostrar 


\section{Summary}

persistencia frente a los obstáculos, expresar entusiasmo y orgullo hacia las tareas que se realizan, o perder la noción del tiempo mientras se trabaja) pueden ser percibidos y compartidos por otros empleados que trabajan en el mismo equipo. Este proceso puede ser generado a través de diversos mecanismos: la frecuencia de las interacciones entre las personas que trabajan juntas (Bakker, Westman, \& van Emmerik, 2009 ) y/o la empatía por medio de nuestra tendencia innata a imitar los gestos de otros, así como las posturas corporales y las expresiones verbales (llies et al., 2007).

PI3: ¿Puede desarrollarse una herramienta fiable y válida para la evaluación y la medida del engagement con el trabajo en equipos?

En el tercer artículo empírico (Capítulo 4), hemos desarrollado una validación factorial de una medida de engagement con el trabajo en equipos basado en el cuestionario UWES usando datos agregados a nivel de equipos. Se planteó la hipótesis de que el engagement con el trabajo en equipos replicaría la estructura trifactorial del engagement a nivel individual, esto es: vigor, dedicación y absorción. Asimismo también se esperaba que esta estructura se ajustara mejor a los datos que un modelo que considere un único factor general en el que carguen todos los ítems del cuestionario. Tal como se esperaba, el modelo de tres factores mostró un ajuste superior a los datos, replicando la estructura del engagement con el trabajo en equipos. Este descubrimiento proporcionó apoyo para la validez de constructo de engagement con el trabajo a través de diferente niveles de análisis y ofreció una herramienta específica de medición y evaluación para fines tanto académicos como aplicados.

PI4 : ¿Es el engagement con el trabajo en equipos un estado compartido que media entre los recursos sociales y el desempeño laboral de los equipos utilizando una medida objetiva? 
En el cuarto artículo empírico (Capítulo 5), se planteó la hipótesis de que el engagement con el trabajo en equipos juega un papel mediador entre los recursos sociales del equipo (es decir, el clima de apoyo del equipo, el trabajo en equipo y la coordinación) y el desempeño del equipo (es decir, el desempeño in-rol y extra-rol), evaluado por el supervisor inmediato. La inclusión de una medida de desempeño laboral evaluada a través del supervisor inmediato es una novedad de este artículo en el estudio del engagement con el trabajo en equipos ya que supone una medida objetiva de rendimiento laboral. Los resultados indican que los recursos sociales del equipo se relacionan positivamente con el engagement con el trabajo en equipos, que a su vez se relaciona con el rendimiento del equipo. El modelo de mediación total se ajustaba mejor a los datos que el de mediación parcial. Por lo tanto, se concluye que los recursos sociales de los equipos tienen una influencia en el desempeño de los equipos a través de un estado compartido de engagement con el trabajo en equipos. Este hallazgo da apoyo al proceso motivacional propuesto por el Modelo JD-R, en este caso a nivel de equipos de trabajo, lo que sugiere el funcionamiento de procesos homólogos a través de niveles de análisis: el individual (ya testado por el Modelo) y el que se da a nivel de equipos de trabajo (novedad de este estudio). Por lo que sabemos, este es el primer trabajo empírico que proporciona una definición, junto a un modelo de composición y emergencia del engagement con el trabajo en equipos, poniendo a prueba su rol como estado mediador compartido entre miembros de un equipo de trabajo. Por otra parte, este proceso motivacional colectivo proporciona apoyo a la implementación de una perspectiva transnivel en el Modelo JD-R y puede contribuir a su integración con el Modelo HERO de organizaciones saludables y resilientes, dada la importancia de los fenómenos colectivos que es la piedra de toque de este último modelo.

PI5: ¿Es posible desarrollar un modelo multinivel del engagement con el trabajo en equipos en relación a los antecedentes (recursos y prácticas 


\section{Summary}

organizacionales saludables), los resultados (del equipo y de la organización), y constructos relacionados (el compromiso organizacional afectivo)?

Por último, en el quinto estudio empírico (Capítulo 6), se propone un modelo de multinivel en el que el engagement con el trabajo en equipos media entre la coordinación y el rendimiento de los equipos, y el compromiso organizacional afectivo media entre las prácticas organizacionales saludables y la lealtad evaluada por los propios clientes de las organizaciones. En este estudio se analiza el papel del engagement con el trabajo en equipos dentro de un contexto organizacional más amplio. La coordinación de los equipos es un recurso que fomenta el engagement colectivo que asimismo se relaciona con un mayor engagement. La propia coordinación promueve la transmisión y el contagio del engagement con el trabajo en equipos a través de las interacciones resultantes. Además, el engagement de los equipos convive con otros estados colectivos que se dan dentro de las organizaciones. En este caso, nos centramos en el compromiso organizacional afectivo, que puede ser fomentado a través de prácticas organizacionales y vincularse así al rendimiento de la empresa, según perciben los propios clientes. La inclusión de una medida de lealtad evaluada por los clientes introdujo mayor robustez al diseño de investigación. Los resultados confirmaron las hipótesis relacionadas con el engagement con el trabajo en equipos e indican que éste estado compartido juega un papel mediador entre la coordinación y el rendimiento de los equipos. Por otra parte, el compromiso organizacional afectivo está relacionado significativamente con la lealtad de los clientes. Sin embargo, su papel como mediador no encontró apoyo en los resultados. Así mismo, el compromiso organizacional afectivo sí estuvo relacionado con el rendimiento de los equipos resultando en un efecto transnivel significativo. En cuanto a las hipótesis de mediación multinivel, el engagement con el trabajo en equipos es un mediador multinivel significativo entre las prácticas organizacionales saludables y el rendimiento del equipo. Por su parte, los resultados indican que el compromiso afectivo organizacional no media entre prácticas organizacionales saludables y 
rendimiento del equipo. Esto subraya la importancia del proceso transnivel por el cual las prácticas de la organización se relacionan con el desempeño de los equipos a través de un estado compartido de engagement con el trabajo que se da en el seno de los propios equipos de trabajo.

Así, el Capítulo 5 da apoyo a los supuestos del modelo HERO ya que este modelo de investigación está dirigido a abordar el bienestar en el trabajo desde un punto de vista colectivo. Este capítulo propuso un proceso mediador explicativo entre los factores críticos dentro de las empresas tratando de aunar la Psicología de la Salud Ocupacional y la gestión de recursos humanos. En línea con los principios del Modelo HERO, los resultados sugieren que existe un proceso de motivación en los equipos que puede ser provocada por aspectos contextuales de trabajo, tales como las prácticas saludables de organización y la coordinación de los equipos. Estos recursos están asociados a un estado colectivo de engagement en el trabajo dentro de los equipos, lo que a su vez puede conducir a un desempeño in-rol y extra-rol.

Las conclusiones de esta tesis tiene implicaciones para el Modelo HERO (Salanova, 2008, 2009; Salanova, Llorens, Cifre, \& Martínez, 2012). Aunque tanto el Modelo JD-R y el Modelo HERO son heurísticos y parten de supuestos similares, pueden destacarse algunas diferencias. El Modelo HERO destaca el papel de los recursos colectivos, los estados compartidos y los resultados positivos que se encuentran en el núcleo de organizaciones saludables y resistentes, mientras que el Modelo JD-R se centra en el bienestar individual. De hecho, la aparición y el énfasis en los fenómenos colectivos, que es la piedra angular del modelo HERO, llega en un momento en el que se está llamando al desarrollo de una perspectiva multinivel en el Modelo JD-R (Demerouti et al., 2001; Schaufeli, 2012a; Schaufeli\&Taris, 2014).

En el Capítulo 6 el engagement con el trabajo en equipos se integra en un contexto organizacional más amplio. Las prácticas organizacionales saludables se asociaron a mayor compromiso afectivo organizacional y a mayores puntuaciones en engagement con el trabajo en equipos, lo que a su vez puede dar lugar a mayores 


\section{Summary}

beneficios para el rendimiento del equipo. De acuerdo con este razonamiento, el Modelo HERO hace hincapié en la importancia de las prácticas de gestión de recursos humanos como motores del bienestar de los empleados. Las conclusiones a las que hace referencia el Capítulo 6 proporcionan apoyo al Modelo HERO destacando el papel de los responsables políticos a fomentar el bienestar de equipos y grupos de trabajo a través de prácticas organizacionales saludables (Schaufeli\&Salanova, 2008, 2010) tal como veremos en la siguiente sección.

\section{Implicaciones prácticas}

Los resultados de este proyecto de tesis nos permiten inferir implicaciones prácticas para las organizaciones interesadas en la promoción de un estado compartido de engagement con el trabajo en equipo. De hecho, algunas de las iniciativas para mejorar el bienestar de los empleados están en las manos de las personas con mayor responsabilidad en las empresas. Esta fue la conclusión alcanzada en el Capítulo 2, en el cual se observa que las demandas a nivel de organización pueden ser previstas y reorganizadas por la dirección de las organizaciones o por el supervisor inmediato como vínculo esencial en la cadena de mando. La prevención de las demandas a nivel organizacional sirve a tres propósitos diferentes: (1) compensar el impacto negativo que pueden tener en el engagement con el trabajo individual (Crawford et al., 2005), (2) proteger a los empleados de experimentar síntomas de burnout (Demerouti et al., 2001), y (3) evitar que las demandas actúen como un estresor común y reducir así la posibilidad de un contagio del burnout entre los empleados (González-Morales, Peiró, Rodríguez, \&Bliese, 2011). Con todo, la prevención de las demandas a nivel de organización permitiría la expresión de conductas y emociones más positivas que conduzcan a estados compartidos de engagement con el trabajo (Salanova, Llorens, \&Schaufeli, 2011). Específicamente, las organizaciones pueden promover un estado compartido de engagement con el trabajo en equipos a través de la implementación de prácticas 
organizacionales saludables que abordan este estado colectivo dentro de los equipos directamente. Tres grupos de prácticas mostraron la aplicabilidad como recursos organizacionales saludables a través de: garantizar que los equipos llevan a cabo su labor en consonancia con los objetivos de la organización (lo que agrupa las prácticas organizacionales de información y comunicación, y la responsabilidad social de las empresas), la prevención de las demandas amenaza (es decir, las conductas de mobbing, la inequidad y el conflicto trabajo-familia), y es desarrollo de las fortalezas de los equipos (es decir, el desarrollo de carrera, el desarrollo de habilidades y las prácticas de salud y bienestar en el trabajo).

Otra implicación con respecto al engagement con el trabajo en el contexto de las organizaciones se refiere al contagio positivo de este estado compartido entre los individuos. Esta tesis sugiere que los compañeros de trabajo pueden actuar como recursos influyendo recíprocamente en los niveles de engagement con el trabajo de cada uno de ellos a través de la interacción cotidiana y las experiencias compartidas. Por lo tanto, los empleados son recursos positivos para el resto de los miembros de sus equipos. Esto se pudo comprobar a través de la condición de similitud del proceso de contagio del engagement con el trabajo en equipos. Esta implicación sugiere la necesidad de prestar atención a los procesos de contagio en base a la similitud dentro de los equipos y se suma a la literatura existente sobre gestión de la diversidad introduciendo mayor complejidad en este debate. Los procesos de selección deben considerar la posibilidad de influir a los demás hacia estados emocionales positivos en función del género y los años de experiencia en la empresa. Los resultados mostraron que, mientras los equipos que se componen de más miembros del mismo género, son más propensos a alcanzar un estado similar de engagement con el trabajo en equipos. No obstante, las cuestiones éticas no están ausentes en esta discusión ya que el género no puede convertirse en una característica en base a la cual reclutar y seleccionar a miembros de un equipo. La complejidad de este hallazgo conecta con el debate abierto acerca de las ventajas y desventajas de similitud dentro de los equipos. 


\section{Summary}

En base a la literatura científica, se espera que los equipos diversos muestren mayor creatividad y rendimiento (Tsui\&Gutek, 1999). Sin embargo, basándose en los resultados del Capítulo 2, podemos esperar un rendimiento inferior ya que la diversidad dificulta el contagio positivo del engagement con el trabajo en equipos que, como vimos en los Capítulos 6 y 7 , se relaciona con el rendimiento de los equipos. Por otra parte, los equipos que se componen de miembros con diferente número de años de experiencia en la empresa son más propensos a converger en un nivel similar de engagement con el trabajo en equipos. Esto sugiere que los procesos de socialización no sólo están jugando un papel importante en el apoyo y en la guía y orientación de nuevos empleados, sino también en la formación de sus emociones hacia el trabajo dentro de los equipos (Bauer, Morrison, \&Callister, 1998). Así, los supervisores o colaboradores encargados de los procesos de socialización tienen la oportunidad de motivar y aumentar los niveles de engagement de los recién llegados. Por lo tanto, el papel de guía en el proceso de socialización debe ser llevado a cabo por aquellos que son más propensos a conectar y transmitir emociones positivas a los demás. Podríamos esperar que las personas empáticas que captan las emociones de sus colegas más fácilmente (Bakker et al., 2009) o aquéllos con un perfil de personalidad con altas puntuaciones en extroversión que buscan abiertamente la interacción social (Langelaan, Bakker, Schaufeli, \& van Doornen, 2006) pueden servir exitosamente como socializadores positivos.

Otra consecuencia práctica importante que plantea este proyecto de tesis es la medida del engagement con el trabajo en equipo con fines de investigación o con propósitos aplicados. Con el objetivo de dar respuesta a nuestras preguntas de investigación se desarrolló y se validó factorialmente una escala de engagement con el trabajo adaptada a equipos. El instrumento resultante constituye una herramienta de medida específica que permite medir y evaluar el engagement con el trabajo en equipos y supone una aplicación práctica de este proyecto de tesis doctoral. Las percepciones resultantes de la administración de esta escala se promedian —bajo 
criterios de agregación — para alcanzar una media fiable del nivel de engagement con el trabajo en equipos. También resultan altamente informativas las diferencias y similitudes entre las percepciones individuales obtenidas en términos de desviación o, en el polo opuesto, de acuerdo y consistencia entre las puntuaciones (Brown \&Kozlowski, 1999). Como resultado, se ha obtenido una herramienta de medición del engagement con el trabajo en equipo en base al cuestionario UWES, un cuestionario que ha sido ampliamente validado a través de muchos países y ocupaciones (Schaufeli\&Bakker, 2003, 2010). La validez factorial de la escala de engagement con el trabajo en equipos se puso a prueba replicando la estructura trifactorial del engagement con el trabajo a nivel de equipos. Este cuestionario permite desarrollar futuras investigaciones en el campo y un análisis más preciso del engagement con el trabajo dentro de equipos en el contexto de las organizaciones.

Finalmente, en este apartado cabe referirse a las conclusiones sobre el papel mediador del engagement con el trabajo en equipos. De este modo, los recursos y prácticas de la organización se asocian con mayores niveles de vigor, dedicación y absorción en los equipos, lo que a su vez está relacionado con mayor productividad en términos de rendimiento in-rol (es decir, las tareas que se espera que se cumplan por contrato) y el rendimiento extra-rol (por ejemplo, ayudar a otros compañeros o la puesta en marcha de acciones que mejoran la eficiencia o la imagen de la empresa). Así, a modo de recomendación práctica, la implementación de prácticas organizacionales saludables como se mencionó anteriormente, y de recursos sociales del equipo (en la forma de coordinación, trabajo en equipo, y clima del equipo de apoyo). La promoción de un clima de seguridad psicológica y la crítica constructiva gratificante, así como hacer frente a los problemas interpersonales contribuyen a fomentar un clima de apoyo del equipo. La coordinación puede ser fomentada por medio de garantizar la existencia de canales adecuados de comunicación entre los miembros del equipo. Un reclutamiento y selección de candidatos que complementen las habilidades del equipo, así como la consideración de la posibilidad de introducir 


\section{Summary}

sistemas de retribución basados en el desempeño del equipo, ayudan a impulsar el trabajo en equipo. Este hallazgo se replicó utilizando dos medidas de desempeño diferente: el propio supervisor inmediato como una fuente de información objetiva, y los propios trabajadores que informan sobre la experiencia de su propio desempeño. Teniendo en cuenta que los empleados podrían estar sobreestimando su desempeño debido al sesgo de la deseabilidad social o a la varianza común debida al uso de autoinformes, el uso de las percepciones de supervisor apoyó la robustez de este conjunto de resultados.

\section{Fortalezas de este proyecto de tesis}

Las implicaciones de este proyecto de tesis se apoyan en los métodos y técnicas utilizadas a lo largo de los capítulos y que constituyen algunas de las principales fortalezas de esta tesis que se presentan en esta sección. En primer lugar, el uso de diferentes enfoques teóricos refuerzan los hallazgos presentados y proporcionaron un mayor refinamiento para el funcionamiento de los procesos propuestos. El Modelo JDR (Demerouti et al., 2001) proporcionó la base teórica para la mayoría de los procesos propuestos en términos de demandas y recursos en relación con el burnout y el engagement con el trabajo. La perspectiva multinivel se puso de relieve por medio del Modelo HERO (Salanova et al., 2012) y proporciona la justificación de una visión colectiva de los estados positivos dentro de las empresas y su relación con sus antecedentes y resultados. Así, una fortaleza teórica de este proyecto de tesis se sustenta en la combinación e integración de los procesos propuestos por ambos marcos teóricos en la construcción de un modelo preliminar de engagement con el trabajo a través de diversos niveles de análisis. Por otra parte, también se aplicó la teoría del contagio emocional (Hatfield et al., 1994) que argumenta a favor de un mecanismo explicativo de la generación y el contagio positivo del engagement con el trabajo en equipos. Este enfoque teórico fue crucial para la conceptualización del 
engagement con el trabajo en equipo como fenómeno colectivo ya que permite comprender cómo los individuos son capaces de sentir un estado compartido de engagement en el trabajo en equipos, y no sólo como mera característica de los individuos.

La escala de engamement con el trabajo en equipos presentada en el Capítulo 4 fue desarrollada para evaluar equipos de trabajo a través de medidas agregadas, lo que constituye un primer paso en la validación de este instrumento para su uso en un contexto multinivel como son las organizaciones (Chen, Mathieu\&Bliese, 2005). Sin embargo, futuras investigaciones orientadas a validar más ampliamente la escala deberían considerar simultáneamente los niveles de análisis evaluados (por ejemplo, individuos anidados en equipos y equipos anidados en organizaciones). Este procedimiento permite la discriminación adecuada de la escala, no sólo entre individuos, sino también entre equipos o entre otras unidades de agrupación (por ejemplo, unidades de negocio, organizaciones o países). En este sentido, los resultados de esta tesis doctoral se unen a otros esfuerzos de validación multinivel de la escala UWES de engagement con el trabajo individual. Por ejemplo, Breevaart, Bakker, Demerouti y Hetland (2012) desarrollaron una validación multinivel del cuestionario UWES con el objetivo de poner a prueba su capacidad para discriminar entre dos niveles de análisis: intra y entre individuos (i.e., en distintos intervalos de tiempo). Los resultados indicaron que este cuestionario es una herramienta fiable y válida en estudios de diario, es decir, estudios que se llevan a cabo en un contexto multinivel y que hacen hincapié en las diferencias dentro de los individuos en períodos cortos de tiempo (por ejemplo, horas o días; Oerlemans\&Bakker, 2013). Un enfoque similar se consideró en esta tesis para el engagement con el trabajo en equipos al comprobar la validez de la escala dentro y entre los equipos.

Aunque en este proyecto de tesis fueron incluidos datos de dos países, la validez de sus conclusiones en otros contextos nacionales ayudaría a una mayor generalización y robustez de los resultados. En este sentido, una interesante línea de 


\section{Summary}

investigación podría llevarse a cabo a través de estudios interculturales (i.e., individualistas vs. colectivistas) o estudios con muestras ocupacionales específicas. Por ejemplo, hasta lo que sabemos Japón es el país que muestra los niveles más bajos de engagement con el trabajo a nivel individual entre su población activa en comparación con otros países (Shimazu, Miyanaka\&Schaufeli, 2010). Replicar los hallazgos de esta investigación utilizando muestras de diferentes países y ocupaciones fortalecería la robustez del engagement con el trabajo en equipos. El estudio del engagement con el trabajo en equipos en diferentes contextos también podría ayudar a replicar su estructura tri-factorial: vigor, dedicación y absorción del equipo. Por ejemplo, un reciente estudio que trataba de validar una escala de engagement con el trabajo en equipos en base al cuestionario UWES (Costa, Passos\&Bakker, 2014) no pudo demostrar la estructura factorial basada en los tres componentes de la escala original. Las diferencias entre estos hallazgos y el Capítulo 4 de esta tesis enriquecen el campo de estudio y proporcionan una fructífera línea de investigación con el objetivo de encontrar las causas de estos resultados contradictorios en el número de dimensiones del engagement con el trabajo en equipos.

En este proyecto de tesis, el engagement con el trabajo en equipos se ha estudiado como un factor latente (Capítulo 5) o como una medida compuesta (Capítulos 2, 3, 4 y 6). Por tanto, la investigación relacionada a las dimensiones específicas del engagement con el trabajo en equipos puede abrir interesantes vías de investigación tal como se ha sugerido para el engagement individual (Bakker\& Leiter, 2010; Demerouti, Mostert, \&Bakker, 2010). A partir de estos resultados, la investigación sobre el vigor, la dedicación y la absorción del equipo pueden contribuir a obtener una mejor comprensión de los procesos psicológicos específicos involucrados en estas dimensiones. Aunque no se detalla en profundidad, esta idea fue señalada por Bakker et al. (2006), los cuales sugieren que el vigor y la absorción del equipo podrían seguir un mecanismo de contagio inconsciente. Por su parte, los autores 
sugieren que la dedicación del equipo sigue un proceso de contagio consciente a través de, por ejemplo, la expresión de sentimientos de entusiasmo por la tarea del equipo. El estudio específico de las dimensiones específicas tienen más tradición entre los académicos que investigan el síndrome de burnout como fenómeno opuesto e interrelacionado con el engagement con el trabajo. Concretamente, algunos autores han detectado patrones de causalidad entre las dimensiones del síndrome de burnout, lo que sugiere que puede ocurrir un fenómeno similar entre las diferentes dimensiones del engagement individual (Taris, Le Blanc, Schaufeli, \&Schreurs, 2005).

Comparar el síndrome de burnout y el engagement con el trabajo y sus procesos de contagio a través del tiempo abre interesantes vías de investigación, tanto para el desarrollo de la teoría como para sus procesos psicológicos subyacentes. El trabajo de Baumeister y colegas (Baumeister, Bratslavsky, Finkenauer, \&Vohs, 2001; Baumeister, Vohs, DeWall, \& Zhang, 2007) concluye que los estados y las emociones negativas tienen un efecto mayor que los positivos. Enmarcando estos resultados en el contexto del engagement con el trabajo en equipos, es decir, en el contexto de empleados que trabajan en equipos, se podría esperar que los individuos "quemados" pudieran tener una mayor influencia en el tono emocional del equipo que los empleados engaged. Implementar diseños de investigación destinados a probar esta hipótesis pueden constituir una mayor comprensión acerca de cómo se genera el engagement con el trabajo en equipos a través del tiempo.

Por último, es importante señalar que estos hallazgos podrían dar lugar a intervenciones que ayuden a promover el engagement con el trabajo en equipos tomando una perspectiva grupal, lo que puede conducir a organizaciones más saludables. Específicamente, las intervenciones colectivas están dirigidas a un número mayor de empleados, y por tanto, tienen menos costes asociados (Schneider, Macey, Barbera, \& Young, 2010). Esto supone una importante razón para invertir en el fomento del engagement con el trabajo en equipos debido a que resulta ser una aproximación más eficiente que centrarse meramente en el engagement don el trabajo 


\section{Summary}

individual. Las investigaciones futuras pueden traducir estos resultados empíricos en intervenciones estandarizadas y prácticas, útiles para el contexto organizacional actual, que es el objetivo final de toda investigación aplicada.

\section{Nota final}

Este proyecto de tesis ha tratado de arrojar luz sobre la transmisión y el rol mediador del engagement con el trabajo en equipos. Las propiedades emergentes específicas y los procesos colectivos que subyacen al engagement con el trabajo en equipos se pusieron de relieve como mejora y complemento a una perspectiva más tradicional enfocada en el estudio del engagement con el trabajo individual. Se han dado algunos pasos importantes hacia la construcción de un modelo de engagement con el trabajo en equipos a través de múltiples niveles de análisis, lo que estimula futuras investigaciones en el campo lo que prevé un terreno fértil y un creciente interés en esta área de estudio para los próximos años. El futuro parece prometedor en términos de vías de investigación sobre un tema que sin duda bien vale el esfuerzo de seguir desarrollando: mantener la vinculación psicológica con nuestro trabajo sin dejar de estar conectados a los demás, construir equipos de trabajo engaged que nos permitan conseguir organizaciones más saludables. 


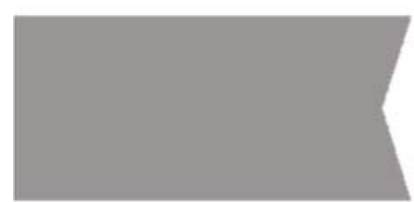

농

()

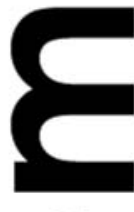

(1)

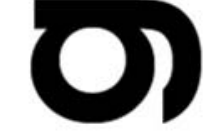

8

(1)
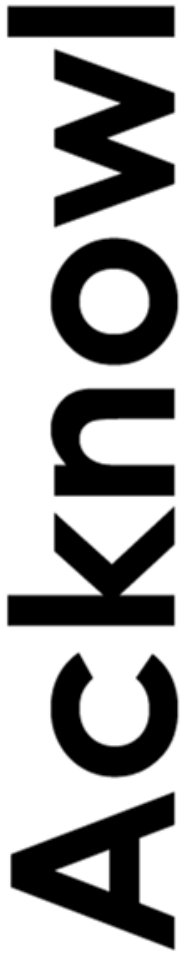


\section{Acknowledgements}

\section{Agraïments (Acknowledgements)}

Com no podria ser d'una altra manera en una tesi sobre engagement col·lectiu, no puc deixar d'agrair la seua contribució a totes aquelles persones que d'una forma o altra han fet possible el naixement $\mathrm{i}$ el desenvolupament d'este projecte de tesi doctoral.

El meu primer pensament és per als meus pares. Ells han hagut de confiar, a voltes cegament, en la bondat de les meues decisions i del meu projecte professional. Primer amb la llicenciatura en Psicologia i després amb el doctorat. Estos anys de tesi han suposat dubtes i grans reptes que irremeiablement s'han vist reflexats en el meu comportament diari. A ells cal agrair la seua opinió i el seu consol quan perdia la perspectiva del meu objectiu final i em perdia amb divagacions inútils.

Marisa, Susana i Wilmar conformen un equip de supervisors de tesi difícil de millorar. Cadascú ha deixat un profunda empremta en cada línia i en cada paraula d'estes pàgines, complementant-se i orientant-me amb decisió en aquest camí d'aprenentatge que ara tot just comença. Cal agrair-los la seua guia i el suport intel·lectual, professional i emocional que requeria a cada moment.

Amb qui més he compartit el dia a dia d'aquesta tesi és amb Hedy. Compartir despatx amb ella m'ha permés trobar una persona ben afí amb qui desenvolupar habilitats de treball. La constant retroalimentació i la recerca de la perfecció que hem fet conjuntament han constituït els pilars fonamentals sense els quals aquesta tesi no haguera sigut la mateixa.

El meu sincer agraïment va també per a tots els membres de l'Equip WoNT que són el brou de cultiu de les millors idees i per a tots els meus amics als quals no he pogut resoldre una senzilla pregunta:

"Pedro, què has estat fent tots estos anys a l'UJI?" 